\author{
UNIVERSIDADE DE SÃO PAULO \\ INSTITUTO DE FÍSICA DE SÃO CARLOS
}

BRUNO SPOLON MARANGONI

Colisões heteronucleares em uma armadilha de dipolo

São Carlos

2013 

BRUNO SPOLON MARANGONI

\title{
Colisões heteronucleares em uma armadilha de dipolo
}

\author{
Tese apresentada ao Programa de Pós- \\ Graduação em Física do Instituto de \\ Física de São Carlos da Universidade de \\ São Paulo, para obtenção do título de \\ Doutor em Ciências. \\ Área de concentração: Física Básica \\ Orientador: Prof. Dr. Luís Gustavo \\ Marcassa
}

Versão Corrigida

(Versão original disponível na Unidade que aloja o Programa)

São Carlos

2013 
AUTORIZO A REPRODUÇÃO E DIVULGAÇÃO TOTAL OU PARCIAL DESTE TRABALHO, POR QUALQUER MEIO CONVENCIONAL OU ELETRÔNICO PARA FINS DE ESTUDO E PESQUISA, DESDE QUE CITADA A FONTE.

Ficha catalográfica elaborada pelo Serviço de Biblioteca e Informação do IFSC, com os dados fornecidos pelo autor

Marangoni, Bruno Spolon

Colisões heteronucleares em uma armadilha de dipolo / Bruno Spolon Marangoni; orientador Luis Gustavo Marcassa - versão corrigida - São Carlos, 2013. $137 \mathrm{p}$.

Tese (Doutorado - Programa de Pós-Graduação em Física Básica) - Instituto de Física de São Carlos, Universidade de São Paulo, 2013.

1. Átomos frios. 2. Armadilha de dipolo. 3. Fotoassociação. 4. Colisões frias. I. Marcassa, Luis Gustavo, orient. II. Título. 


À minha família, com amor, admiração e gratidão. 



\section{AGRADECIMENTOS}

À minha família Adenir, Márcia e Valéria pelo amor, carinho e apoio no desenvolvimento desse trabalho e ao longo de toda a minha vida.

Ao professor Dr. Luís Gustavo Marcassa pela orientação, profissionalismo e amizade durante todo esse caminho.

Ao Carlos Renato Menegatti pela amizade de longa data, pela decisiva contribuição com a parte experimental do projeto e principalmente pela persistência na obtenção dos resultados, o qual foi fundamental para a conclusão deste trabalho.

Aos companheiros de laboratório e amigos Jader de Souza Cabral, Jorge Kondo, Luis Barbosa e Jonathan Tallant pelo convívio e apoio mútuo em questões tanto científico quanto pessoais.

Aos eternos amigos Rafael Rothganger de Paiva, Marco Hachiya, Filipe Sammarco e Jader Cabral, pelo convívio, pelas discussões científicas e momentos de distração.

Ao professor Daniel Varela Magalhães pelo suporte técnico, pelas longas discussões em eletrônica e LabView e pela sua disposição em sempre ajudar a todos com muita paciência.

A todos os companheiros de trabalho do grupo de Fotônica que estão sempre dispostos a ajudar e esclarecer dúvidas.

Ao pessoal do serviço de apoio à pós-graduação pela agilidade e competência.

Ao pessoal da oficina mecânica pela grande amizade e ajuda na construção de vários componentes deste trabalho.

Ao pessoal da biblioteca que nos atendem sempre com grande carinho e paciência.

Ao secretário Daniel do grupo de Fotônica pela eficiência, camaradagem e paciência. 
Aos amigos de São Carlos: Simoni Sayuri, Kristen Tallant, Gustavo Nicolodelli, Mikhail Ajukas e Renata Florindo, pelas conversas e amizade sincera.

Aos eternos amigos da minha cidade natal: Alessandro Cavalcanti, Wellington Troiano, Diego Gonçalves, Paulo Martinez, Gustavo Viana, Gustavo Tavares e Rodolfo Kamá pela amizade e presença constante em minha vida, pela alegria que sinto em saber que são pessoas com quem poderei contar pelo resto da minha vida.

À Daniele de Almeida Soares, companheira muito especial. Pela força transmitida, paciência e Amor demonstrado em todo o caminho que já percorremos juntos e que ainda iremos percorrer.

À FAPESP, pelo apoio financeiro.

À Deus, pela paz, saúde e o equilíbrio que me percorre. 
Uma vida boa é aquela inspirada pelo amor e guiada pelo conhecimento" Bertrand Russell 



\section{Resumo}

MARANGONI, B. S. Colisões heteronucleares em uma armadilha de dipolo. 2013. 137p. Tese (Doutorado em Ciências) - Instituto de Física de São Carlos, Universidade de São Paulo, São Carlos, 2013.

Neste trabalho, apresentamos uma montagem experimental capaz de aprisionar átomos de $\mathrm{K}$ e $\mathrm{Rb}$ simultaneamente em uma armadilha óptica de dipolo cruzada. Contudo, para atingir este feito foi necessário, durante o desenvolvimento do projeto, estudar cada espécie atômica de forma isolada. Assim, desenvolvemos uma técnica inédita para carregar uma armadilha de dipolo diretamente de uma armadilha magneto-óptica de ${ }^{39} \mathrm{~K}$, constatando a importância da estrutura hiperfina do estado $4 \mathrm{P}_{3 / 2}$ no processo de carregamento. Também observamos e explicamos o processo de fotoassociação de $\mathrm{Rb}$ devido ao laser em $1071 \mathrm{~nm}$, inclusive a diferença isotópica entre ${ }^{85} \mathrm{Rb}$ e ${ }^{87} \mathrm{Rb}$. Na sequência, realizamos o carregamento duplo com $\mathrm{K}$ e Rb na armadilha e observamos a fotoassociação de KRb. Um modelo teórico simples prevê a distribuição dos níveis vibracionais obtidos. O mesmo modelo abre caminho para um possível bombeamento óptico para a produção e acúmulo de moléculas de KRb no estado $X^{1} \Sigma^{+}(v=0)$.

Palavras-chave: Átomos frios. Armadilha de dipolo. Fotoassociação. Colisões frias. 



\begin{abstract}
MARANGONI, B. S. Heteronuclear colisions in a dipole trap. 2013. 137p. Tese (Doutorado em Ciências) - Instituto de Física de São Carlos, Universidade de São Paulo, São Carlos, 2013.

In this paper, we present an experimental setup to simultaneously trap atoms of $\mathrm{K}$ and $\mathrm{Rb}$ in a crossed optical dipole trap. This accomplishment required the individual study of each atomic species during the project development. This allowed the development of a new technique for loading a dipole trap directly from a magneto-optical trap of ${ }^{39} \mathrm{~K}$, providing evidence of the importance of the hyperfine structure of the state $4 \mathrm{P}_{3 / 2}$ in the loading process. We also observe and explain the photoassociation process of $\mathrm{Rb}_{2}$ due to the dipole trap laser at $1071 \mathrm{~nm}$, including an isotopic difference between ${ }^{85} \mathrm{Rb}$ and ${ }^{87} \mathrm{Rb}$. In the sequence, we performed dual species loading of $\mathrm{K}$ and $\mathrm{Rb}$ and observed the photoassociation process of $\mathrm{KRb}$. A simple theoretical model predicts the final distribution of vibrational levels obtained. The same model provides a potential path to optically pump the molecules and accumulate them in the molecular ground state $X^{1} \Sigma^{+}(v=0)$ for $\mathrm{KRb}$.
\end{abstract}

Keywords: Cold atoms. Dipole trap. Photoassociation. Cold colisions. 



\section{Lista de figuras}

Figura 1 - Potenciais moleculares relevantes para o experimento. (A) Fotoassociação de átomos e formação de moléculas frias. O laser de PA foi dessintonizado $1 \mathrm{~cm}^{-1}$ abaixo da transição $6 \mathrm{~S}_{1 / 2} \rightarrow 6 \mathrm{P}_{3 / 2}$ para o potencial $1 \mathrm{~g}$. São formadas moléculas no estado fundamental $X^{1} \Sigma_{g}^{+}$ via decaimento espontâneo em cascata através do potencial $0_{u}^{+}$. (B) Processo de ionização via estado $C^{1} \Pi_{u}$ e transição eletrônica $X^{1} \Sigma_{g}^{+} \rightarrow B^{1} \Pi_{u}$ induzida pelo laser de femtossegundo (fs) (46) ........

Figura 2 - Espectro remodelado do laser de femtossegundo e técnica para bloqueio de determinada faixa espectral. b) Fator de Franck Condon entre os estados vibracionais $\left(X^{1} \Sigma_{g}^{+}, V_{x}\right)$ e $\left(B^{1} \Pi_{u}, V_{B}\right)(46)$

Figura 3 - $\quad$ Transições utilizadas para a manipulação dos estados rovibracionais do $\mathrm{Cs}_{2}$. O retângulo vermelho representa as transições realizadas pelo laser banda larga de femtossegundo. O retângulo hachurado em laranja apresenta os níveis rotacionais afetados pela varredura do laser de diodo (45)

Figura 4 - Transições utilizadas para a produção e detecção de moléculas de LiCs no estado rovibrônico fundamental. A seta verde (a) representa o processo de fotoassociação com o decaimento espontâneo para o estado rovibrônico fundamental dado pela seta azul (b). A seta amarela (c) indica o processo de ionização via dois fótons. A transição em (d) foi utilizada para realizar a detecção dos estados rotacionais pela depleção induzida por um laser de diodo. O decaimento espontâneo em (e) advém da transição induzida em (d) e não participa do processo de fotoionização (52)

Figura 5 - $\quad$ Esquema experimental mostrando a posição das armadilhas ópticas do sistema (dipolo cruzado + rede óptica) juntamente com a direção de aplicação do campo elétrico externo de alinhamento dos dipolos moleculares

Figura 6 - Diagrama de níveis de energia da molécula de ${ }^{40} \mathrm{~K}^{87} \mathrm{Rb}$ mostrando o processo de transferência coerente via 2 fótons (STIRAP) das moléculas fracamente ligadas, formadas via ressonância de Feshbach, para o estado rovibrônico fundamental (11)

Figura 7 - Esquema de colisão para moléculas fermiônicas polares em uma geometria de colisão 2D. a) Representação dos planos criados pelo 
potencial da rede óptica 1D e a direção de aplicação do campo elétrico externo $\mathrm{E}(\hat{z})$. As cores azul e vermelho representam moléculas em diferentes estados internos moleculares. b) Representação dos três possíveis potenciais de interação com menores barreiras. c) Descrição dos estados internos de colisão: Em |1) temos as colisões entre partículas com estados internos diferentes que não apresentam barreira centrífuga. Em $|2\rangle$, as moléculas estão no mesmo estado interno e diferentes níveis vibracionais, representando as colisões entre dipolos anti-paralelos. Em $|3\rangle$ as partículas estão no mesmo estado interno e vibracional, essa é a colisão com maior barreira centrífuga e representa a colisão entre dipolos paralelos (11)

Figura 8 - Medidas das taxas de perda em função do momento de dipolo da amostra. A curva em verde representa a medida feita para estados internos diferentes, a curva preta representa a taxa de perda para dipolos paralelo e em vermelho a configuração anti-paralelo para o alinhamento do dipolo (11)

Figura 9 - $\quad$ Forno misto para a produção de vapor de Rb e K. Os compartimentos em $(\mathrm{Rb})$ e $(\mathrm{K})$ contém de 5 a 10 gramas do respectivo elemento e são mantidos a uma temperatura média de $140{ }^{\circ} \mathrm{C}$. Um tubo diferencial em (1) mantém o fluxo de K e Rb similares na saída do forno (2). Em (3) temos uma placa fria de cobre que impede que o vapor residual e quente se propague até o experimento. Uma válvula pneumática de segurança (4) isola o forno da parte de ultra alto vácuo em caso de emergência, e em (5) com diâmetro de 4,77 mm e comprimento de $127 \mathrm{~mm}$ temos o tubo diferencial de pressão que mantém a região do experimento e do forno com uma diferença de pressão de $10^{-3}$ Torr....

Figura 10 - Campo magnético do desacelerador. Os pontos em azul e a linha preta são os campos teóricos e projetados respectivamente. A linha vermelha mostra o valor que foi aferido, mostrando bom acordo com o projetado.

Figura 11 - Imagem ilustrativa da câmara de aprisionamento. Indicado com uma seta, temos os elementos mais relevantes para o experimento. A pressão de trabalho é inferior a $10^{-10}$ Torr

Figura 12 - a) Configuração do campo magnético em 1D para a obtenção do MOT. b) Abertura dos estados hiperfinos devido ao campo magnético e polarização dos lasers contrapropagantes.

Figura 13 - Transições para os elementos atômicos: ${ }^{85} \mathrm{Rb},{ }^{87} \mathrm{Rb}$ e ${ }^{39} \mathrm{~K}$. Os feixes de aprisionamento correspondem às setas azuis e o rebombeio as 
Figura 14 - Amplificador óptico utilizado para aumentar a potência disponível para o MOT de 39K. A esquerda temos o desenho técnico com uma foto do laser construído a direita.

Figura 15 - Montagem óptica para o ${ }^{39} \mathrm{~K}$. Para gerar as frequências do experimento, foram utilizados $5 \mathrm{AOMs}$ com as seguintes frequências centrais: (i) $80 \mathrm{MHz}$ para o AOM1, AOM4 e AOM5; (ii) $300 \mathrm{MHZ}$ para o AOM2; (iii) $250 \mathrm{MHz}$ para o AOM3. Todos os moduladores estavam em uma configuração de dupla passagem, sendo que o AOM3 era o único que operava com a ordem de difração negativa. Um EOM de $435 \mathrm{MHz}$ gerava a frequência de rebombeio para o desacelerador.

Figura 16 - Montagem óptica para o Rb. AOM1 (-93,5 MHz) com total de -187 $\mathrm{MHz}$ para a espectroscopia de absorção saturada I e travamento na transição de aprisionamento $5 \mathrm{~S}_{1 / 2}(\mathrm{~F}=2,3)-5 \mathrm{P}_{3 / 2}\left(\mathrm{~F}^{\prime}=3,4\right)$ do ${ }^{87} \mathrm{Rb}$ e ${ }^{85} \mathrm{Rb}$ respectivamente. AOM2 $(+83,5 \mathrm{MHz})$ com total de $+167 \mathrm{MHz}$ produzindo o feixe de aprisionamento do MOT a $-20 \mathrm{MHz}$ da transição. AOM3 (-200 MHz) com total de $-400 \mathrm{MHz}$ gerando o feixe de aprisionamento do desacelerador a $-687 \mathrm{MHz}$. Espectroscopia de absorção saturada II travado a $-80 \mathrm{MHz}$ da transição de rebombeio $5 \mathrm{~S}_{1 / 2}(\mathrm{~F}=1,2)-5 \mathrm{P}_{3 / 2}\left(\mathrm{~F}^{\prime}=2,3\right)$ do ${ }^{87} \mathrm{Rb}$ e ${ }^{85} \mathrm{Rb}$ respectivamente. AOM4 $(-175 \mathrm{MHz})$ com total de $-350 \mathrm{MHz}$ produzindo o feixe de rebombeio para a desaceleração a $-430 \mathrm{MHz}$ da transição. AOM5 (+80 MHz) produz o feixe para o rebombeio do MOT na transição. AOM6 (+93,5 MHz) com total de $+187 \mathrm{MHz}$ produz o feixe de imagem na transição de aprisionamento. As frequências para a desaceleração são misturadas em um cubo divisor e injetados em um laser DL da Toptica com saída de $80 \mathrm{~mW}$

Figura 17 - Sistema de junção das fibras de desaceleração. A dispersão dos feixes era de $15 \%$ a $3 \mathrm{~m}$ da fibra (63)....

Figura 18 - Montagem ótica para a obtenção da armadilha de dipolo cruzada. Nessa configuração, utilizando o AOM para o controle de potência do laser, a cintura do feixe era de $72 \mu \mathrm{m}$ para os dois feixes do dipolo cruzado.

Figura 19 - Programa de controle do experimento. Delimitado pela linha vermelha, temos a parte responsável pela geração de trens de pulso. Em amarelo, o controle dos canais digitais, divididos temporalmente em 20 partes. Cada parte temporal pode ser desabilitada independentemente pelos LEDs verdes na parte inferior. Em azul 
temos o gerador de rampa para os canais analógicos, com capacidade de 8 rampas. Finalmente em verde temos o controle dos canais analógicos. A esquerda da área delimitada em verde, temos dois LEDs que desabilitam todos os canais analógicos ou digitais a escolha, e um campo onde podemos escolher a frequência de sincronia do experimento e o atraso inicial....

Figura 20 - Técnica de normalização de pontos sucessivos: "pontos gêmeos". As curvas em verde, azul e vermelho representam curvas de decaimento dos átomos na armadilha de dipolo decorrentes da flutuação do número inicial $\left(\mathrm{P}_{\mathrm{ti}}\right)$. O método de aquisição é alternado, sendo obtidos os valores de $\mathrm{P}_{\mathrm{ti}} \mathrm{e}$ em seguida o valor de $\mathrm{P}_{\mathrm{t}}$ para a normalização $\mathrm{P}_{\mathrm{t}} / \mathrm{P}_{\mathrm{ti}}$. $\mathrm{O}$ processo é repetido para a obtenção de vários pontos para a média

Figura 21 - Sequência para obtenção das três imagens $\left(I, I_{0}\right.$ e $\left.I_{B}\right)$ que compõe a imagem de absorção ( $\mathrm{I}_{\mathrm{OD}}$ ). $\mathrm{O}$ tempo de $1 \mathrm{~s}$ entre a aquisição das imagens servia para garantir o processamento correto pelo computador. A obtenção de cada imagem era feita em $100 \mu \mathrm{s}$. b) Sequência de imagens aquisicionadas, onde I representa a imagem dos átomos na armadilha, $\mathrm{I}_{0}$ somente os feixes laser, sem átomos, $\mathrm{I}_{\mathrm{B}} \mathrm{O}$ plano de fundo para eventuais ruídos da câmera e $\mathrm{I}_{\mathrm{OD}}$ a imagem processada

Figura 22 - Programa de aquisição e processamento de imagens. a) Na parte delimitada em amarelo temos os resultados que foram obtidos durante o dia, como um número proporcional ao número de átomos no MOT e na armadilha de dipolo do $\mathrm{K}$ e do $\mathrm{Rb}$ junto com o horário da aquisição. O botão "Salva dados" serve para habilitar essa opção. Em vermelho, temos os controles gerais do programa, como a opção de salvar as imagens em arquivos, alterar o tamanho do ROI de uma sequência pra outra, criar caminho automático ou manual para salvar as imagens e rodar o experimento continuamente ou executar a sequência uma única vez. A parte verde mostra a imagem de absorção do dipolo duplo para $\mathrm{Rb}$ a esquerda e $\mathrm{K}$ a direita. Em b) temos a parte responsável pelo monitoramento do MOT. A cada 50 ms uma imagem de fluorescência é tirada e integrada em uma região de interesse escolhida, retornando um valor proporcional ao tamanho do MOT que é graficado, servindo para monitorar a armadilha

Figura 23 - Parte do programa responsável pela obtenção da cintura da armadilha de dipolo e temperatura. Na parte em a) temos um cursor que é posicionado no centro da amostra e retira um perfil de intensidade indicado pela linha amarela. Em b) temos o programa que faz o ajuste de uma gaussiana no perfil e extrai o valor da cintura. No centro temos um campo denominado "Tempo", tal campo indica a separação no tempo de expansão entre duas imagens consecutivas em 
"ms" e o campo "Pa" indica o peso atômico do elemento estudado. Ambos os campos, junto com a cintura de duas imagens consecutivas, servem para a obtenção de uma estimativa da temperatura

Figura 24 - Esquema de níveis de transições para o ${ }^{39} \mathrm{~K}$ incluindo o feixe de aprisionamento $\left(\omega_{1}\right)$ e rebombeio $\left(\omega_{2}\right)$, onde $\delta_{\mathrm{w} 1}$ é a dessintonia referente à transição $4 \mathrm{~S}_{1 / 2}(\mathrm{~F}=2) \rightarrow 4 \mathrm{P}_{3 / 2}\left(\mathrm{~F}^{\prime}=3\right)$ e $\Delta$ é referente à $4 \mathrm{~S}_{1 / 2}(\mathrm{~F}=1) \rightarrow 4 \mathrm{P}_{3 / 2}\left(\mathrm{~F}^{\prime}=2\right)$.

Figura 25 - a) Sequencia experimental otimizada para carregamento da armadilha de dipolo. b) Imagem de absorção da armadilha de dipolo cruzado e c) imagem de fluorescência. A frequência do laser de rebombeio era sempre fixa em $\Delta=-18 \mathrm{MHz}$.

Figura 26 - a) Imagem de absorção obtida. Como a imagem é feita no mesmo plano que contém os feixes, a linha tracejada em azul corresponde a superposição do carregamento de dois feixes simples da armadilha e a região em vermelho corresponde a região cruzada. b) Gráfico de intensidade 3D da imagem de absorção para o ${ }^{39} \mathrm{~K}$. As coordenadas $\mathrm{X}$ e $\mathrm{Y}$ correspondem aos pixels da CCD enquanto que a coordenada $\mathrm{Z}$ representa a densidade ótica (OD) da amostra, com valor máximo OD $=1,1$. As setas vermelha e azul correspondem respectivamente as áreas vermelha e azul delimitadas em "a". As imagens em "a" e "b" correspondem exatamente à mesma imagem com tratamento matemático diferente.

Figura 27 - a) Número de átomos em função da variação do tempo de carregamento. b) Número de átomos carregados em função da potência final do laser de dipolo no processo de carregamento.

Figura 28 - Variação da dessintonia do laser de aprisionamento $\left(\delta_{\omega 1}\right)$ em relação a transição $4 S_{1 / 2}(F=2) \rightarrow 4 P_{3 / 2}\left(F^{\prime}=3\right)$.

Figura 29 - Diagrama de transições para o ${ }^{39} \mathrm{~K}$ indicando as regiões de alcance do laser. b) Medida da temperatura da amostra através da aplicação de rampa na dessintonia do laser de aprisionamento (círculos vermelhos) e através da mudança abrupta (quadrados pretos). c) Medida do número remanescente de átomos após o processo de resfriamento com (círculos vermelhos) e sem (quadrados pretos) a aplicação de rampa. As regiões I, II e III nos gráficos b) e c) são correspondentes as mesmas regiões em a) entre $F^{\prime}=2$ e $F^{\prime}=3$. Figura extraída de (62). ..

Figura 30 - Esquema de variação da dessintonia efetiva do laser de 
aprisionamento $\left(\delta_{e f f}=\delta_{w 1}+\delta_{a c}\right)$ em função do aumento da potência do laser de dipolo.

Figura 31 - Variação das intensidades dos lasers de a) aprisionamento e b) rebombeio na fase de carregamento. As intensidades são representadas por braço do MOT.

Figura 32 - Sequência temporal para o carregamento de uma armadilha de dipolo de ${ }^{85} \mathrm{Rb}$ ou ${ }^{87} \mathrm{Rb}$.

Figura 33 - Variação da densidade em função do tempo da armadilha de dipolo para a) ${ }^{85} \mathrm{Rb}$ e b) ${ }^{87} \mathrm{Rb}$.

Figura 34 - $\quad$ Medida do parâmetro de perda devido ao vácuo $(\gamma)$. O ponto inicial de ajuste é $\mathrm{t}=500 \mathrm{~ms}$, onde a perda devido a dois corpos se torna desprezível

Figura 35 - Processo de colisão com inversão da estrutura hiperfina. A energia remanescente da inversão $(\Delta \mathrm{E})$ é convertida em energia cinética para os átomos

Figura 36 - Transições do tipo Raman induzidas devido ao caráter multimodo do laser. Em a) temos uma representação dos modos do laser e em b) $\mathrm{O}$ bombeamento realizado para $\mathrm{F}=2$ através de um estado virtual

Figura 37 - Fração de átomos no estado hiperfino mais elevado $\left(F_{u h}\right)$ como função do tempo de aprisionamento para ambos os isótopos. b) Temperatura dos átomos em função do tempo de aprisionamento (49)

Figura 38 - Esquema proposto para a formação de moléculas frias. Os estados importantes para o processo de fotoassociação (PA) estão indicados (estado fundamental $X^{1} \Sigma_{g}^{+}$, extraído de (70) e estados excitados $A^{1} \Sigma_{u}^{+}$ e $b^{3} \Pi_{u}^{+}$, extraídos de (71)). O nível $v^{\prime}=137$ para o estado $0_{u}^{+}$ $\left({ }^{87} \mathrm{Rb} 2\right)$ indicado, é populado devido ao processo de PA pelo laser de $1071 \mathrm{~nm}$ (seta azul). O processo de emissão espontânea (SE) é sugerido pelas setas verdes nos pontos de maior probabilidade de decaimento no estado $X^{1} \Sigma_{g}^{+}$.

Figura 39 - Variação da densidade de ${ }^{39} \mathrm{~K}$ na armadilha de dipolo juntamente com o ajuste da curva teórica. b) Evolução da temperatura no sistema, demonstrando que não houve aquecimento na amostra

Figura 40 - Carregamento duplo de K e Rb na armadilha de dipolo. Nota-se que a 
quantidade total de átomos carregados é aproximadamente constante, porém a proporção pode ser manipulada sem muitos problemas

Figura 41 - Caracterização para o carregamento duplo de K e Rb na armadilha de dipolo. a) Temos o número de átomos em função da potência final da rampa de dipolo. Em b) temos o número de átomos carregados em função do tempo de aplicação da rampa de potência para o feixe de dipolo e em c) em função do tempo de carregamento após a rampa, com o laser de $1071 \mathrm{~nm}$ na potência máxima $(40 \mathrm{~W})$.

Figura 42 - Sequência temporal para o carregamento duplo de $\mathrm{K}$ e $\mathrm{Rb}$ na armadilha de dipolo.

Figura 43 - Variação da densidade em função do tempo da armadilha para o carregamento duplo

Figura 44 - Evolução da temperatura em função do tempo da armadilha para o carregamento duplo

Figura 45 - Esquema de fotoassociação (PA) e decaimento espontâneo em átomos livres (SE1) e em moléculas (SE2).

Figura 46 - Distribuição dos estados vibracionais no estado eletrônico fundamental $\left(X^{1} \Sigma_{g}^{+}\right)$após a fotoassociação (PA) do ${ }^{85} \mathrm{Rb}$

Figura 47 - Distribuição dos estados vibracionais no estado eletrônico fundamental $\left(X^{1} \Sigma_{g}^{+}\right)$após o equilíbrio para o ${ }^{85} \mathrm{Rb}$.

Figura 48 - Distribuição dos estados vibracionais no estado eletrônico fundamental $\left(X^{1} \Sigma_{g}^{+}\right)$após a fotoassociação (PA) do ${ }^{87} \mathrm{Rb}_{2}$.

Figura 49 - Distribuição dos estados vibracionais no estado eletrônico fundamental $\left(X^{1} \Sigma_{g}^{+}\right)$após o equilíbrio para o ${ }^{87} \mathrm{Rb}_{2}$

Figura 50 - Processo de ionização do $\mathrm{Rb}_{2}$ para detecção iônica. O estado intermediário $2 \Pi_{u}$ foi escolhido por apresentar alto FCF com os níveis $v<20$ para o estado fundamental $X^{1} \Sigma_{g}^{+}$

Figura 51 - Gráfico de intensidade do FCF entre os níveis vibracionais do estado fundamental $\left(X^{1} \Sigma_{g}^{+}\right)$e intermediário $\left(2 \Pi_{u}\right)$ para o processo de ionização do $\mathrm{Rb}_{2}$. 
Figura 52 - Potenciais de interação atômico de interesse para a fotoassociação (PA) do KRb e bombeamento vibracional. a) Curvas de potencial do estado excitado considerando a estrutura hiperfina do $\mathrm{Rb}(5 \mathrm{P})$. b) Estados eletrônicos fundamentais

Figura 53 - Distribuição dos estados vibracionais no estado eletrônico fundamental $\left(X^{1} \Sigma^{+}\right)$após a fotoassociação (PA) do ${ }^{39} \mathrm{~K}^{87} \mathrm{Rb}$

Figura 54 - Distribuição dos estados vibracionais no estado eletrônico fundamental $\left(X^{1} \Sigma^{+}\right)$após o equilíbrio para o ${ }^{39} \mathrm{~K}^{87} \mathrm{Rb}$

Figura 55 - Distribuição dos estados vibracionais no estado eletrônico fundamental $\left(X^{1} \Sigma^{+}\right)$após a fotoassociação (PA) do ${ }^{39} \mathrm{~K}^{85} \mathrm{Rb}$

Figura 56 - Distribuição dos estados vibracionais no estado eletrônico fundamental $\left(X^{1} \Sigma^{+}\right)$após o equilíbrio para o ${ }^{39} \mathrm{~K}^{85} \mathrm{Rb}$

Figura 57 - Gráfico de intensidade do FCF entre os níveis vibracionais do estado fundamental $\left(X^{1} \Sigma^{+}\right)$e intermediário $\left({ }^{1} \Pi\right)$ para o processo de ionização do $\mathrm{KRb}$.

Figura 58 - Gráfico de intensidade do FCF entre os níveis vibracionais do estado fundamental $\left(X^{1} \Sigma^{+}\right)$e intermediário $\left({ }^{1} \Pi\right)$ para o processo de bombeamento do $\mathrm{KRb}$. Os valores representados por quadrados brancos são transições proibidas devido ao corte de frequência em $15031 \mathrm{~cm}^{-1}$.

Figura 59 - Transições permitidas (quadrados pretos) entre o estado fundamental $\left(X^{1} \Sigma^{+}\right)$e intermediário $\left({ }^{1} \Pi\right)$ para o processo de bombeamento do $\mathrm{KRb}$ para $\left(X^{1} \Sigma^{+} ; v=0\right)$ estando o laser de bombeamento limitado espectralmente $\left(14900-15030 \mathrm{~cm}^{-1}\right)$. 


\section{Lista de Tabelas}

Tabela 1 - Resultados para a fotoassociação do ${ }^{87} \mathrm{Rb}$ e ${ }^{85} \mathrm{Rb}$.

Tabela 2 - Resultado dos parâmetros de perda da armadilha de dipolo cruzado com apenas um elemento carregado.

Tabela 3 - Resultado dos parâmetros de perda da armadilha de dipolo duplo. A descrição do carregamento é dado como "X com (Y)", onde "X" é o elemento que está sendo estudado na presença do elemento "Y". O valor de $\beta^{\prime}$ está em uma célula mesclada, pois é um parâmetro referente ao carregamento das duas espécies simultaneamente 



\section{Sumário}

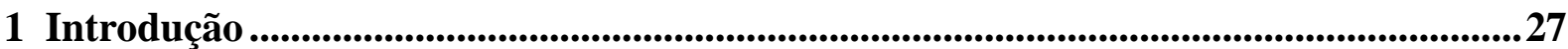

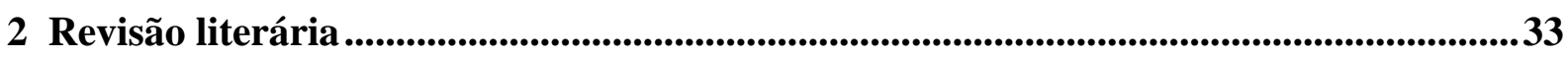

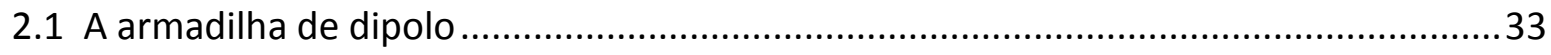

2.2 A busca por moléculas frias no estado vibracional fundamental ...............................36

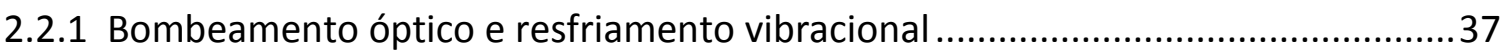

2.2.2 Bombeamento óptico e resfriamento vibracional e rotacional..............................39

2.2.3 Formação de molécula no estado rovibrônico fundamental através de fotoassociação e decaimento espontâneo. .................................................................. 40

2.2.4 Controle da dinâmica colisional molecular ........................................................... 42

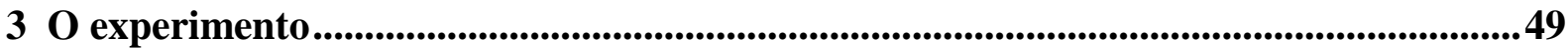

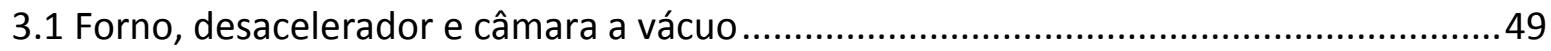

3.2 Armadilha magneto óptica dupla: Potássio e Rubídio.................................................54

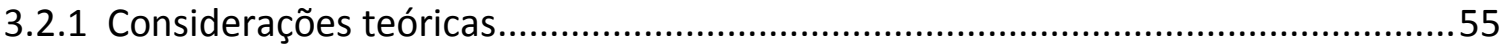

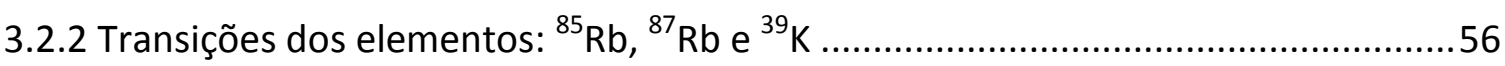

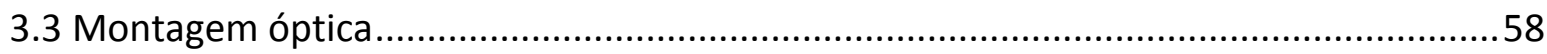

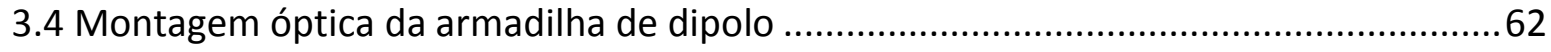

3.5 Sistemas de controle a aquisição de dados .................................................................64

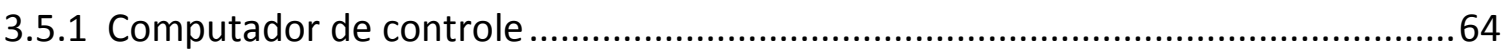

3.5.2 Computador de aquisição de imagens ...............................................................67

3.5.3 Computador de aquisição de dados....................................................................... 73

4 Átomos de ${ }^{39} \mathrm{~K}$ em uma armadilha de dipolo ......................................................................75

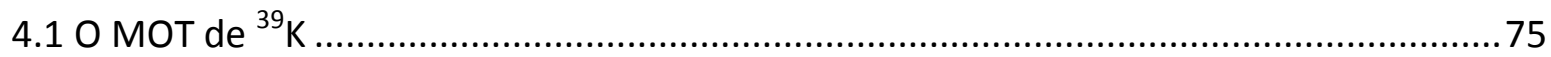

$4.2 \mathrm{O}$ resfriamento sub-Doppler do MOT de ${ }^{39} \mathrm{~K}$ e carregamento da armadilha de dipolo .77

4.3 Caracterização do carregamento de ${ }^{39} \mathrm{~K}$ na armadilha dipolo.....................................79

5 Carregamento da armadilha de dipolo dupla de $\mathrm{Rb}$ e $\mathrm{K}$...............................................887

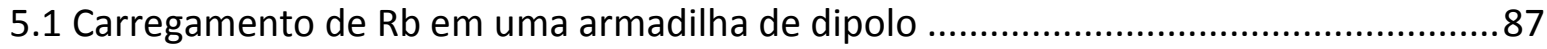

5.2 Taxas de perda e evolução da temperatura de Rb em uma armadilha de dipolo ..........88

5.3 Carregamento duplo de K-Rb em uma armadilha de dipolo .......................................97

5.4 Perdas em uma armadilha de dipolo dupla de $\mathrm{K}$ e Rb............................................103

6 Bombeamento Óptico molecular em uma armadilha de dipolo....................................109 


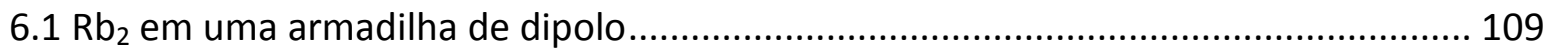

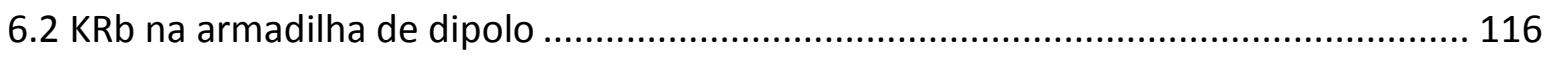

6.2.4 Ionização e detecção molecular do KRb.............................................................. 122

6.3 Bombeamento de moléculas de KRb para o estado vibrônico fundamental .............. 123

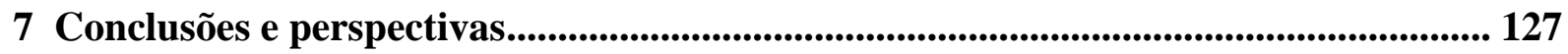

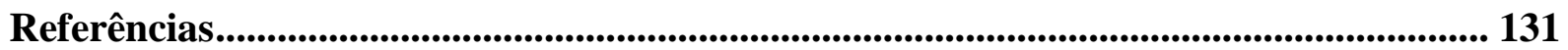




\section{Introdução}

O regime de produção de gases ultrafrios $(T \leqslant 1 \mathrm{mK})$ tem revolucionado o mundo da física com prêmios Nobel em aprisionamento e resfriamento atômico (1-3) e na produção de condensados atômicos de Bose-Einstein (4-5). Nos últimos anos, temos visto um progresso na produção de moléculas ultrafrias, um pouco mais lento do que aconteceu com átomos frios. Contudo, o problema é mais complexo visto que moléculas têm vários graus de liberdade, exigindo técnicas experimentais mais avançadas.

Além de maior grau de complexidade, moléculas apresentam uma gama maior de aplicações se comparada aos átomos, como o estudo de reações químicas no regime ultrafrio (6), a busca pelo momento de dipolo permanente do elétron (EDM) (7) e estudo de um novo regime de transição quântica com gases moleculares (8). A produção de moléculas polares tem despertado ainda mais o interesse de laboratórios ao redor do mundo (9). Devido ao seu momento de dipolo elétrico permanente, campos externos podem controlar o alinhamento dipolar e reger a dinâmica das colisões através da interação anisotrópica de longo alcance do tipo dipolo-dipolo. Esse tipo de manipulação apresenta grande potencial, sendo esperada uma série de novos fenômenos. Também tem sido mostrado que a taxa de colisão entre duas moléculas polares é muito sensível à aplicação de campos externos (10-12). Tais experimentos podem servir de plataforma para a realização do controle de reações químicas. Por isso, é importante produzir moléculas polares em regimes ultrafrios e no estado rovibrônico fundamental para que se tenha um controle mais efetivo sobre as colisões inelásticas.

Os métodos de produção de moléculas frias são bastante variados e podem ser divididos em duas vertentes. A primeira consiste em resfriar a molécula já formada reduzindo sua energia cinética e interna. Uma técnica proposta por Bahns e colaboradores (13) utiliza um laser multi-espectral para resfriar sequencialmente a energia rotacional, translacional e vibracional, demandando um sistema muito complexo com múltiplas transições.

Outra técnica interessante consiste no resfriamento devido à colisão com átomos de Hélio criogênico, denominada de buffer gas cooling, proposto inicialmento por J. Doyle e colaboradores (14). A maior vantagem é que a técnica se baseia em colisões elásticas entre as moléculas e o gás de Hélio, não dependendo da estrutura interna da partícula a ser refrigerada. Outra vantagem é o poder de resfriamento, podendo desacelerar uma grande quantidade de 
partículas. Uma desvantagem da técnica é a temperatura limite de resfriamento ( 300 mK). Para partículas que apresentam momentos magnéticos significantes, uma alternativa possível para diminuir a temperatura seria o aprisionamento molecular em uma armadilha magnética e a realização de um processo de evaporação forçada. Contudo, um dos requisitos para uma evaporação eficiente é o domínio das colisões elásticas perante outros tipos de colisão (inelásticas ou reativa). Foi previsto que para o regime de moléculas frias nessa faixa de temperatura $(\sim 300 \mathrm{mK})$ ocorre uma alta taxa de colisão inelástica por causa das estruturas rotacionais internas energéticas (15). Outro fator que prejudica a evaporação é o tempo de vida limitado da amostra devido aos átomos de Hélio remanescentes no gás de fundo. Assim, o resfriamento evaporativo não pode ser realizado nesse tipo de armadilha. Contudo a técnica tem grande potencial para a geração de moléculas frias e na geração de feixes moleculares (16), podendo servir como fonte molecular para outro tipo de armadilha no futuro. O buffer gas cooling já foi demostrado no resfriamento de várias moléculas, como $\mathrm{CaH}$ (17), $\mathrm{NH}$ e $\mathrm{CaF}$ (18) e $\mathrm{PbO}$ (17). Em específico, no resfriamento das moléculas de $\mathrm{PbO}$, considerada uma grande candidata para a medição do EDM eletrônico, foram obtidas cerca de $10^{12}$ moléculas a uma temperatura de $4 \mathrm{~K}$.

Uma alternativa ao buffer gas cooling é a técnica baseada no efeito Stark para a desaceleração molecular (19). Tal técnica se baseia na mudança energética que uma molécula polar experimenta quando colocada em um campo elétrico. Supondo que uma molécula aumente a sua energia potencial quando se mover na direção do aumento de um campo elétrico, terá como resultante uma redução na sua energia cinética. Contudo, quando a molécula deixa a região de alto campo elétrico, a velocidade é recuperada. Se o campo elétrico for desligado quando a molécula estiver na região de alto campo elétrico, a velocidade não é recuperada e a molécula resfria. Aplicando esse processo repetidas vezes através da modulação de um campo elétrico inomogêneo, é possível obter amostras com temperaturas da ordem de $1 \mathrm{~K}$. Moléculas de $\mathrm{CO}(19), \mathrm{ND}_{3}(20)$ e $\mathrm{OH}$ (7) foram resfriadas com essa técnica, embora com baixa densidade. Apesar de ter apresentado resultados importantes com moléculas frias (21), a técnica não é viável para obtenção direta de moléculas ultrafrias. Algumas propostas para contornar esse problemas foram sugeridas, uma delas é a utilização de átomos ultrafrios para resfriar as moléculas através de resfriamento simpático (22).

As técnicas descritas até o momento partem de amostras com altas energias cinéticas, geralmente temperatura ambiente $(\sim 300 \mathrm{~K})$. Uma proposta realizada por R. Lambo e colaboradores (23) sugere a construção de uma matriz sólida de gás nobre (Neônio) com as 
partículas de interesse implantadas no interior dessa matriz. As partículas podem ser átomos, moléculas e até íons, desde que sejam estáveis na formação da matriz. Através de um pulso de ablação, camadas sucessivas da matriz são sublimadas, liberando a molécula em baixas temperaturas que se acumulam em uma armadilha magnética. Como a densidade de Neônio decai rapidamente $(\sim 60 \mu s)$ consegue-se a dissipação do gás em tempo hábil para o não comprometimento da amostra aprisionada, possibilitando maiores tempos de vida (23). Esse trabalho foi realizado com átomos de Crômio em uma matriz de Neônio, resultando em uma amostra com $13 \mathrm{~K}$ e densidade $10^{12} \mathrm{~cm}^{-3}$, abrindo a perspectiva para realização do experimento em moléculas polares.

Uma segunda maneira de obtermos moléculas frias é através da conversão de átomos em moléculas. Duas técnicas comumente usadas para esse fim é a magneto associação (MA) através de ressonâncias de Feshbach e a fotoassociação (PA).

A ressonância de Feshbach em átomos frios foi proposta por W. Stwalley (24). O princípio é baseado na igualdade da energia de colisão entre dois átomos livres com a energia de ligação de um estado molecular. Esse problema se reduz a um problema de dois canais onde um canal corresponde aos átomos livres e o outro aos estados moleculares. Como os canais possuem diferentes momentos de dipolo, um campo magnético pode ser usado para ajustar o deslocamento energético entre os canais. Aplicando um campo magnético variável no tempo, temos que para uma dada separação internuclear, os canais apresentam a mesma energia e a conversão de átomos em moléculas se torna possível. As primeiras observações de moléculas obtidas com essa técnica foram feitas em 1998 (25-28).

As moléculas produzidas via ressonância de Feshbach se apresentam nos mais altos níveis vibracionais e em temperaturas perto da degenerescência dos gases atômicos. Uma maneira de se trazer essas moléculas para níveis rovibracionais fundamentais é utilizando uma técnica denominada STIRAP (Stimulated Raman Adiabatic Passage) (29, 30). Com essa técnica, Miranda e colaboradores (11) foram capazes de formar moléculas de $\mathrm{Rb}_{2}$ via MA e transferi-las para o estado rovibracional fundamental usando STIRAP com eficiência de $90 \%$.

Já a fotoassociação (PA) é um processo em que dois átomos colidentes absorvem um fóton formando um estado molecular excitado. Por meio de um decaimento espontâneo, a molécula pode ir para um estado de átomos livres ou decair em uma molécula no estado fundamental eletrônico. A PA tem se tornado uma área em branda expansão, sendo objeto de várias revisões literárias (31-33) e responsável pela produção de vários tipos de moléculas. Citando alguns experimentos bem sucedidos, temos a produção de $\mathrm{Cs}_{2}(34), \mathrm{K}_{2}(35,36), \mathrm{Rb}_{2}$ (37-40), RbCs (41), KRb (42), NaCs (43) e LiCs (44). 
Contudo, como as moléculas são formadas via decaimento espontâneo, a distribuição dos níveis vibracionais depende do fator de Franck Condon (FCF) e geralmente culmina em uma distribuição de níveis vibracionais no estado fundamental. A purificação para um determinado nível vibracional não é uma tarefa fácil. Porém, propostas para bombeamento dessas moléculas para o nível vibracional e rovibracional fundamental foram realizadas experimentalmente (45-46). Tais trabalhos serão discutidos em detalhes no capítulo seguinte.

Diante do desafio de produzir moléculas de uma maneira eficiente e aprisioná-las, o desenvolvimento de novos caminhos é bem-vindo. Este é o objetivo deste trabalho, onde montamos um experimento com o intuito de aprisionar átomos e moléculas através de uma armadilha de dipolo com potência de $40 \mathrm{~W}$ e comprimento de onda de $1071 \mathrm{~nm}$. O princípio dessa armadilha é baseado na indução de um momento de dipolo e o confinamento das partículas na região de maior intensidade do feixe, ou seja, no foco. Devido à grande dessintonia do laser em relação às transições ressonantes, o espalhamento de fótons é reduzido, acarretando em um alto tempo de vida, limitado apenas pelo vácuo da câmara.

Nesse sistema será possível o aprisionamento de átomos de $\mathrm{K}$ e $\mathrm{Rb}$ e moléculas de $\mathrm{K}_{2}$, $\mathrm{Rb}_{2}$ e $\mathrm{KRb}$ por períodos maiores que 2 segundos. Como destaque nesse experimento, carregamos uma amostra de ${ }^{39} \mathrm{~K}$ na armadilha de dipolo diretamente da armadilha magnetoóptica (MOT) (47) e observamos moléculas de $\mathrm{Rb}_{2}$ aprisionadas na armadilha de dipolo (48). Também realizamos o carregamento duplo de $\mathrm{K}-\mathrm{Rb}$ na armadilha dipolar, onde verificamos perdas relacionadas a densidade causadas possivelmente pela fotoassociação do laser de 1071 $\mathrm{nm}$ [artigo será submetido]. Estudamos também as perdas de ${ }^{87} \mathrm{Rb}$ e ${ }^{85} \mathrm{Rb}$ na armadilha de dipolo, de onde deduzimos, através de cálculos teóricos, que as perdas ocorriam devido ao processo de fotoassociação do laser de $1071 \mathrm{~nm}$, predizendo a diferença de PA entre os isótopos medidos experimentalmente (49).

No capítulo 2, apresentaremos os fundamentos teóricos sobre a armadilha de dipolo e cálculos referentes a sua profundidade e taxa de espalhamento de fótons para as configurações da nossa armadilha. Também iremos revisar os principais trabalhos sobre formação de moléculas via fotoassociação e magnetoassociação. Técnicas usadas para levar tais moléculas para o estado rovibracional fundamental também serão abordadas.

No capítulo 3, iremos descrever a montagem experimental necessária para a desaceleração, aprisionamento em uma armadilha magneto-óptica (MOT) e transferência para uma armadilha de dipolo dos elementos ${ }^{39} \mathrm{~K},{ }^{87} \mathrm{Rb}$ e ${ }^{85} \mathrm{Rb}$. Apresentaremos o princípio básico de funcionamento de uma armadilha magneto-óptica e as linhas de transição importantes para o confinamento. Por fim, mostraremos o sistema de controle e automação do experimento e 
aquisição de dados juntamente com a sequência temporal para a obtenção das imagens de absorção. A matemática necessária para analisar as imagens de absorção e extrair as informações relevantes, como cintura e densidade máxima, também será apresentada.

No capítulo 4, iremos descrever o processo para o carregamento de um MOT de ${ }^{39} \mathrm{~K}$ e transferência para uma armadilha de dipolo cruzada com comprimento de onda de $1071 \mathrm{~nm}$. Como não havia registro na literatura desse tipo de transferência para o ${ }^{39} \mathrm{~K}$, uma caracterização detalhada foi realizada com o objetivo de maximizar o número total de átomos na armadilha.

No capítulo 5, apresentaremos o processo de carregamento de $\mathrm{Rb}$ em uma armadilha de dipolo, onde estudaremos o processo de decaimento da densidade em função do tempo da armadilha. Um modelo teórico baseado na perda de átomos devido à fotoassociação de $\mathrm{Rb}$ pelo laser de $1071 \mathrm{~nm}$ foi desenvolvido. O resultado concorda com a diferença isotópica entre $\mathrm{o}{ }^{85} \mathrm{Rb}$ e ${ }^{87} \mathrm{Rb}$ observado experimentalmente, reforçando a tese de fotoassociação pelo laser de aprisionamento de dipolo. Em seguida, usando os conhecimentos gerados nos carregamentos individuais de $\mathrm{K}$ e $\mathrm{Rb}$, realizamos um carregamento duplo da armadilha de dipolo. Com base em um modelo fenomenológico de equações de taxas, extraímos a perda devido à colisão inter-espécies.

No capítulo 6, mostramos quais seriam os possíveis canais de fotoassociação e bombeamento devido ao laser de dipolo para as moléculas de ${ }^{87} \mathrm{Rb}_{2},{ }^{85} \mathrm{Rb}_{2},{ }^{39} \mathrm{~K}^{87} \mathrm{Rb}$ e ${ }^{39} \mathrm{~K}^{85} \mathrm{Rb}$. Uma situação estacionária para a distribuição de níveis vibracionais no estado eletrônico fundamental também será apresentada. Por meio dessa distribuição, foi possível inferir um caminho para realizar a ionização e detecção de tais moléculas. Por fim, apresentaremos a atual situação do experimento e as perspectivas para trabalhos futuros. 


\section{Revisão literária}

Nesse capítulo, mostramos os aspectos teóricos de uma armadilha de dipolo e calculamos parâmetros importantes, como sua profundidade e tempo de vida. Também apresentamos uma revisão da literatura sobre a formação e manipulação de moléculas no estado rovibracional fundamental.

\subsection{A armadilha de dipolo}

Nesse tópico, descreveremos brevemente o conceito teórico fundamental de uma armadilha de dipolo. Como é de conhecimento geral, o confinamento de átomos e moléculas nesse tipo de armadilha depende exclusivamente da presença de um gradiente de campo elétrico, criando um potencial confinante através da indução de um momento de dipolo. Temos que um campo elétrico oscilante proveniente de uma radiação eletromagnética que pode ser descrito de acordo com a equação (1).

$$
\vec{d}=\alpha(w) \vec{E}, \quad \vec{E}=\tilde{E} . \hat{e}, \quad \widetilde{E}=E_{0} \cdot e^{-i w t}
$$

Em que $\alpha(w)$ representa a polarizabilidade complexa do átomo, $\vec{d}$ a amplitude do dipolo induzido e $\hat{e}$ a direção de oscilação do campo elétrico. O potencial de interação é dado pela média geométrica entre o produto escalar do dipolo e do campo elétrico, da forma:

$$
V_{\mathrm{int}}=-\frac{\langle\vec{d} \cdot \vec{E}\rangle}{2}=-\frac{1}{4}|E|^{2} \cdot \operatorname{Re}\{\alpha(w)\}=-\frac{1}{2} \frac{I}{\varepsilon_{0} \cdot c} \cdot \operatorname{Re}\{\alpha(w)\}
$$

Sendo:

$$
I=\frac{1}{2} \varepsilon_{0} \cdot c \cdot|E|^{2}
$$


Em que $\vec{E}$ e $\vec{d}$ representam o campo elétrico e o dipolo induzido respectivamente e $I$ a intensidade do laser. O fator " 2 " dividindo o potencial de interação advém do fato de o momento de dipolo que interage com o campo ser induzido e não permanente (50).

Pela equação (2), vê-se que o potencial de interação $\left(V_{\text {int }}\right)$ depende diretamente da intensidade do laser e da parte real da polarizabilidade atômica. Tal resultado é muito importante, pois mostra que a profundidade da armadilha irá depender da potência e do comprimento de onda do laser confinante, variando também a profundidade entre os diversos elementos atômicos, pois este irá depender diretamente da parte real de $\alpha(\omega)$.

Outra variável a ser levada em conta e que pode influenciar muito o comportamento da armadilha é a potência da luz espalhada pela amostra. Tal valor é dado pela derivada temporal do potencial de interação, como mostrado na equação (4).

$$
P_{e s p}=\langle\dot{\vec{d}} \cdot \vec{E}\rangle=2 \omega \operatorname{Im}\left\{\vec{d} \cdot \vec{E}^{*}\right\}=\frac{\omega}{\varepsilon_{0} \cdot c} \operatorname{Im}\{\alpha(\omega)\} \cdot I(\vec{r})
$$

Como a energia do fóton absorvido é dada por $\hbar \omega$, dividindo a equação (4) por esse valor, encontraremos a taxa de espalhamento de fótons, dado pela equação (5).

$$
\Gamma_{e s p}=\frac{P_{e s p}}{\hbar \omega}=\frac{1}{\hbar \varepsilon_{0} c} \operatorname{Im}\{\alpha(\omega)\} I(\vec{r})
$$

Os parâmetros encontrados $\left(\Gamma_{e s p}\right.$ e $\left.V_{\text {int }}\right)$ estão dados em função da dependência espacial da intensidade do laser $I(\vec{r})$ e da polarizabilidade $\alpha(\omega)$. Vale ressaltar que tais expressões são válidas para qualquer partícula neutra polarizada em um campo elétrico oscilante.

Como iremos trabalhar com o laser em uma frequência longe da ressonância atômica, podemos aproximar $\alpha(\omega)$ pela polarizabilidade do oscilador harmônico clássico devido a um campo elétrico clássico, sem perda de precisão. Utilizando o modelo de Lorentz do oscilador harmônico amortecido (51), teremos como resultado o valor descrito na equação (6).

$$
\alpha(\omega)=6 \pi \varepsilon_{0} c^{3} \frac{\Gamma_{\omega} / \omega_{0}{ }^{2}}{\omega_{0}{ }^{2}-\omega^{2}-i\left(\omega^{3} / \omega_{0}{ }^{2}\right) \Gamma_{\omega}}
$$


Sendo:

$$
\Gamma_{\omega}=\frac{\omega^{3} e^{2}}{6 \pi \varepsilon_{0} m_{e} c^{3}}
$$

Em que $\omega_{0}$ e $\omega$ representam a frequência de oscilação do oscilador e do laser respectivamente e $\Gamma_{\omega}$ a taxa de amortecimento ressonante. Para a linha D de átomos alcalinos, temos que a expressão clássica para a taxa de amortecimento concorda bem com a observação experimental (50). Considerando tais aproximações, e substituindo as equações (6) e (7) nas equações (5) e (2), chegamos aos resultados finais para o potencial de interação e para a taxa de espalhamento:

$$
\begin{gathered}
V_{\mathrm{int}}(\vec{r}, \omega)=-\frac{3 \pi c^{2}}{2 \omega_{0}^{3}}\left(\frac{\Gamma_{\omega}}{\omega_{0}-\omega}+\frac{\Gamma_{\omega}}{\omega_{0}+\omega}\right) I(\vec{r}) \\
\Gamma_{e s p}(\vec{r}, \omega)=\frac{3 \pi c^{2}}{2 \hbar \omega_{0}{ }^{3}}\left(\frac{\omega}{\omega_{0}}\right)^{3}\left(\frac{\Gamma_{\omega}}{\omega_{0}-\omega}+\frac{\Gamma_{\omega}}{\omega_{0}+\omega}\right)^{2} I(\vec{r})
\end{gathered}
$$

Pela equação (8), notamos que o sinal da dessintonização pode gerar um potencial tanto atrativo, como repulsivo. Para o caso em que $\omega_{0}>\omega$ (deslocamento para o vermelho), teremos $V_{\text {int }}(\vec{r}, \omega)<0$, gerando um potencial atrativo com o gradiente de $I(\vec{r})$. Para $\omega_{0}<\omega$ (deslocamento para o azul), teremos $V_{\text {int }}(\vec{r}, \omega)>0$, resultando em um potencial repulsivo. Como a armadilha de dipolo consiste no confinamento das partículas no foco do laser, a única forma de aprisionarmos tais partículas, no caso de um feixe com perfil gaussiano, é pela utilização de uma frequência abaixo da ressonância atômica.

A profundidade da armadilha e a taxa de espalhamento são calculadas para o ponto central do foco da armadilha e para o valor de $\omega$ correspondente à frequência do laser de aprisionamento $\left(\omega=\frac{2 \pi c}{\lambda}\right)$, onde $c$ é a velocidade da luz no vácuo e $\lambda=1071.3 \mathrm{~nm}$ é o comprimento de onda central do laser. Utilizamos ao longo do desenvolvimento do trabalho duas configurações distintas para a cintura do feixe $\left(w_{0}\right)$ e potência do laser $(P)$. Na primeira 
configuração, tínhamos $w_{0}=72 \mu \mathrm{m}$ e $P=25 \mathrm{~W}$, gerando uma profundidade da armadilha de aproximadamente $1,4 \mathrm{mK}$ e $1,3 \mathrm{mK}$ para $\mathrm{Rb}$ e $\mathrm{K}$ respectivamente. $\mathrm{Na}$ segunda configuração, tínhamos $w_{0}=42 \mu \mathrm{m}$ e $P=40 \mathrm{~W}$, o que elevou a profundidade para $6,3 \mathrm{mK}$ e 5,9 $\mathrm{mK}$ para $\mathrm{Rb}$ e $\mathrm{K}$ respectivamente. $\mathrm{O}$ valor de $\Gamma_{e s p}$ e da profundidade encontrada sugeria um tempo de vida de aproximadamente 500 segundos para o K e de 1000 segundos para o Rb para ambas as configurações, o que leva a crer que o limitante do tempo de vida da amostra será devido ao vácuo da câmara.

\subsection{A busca por moléculas frias no estado vibracional fundamental}

Nesse tópico, descrevemos os principais trabalhos experimentais relacionados à produção e manipulação de moléculas ultrafrias. Daremos ênfase aos trabalhos que obtiveram êxito em manipular os estados internos das moléculas de uma maneira simples e eficaz, visto que técnicas muito complexas limitam a obtenção de tais amostras para futuros experimentos.

O primeiro trabalho, desenvolvido por Matthiew Viteau e colaboradores (46) apresenta uma maneira eficiente de manipular os níveis vibracionais das moléculas de $\mathrm{Cs}_{2}$ utilizando um laser de femtossegundo com o espectro remodelado. A taxa de formação de moléculas no estado vibracional fundamental é de aproximadamente $10^{5}$ moléculas/s. Na continuação desse trabalho, I. Manai e colaboradores (45) adicionaram um laser de diodo para manipular os níveis rotacionais das moléculas que já estavam no nível vibracional fundamental. Ambos os trabalhos foram desenvolvidos em uma armadilha magneto-óptica e tem forte potencial de aplicação em uma armadilha de dipolo.

Em outro trabalho, desenvolvido por J Deiglmayr e colaboradores (52), foram produzidas moléculas no estado rovibrônico fundamental de LiCs no MOT através de apenas um processo de fotoassociação (PA) seguido de um decaimento espontâneo. A taxa de formação molecular no estado rovibrônico fundamental foi de aproximadamente $10^{2}$ moléculas/s, sendo insatisfatório para um MOT, porém também apresenta grande potencial para aplicação em uma armadilha de dipolo. O último trabalho que iremos abordar foi desenvolvido por M. H. G. Miranda e colaboradores (11) e trata da manipulação da dinâmica das colisões entre as moléculas no estado rovibrônico fundamental de maneira a suprimir as 
colisões inelásticas e aumentar o tempo de vida dessas moléculas em uma rede óptica. Essa técnica abre o caminho para a realização do processo de resfriamento evaporativo e obtenção do estado de degenerescência, exigindo a obtenção de gases atômicos em regime próximo a degenerescência quântica e a utilização de um pente de frequência (53). Neste sentido, esta técnica esta limitada a poucos laboratórios no mundo.

\subsubsection{Bombeamento óptico e resfriamento vibracional}

No trabalho desenvolvido por Matthiew Viteau e colaboradores (46) as moléculas foram formadas através de um processo de fotoassociação (PA) para átomos de Cs. O decaimento espontâneo dessas moléculas fez com que houvesse uma distribuição de estados vibracionais para o estado eletrônico fundamental $\left(X^{1} \Sigma_{g}^{+}\right)$, que foram então bombeados para o estado vibrônico fundamental $\left(X^{1} \Sigma_{g}^{+}, v_{x}=0\right)$ através de um bombeamento óptico.

$\mathrm{O}$ processo de PA foi realizado $1 \mathrm{~cm}^{-1}$ para o vermelho da assíntota $\left(6 S_{1 / 2}+6 P_{3 / 2}\right)$ no potencial molecular $1_{g}$ em uma armadilha magneto óptica. O método de detecção molecular é baseado na fotoionização e deteç̧ão iônica, sendo os íons atômicos e moleculares separados pela diferença no tempo de voo. O processo de PA e de fotoionização estão esquematizados na Figura 1.
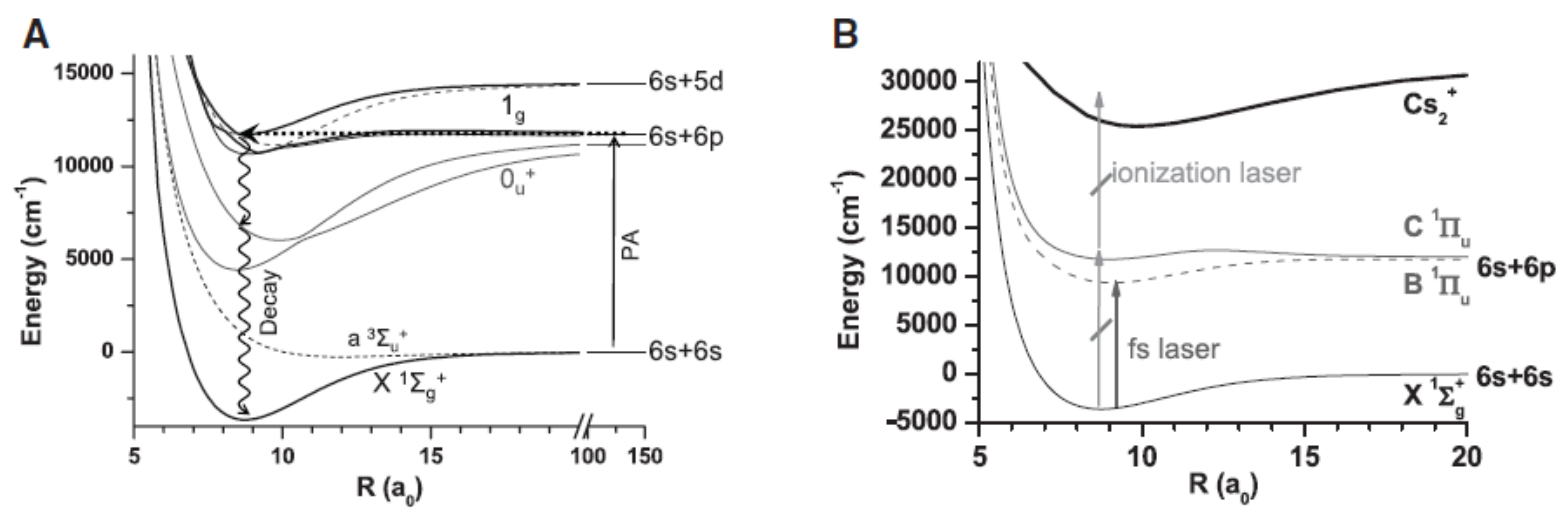

Figura 1 - Potenciais moleculares relevantes para o experimento. (A) Fotoassociação de átomos e formação de moléculas frias. O laser de PA foi dessintonizado $1 \mathrm{~cm}^{-1}$ abaixo da transição $6 \mathrm{~S}_{1 / 2} \rightarrow 6 \mathrm{P}_{3 / 2}$ para o potencial $1 \mathrm{~g}$. São formadas moléculas no estado fundamental $X^{1} \Sigma_{g}^{+}$ via decaimento espontâneo em cascata através do potencial $0_{u}^{+}$. (B) Processo de ionização via estado $C^{1} \Pi_{u}$ e transição eletrônica $X^{1} \Sigma_{g}^{+} \rightarrow B{ }^{1} \Pi_{u}$ induzida pelo laser de femtossegundo (fs) (46). 
Para o processo de resfriamento vibracional é utilizado um laser de femtossegundo, centrado em $772 \mathrm{~nm}$ e com largura espectral de $54 \mathrm{~cm}^{-1}$. Para controlar o processo de bombeamento óptico, o perfil espectral do laser de femtossegundo foi remodelado de forma a excluir qualquer transição mais energética que $13.030 \mathrm{~cm}^{-1}$. Com isso, o estado vibrônico fundamental não realizava qualquer tipo de transição, sendo um estado escuro onde as moléculas se acumulavam. O espectro era manipulado com o auxílio de uma grade de difração, que abria o espectro espacialmente, permitindo o bloqueio de frequências indesejadas mecanicamente. $\mathrm{O}$ espectro remanescente era então retro refletido na grade e voltava ao seu estado original, porém, com um corte na frequência, como representado na Figura 2a.
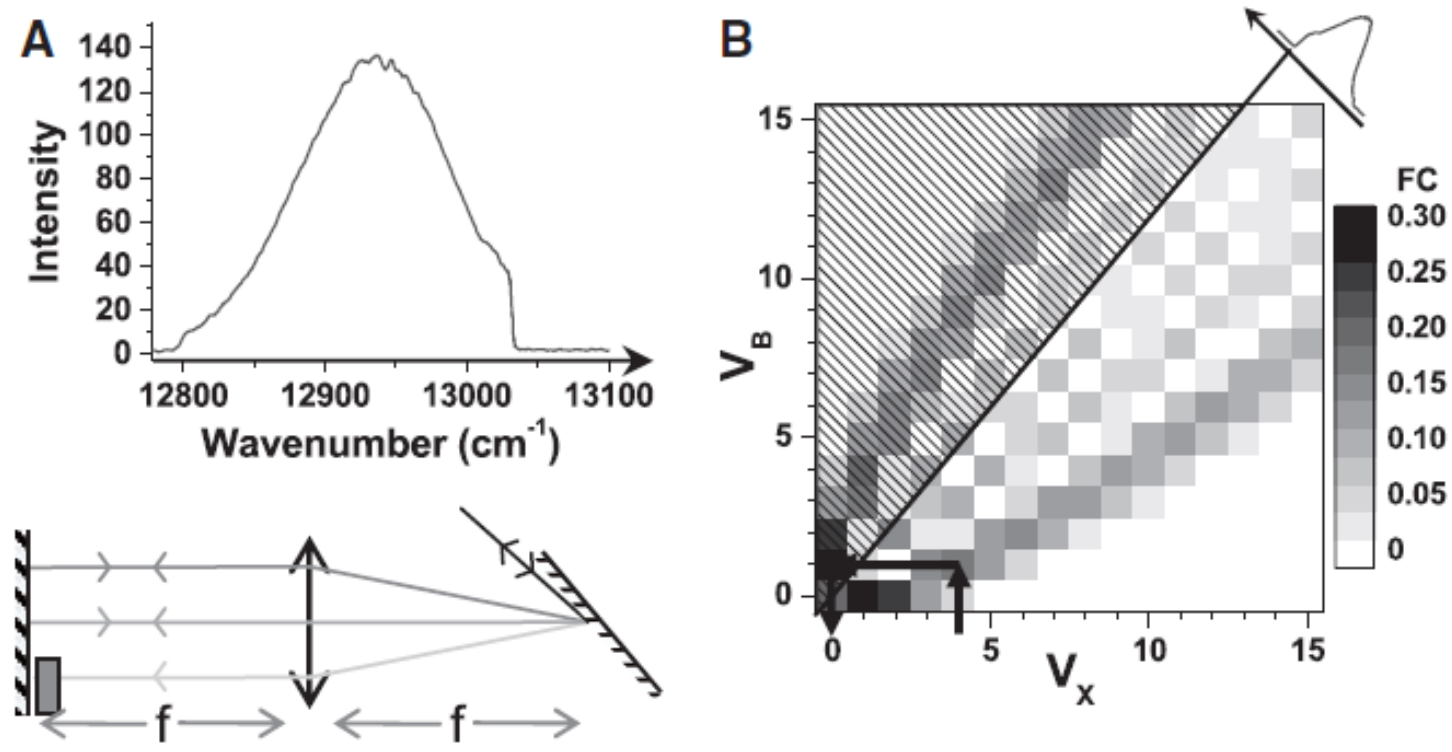

Figura 2 - Espectro remodelado do laser de femtossegundo e técnica para bloqueio de determinada faixa espectral. b) Fator de Franck Condon entre os estados vibracionais $\left(X^{1} \Sigma_{g}^{+}, V_{x}\right)$ e $\left(B{ }^{1} \Pi_{u}, V_{B}\right)(46)$.

O potencial escolhido para o bombeamento foi o $B^{1} \Pi_{u}$, onde a força das transições entre os estados vibracionais no estado fundamental está mostrado na Figura 2b, sendo a parte hachurada correspondente às transições proibidas devido à manipulação do espectro do laser de bombeamento.

Com esse sistema, eles foram capazes de bombear cerca de $70 \%$ das moléculas fotoassociadas para o estado $v_{x}=0$, com uma taxa de $10^{5}$ moléculas/s. Um dos limitantes para o aumento da eficiência no bombeamento foi a largura espectral do laser, que com o valor de $54 \mathrm{~cm}^{-1}$ é capaz de bombear apenas moléculas que estão abaixo de $v_{x}=7$. A 
distribuição final para o bombeamento é atingida após 5 ciclos de absorção e emissão, não provocando aquecimento da amostra.

\subsubsection{Bombeamento óptico e resfriamento vibracional e rotacional}

Uma continuação do trabalho anterior, desenvolvido por I. Manai e colaboradores (45), utiliza as técnicas descritas para resfriamento vibracional com a adição de um laser extra para a manipulação dos estados rotacionais. No processo de produção molecular e resfriamento dos níveis rovibracionais ( $v e J)$ são utilizados três lasers distintos. O primeiro laser realiza o processo de PA para o estado $0_{g}^{-}\left(6 S_{1 / 2}+6 P_{1 / 2}\right)\left(v^{\prime}=26, J^{\prime}=1\right)$ e os outros dois lasers realizavam o resfriamento vibracional e rotacional.

O resfriamento vibracional era feito de acordo com o trabalho descrito no tópico anterior (46). Utiliza um laser de femtossegundo com a banda espectral modificada, sendo as moléculas gradativamente bombeadas para o estado $X^{1} \Sigma_{g}^{+}(v=0)$. Para a manipulação dos estados rotacionais é utilizado um laser de diodo contínuo e de banda estreita ( $2 \mathrm{MHz})$ que realiza uma varredura em torno da transição $X^{1} \Sigma_{g}^{+}(v=0, J=1) \rightarrow B{ }^{1} \Pi_{u}\left(v_{B}=3 \leq J_{B} \leq\right.$ 6), cobrindo principalmente as transições de ramo tipo $\mathrm{P}$, onde o valor de $\mathrm{J}$ é mantido ou diminuído em 2 unidades em um ciclo de absorção e emissão. As posições energéticas dos lasers de resfriamento vibracional e rotacional estão esquematizadas na Figura 3. 


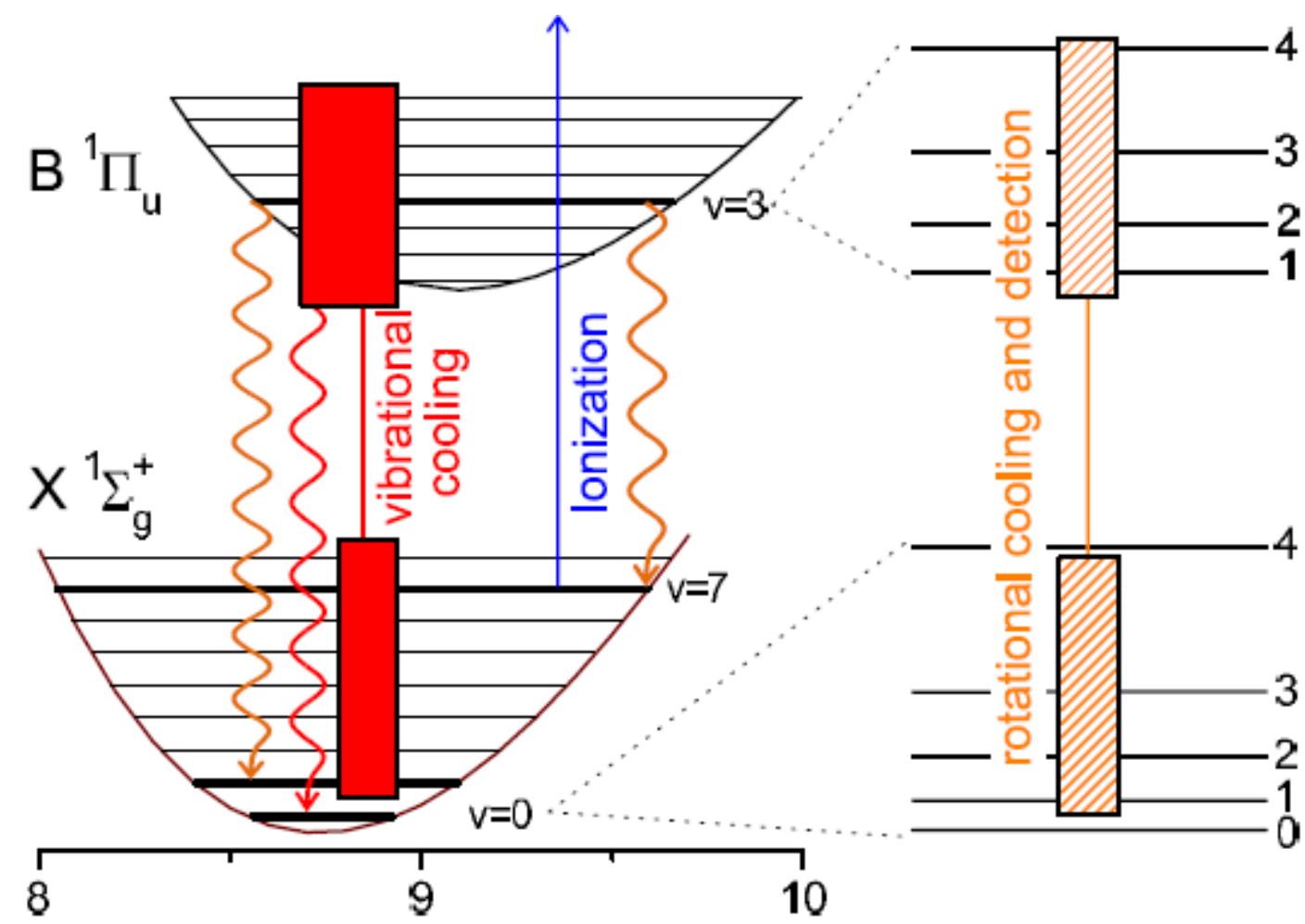

Figura 3 - Transições utilizadas para a manipulação dos estados rovibracionais do $\mathrm{Cs}_{2}$. O retângulo vermelho representa as transições realizadas pelo laser banda larga de femtossegundo. O retângulo hachurado em laranja apresenta os níveis rotacionais afetados pela varredura do laser de diodo (45).

A eficiência do bombeamento dessas moléculas para $J=0$ é de aproximadamente 40\%. Esse valor é calculado considerando a quantidade de moléculas que são bombeadas para $J=0$ dividido pelo número inicial de moléculas que estão presentes nos demais estados rotacionais. Essa técnica pode ser estendida para qualquer tipo de molécula e pode agir em conjunto com uma armadilha de dipolo, possibilitando o aprisionamento e acúmulo de moléculas.

\subsubsection{Formação de molécula no estado rovibrônico fundamental através de fotoassociação e decaimento espontâneo.}

O trabalho realizado por J. Deiglmayr e colaboradores (52) para a produção de LiCs no estado rovibrônico fundamental $X^{1} \Sigma_{g}^{+}(v=0, J=0)$ merece destaque, pois utiliza apenas um processo simples de fotoassociação (PA) para produzir tais moléculas. Os átomos são 
carregados em um MOT duplo de ${ }^{133} \mathrm{Cs}$ e ${ }^{7} \mathrm{Li}$ com temperaturas de $250 \mu \mathrm{K}$ para o Cs e milhares de $\mu \mathrm{K}$ para o Li. A temperatura do ${ }^{7} \mathrm{Li}$ é mais alta por causa da sua estrutura hiperfina ser da ordem da largura natural de linha, similar ao ${ }^{39} \mathrm{~K}$. Esse efeito será abordado mais adiante para o ${ }^{39} \mathrm{~K}$ e a mesma explicação cabe para o ${ }^{7} \mathrm{Li}$.

O processo de PA ocorre de acordo com a Figura 4. Indicado pela seta verde (a), temos a transição de PA realizada por um laser de Ti:Safira com 500 mW em 946 nm. Após fotoassociado, as moléculas decaem espontaneamente para o estado fundamental (b) e são detectadas via ionização por dois fótons (c). A seta vermelha (d) indica a transição utilizada para a detecção dos estados rotacionais via depleção do sinal molecular. As moléculas excitadas em (d) se redistribuem em níveis vibracionais mais altos (e) e não são detectadas pelo laser de ionização.

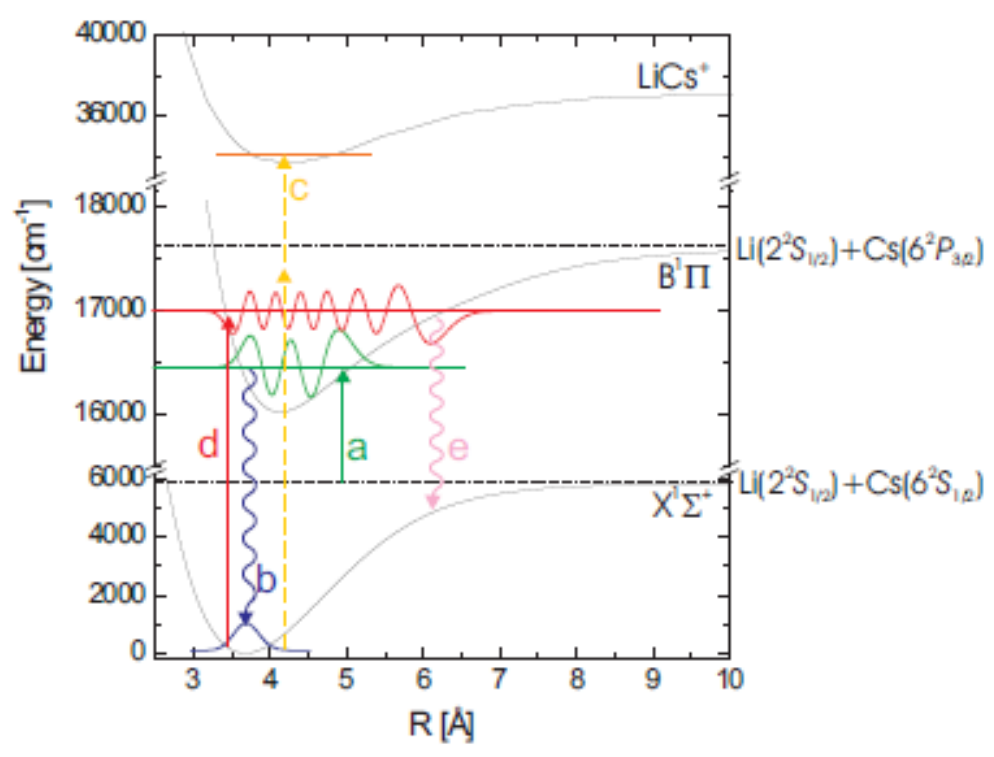

Figura 4 - Transições utilizadas para a produção e detecção de moléculas de LiCs no estado rovibrônico fundamental. A seta verde (a) representa o processo de fotoassociação com o decaimento espontâneo para o estado rovibrônico fundamental dado pela seta azul (b). A seta amarela (c) indica o processo de ionização via dois fótons. A transição em (d) foi utilizada para realizar a detecção dos estados rotacionais pela depleção induzida por um laser de diodo. O decaimento espontâneo em (e) advém da transição induzida em (d) e não participa do processo de fotoionização (52).

Para a produção de moléculas no estado fundamental, a fotoassociação ocorre através do estado molecular $B^{1} \Pi$. Os níveis rovibracionais escolhidos foram $v^{\prime}=4, J^{\prime}=1$ com laser de PA em 946,56 nm. Nesse nível vibracional, $23 \%$ das moléculas são esperadas decair em $X^{1} \Sigma_{g}^{+}(v=0)$. O método de detecção envolve ionização através de um único estado 
intermediário, como indicado na Figura 4. Como o laser de ionização não conseguia resolver a estrutura rotacional para $v=0$, foi medido a perda de íons na detecção devido a inserção de um laser extra de banda estreita que realizava a transição de moléculas em níveis $(v=0, J)$ para outros níveis moleculares, indicado pela seta vermelha (e) na Figura 4. Quando o laser entrava em ressonância com alguma transição para um determinado estado rotacional, o número de íons diminuía, possibilitando a medição da população em J. A taxa de produção de moléculas em $X^{1} \Sigma_{g}^{+}(v=0, J=0)$ foi de aproximadamente 100 moléculas/s. Levando em consideração apenas a formação em $X^{1} \Sigma_{g}^{+}(v=0)$, tem-se uma produção total de $5 \times 10^{3}$ moléculas/s. A distribuição teórica prevista para a produção total de moléculas é de $23 \%$ para o nível $X^{1} \Sigma_{g}^{+}(v=0)$ enquanto o restante está distribuídos em níveis $X^{1} \Sigma_{g}^{+}(0<v \leq 20)$.

Esse método de produção molecular é bem simples e abre a possibilidade para o acúmulo molecular em uma armadilha de dipolo. Como em tal armadilha a densidade é mais alta, também é esperada uma taxa de formação bem superior a que foi aferida no MOT. O único inconveniente é a distribuição final de muitos níveis vibracionais, que pode ser contornado através da utilização de uma técnica de bombeamento similar a que foi descrita no tópico anterior (46).

\subsubsection{Controle da dinâmica colisional molecular}

No trabalho desenvolvido por M. H. G. de Miranda e colaboradores (11), é mostrado como a geometria da colisão, o estado interno molecular e o nível vibracional harmônico das moléculas em uma rede óptica podem ser manipulados de forma a aumentar ou suprimir colisões entre moléculas de ${ }^{40} \mathrm{~K}^{87} \mathrm{Rb}$.

O experimento consiste em duas câmaras de vácuo conectadas por um tubo estreito. A primeira câmara carrega as amostras em uma armadilha magneto óptica (MOT) dupla (K e $\mathrm{Rb}$ ). Após carregado o MOT, os átomos são transferidos para a segunda câmara, denominada câmara científica, que apresenta pressão da ordem de $10^{-11}$ Torr. Na câmara científica, a amostra é aprisionada em um dark MOT (dMOT), que consiste em um MOT com potência do feixe de rebombeio reduzida, limitando o número de transições ópticas, resultando em uma amostra mais fria. Após $\simeq 10 \mathrm{~s}$ de carregameto do $d M O T$, as amostras são bombeadas para os 
estados: ${ }^{87} \mathrm{Rb}\left|F=2, m_{f}=2\right\rangle$ e ${ }^{40} \mathrm{~K}\left|F=9 / 2, m_{f}=9 / 2\right\rangle$ onde são aprisionadas em uma armadilha magnética Ioffe-Pritchard (54).

Aplicando a evaporação forçada, a amostra de $\mathrm{K}$ e $\mathrm{Rb}$ atinge temperaturas perto da degenerescência quântica $(T \cong 800 n K)$. Uma armadilha de dipolo óptica (ODT) cruzada em 1064 nm é então ligada gradualmente e os átomos são transferidos. Por fim, uma rede óptica de mesmo comprimento de onda é adicionada a direção $\hat{z}$, perpendicular à armadilha de dipolo (Figura 5).

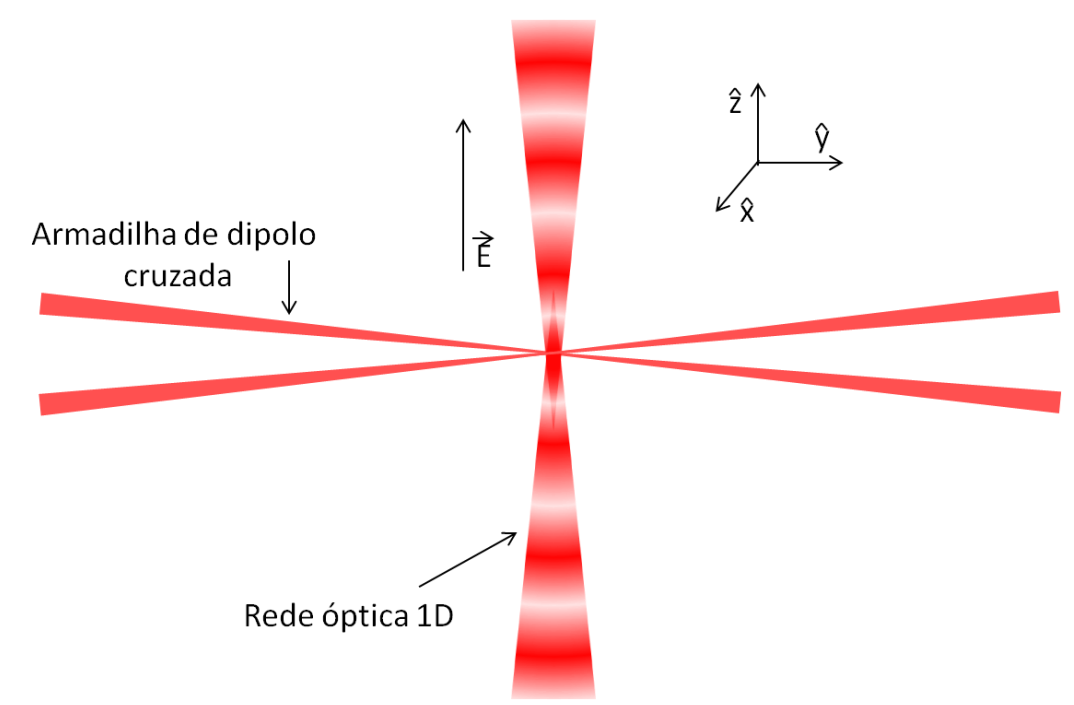

Figura 5 - Esquema experimental mostrando a posição das armadilhas ópticas do sistema (dipolo cruzado + rede óptica) juntamente com a direção de aplicação do campo elétrico externo de alinhamento dos dipolos moleculares.

Uma vez aprisionados na rede óptica, os átomos são convertidos em moléculas fracamente ligadas via ressonância de Feshbach. A energia de ligação de tais moléculas é de aproximadamente $h \times 230 \mathrm{KHz}$. O sistema de detecção consiste em imagens de absorção das moléculas fracamente ligadas (55). As moléculas são então transferidas para o estado rovibrônico (rotacional, vibracional e eletrônico) fundamental $\mathrm{X}^{1} \Sigma_{\mathrm{g}}^{+}\left(\mathrm{v}_{\mathrm{x}}=0, \mathrm{~J}=0\right)$, via transição estimulada STIRAP, como esquematizado na Figura 6. Placas paralelas são responsáveis pela aplicação de um campo elétrico constante que provocará o alinhamento dos dipolos moleculares na armadilha.

A temperatura das moléculas no estado rovibrônico fundamental é dado pelas condições iniciais da amostra na armadilha magnética após o processo de evaporação. Como a rede óptica consiste em um aprisionamento harmônico, dependendo da temperatura da amostra, podemos popular diversos estados vibracionais da rede $\left(k_{b} T \approx h v\right)$. Outra maneira 
de popular diferentes níveis vibracionais é utilizando a excitação paramétrica, que consiste em modular o potencial da rede em múltiplos da frequência natural de vibração. $\mathrm{O}$ controle dos números quânticos translacionais e internos da molécula são extremamente importantes para o desenvolvimento do experimento e comparação com a teoria.

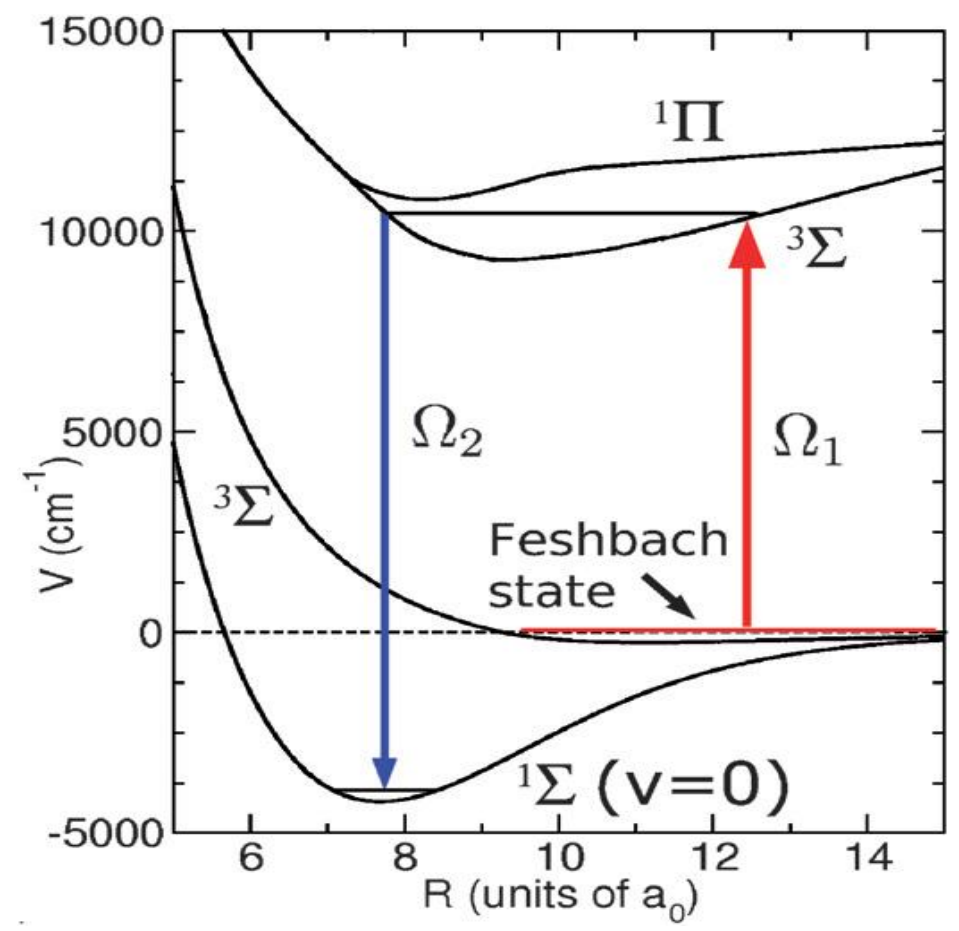

Figura 6 - Diagrama de níveis de energia da molécula de ${ }^{40} \mathrm{~K}^{87} \mathrm{Rb}$ mostrando o processo de transferência coerente via 2 fótons (STIRAP) das moléculas fracamente ligadas, formadas via ressonância de Feshbach, para o estado rovibrônico fundamental (11).

Variando a intensidade do alinhamento dos dipolos moleculares e dos graus de liberdade interno e translacional, obtêm-se resultados que confirmam o aumento ou a supressão nas taxas de colisões moleculares. Esse tipo de manipulação abre a possibilidade para a geração de moléculas no estado rovibrônico fundamental com supressão das colisões inelásticas, possibilitando o resfriamento evaporativo e a obtenção de um estado degenerado puramente molecular.

Para um arranjo de moléculas em uma configuração 2D (Figura 7a), podemos descrever as funções de troca que teremos para as colisões em diferentes estados internos e translacionais da geometria 2D. Considerando os estados de menor barreira centrífuga para a colisão, identificamos 3 possíveis canais de colisões. A Figura 7 exemplifica o sistema. 
a

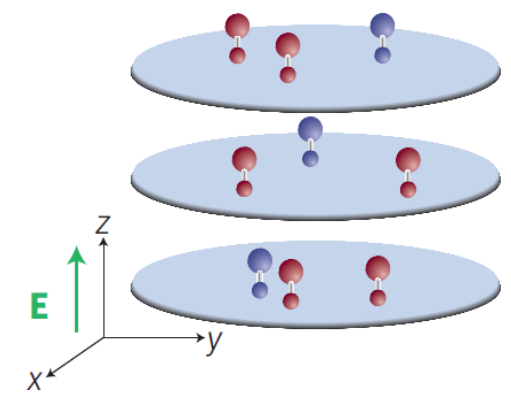

C

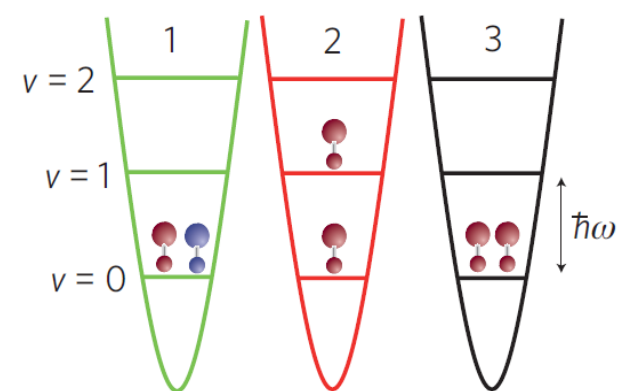

b

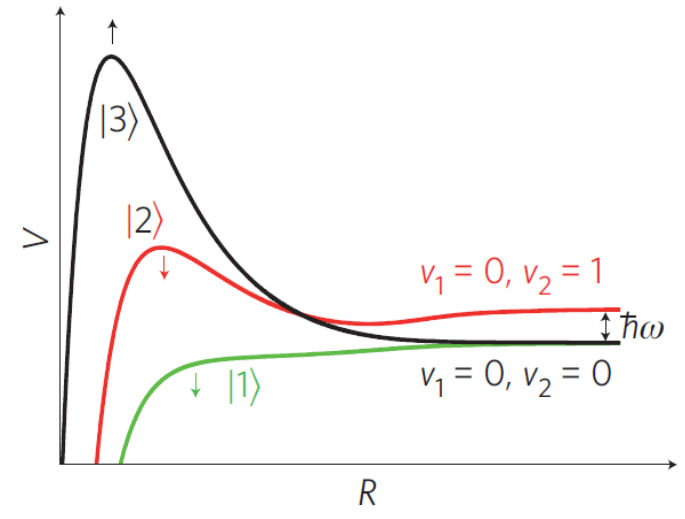

Figura 7 - Esquema de colisão para moléculas fermiônicas polares em uma geometria de colisão 2D. a) Representação dos planos criados pelo potencial da rede óptica 1D e a direção de aplicação do campo elétrico externo $\mathrm{E}(\widehat{\mathbf{z}})$. As cores azul e vermelho representam moléculas em diferentes estados internos moleculares. b) Representação dos três possíveis potenciais de interação com menores barreiras. c) Descrição dos estados internos de colisão: Em |1) temos as colisões entre partículas com estados internos diferentes que não apresentam barreira centrífuga. Em $|2\rangle$, as moléculas estão no mesmo estado interno e diferentes níveis vibracionais, representando as colisões entre dipolos anti-paralelos. Em $|3\rangle$ as partículas estão no mesmo estado interno e vibracional, essa é a colisão com maior barreira centrífuga e representa a colisão entre dipolos paralelos.(11).

O canal de colisão $|1\rangle$ correspondente às colisões isotrópicas. Apresenta as partículas em estados quânticos internos diferentes, sendo possível $L=0$. Em $|2\rangle$ e $|3\rangle$ as moléculas se encontram no mesmo estado interno e em níveis vibracionais da rede diferentes em $|2\rangle$ e em níveis vibracionais da rede iguais em $|3\rangle$. O fato de estarem no mesmo estado interno, devido ao princípio de exclusão de Pauli, faz com que a onda $\mathrm{L}$ que tenha a menor barreira seja $\mathrm{L}=$ 1, não sendo permitida a onda $L=0$.

Pela Figura 7c, temos que o aumento do campo elétrico para o estado $|1\rangle$ é responsável por um aumento na taxa de colisões devido a uma diminuição da altura da barreira centrífuga. Pensando no caráter isotrópico da colisão, esse caso é representado pelas colisões em 3D, sendo esse comportamento comprovado experimentalmente em (56). O estado $|2\rangle$ também aumenta a taxa de colisões com o aumento do alinhamento dipolar. Esse caso corresponde aos dipolos anti-paralelos, que são atrativos, e diminuem a barreira 
centrífuga, facilitando a colisão. Já no estado $|3\rangle$, as colisões são suprimidas conforme alinhamos os dipolos, esse caso é o mais interessante para o estudo, pois reduz a perda devido a colisões inelásticas, aumentando o tempo de vida da amostra.

Os casos $|2\rangle$ e $|3\rangle$ podem ser interpretados como colisões entre moléculas com o momento de dipolo anti-paralelo e paralelo respectivamente, fazendo com que a inserção de um campo elétrico externo aumente ou diminua a barreira centrífuga da colisão. O caso mais interessante é o $|3\rangle$, onde a aplicação de um campo elétrico pode diminuir a taxa de colisões inelásticas.

Fazendo uma análise das colisões para as diferentes simetrias abordadas, vemos pela Figura 8 que a taxa de colisão diminuí para a condição de dipolos alinhados (Curva preta), enquanto que o valor era de duas a três ordens de grandezas maior para a colisão entre dipolos anti-paralelos (curva vermelha) e a configuração de colisão isotrópica (curva verde).

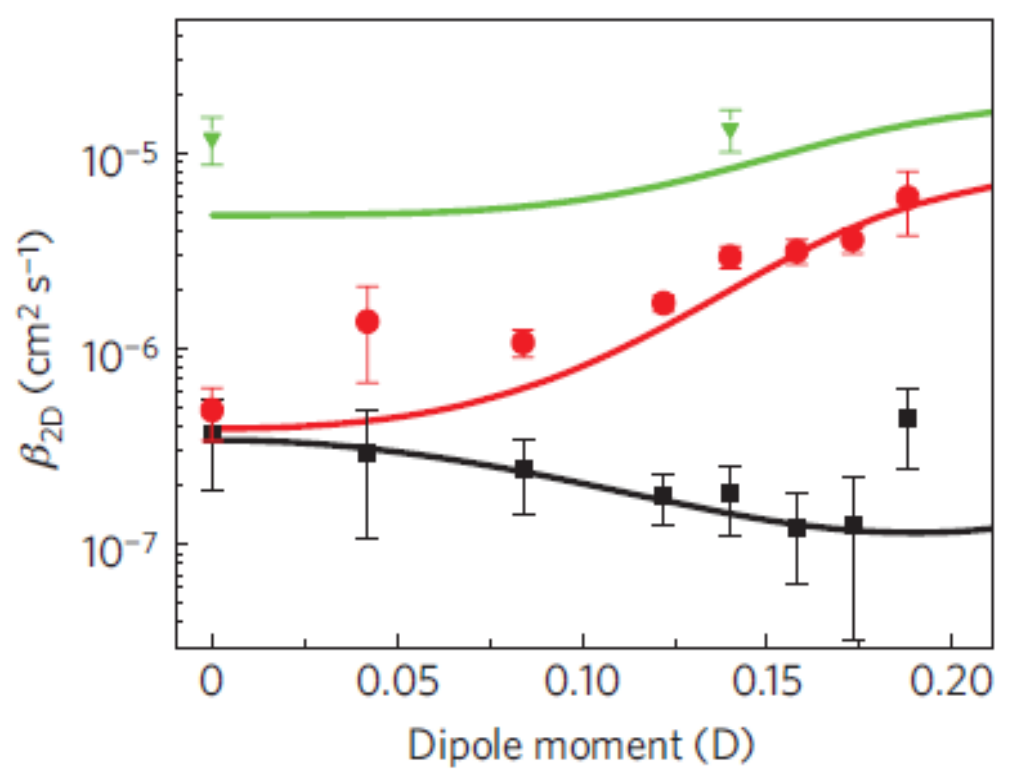

Figura 8 - Medidas das taxas de perda em função do momento de dipolo da amostra. A curva em verde representa a medida feita para estados internos diferentes, a curva preta representa a taxa de perda para dipolos paralelos e em vermelho para a configuração anti-paralela para o alinhamento do dipolo (11).

Por meio desse trabalho, vimos que selecionando a geometria da colisão e controlando o momento de dipolo de uma amostra de moléculas polares, pode-se suprimir a taxa de colisões por mais de duas ordens de grandeza. Campos elétricos externos mais intensos, juntamente com uma profundidade maior na armadilha óptica podem resultar em um fator de supressão bem superior ao que foi encontrado (57). Uma forte supressão colisional abre 
caminho para a criação de amostras moleculares muito mais estáveis em relação a reações químicas, possibilitando o resfriamento evaporativo da amostra molecular até níveis de degenerescência quântica. 


\section{0 experimento}

Nesse capítulo, descreveremos a montagem experimental para a produção de átomos e moléculas de ${ }^{39} \mathrm{~K},{ }^{85} \mathrm{Rb}$ e ${ }^{87} \mathrm{Rb}$ e todos os equipamentos necessários para a detecção das partículas e automação do experimento. A câmara de aprisionamento, os arranjos ópticos das armadilhas magneto-óptica (MOT) e da armadilha óptica de dipolo (ODT), o sistema de desaceleração de átomos e os equipamentos de aquisição de dados e controle do experimento serão descritos com detalhes. Serão apresentados os princípios básicos de desaceleração dos átomos e do aprisionamento em um MOT e em uma ODT. Por fim, apresentaremos o sistema utilizado para controle do experimento e aquisição de dados juntamente com a sequência experimental utilizada para obter as imagens de absorção e o processamento de dados necessário pra extrair a densidade e cintura da amostra.

\subsection{Forno, desacelerador e câmara a vácuo}

Os átomos de nosso experimento são oriundos de um feixe atômico, obtido a partir de um forno atômico. Nosso forno misto de rubídio $\mathrm{Rb}$ e potássio $\mathrm{K}$ opera a uma temperatura fixa de $140^{\circ} \mathrm{C}$. Devido a pressão de vapor ser maior para o $\mathrm{Rb}$, o sistema foi projetado para dificultar a saída de $\mathrm{Rb}$ através de uma válvula estreita 1 conectada entre os dois compartimentos da Figura 9. Tal válvula faz com que o fluxo de átomos de $\mathrm{K}$ e Rb sejam aproximadamente iguais à $2 \times 10^{16}$ átomos/s em 2 , sendo suficiente para a execução do experimento. Esse valor é baseado em experimentos semelhantes realizados por outros grupos de pesquisa (58-59). 


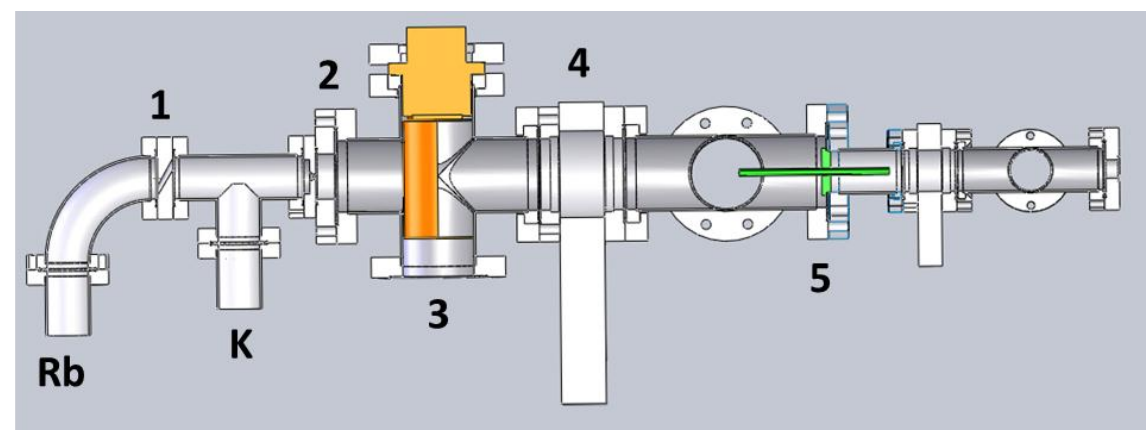

Figura 9 - Forno misto para a produção de vapor de Rb e K. Os compartimentos em $(\mathrm{Rb})$ e $(\mathrm{K})$ contém de 5 a 10 gramas do respectivo elemento e são mantidos a uma temperatura média de $140{ }^{\circ} \mathrm{C}$. Um tubo diferencial em (1) mantém o fluxo de K e Rb similares na saída do forno (2). Em (3) temos uma placa fria de cobre que impede que o vapor residual e quente se propague até o experimento. Uma válvula pneumática de segurança (4) isola o forno da parte de ultra alto vácuo em caso de emergência, e em (5) com diâmetro de $4,77 \mathrm{~mm}$ e comprimento de $127 \mathrm{~mm}$ temos o tubo diferencial de pressão que mantém a região do experimento e do forno com uma diferença de pressão de $10^{-3}$ Torr.

Somente átomos dentro do ângulo sólido definido pelos furos em $\mathbf{2}$ e $\mathbf{5}$ seguirão para a desaceleração $(\sim 0,5 \%)$, o restante é barrado por uma placa fria de cobre 3 com um furo de $7,4 \mathrm{~mm}$ mantida a uma temperatura de $-15^{\circ} \mathrm{C}$. Como sistema de segurança, temos uma válvula pneumática 4 que isola o sistema do forno e da câmara em caso de queda de energia.

O feixe de átomos quentes e colimados é então submetido ao processo de desaceleração. Uma das melhores maneiras de se fazer isso é utilizando um feixe ressonante contrapropagante. Dessa maneira, a absorção dos fótons se dará na direção contrária ao movimento enquanto que a emissão terá direção aleatória. Como o fóton carrega um momentum $p=h / \lambda$, onde $\lambda$ é o comprimento de onda da radiação e $h$ é a constante de Planck, teremos que o átomo sofrerá uma redução de velocidade dada por:

$$
\Delta V=h / m \lambda
$$

onde $\mathrm{m}$ é a massa do elemento atômico. Para os elementos ${ }^{85} \mathrm{Rb}\left({ }^{39} \mathrm{~K}\right)$ cujo a massa corresponde a $1,41 \times 10^{-25} \mathrm{Kg}\left(6,48 \times 10^{-26} \mathrm{Kg}\right)$, com comprimento de onda ressonante na linha $\mathrm{D}_{2}$ de transição de $780 \mathrm{~nm}(766 \mathrm{~nm})$, teremos um recuo de $0,6 \mathrm{~cm} / \mathrm{s}(1,34 \mathrm{~cm} / \mathrm{s})$ por fóton. Como o forno se encontra a uma temperatura média de $420 \mathrm{~K}$, a velocidade inicial média dos átomos será de $350 \mathrm{~m} / \mathrm{s}(520 \mathrm{~m} / \mathrm{s})$, sendo necessário aproximadamente 85 (40) mil fótons para trazer tais átomos para o repouso. Esse processo só é válido se o fóton se mantiver 
ressonante durante todo o processo de desaceleração. Porém, conforme o átomo vai perdendo velocidade, a frequência com a qual o átomo vê a radiação é alterada devido ao efeito Doppler. Como o átomo se move em uma direção contrária a direção de propagação do fóton, este irá experimentar uma frequência maior do que a operada pelo laser. Para o cálculo do incremento na frequência $(\Delta \vartheta)$ é levado em conta apenas a velocidade do átomo $(V)$ e o comprimento de onda da radiação $(\lambda)$, descrito na equação (11).

$$
\Delta \vartheta=V / \lambda
$$

Para se ter uma ideia da importância desse efeito no experimento, temos que a largura natural de linha para o rubídio e potássio é de $\Gamma \sim 6 \mathrm{MHz}$ (60). Contudo, levando em conta as velocidades iniciais com que os elementos saem do forno, teríamos uma dessintonia na frequência de $450 \mathrm{MHz}$ e $700 \mathrm{MHz}$ para Rb e K respectivamente. Fazendo uma análise rápida, temos que após um ciclo de aproximadamente 50 fótons absorvidos, a dessintonia seria equivalente a largura natural de linha $(\Gamma)$ e o átomo sairia completamente da ressonância.

Existem duas maneiras de manter o átomo em ressonância com o feixe de desaceleração. A primeira técnica consiste em variar a frequência do laser para compensar a variação da velocidade do átomo. Tal técnica produz pulsos de feixes atômicos desacelerados e permite a seleção de apenas uma determinada velocidade inicial, não sendo um método muito eficiente. A segunda consiste em aplicar um campo magnético variável ao longo do trajeto de desaceleração, utilizando o deslocamento de frequência devido ao efeito Zeeman para compensar o efeito Doppler, desacelerando um intervalo maior de velocidades iniciais e de maneira contínua. Devido a maior eficiência e praticidade, adotamos a segunda técnica em nosso experimento.

Essa técnica recebe o nome de "Zeeman tuning technique", implementada por Will Phillips em 1982 (61) e utilizada por inúmeros experimentos desde então. Considerando a linha $\mathrm{D}_{2}$ de transição para o $\mathrm{K}$ e o Rb, temos que o desvio de energia pelo efeito Zeeman será dado por $\mu_{B} . B(z)$, onde $\mu_{B}$ é o magnéton de Bohr e $B(z)$ é o campo magnético ao longo do desacelerador. Existem estados em que a energia cresce com a aplicação de um campo magnético e outros decrescem. No nosso caso, para os estados escolhidos a diferença de energia sempre decresce com o aumento do campo, assim optamos por trabalhar com um desacelerador inverso. Para um átomo contrapropagante ao feixe, teremos um deslocamento de $k . V(z)$, onde $k$ é o vetor de onda da radiação e $V(z)$ é a velocidade do átomo. Sendo $\vartheta_{0}$ a 
frequência de ressonância do laser e $\vartheta_{l}$ a frequência da radiação, temos que a condição para que o feixe se mantenha sempre ressonante é dada por:

$$
k . V(z)+\mu_{B} B(z)=\vartheta_{0}-\vartheta_{l}
$$

Esta configuração é interessante, porque o laser de desaceleração terá uma dessintonia de centenas de $\mathrm{MHz}$ em relação à transição atômica para o átomo em repouso, não perturbando assim a armadilha magneto-óptica que se encontra no mesmo eixo. Dada a velocidade inicial do átomo $\left(V_{i}\right)$, e supondo que a desaceleração será constante, temos que a velocidade irá variar ao longo do desacelerador de acordo com a equação (13).

$$
V(z)^{2}=V_{i}^{2}-2 a z
$$

Sendo o valor de " $a$ " é uma fração da aceleração máxima sofrida pela partícula, onde a aceleração máxima é dada por $a_{\max }=\frac{\hbar k \Gamma}{2 m}=0,11 \times 10^{6} \mathrm{~m} / \mathrm{s}^{2}$ e $0,25 \times 10^{6} \mathrm{~m} / \mathrm{s}^{2}$ para Rb e $\mathrm{K}$ respectivamente. Juntando as equações (12) e (13), chegamos à forma final do campo magnético para o desacelerador:

$$
B(z)=B_{i}-B_{0}(1-\beta z)^{1 / 2}
$$

Onde $B_{0}=\frac{k V_{i}}{\mu_{B}}, \beta=\frac{2 a}{V_{i}{ }^{2}}$ e $B_{i}$ é uma constante escolhida considerando a velocidade inicial dos átomos e a dessintonia do laser. Escolhemos trabalhar em $60 \%$ da aceleração máxima dos elementos, o que torna o desacelerador mais tolerável a imperfeições no campo magnético, porém, necessita um caminho maior para a desaceleração. A configuração teórica do campo do desacelerador, que leva em conta a dessintonia inicial do laser de desaceleração $\vartheta_{0}$ e a velocidade inicial dos átomos, permitia desacelerar átomos que estavam com velocidades abaixo de 346 m/s e 525 m/s para $\mathrm{Rb}$ e K respectivamente.

É claro da equação (14), que o campo apresenta um perfil parabólico. Visto que seria muito complicado construir um campo assim, optamos por dividir o desacelerador em 38 bobinas aglomeradas em 4 blocos que funcionavam com correntes de 3; 3,5; 4 e -4 Ampères. Este último bloco com corrente negativa, é utilizado para zerar o campo magnético residual no centro da câmara, onde a armadilha magneto-óptica se localiza. O campo teórico da equação (14) foi ajustado ao campo magnético dado pelas bobinas através de um programa 
que tinha como única variável o números de voltas de cada bobina. O programa desenvolvido em Mathematica 8, otimizava a configuração das bobinas dada a corrente disponível. O campo magnético era calculado para uma dada configuração inicial de bobinas e correntes que era comparado com o campo teórico a ser ajustado. A comparação era feita através de um número de correlação, que consistia na subtração de pontos equivalentes entre os dois gráficos, onde o valor resultante era elevado ao quadrado e somado para todos os pontos. Quanto menor fosse esse valor, maior seria a correlação entre os gráficos. O programa variava automaticamente o número de bobinas de cada volta, salvando a configuração que apresentasse o menor número de correlação. Esse processo era repetido diversas vezes, até que o número de correlação atingisse um valor mínimo, mostrando a melhor configuração para o arranjo. O processo levou cerca de sete dias para otimizar o sistema. Como resultado final, temos o gráfico na Figura 10 mostrando o campo magnético teórico (pontos azuis), projetado (linha preta) e medido (linha vermelha) para o desacelerador.

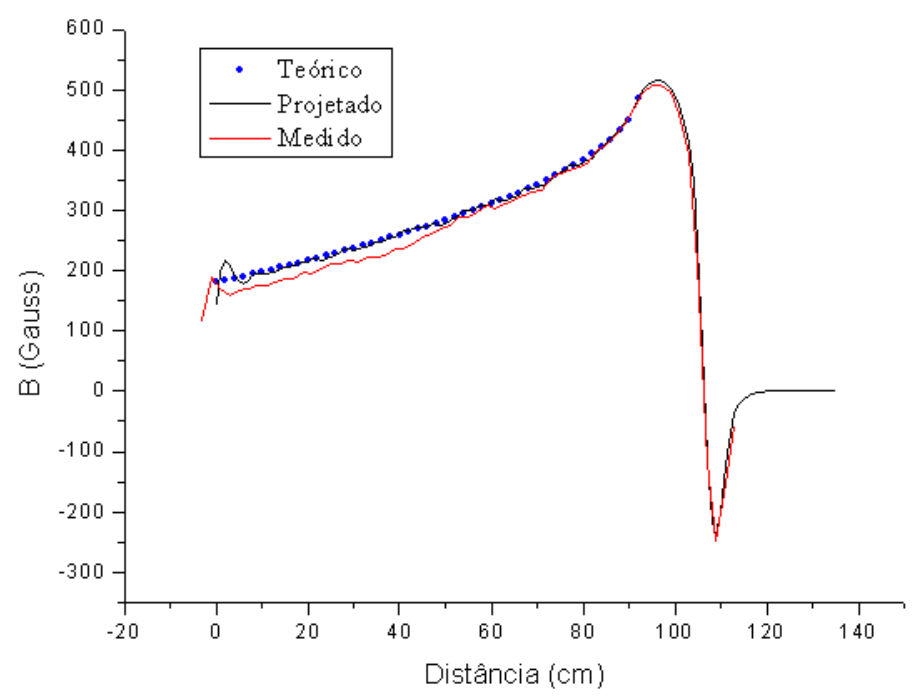

Figura 10 - Campo magnético do desacelerador. Os pontos em azul e a linha preta são os campos teóricos e projetados respectivamente. A linha vermelha mostra o valor que foi aferido, mostrando bom acordo com o projetado.

Por fim, temos a câmara de aprisionamento, com pressão inferior a $10^{-10}$ Torr, ou seja um ambiente propício para o aprisionamento de átomos e moléculas frias. Na Figura 11 temos um desenho da câmara esquematizando os seis suportes de fibras que são fixados na base das seis janelas (2-3/4") e são responsáveis pela luz do MOT, sendo três para acoplamento de fibras e outros três para a retroreflexão. Cada suporte contém uma lâmina de meia onda, um cubo polarizador e uma lâmina de quarto de onda, responsáveis pela geração da polarização 
circular. As bobinas do MOT são encaixadas nas laterais da câmara e não necessitam de suporte, apenas parafusos de fixação. A bomba de sublimação de titânio contém filamentos de titânio, os quais são aquecidos através de alta corrente (30A), liberando assim o elemento por sublimação que é aderido a parede e captura átomos quentes. Uma bomba de ionização auxilia na manutenção do alto vácuo. As janelas menores (1-1/3”) são utilizadas como aceso óptico para o feixe de aprisionamento de dipolo (4 janelas) e de ionização molecular (2 janelas).

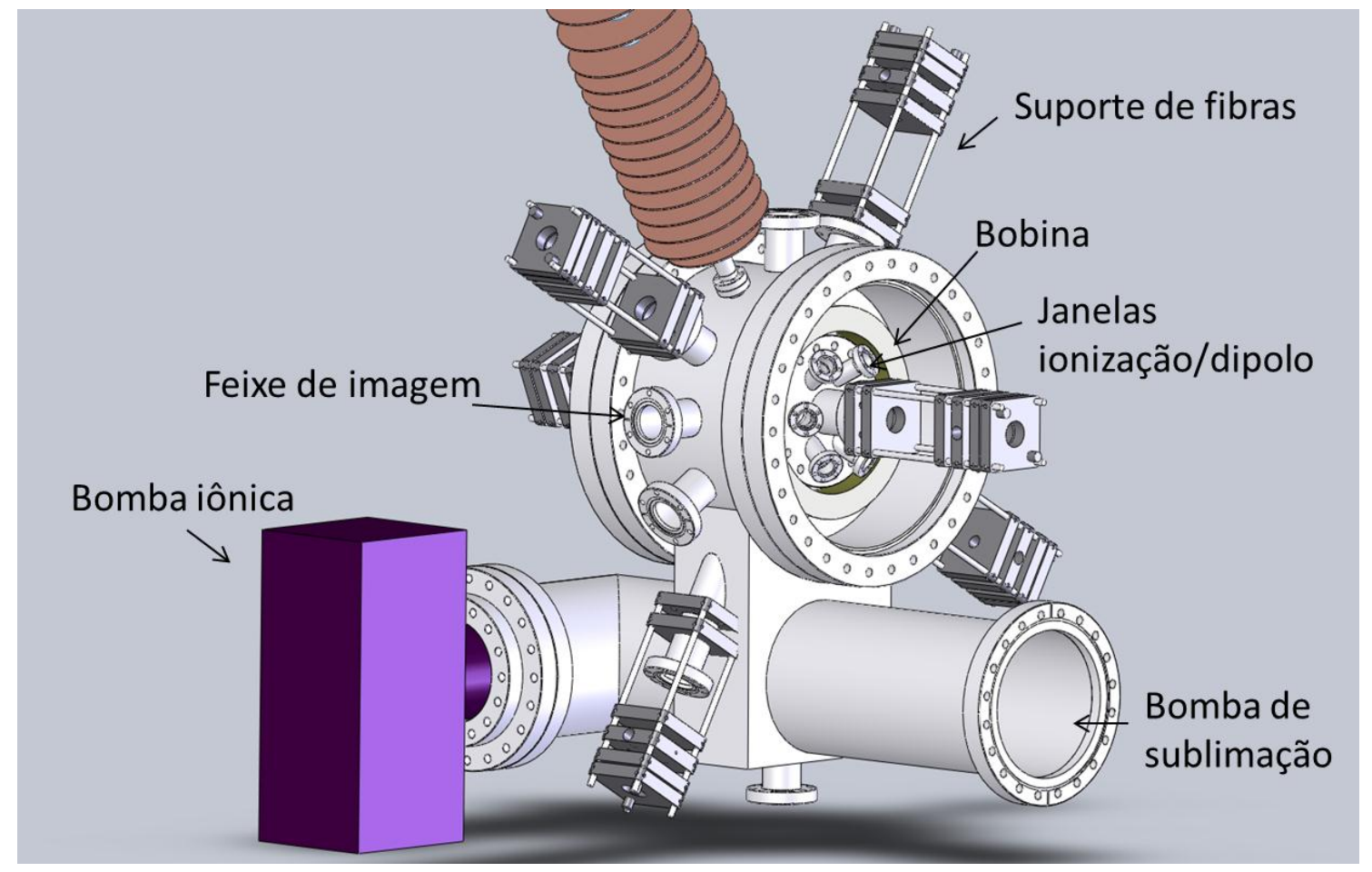

Figura 11 - Imagem ilustrativa da câmara de aprisionamento. Indicado com uma seta, temos os elementos mais relevantes para o experimento. A pressão de trabalho é inferior a $10^{-10}$ Torr.

\subsection{Armadilha magneto óptica dupla: Potássio e Rubídio}

Com a câmara apresentando uma pressão inferior a $10^{-10}$ Torr e os átomos de $\mathrm{K}$ e Rb desacelerados a velocidades inferiores a $20 \mathrm{~m} / \mathrm{s}$, o sistema esta pronto para passarmos ao próximo passo: a armadilha magneto óptica mista (MOT), ponto de partida para a realização da armadilha óptica de dipolo (MOT) e da formação molecular. Nessa seção, daremos uma breve descrição teórica do MOT e em seguida descreveremos as montagens experimentais do MOT e da ODT. 


\subsubsection{Considerações teóricas}

O resfriamento atômico ocorre em um arranjo óptico tridimensional, constituído por três pares de feixes laser contrapropagantes e ortogonais entre si. Sintonizando a frequência do laser pouco abaixo da transição atômica, o átomo estará mais ressonate com feixes contrapropagantes do que com copropagantes, devido ao efeito Doppler. Isso faz com que a absorção do fóton ocorra preferencialmente na direção oposta ao movimento, criando uma força de fricção e resfriando a amostra. Porém, esse método não permite confinar os átomos espacialmente. A nuvem atômica tem a velocidade reduzida, mas continua a se expandir e difundir na câmara.

Esse problema é contornado através da aplicação de um campo magnético externo e da escolha adequada da polarização circular entre os feixes contrapropagantes (2). Para simplificar a explicação, passemos da configuração 3D para 1D, considerando apenas 2 feixes contrapropagantes e um campo magnético linear, como mostrado na Figura 12. O campo magnético (Figura 12a) irá abrir os estados hiperfinos de acordo com a Figura 12b. Segundo a regra de seleção para as transições hiperfinas, uma polarização circular à direita $\left(\sigma^{+}\right)$ promove transições para $\Delta m_{F}=+1$. Para átomos em $\mathrm{F}=0$, a transição ocorre para $\mathrm{F}^{\prime}=1$. Para a polarização $\sigma^{-}$a regra de seleção é $\Delta m_{F}=-1$ e a transição ocorre de $\mathrm{F}=0$ para $\mathrm{F}^{\prime}=$ -1. Escolhendo a polarização dos feixes de acordo com a Figura 12b, temos que para o átomo localizado em uma posição $\mathrm{z}>0$, o fóton de polarização $\sigma^{-}$terá probabilidade maior de ser absorvido. Para $\mathrm{z}<0$, a preferência é para $\sigma^{+}$. Com isso temos uma força restauradora que aponta sempre para o ponto de campo nulo no espaço, confinando espacialmente a amostra. Para a obtenção do MOT, estendemos esse modelo para as dimensões $x$ e $y$ adicionando os feixes laser e gerando o campo magnético com bobinas na configuração anti-Helmholtz. 

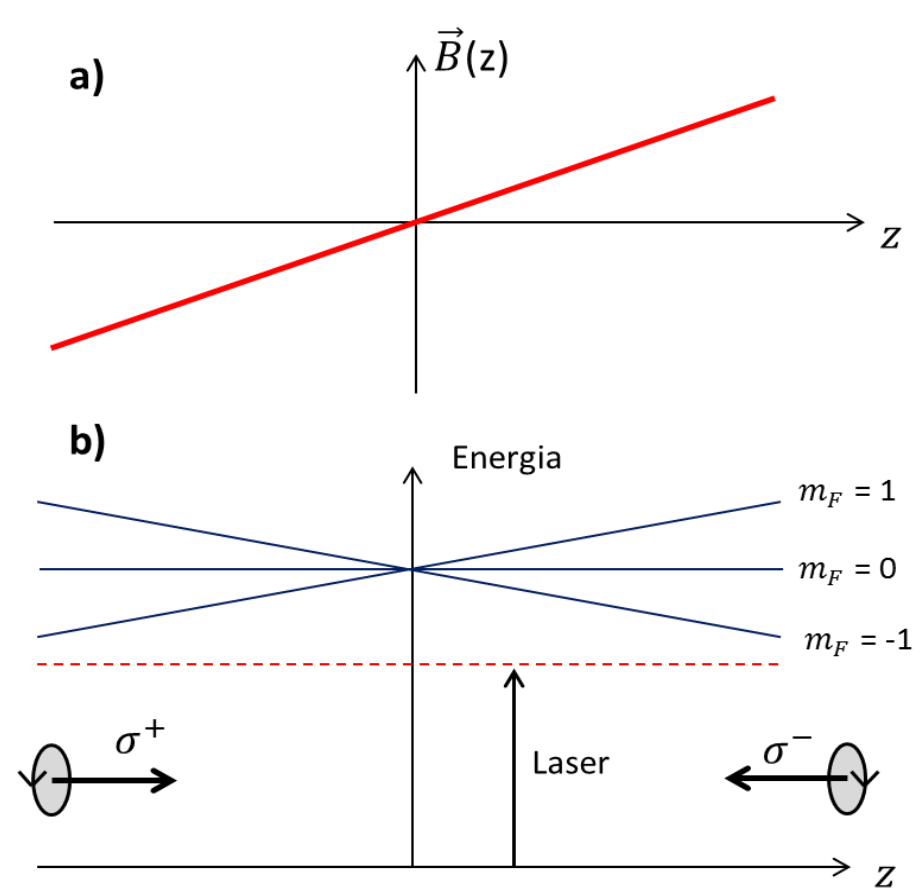

Figura 12 - a) Configuração do campo magnético em 1D para a obtenção do MOT. b) Abertura dos estados hiperfinos devido ao campo magnético e polarização dos lasers contrapropagantes.

\subsubsection{Transições dos elementos: ${ }^{85} \mathrm{Rb},{ }^{87} \mathrm{Rb} \mathrm{e}{ }^{39} \mathrm{~K}$}

Para o aprisionamento dos átomos no MOT, utilizamos à transição correspondente a linha D2 de cada elemento. Na Figura 13, temos os níveis hiperfinos do estado fundamental $\left(\mathrm{S}_{1 / 2}\right)$ e primeiro excitado $\left(\mathrm{P}_{3 / 2}\right)$ para ${ }^{85} \mathrm{Rb},{ }^{87} \mathrm{Rb}$ e ${ }^{39} \mathrm{~K}$. Considerando o ${ }^{85} \mathrm{Rb}$ como exemplo, temos o laser de aprisionamento travado com uma dessintonia para o vermelho em relação a transição $5 \mathrm{~S}_{1 / 2}(\mathrm{~F}=3) \rightarrow 5 \mathrm{P}_{3 / 2}\left(\mathrm{~F}^{\prime}=4\right)$, representado pela seta azul da Figura 13. Essa é uma transição fechada, pois um átomo que esteja em $\mathrm{F}^{\prime}=4$ decairá espontaneamente para o estado $F=3$ no estado fundamental. Porém, há uma pequena probabilidade do estado $F^{\prime}=3$ ser populado, acarretando em decaimento para $\mathrm{F}=2$ e $\mathrm{F}=3$. Uma vez que os átomos atingem o estado hiperfino $\mathrm{F}=2$, estes entram em um estado escuro e saem do ciclo de aprisionamento. Para devolvê-los ao ciclo, um feixe de rebombeio (setas vermelhas) é adicionado ao experimento na transição $5 \mathrm{~S}_{1 / 2}(\mathrm{~F}=2) \rightarrow 5 \mathrm{P}_{3 / 2}\left(\mathrm{~F}^{\prime}=3\right)$.

$\mathrm{O}$ laser de rebombeio apresenta intensidade inferior ao feixe de aprisionamento para a maioria dos alcalinos. Uma das exceções é o ${ }^{39} \mathrm{~K}$. Devido à proximidade entre os estados 
hiperfinos do estado $4 \mathrm{P}_{3 / 2}$, os lasers não conseguem definir muito bem uma transição, fazendo com que o decaimento para o estado escuro $(\mathrm{F}=1)$ ocorra com maior frequência. Para contornar esse problema, temos as duas frequências operando com potências similares, fazendo com que a distinção entre rebombeio e aprisionamento seja uma mera convenção (62). Como pode ser visto no diagrama de transições para o ${ }^{39} \mathrm{~K}$ (Figura 13), o feixe de rebombeio é dessintonizado de todos os níveis hiperfinos. Isso faz com que o número de transições cíclicas seja diminuído, acarretando em uma diminuição da taxa de captura do MOT, porém, uma temperatura mais baixa é alcançada, o que se mostrou mais eficiente em nosso experimento.

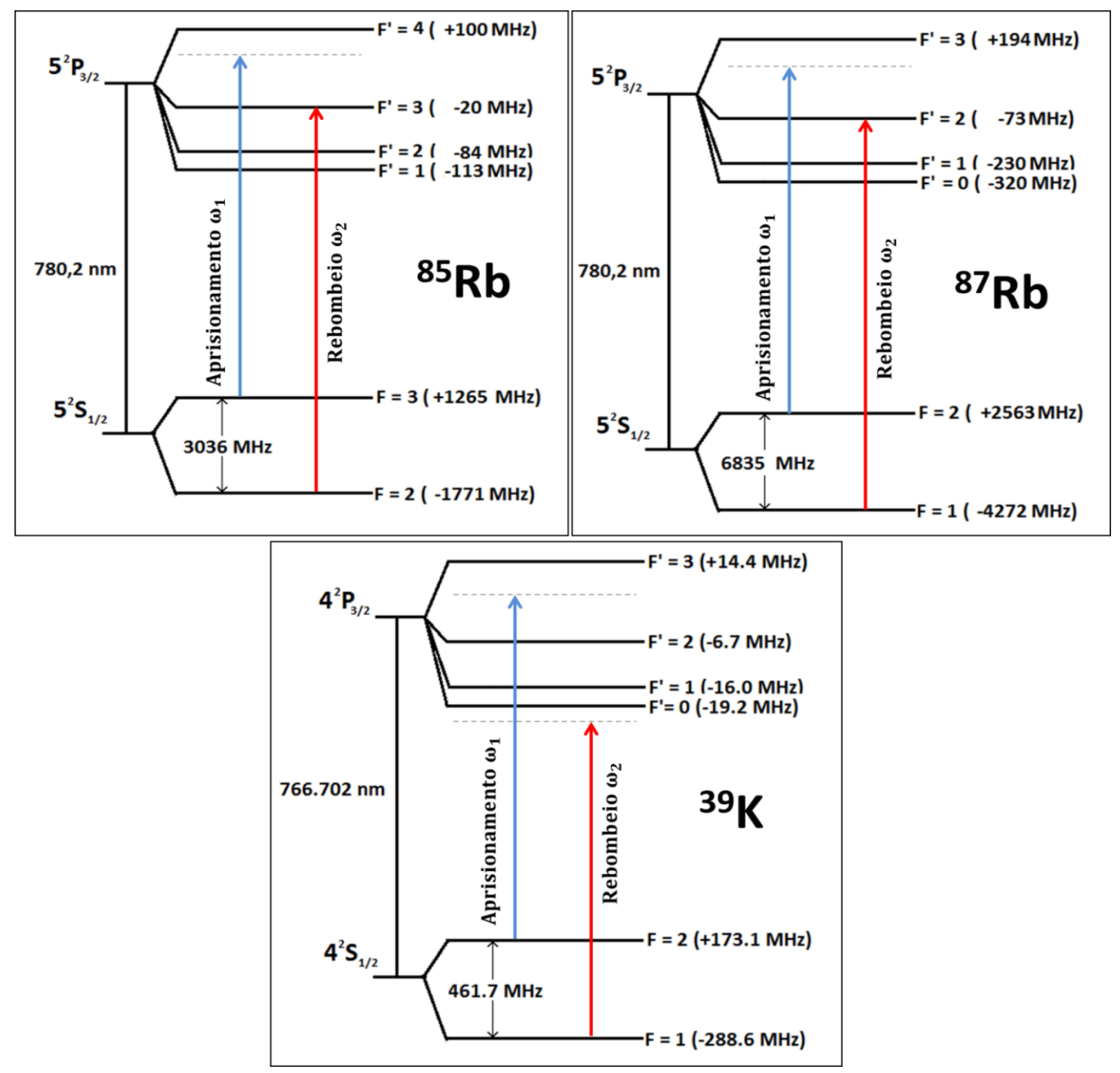

Figura 13 - Transições para os elementos atômicos: ${ }^{85} \mathrm{Rb},{ }^{87} \mathrm{Rb}$ e ${ }^{39} \mathrm{~K}$. Os feixes de aprisionamento correspondem às setas azuis e o rebombeio as setas vermelhas. 


\subsection{Montagem óptica}

Em trabalhos anteriores (63), obtivemos uma armadilha de dipolo de ${ }^{39} \mathrm{~K}$ insatisfatória, com baixa densidade e número de átomos. Atribuímos esse problema a falta de potência para gerar um MOT mais robusto de ${ }^{39} \mathrm{~K}$ e a impossibilidade de controlarmos a frequências dos feixes de aprisionamento e rebombeio de maneira independente $(62,64)$. Esse problema foi contornado com a construção de um amplificador óptico caseiro com um chip Tapered Amplifier (TA) fabricado pela empresa $m 2 k$ com capacidade de gerar $1 \mathrm{~W}$ de potência. Utilizamos dois moduladores acusto-ópticos (AOMs) independentes para gerar as frequências de rebombeio e aprisionamento para serem injetados no TA, dando total independência aos feixes. O desenho técnico e uma foto do amplificador montado na mesa óptica estão representados na Figura 14.

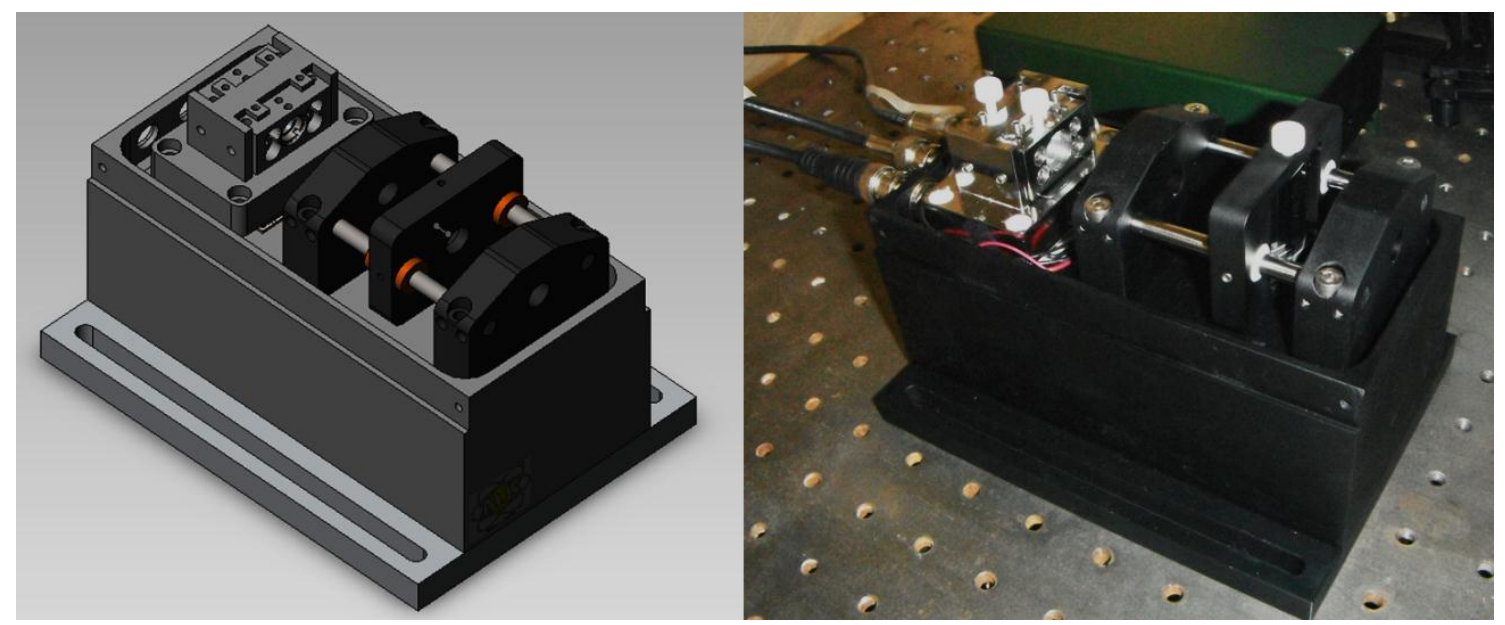

Figura 14 - Amplificador óptico utilizado para aumentar a potência disponível para o MOT de ${ }^{39} \mathrm{~K}$. A esquerda temos o desenho técnico com uma foto do amplificador construído a direita.

$\mathrm{Na}$ Figura 15, temos a montagem experimental para a geração das frequências necessárias para a desaceleração e aprisionamento do ${ }^{39} \mathrm{~K}$. Todas as frequências são providas por um laser DLX da Toptica com largura espectral de aproximadamente $1 \mathrm{MHz}$ e potência de saída de $400 \mathrm{~mW}$. Para a geração das frequências necessárias, utilizamos 5 moduladores acusto ópticos (AOM) na configuração de dupla passagem. Inicialmente, $10 \mathrm{~mW}$ são desviados para o AOM1 para a geração do sinal de absorção saturada. Com o auxílio de um módulo Digilock da Toptica, o sinal de referência é travado na transição atômica $4 \mathrm{~S}_{1 / 2}(\mathrm{~F}=2)$ 
$\rightarrow 4 \mathrm{P}_{3 / 2}\left(\mathrm{~F}^{\prime}=3\right)$ do ${ }^{39} \mathrm{~K}$. Cerca de $100 \mathrm{~mW}$ são desviados para o AOM2 para a geração do feixe de rebombeio da armadilha, resultando no final em $30 \mathrm{~mW}$. Para produzir o feixe de desaceleração, $40 \mathrm{~mW}$ são enviados para o AOM3, único modulador que trabalha com a ordem negativa de difração, onde $5 \mathrm{~mW}$ são produzidos. Devido à baixa potência gerada, utilizamos um laser escravo de $50 \mathrm{~mW}$, o qual é injetado para gerar o feixe de desaceleração. Um modulador eletro óptico (EOM) gera a frequência de rebombeio para o desacelerador e então a luz é acoplada em uma fibra mono modo com uma eficiência de 50\%. Por fim, o AOM4 recebe $80 \mathrm{~mW}$ para produzir o feixe de aprisionamento do MOT. O feixe de aprisionamento e rebombeio são misturados por um cubo divisor 50/50 resultando em $15 \mathrm{~mW}$ de cada frequência que são injetados em um laser Tampered Amplifier caseiro gerando 350 $\mathrm{mW}$ totais. O feixe é então acoplado em uma fibra mono modo e entregue ao experimento. $\mathrm{O}$ restante da luz inicial é enviado ao AOM5 para a geração do feixe de imagem. Mais detalhes sobre as frequências centrais de cada AOM se encontram na legenda da Figura 15.

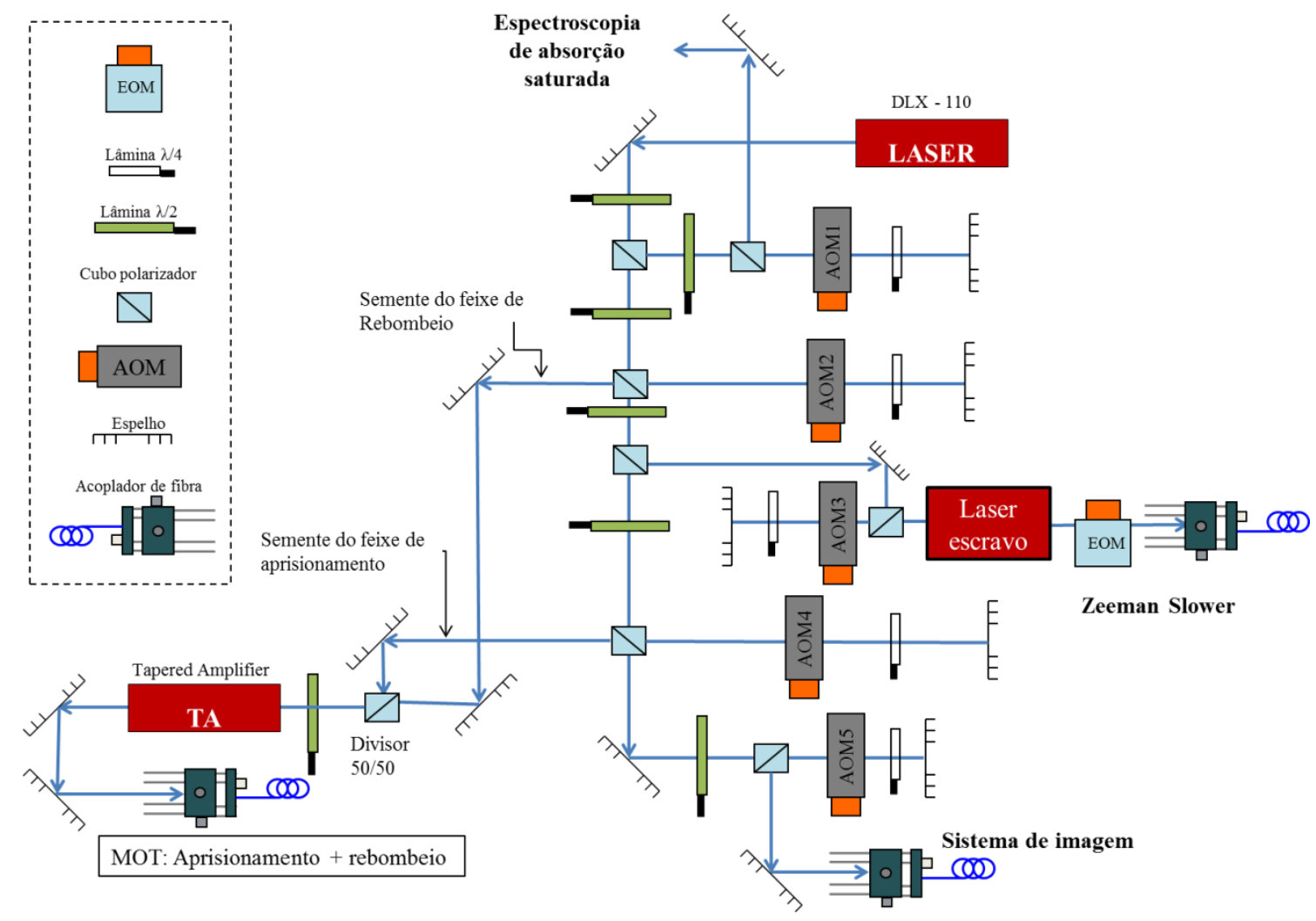

Figura 15 - Montagem óptica para o ${ }^{39} \mathrm{~K}$. Para gerar as frequências do experimento, foram utilizados 5 AOMs com as seguintes frequências centrais: (i) $80 \mathrm{MHz}$ para o AOM1, AOM4 e AOM5; (ii) $300 \mathrm{MHZ}$ para o AOM2; (iii) $250 \mathrm{MHz}$ para o AOM3. Todos os moduladores estavam em uma configuração de dupla passagem, sendo que o AOM3 era o único que operava com a ordem de difração negativa. Um EOM de $435 \mathrm{MHz}$ gerava a frequência de rebombeio para o desacelerador. 
Para a geração das frequências de MOT e desacelerador para o Rb, utilizamos dois lasers, como pode ser observado na Figura 16. O primeiro é um Toptica DLX com saída de $600 \mathrm{~mW}$, responsável por gerar as frequências de aprisionamento tanto do MOT quanto da desaceleração e o feixe de imagem. O segundo é um DL-100 da Toptica com 130 mw que gera as frequências de rebombeio do MOT e do desacelerador. As frequências necessárias para a desaceleração necessitam de amplificação, sendo assim, elas são misturadas e o resultante (1 $\mathrm{mW}$ no total) é injetado em um laser escravo fabricado pela Toptica modelo LD com saída de $80 \mathrm{~mW}$ sendo acoplada em uma fibra mono modo com 50\% de eficiência.

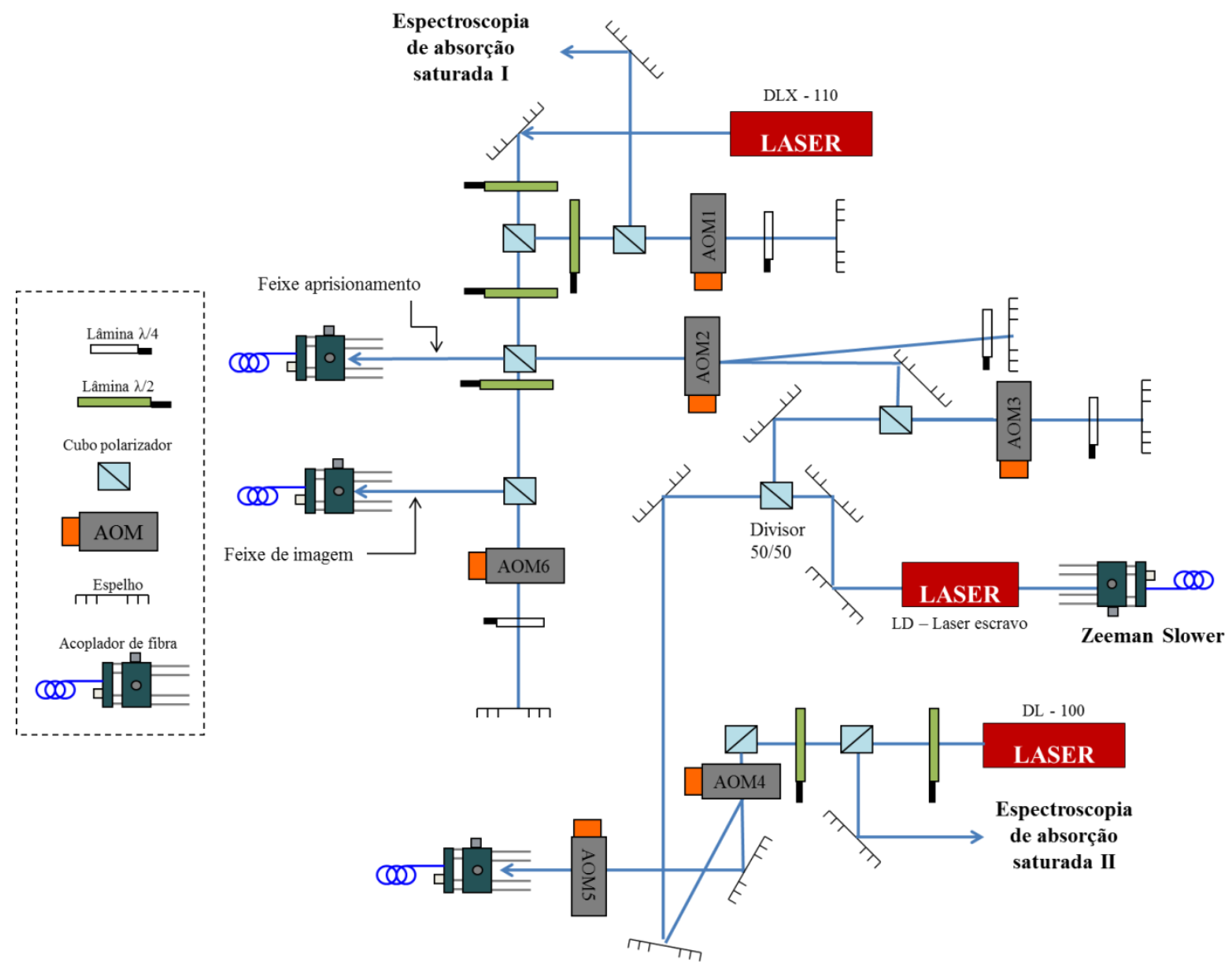

Figura 16 - Montagem óptica para o Rb. AOM1 (-93,5 MHz) com total de $-187 \mathrm{MHz}$ para a espectroscopia de absorção saturada I e travamento na transição de aprisionamento $5 \mathrm{~S}_{1 / 2}(\mathrm{~F}=2,3)-5 \mathrm{P}_{3 / 2}\left(\mathrm{~F}^{\prime}=3,4\right)$ do ${ }^{87} \mathrm{Rb}$ ou ${ }^{85} \mathrm{Rb}$ respectivamente. AOM2 $(+83,5 \mathrm{MHz})$ com total de $+167 \mathrm{MHz}$ produzindo o feixe de aprisionamento do MOT a $-20 \mathrm{MHz}$ da transição. AOM3 (-200 $\mathrm{MHz}$ ) com total de $-400 \mathrm{MHz}$ gerando o feixe de aprisionamento do desacelerador a $-687 \mathrm{MHz}$. Espectroscopia de absorção saturada II travado a $-80 \mathrm{MHz}$ da transição de rebombeio $5 \mathrm{~S}_{1 / 2}(\mathrm{~F}=1,2)-5 \mathrm{P}_{3 / 2}\left(\mathrm{~F}^{\prime}=2,3\right)$ do ${ }^{87} \mathrm{Rb}$ ou ${ }^{85} \mathrm{Rb}$ respectivamente. AOM4 $(-175 \mathrm{MHz})$ com total de $-350 \mathrm{MHz}$ produzindo o feixe de rebombeio para a desaceleração a $-430 \mathrm{MHz}$ da transição. AOM5 $(+80 \mathrm{MHz})$ produz o feixe para o rebombeio do MOT na transição. AOM6 $(+93,5 \mathrm{MHz})$ com total de $+187 \mathrm{MHz}$ produz o feixe de imagem na transição de aprisionamento. As frequências para a desaceleração são misturadas em um cubo divisor e injetados em um laser LD da Toptica com saída de $80 \mathrm{~mW}$. 
As fibras óticas que compõe o MOT fazem parte de um conjunto composto por 4 fibras de entrada e 6 fibras de saída, onde a luz acoplada na entrada é igualmente distribuída entre o 6 braços de saída. Para o acoplamento dos feixes de aprisionamento e rebombeio do $\mathrm{Rb}$, utilizamos 2 fibras de entrada, uma para cada frequência. Para o K, utilizamos somente uma fibra, pois as frequências são misturadas previamente. Esse conjunto apresenta cerca de $40 \%$ de eficiência no acoplamento e é fabricado pela Canadian Instrumentation \& Research Ltd. As potências totais que constituem o MOT são: $90 \mathrm{~mW}$ para o aprisionamento e $10 \mathrm{~mW}$ para o rebombeio do $\mathrm{Rb}$ e $60 \mathrm{~mW}$ para o aprisionamento e rebombeio do $\mathrm{K}$. O arranjo experimental para o $\mathrm{Rb}$ (Figura 16) vale tanto para o ${ }^{87} \mathrm{Rb}$ quanto para o ${ }^{85} \mathrm{Rb}$, mudando apenas o ponto de travamento do laser para migrar de uma armadilha para a outra. As linhas atômicas de transição para os dois isótopos, estão descritas na legenda da Figura 16.

Já as fibras que compõem o desacelerador são de fabricação caseira. Os feixes do K e $\mathrm{Rb}$ são acoplados em fibras independentes que são descascada e unidas na outra extremidade, como mostrado na Figura 17. Na saída da fibra, os feixes são expandidos em uma cintura de 8,5 $\mathrm{mm}$ e percorrem uma distância de aproximadamente 3 metros, passando pelo desacelerador e atingindo a região do forno com aproximadamente $2 \mathrm{~mm}$ de cintura. Apesar de uma dispersão de $15 \%$ entre os feixes, o resultado da desaceleração é superior ao caso em que os feixes são todos misturados e acoplados na mesma fibra. Com duas CCDs, uma colocada na janela logo após o forno e outra no começo do desacelerador, podemos alinhar o feixe observando a fluorescência quando o forno está aquecido. As potências finais para o desacelerador são de $30 \mathrm{~mW}$ e $10 \mathrm{~mW}$ para a frequência de aprisionamento e rebombeio do $\mathrm{Rb}$ e $25 \mathrm{~mW}$ totais para o K. Lembrando que a geração do rebombeio para o $\mathrm{K}$ é feita por meio de um modulador eletro-óptico, fazendo com que parte dessa potência (aproximadamente 1/3) esteja em um comprimento de onda não aproveitável. 


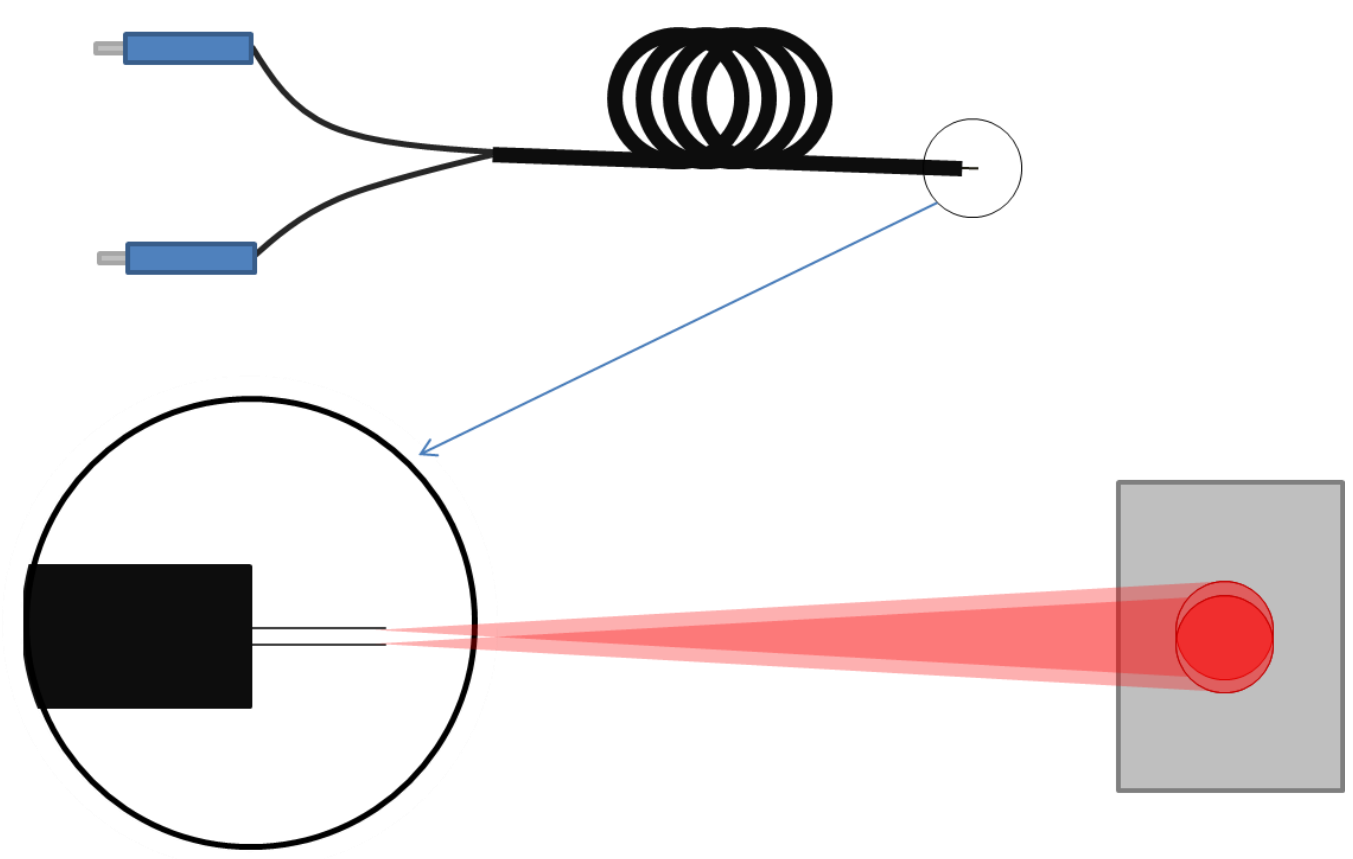

Figura 17 - Sistema de junção das fibras de desaceleração. A dispersão dos feixes era de $15 \%$ a $3 \mathrm{~m}$ da fibra (63).

\subsection{Montagem óptica da armadilha de dipolo}

Para a armadilha de dipolo, utilizamos um laser fabricado pela IPG Photonics modelo YLR-40-1070 com potência máxima de $40 \mathrm{~W}$, comprimento de onda central de $1071 \mathrm{~nm}$ e largura espectral de $1,5 \mathrm{~nm}$. As lentes possuem películas anti-reflexo para o infra vermelho pra não serem danificadas, pois a intensidade do laser podia chegar facilmente a $1 \mathrm{MW} / \mathrm{cm}^{2}$. A montagem experimental é bem simples, sendo usado apenas um conjunto de lentes e espelhos para manipular o feixe, como mostrado na Figura 18. 


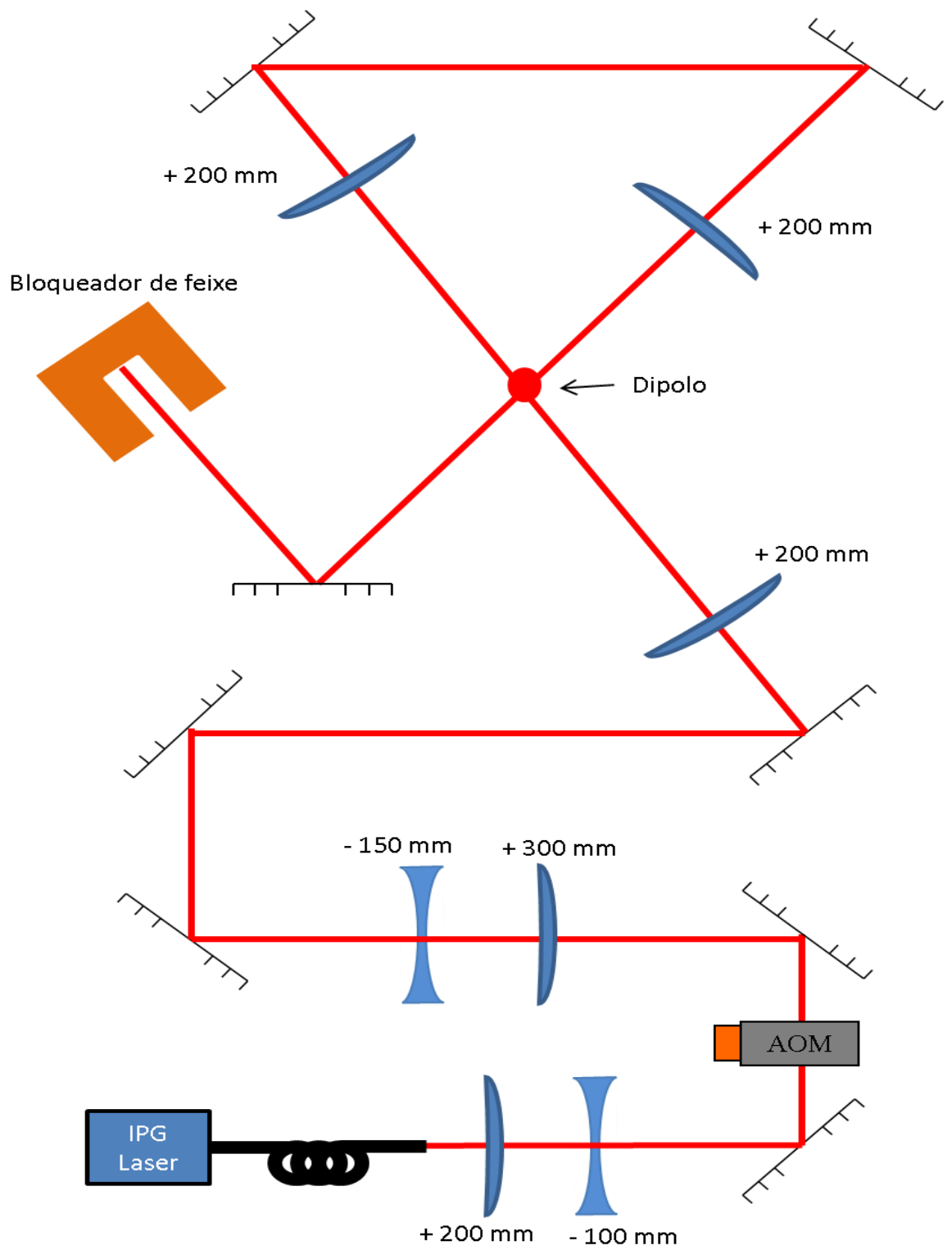

Figura 18 - Montagem ótica para a obtenção da armadilha de dipolo cruzada. Nessa configuração, utilizando o AOM para o controle de potência do laser, a cintura do feixe era de 72 $\mu \mathrm{m}$ para os dois feixes do dipolo cruzado.

Para os resultados desse capítulo, utilizamos um modulador eletro-óptico (AOM - 40 $\mathrm{MHz}$ ) para controlar e estabilizar a potência do laser. Em experimentos posteriores, verificamos que esse sistema não apresentava melhora significativa no carregamento e no tempo de vida do dipolo, com o revés de ter a potência total limitada em $27 \mathrm{~W}$ devido à eficiência do modulador. O arranjo com o modulador necessitava de uma curva de calibração entre a tensão analógica que controlava a radio frequência do modulador e a potência do laser modulada. Como o carregamento da armadilha dipolar necessita de controle de potência e desligamento do feixe, utilizamos um controle de potência analógico $(0-10 \mathrm{~V})$ e um controle 
TTL que liga/desliga o feixe presentes na própria caixa de controle do laser. A resposta do laser com a mudança de tais entradas ocorre em um tempo menor que $50 \mu \mathrm{s}$.

\subsection{Sistemas de controle a aquisição de dados}

O sistema de controle do experimento e aquisição dos dados consiste em hardwares, como placas comerciais de aquisição e placas de vídeo dedicadas. Os softwares são programas feitos em plataformas Labview 7.1 e Labview 8.5 e tem a função de controlar o experimento; aquisicionar, processar, armazenar os dados e monitorar o experimento.

Para o bom andamento do experimento, foram designados dois computadores e um laptop, sendo um responsável pelo controle total do experimento e o segundo trabalhava apenas com a aquisição e manipulação de imagens. O laptop foi designado para aquisição de tensões e comprimentos de onda. Para melhor entendimento, os programas e suas funções serão descritos separadamente neste tópico.

\subsubsection{Computador de controle}

O computador de controle era responsável pelo controle de potência e frequência de todos os lasers usados no experimento (aprisionamento, rebombeio e laser da ODT) e dos obstrutores (shutters), equipamentos que bloqueavam a luz remanescente tanto do desacelerador quanto do MOT. Os hardwares utilizados consistem em duas placas PCI $6221 \mathrm{e}$ uma PCI 6722 ambas fabricadas pela National Instruments $@$ com um total de 12 canais analógicos e 16 digitais sincronizados a uma taxa de atualização de $10 \mathrm{kHz}$. Com um programa construído em interface Labview 7.1, os canais eram sincronizados a uma precisão menor que $100 \mathrm{~ns}$ e uma taxa de atualização de $10 \mathrm{KHz}$, além da possibilidade de gerar uma sequência de pulsos digitais e rampas analógicas. A Figura 19 mostra a interface do programa com mais detalhes. 


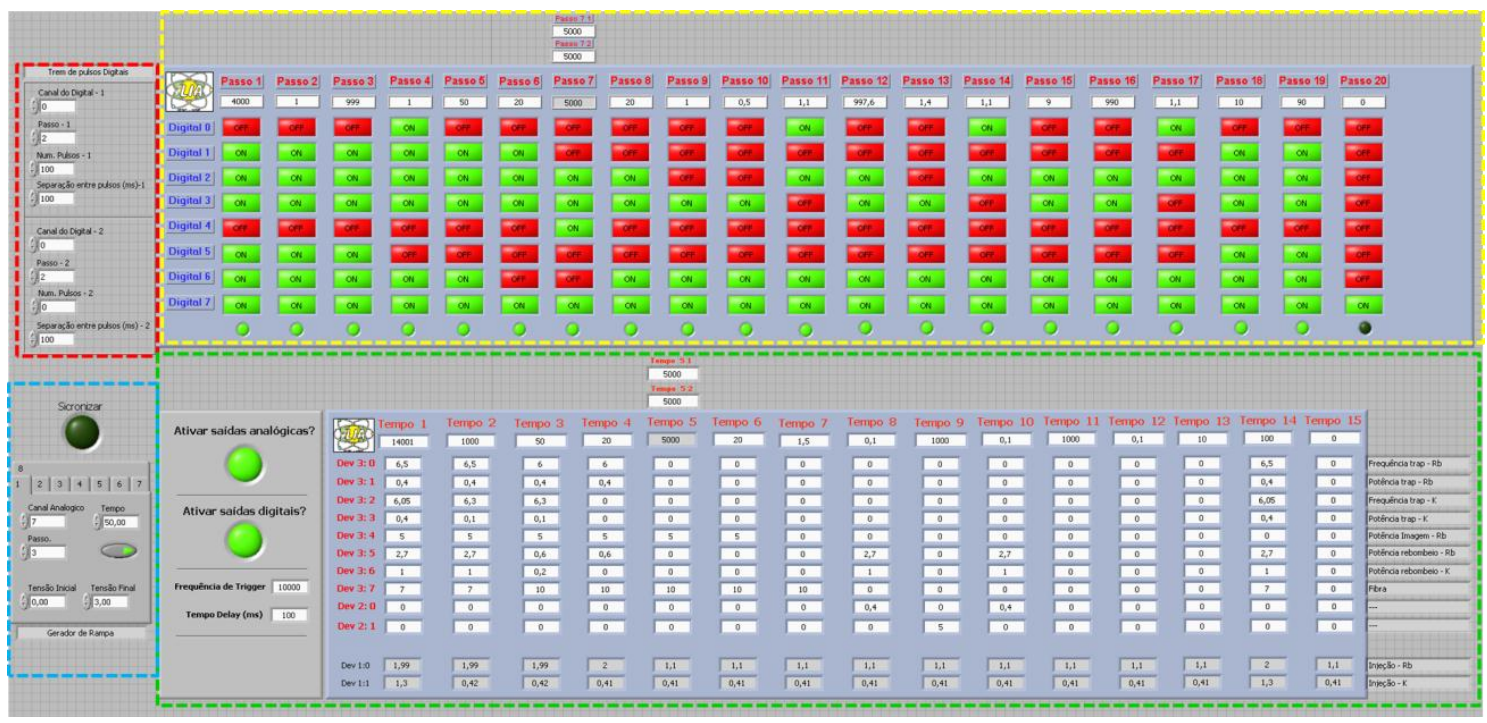

Figura 19 - Programa de controle do experimento. Delimitado pela linha vermelha, temos a parte responsável pela geração de trens de pulso. Em amarelo, o controle dos canais digitais, divididos temporalmente em 20 partes. Cada parte temporal pode ser desabilitada independentemente pelos LEDs verdes na parte inferior. Em azul temos o gerador de rampa para os canais analógicos, com capacidade de 8 rampas. Finalmente em verde temos o controle dos canais analógicos. A esquerda da área delimitada em verde, temos dois LEDs que desabilitam todos os canais analógicos ou digitais a escolha, e um campo onde podemos escolher a frequência de sincronia do experimento e o atraso inicial.

Os campos correspondentes aos tempos devem ser equivalentes entre a parte analógica (verde) e digital (amarelo) para evitar a dessincronizarão entre as placas. O botão "Sincronizar" na parte azul da Figura 19, serve para o caso em que o tempo de duração da ODT é alternado entre dois tempos. Ele indica para o programa de aquisição de imagens qual é o tempo de dipolo que está sendo rodado e sincroniza o controle com a aquisição. Como as imagens são processadas e armazenadas automaticamente pelo programa de aquisição, o botão "Sincronizar" é fundamental para identificação das imagens e tratamento dos dados. Os campos de tempo na parte superior da delimitação verde e amarela servem justamente para alternar esse tempo entre uma sequência e outra. Essa ferramenta foi implementada para dar mais robustez ao experimento, pois no carregamento de duas amostras em uma armadilha de dipolo, muitas variáveis contribuem para o número final de átomos carregados, fazendo com que o dipolo tenha uma reprodutibilidade de apenas alguns minutos. Assim, para cada ponto de tempo de vida obtido, um ponto no tempo inicial era tirado para efeito de normalização. Atribuímos a esse processo de normalização o nome de "pontos gêmeos", para facilitar a descrição dos resultados. Tomemos a Figura 20 como exemplo. 


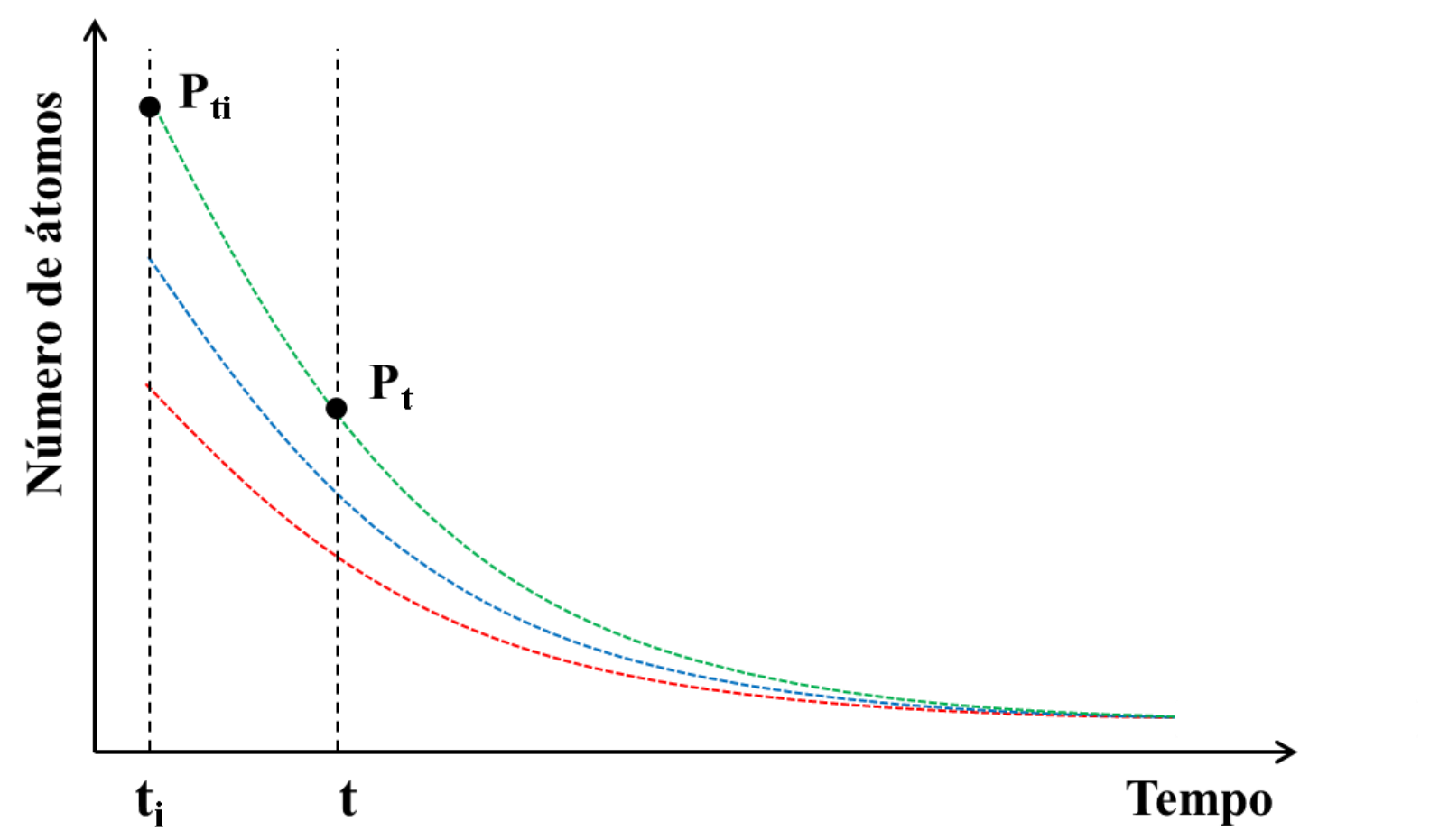

Figura 20 - Técnica de normalização de pontos sucessivos: "pontos gêmeos". As curvas em verde, azul e vermelho representam curvas de decaimento dos átomos na armadilha de dipolo decorrentes da flutuação do número inicial $\left(\mathrm{P}_{\mathrm{ti}}\right)$. O método de aquisição é alternado, sendo obtidos os valores de $\mathrm{P}_{\mathrm{ti}}$ e em seguida o valor de $\mathrm{P}_{\mathrm{t}}$ para a normalização $\mathrm{P}_{\mathrm{t}} / \mathrm{P}_{\mathrm{ti}}$. $\mathrm{O}$ processo é repetido para a obtenção de vários pontos para a média.

Podemos notar que devido a variação inicial do número de átomos carregados $\left(\mathrm{P}_{\mathrm{ti}}\right)$, obtemos três curvas de tempo de vida. Tal variação em nosso experimento gira em torno de $30 \%$ e leva cerca de 5 a 30 minutos para ocorrer. O número de pontos obtidos para um determinado tempo era aproximadamente 50, com um tempo de 15 segundos por medida, levando cerca de 13 minutos para a aquisição completa em um determinado tempo, fazendo com que essa flutuação fosse fortemente sentida. Para evitar esse erro no experimento, utilizamos a técnica batizada de "pontos gêmeos" que consiste em obter de forma alternada o número de " $\mathrm{P}_{\mathrm{t}}$ " e " $\mathrm{P}_{\mathrm{ti}}$ " fazendo uma normalização do tipo $\mathrm{P}_{\mathrm{t}} / \mathrm{P}_{\mathrm{ti}}$ para cada ponto. Os valores de " $\mathrm{P}_{\mathrm{ti}}$ " eram mantidos em um certo valor, variações maiores que $10 \%$ eram descartadas da média final e o sistema era reajustado para a obtenção do " $\mathrm{P}_{\mathrm{ti}}$ " desejado. Desse modo, conseguíamos gráficos de tempo de vida para o carregamento simples e duplo do dipolo com uma boa precisão e sem a necessidade de parar o programa de aquisição para ajustes simples, já que variações superiores a 10\% no valor " $\mathrm{P}_{\mathrm{ti}}$ " eram automaticamente excluídas pelo programa de aquisição. 


\subsubsection{Computador de aquisição de imagens}

Todo o processo de aquisição e análise da nuvem atômica foi implementada em um programa com interface Labview 7.1. Com o auxílio de uma placa de aquisição de imagens NI PCIe 1430 fabricada pela National Instruments@ e duas câmeras JAI CV-M4+CL (Uma para aquisição do $\mathrm{K}$ e outra para o $\mathrm{Rb}$ ) com alta funcionalidade no espectro infravermelho. Cada câmera continha um filtro passa banda que deixava apenas a frequência ressonante de cada elemento passar com largura aproximada de $2 \mathrm{~nm}$. Assim a câmera do potássio, por exemplo, não via a luz proveniente do feixe do rubídio e vice-versa.

O cálculo do número total de átomos na amostra era realizado de maneira instantânea com esse programa. Levando em conta que a diminuição na intensidade do feixe de imagem, devido a absorção pelos átomos aprisionados, segue a lei de beer, podemos assumir a seguinte expressão:

$$
\frac{d I}{d z}=-I \sigma_{0} n(x, y, z)
$$

Sendo $\sigma_{0}=2,9 \times 10^{-9} \mathrm{~cm}^{2}$ a seção de choque de espalhamento e $n(x, y, z)$ o perfil de densidade da amostra. Integrando no eixo $z$ da equação (15), teremos o perfil de intensidade para o feixe de imagem que se propaga através da amostra e atinge a câmera CCD.

$$
I(x, y)=I_{0}(x, y) e^{-\bar{n}(x, y) \cdot \sigma_{0}}-I_{B}(x, y)
$$

Em que $I_{0}(x, y)$ é a intensidade inicial do feixe de imagem, $\bar{n}(x, y)$ é o perfil de intensidade integrado ao longo do eixo z e para levar em conta possíveis defeitos de imagem que são pertinentes da câmera, uma imagem de fundo $\left(I_{B}\right)$, com os lasers totalmente desligados, foi adicionada à equação.

A principal função do programa era a aquisição dessas três imagens em sequência na fase de ODT para cada câmera. As imagens eram tratadas matematicamente, resultando em uma imagem de absorção para cada elemento ( $\mathrm{K}$ e $\mathrm{Rb}$ ). A sequência de imagens é a seguinte: Imagem da ODT é carregado (I), imagem sem átomos com todos os lasers ligados $\left(\mathrm{I}_{0}\right)$ e uma imagem de fundo com todos os lasers desligados $\left(\mathrm{I}_{\mathrm{B}}\right)$. A sequência para a obtenção das três imagens se encontra na Figura 21. 


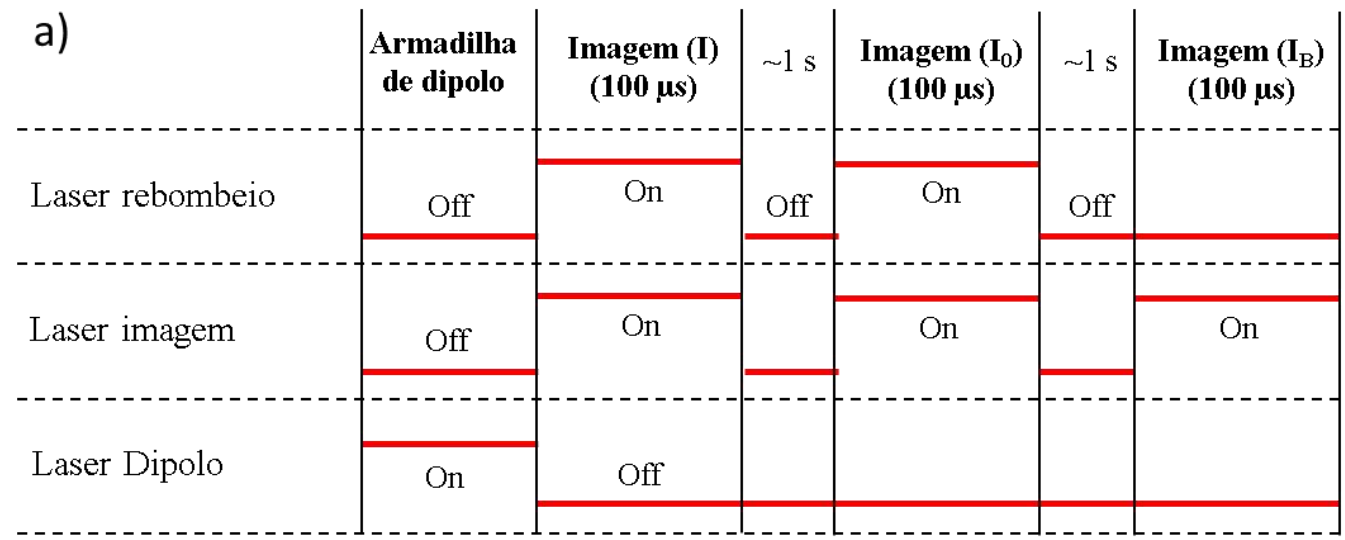

b)
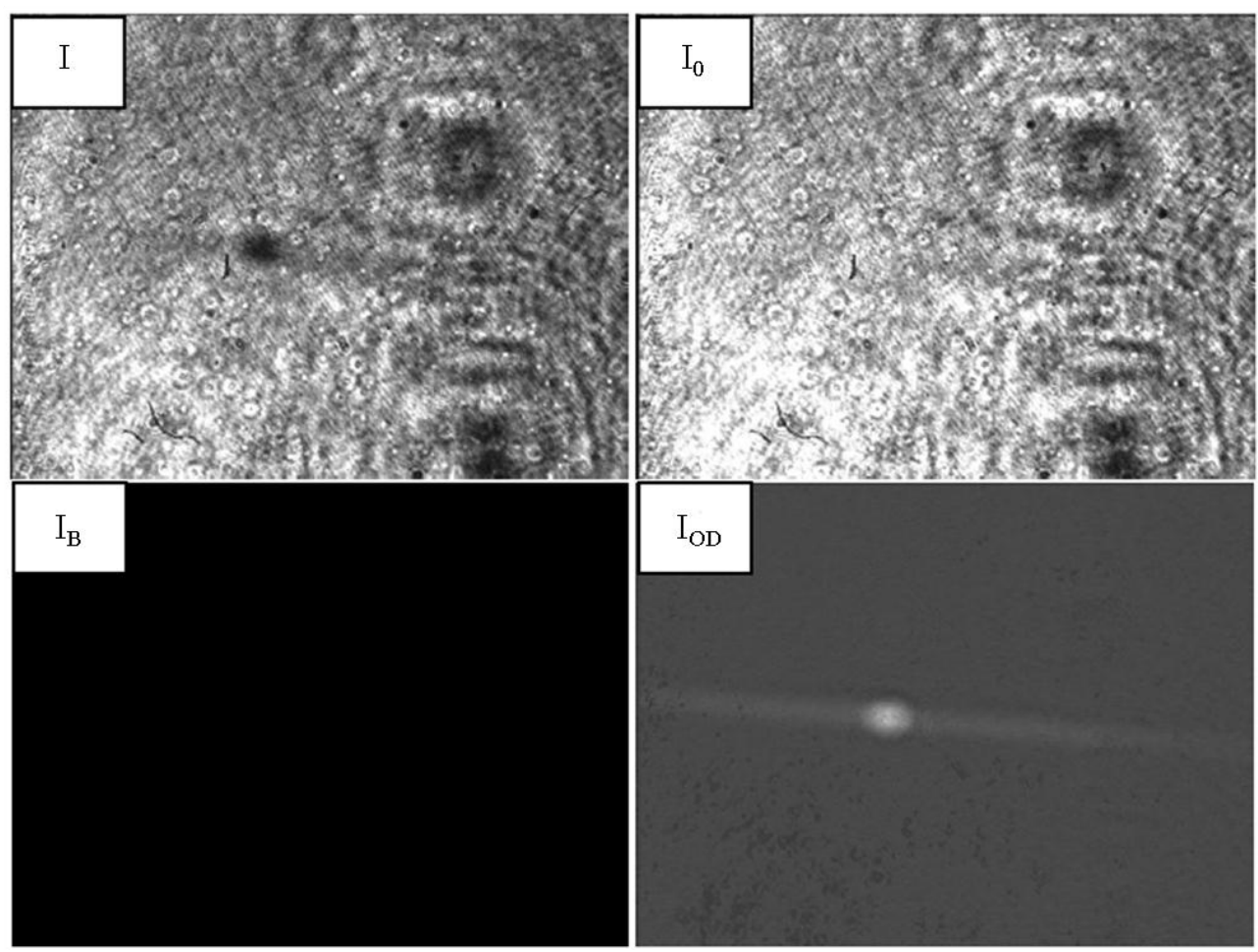

Figura 21 - Sequência para obtenção das três imagens (I, $I_{0}$ e $I_{B}$ ) que compõe a imagem de absorção $\left(\mathrm{I}_{\mathrm{OD}}\right)$. O tempo de $1 \mathrm{~s}$ entre a aquisição das imagens servia para garantir o processamento correto pelo computador. A obtenção de cada imagem era feita em $100 \mu \mathrm{s}$. b) Sequência de imagens aquisicionadas, onde I representa a imagem dos átomos na armadilha, $\mathrm{I}_{0}$ somente os feixes laser, sem átomos, $I_{B}$ o plano de fundo para eventuais ruídos da câmera e $\mathrm{I}_{\mathrm{OD}}$ a imagem processada.

O cálculo da densidade óptica (OD) é feito pixel a pixel e compõe a imagem de absorção ( $\left.\mathrm{I}_{\mathrm{OD}}\right)$ da Figura 21b.

$$
O D(x, y)=-\ln \left(\frac{I(x, y)-I_{B}(x, y)}{I_{0}(x, y)-I_{B}(x, y)}\right)
$$


Das equações (16) e (17), obtemos a densidade para um determinado pixel da CCD:

$$
\bar{n}(x, y)=\frac{O D(x, y)}{\sigma_{0}}
$$

Para a obtenção do número total de átomos na armadilha, basta integrar $\bar{n}(x, y)$ nos eixos x e y:

$$
N=\iint \frac{O D(x, y)}{\sigma_{0}} d x d y=-\frac{A}{\sigma_{0}} \sum_{\text {Pixels }} O D(i, j)=35,9 \sum_{\text {Pixels }} O D(i, j)
$$

Onde $A$ é a área de um pixel da câmera CCD. Levando em conta o fator 2 de amplificação do sistema de imagens e a dimensão de $6,45 \mu \mathrm{m}$ do pixel quadrado, temos $A=\left(\frac{6,45}{2} \times 10^{-4}\right)^{2}=$ $1,04 \times 10^{-7} \mathrm{~cm}^{2}$.

No mesmo programa, como uma função secundária, as câmeras capturavam imagens de fluorescência do MOT a cada $50 \mathrm{~ms}$ e integravam uma região de interesse préestabelecido. $\mathrm{O}$ valor obtido era proporcional ao número de átomos no MOT, possibilitando a detecção de alguma variação no experimento (Figura 22a). Quando ocorriam variações mínimas, como variações de potência no laser ou mudança de corrente no desacelerador, um ajuste era dado sem a interrupção da sequência experimental. A sequência só era parada em caso de uma variação muito brusca ou perda do ponto de travamento do laser, podendo permanecer operante por até uma hora (Figura 22b). As imagens de absorção eram nomeadas com um texto pré-estabelecido mais a hora em que foram obtidas e então eram salvas em uma pasta nomeada com o ano, o mês e o dia corrente para eventuais análises posteriores. 


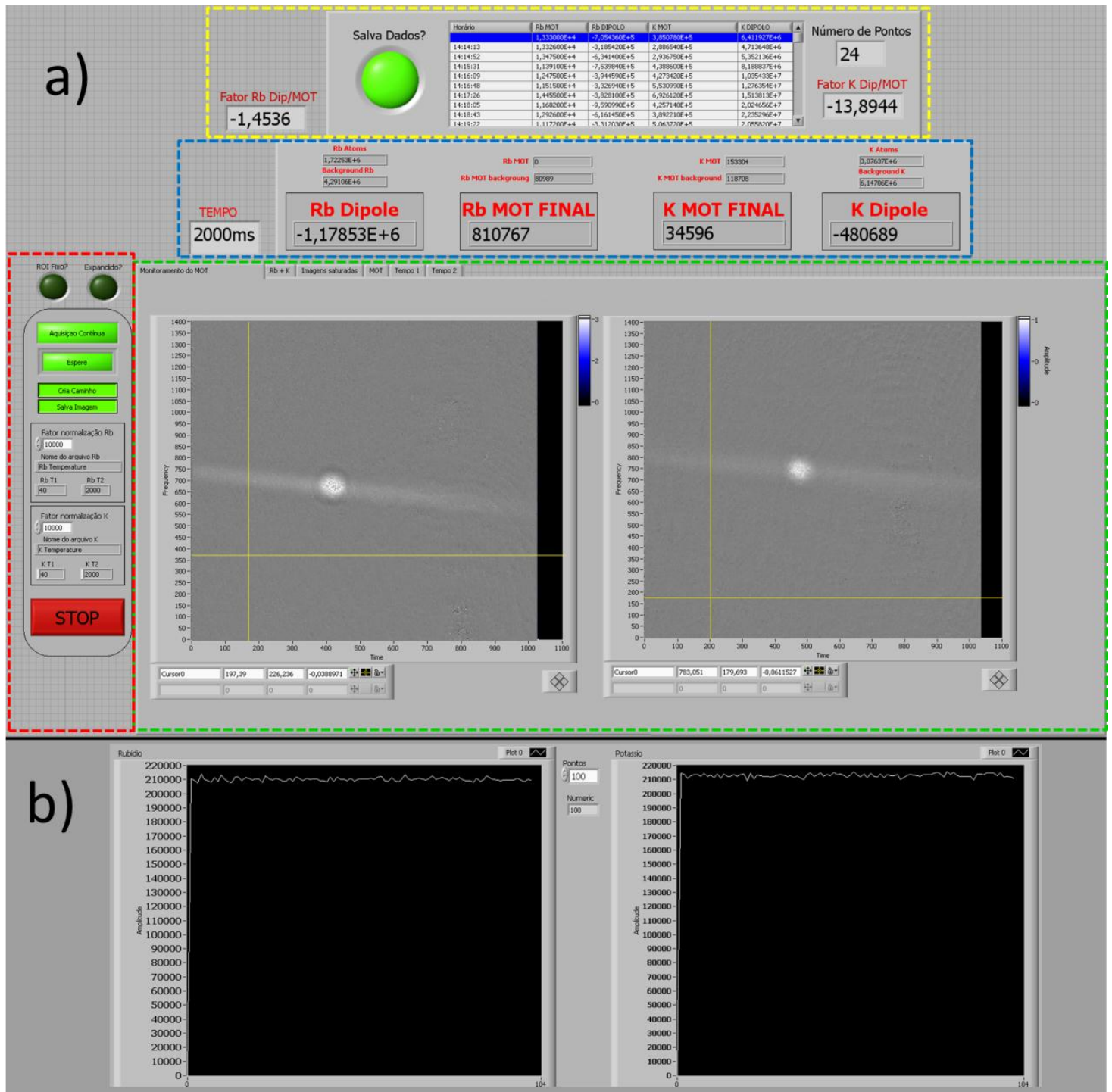

Figura 22 - Programa de aquisição e processamento de imagens. a) Na parte delimitada em amarelo temos os resultados que foram obtidos durante o dia, como um número proporcional ao número de átomos no MOT e na ODT do K e do Rb junto com o horário da aquisição. O botão "Salva dados" serve para habilitar essa opção. Em vermelho, temos os controles gerais do programa, como a opção de salvar as imagens em arquivos, alterar o tamanho do região de interesse (ROI) de uma sequência pra outra, criar caminho automático ou manual para salvar as imagens e rodar o experimento continuamente ou executar a sequência uma única vez. A parte verde mostra a imagem de absorção do dipolo duplo para Rb (à esquerda) e K (à direita). Em b) temos a parte responsável pelo monitoramento do MOT. A cada $50 \mathrm{~ms}$ uma imagem de fluorescência é tirada e integrada em uma região de interesse escolhida, retornando um valor proporcional ao tamanho do MOT que é graficado, servindo para monitorar a armadilha.

Outro programa analisava as imagens individuais de cada elemento, extraindo a cintura gaussiana de cada amostra (Figura 23). Com o valor das cinturas em dois tempos distintos de tempo de voo, era estimada a sua temperatura, processo muito útil para as primeiras tentativas de carregamento, onde o objetivo era a obtenção de temperaturas baixas. 
a)
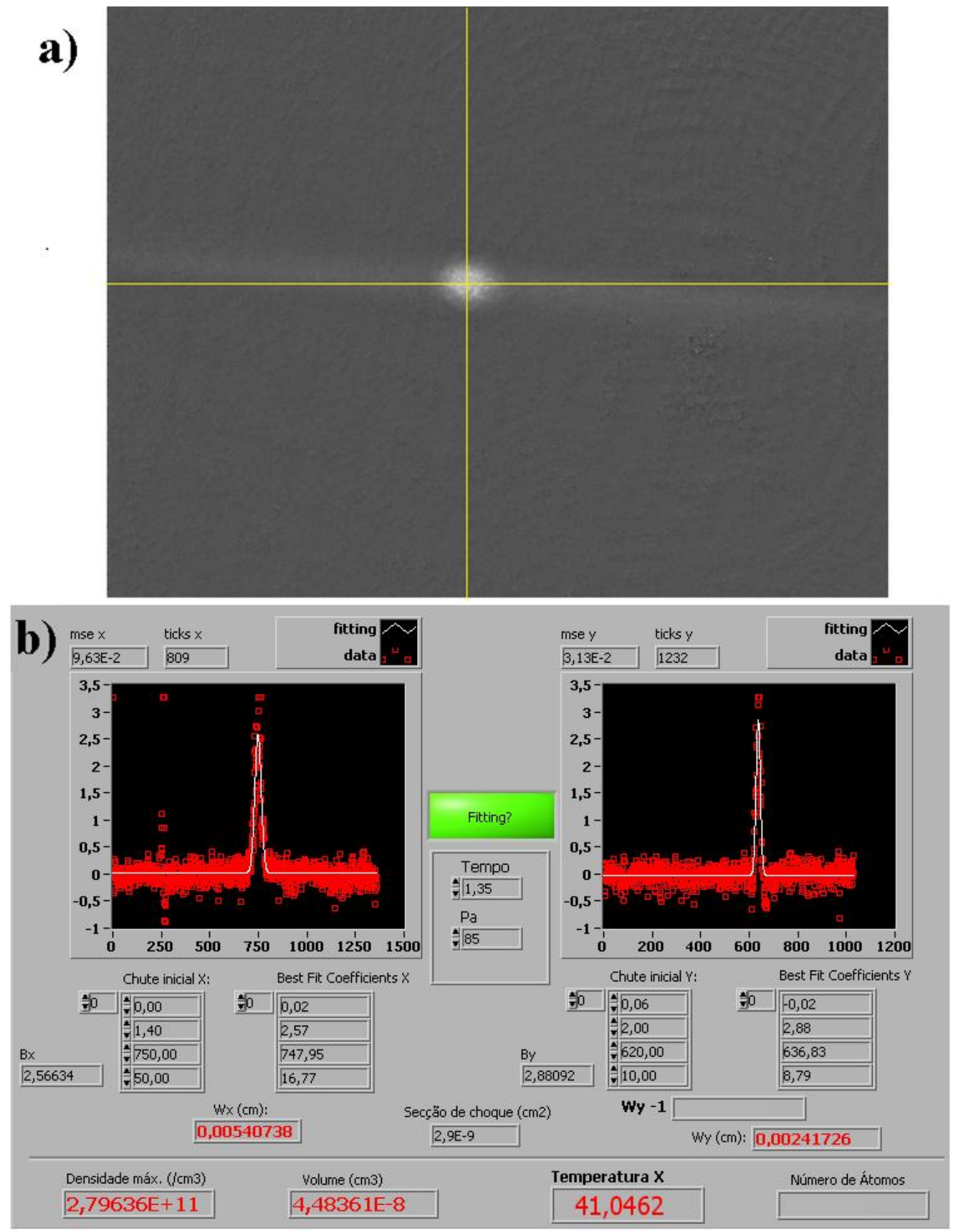

Figura 23 - Parte do programa responsável pela obtenção da cintura da armadilha de dipolo e temperatura. Na parte em a) temos um cursor que é posicionado no centro da amostra e retira um perfil de intensidade indicado pela linha amarela. Em b) temos o programa que faz o ajuste de uma gaussiana no perfil e extrai o valor da cintura. No centro temos um campo denominado "Tempo", tal campo indica a separação no tempo de expansão entre duas imagens consecutivas em "ms" e o campo "Pa" indica o peso atômico do elemento estudado. Ambos os campos, junto com a cintura de duas imagens consecutivas, servem para a obtenção de uma estimativa da temperatura.

A estimativa da temperatura é feita utilizando a expansão da amostra na direção $y$, linha amarela vertical na Figura 23a. O perfil horizontal sofre influência dos átomos que estão nos 
braços da armadilha, apresentando um valor de cintura não condizente com a realidade. A fórmula gaussiana ajustada é dada por:

$$
y=a+b * e^{\frac{(x-c)^{2}}{2 d^{2}}}
$$

onde o valor da cintura era obtido através da calibração da variável " $d$ " levando em conta a dimensão do pixel da CCD $(6,45 \mu \mathrm{m})$ e o fator de amplificação de 2 , ficando da forma:

$$
w=\frac{d * 0,000645}{2}
$$

Com o valor do tempo de expansão da nuvem atômica $(\mathrm{t})$, da variação da cintura e da massa atômico do elemento (m), obtêm-se a temperatura da amostra através da seguinte expressão:

$$
T=\frac{\left(w_{t}^{2}-w_{0}^{2}\right)}{t^{2}} * \frac{m}{k_{b}}
$$

Para medidas de temperatura mais precisas, é necessária a obtenção de vários valores de cintura para diversos tempos de expansão, onde é feito um gráfico de $w_{t}$ versus t que é ajustada a equação (22) devidamente rearranjada.

No cálculo das densidades máximas da amostra aprisionada, assumimos que a distribuição de densidades seja esférica e da forma:

$$
n(r, \theta, \varphi)=n_{0} e^{-\frac{r^{2}}{2 w^{2}}}
$$

Na qual o valor de $w$ é calculado na equação (21).

Integrando essa expressão em todo o espaço, obteremos o número total de átomos aprisionados.

$$
N=\int n(r, \theta, \varphi) d V=4 \pi n_{0} \int_{0}^{\infty} e^{-\frac{r^{2}}{2 w^{2}}} \cdot r^{2} d r=(2 \pi w)^{\frac{3}{2}} \cdot n_{0}
$$


Isolando o termo para a densidade máxima, teremos:

$$
n_{0}=\frac{N}{(2 \pi w)^{\frac{3}{2}}} .
$$

Utilizando o número total de átomos (N) da equação (19) e a cintura obtida do ajuste da gaussiana $(w)$ da equação (21), teremos o valor da densidade máxima $\left(n_{0}\right)$, que será muito importante para a determinação e análise dos tempos de vida da armadilha de dipolo.

\subsubsection{Computador de aquisição de dados}

Um terceiro computador (Laptop) foi designado para a aquisição de dados. Esse computador utilizava uma placa NI USB-6259 com programa construído em interface labview 8.5. O principal objetivo desse programa era realizar a aquisição de dados simples, como o comprimento de onda de um laser em função do tamanho do MOT (utilizado para medir perdas no MOT) ou para controlar e medir o comprimento de onda de um laser de corante (usado na tentativa de ionização molecular). Trata-se de um programa simples, sendo constituído basicamente por uma entrada analógica sincronizada ao computador de controle. 


\section{4 Átomos de ${ }^{39} \mathrm{~K}$ em uma armadilha de dipolo}

Neste capítulo, descreveremos o aprisionamento de átomos de ${ }^{39} \mathrm{~K}$ em uma armadilha magneto óptica (MOT), o seu processo de resfriamento sub-Doppler e transferência para uma armadilha óptica de dipolo cruzada em $1071 \mathrm{~nm}$. Devemos ressaltar que até a realização deste experimento, não havia na literatura nenhum trabalho relacionado ao carregamento de uma armadilha de dipolo de ${ }^{39} \mathrm{~K}$ diretamente de um MOT. Desta forma, uma caracterização detalhada foi realizada com o intuito de maximizarmos o número de átomos carregados na armadilha. Estes resultados foram publicados no periódico J. Phys. B: At. Mol. Opt. Phys. em agosto de 2012 (47).

\subsection{O MOT de ${ }^{39} \mathrm{~K}$}

Utilizando o arranjo experimental para o aprisionamento do potássio, como descrito no capitulo 3 e esquematicamente apresentado na Figura 15, conseguimos realizar o carregamento de um MOT de ${ }^{39} \mathrm{~K}$. A amostra obtida apresentava número e densidade suficientes para a realização do resfriamento e transferência dos átomos para uma armadilha de dipolo. O ponto desta montagem que merece destaque foi a possibilidade de controle independente de frequência e potência dos feixes de aprisionamento e rebombeio. Isto foi crucial para o processo de resfriamento e carregamento da armadilha de dipolo. Para o carregamento do MOT, os feixes de aprisionamento e rebombeio (respectivamente $\omega_{1} e \omega_{2}$ na Figura 24) apresentam intensidades de $I_{\omega 1}=4,3 \mathrm{~mW} / \mathrm{cm}^{2}$ e $I_{\omega 2}=4,1 \mathrm{~mW} / \mathrm{cm}^{2}$ por braço do MOT (em um total de 6 braços).

As frequências dos feixes foram medidas utilizando um medidor de onda WS/7 fabricado pela empresa Highfinesse ${ }^{\circledR}$. Para o MOT, a dessintonia do feixe de aprisionamento era de $\delta_{w 1}=-11 \mathrm{MHz}$ com relação à transição atômica $4 S_{1 / 2}(\mathrm{~F}=2) \rightarrow 4 P_{3 / 2}\left(\mathrm{~F}^{\prime}=3\right)$ e do rebombeio era de $\Delta=-18 \mathrm{MHz}$ em relação a transição $4 S_{1 / 2}(\mathrm{~F}=1) \rightarrow 4 P_{3 / 2}\left(\mathrm{~F}^{\prime}=2\right)$. A Figura 24 mostra a posição energética de cada frequência no diagrama de níveis de energia do ${ }^{39} \mathrm{~K}$. 


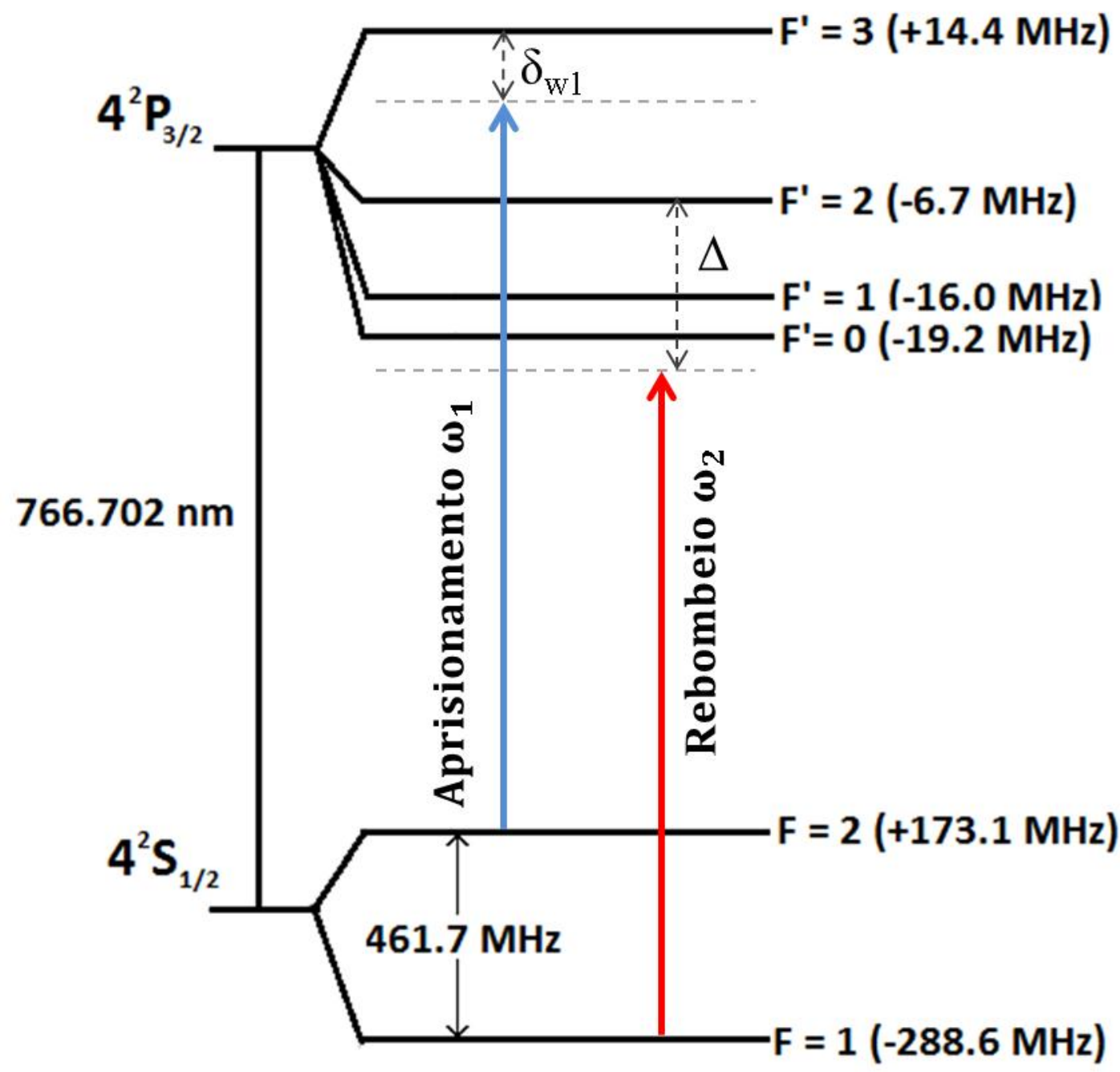

Figura 24 - Esquema de níveis de transições para o ${ }^{39} \mathrm{~K}$ incluindo o feixe de aprisionamento $\left(\omega_{1}\right)$ e rebombeio $\left(\omega_{2}\right)$, onde $\delta_{\mathrm{w} 1}$ é a dessintonia referente à transição $4 \mathrm{~S}_{1 / 2}(\mathrm{~F}=2) \rightarrow 4 \mathrm{P}_{3 / 2}\left(\mathrm{~F}^{\prime}=3\right)$ e $\Delta$ é referente à $4 \mathrm{~S}_{1 / 2}(\mathrm{~F}=1) \rightarrow$ $4 \mathrm{P}_{3 / 2}\left(\mathrm{~F}^{\prime}=2\right)$.

Nessas condições, o MOT era carregado com aproximadamente $3 \times 10^{7}$ átomos e temperatura média de $300 \boldsymbol{\mu} \boldsymbol{K}$, sendo um excelente ponto de partida para o carregamento da armadilha de dipolo. 


\subsection{O resfriamento sub-Doppler do MOT de ${ }^{39} \mathrm{~K}$ e carregamento da armadilha de dipolo}

Com a nossa experiência em carregamentos de armadilhas dipolares $\left({ }^{85} \mathrm{Rb}\right.$ e $\left.{ }^{87} \mathrm{Rb}\right)$ (63), sabemos que a baixa temperatura $(<50 \mu \mathrm{K})$ e uma grande quantidade de átomos no MOT são fatores cruciais para o carregamento de uma boa armadilha de dipolo. Além disso, o potássio apresenta uma peculiaridade em relação ao rubídio: A separação hiperfina do estado excitado $\left(4 \mathrm{P}_{3 / 2}\right)$ é da ordem da largura natural de linha $(\Gamma \simeq 6 \mathrm{MHz})$, dificultando um resfriamento abaixo do limite Doppler. Através da publicação de trabalhos recentes $(62,64)$, conseguimos desenvolver uma técnica de resfriamento eficiente, atingindo uma temperatura média de $40 \mu \mathrm{K}$, suficiente para darmos início ao processo de carregamento da armadilha de dipolo.

O ponto de partida era um MOT de ${ }^{39} \mathrm{~K}$ com aproximadamente $3 \times 10^{7}$ átomos e uma densidade de $5 \times 10^{9} \mathrm{~cm}^{-3}$. No MOT, a intensidade do laser de aprisionamento por braço da armadilha era de $\mathrm{I}_{\omega 1}=4,3 \mathrm{~mW} / \mathrm{cm}^{2}$ com uma dessintonia $\delta_{\mathrm{w} 1}=-11 \mathrm{MHz}$; a intensidade do rebombeio por braço era $\mathrm{I}_{\omega 2}=4,1 \mathrm{~mW} / \mathrm{cm}^{2}$ com uma dessintonia $\Delta=-18 \mathrm{MHz}$. O processo de carregamento seguia a seguinte ordem: i) Uma fase de carregamento do MOT, que durava cerca de $10 \mathrm{~s}$ e apresentava os feixes de aprisionamento e rebombeio com as intensidades e dessintonias fixos nos parâmetros do MOT. O laser de aprisionamento de dipolo permanecia desligado durante todo esse processo; ii) Uma fase de resfriamento do MOT e de carregamento do dipolo com duração de $50 \mathrm{~ms}$. Para o resfriamento, as intensidades e frequências dos feixes do MOT são alteradas para os parâmetros da fase de carregamento $\left(\mathrm{I}_{\omega 1}=0,6 \mathrm{~mW} / \mathrm{cm}^{2}, \delta_{\mathrm{w} 1}=-9,5 \mathrm{MHz} ; \mathrm{I}_{\omega 2}=0,06 \mathrm{~mW} / \mathrm{cm}^{2}\right.$ e $\left.\Delta=-18 \mathrm{MHz}\right)$ e o laser de dipolo é ligado seguindo uma rampa linear de 0 até $14 \mathrm{~W}$. A temperatura no final desse estágio atinge valores pouco abaixo de $40 \mu \mathrm{K}$, sendo consistente com as técnicas de resfriamento desenvolvidas para o ${ }^{39} \mathrm{~K}(62,64)$; iii) Por fim, os feixes do MOT e o campo magnético são desligados e a potência do feixe de dipolo é aumentada de forma linear em 4 ms para o seu valor máximo de $27 \mathrm{~W}$.

O número de átomos e as dimensões da armadilha foram obtidos através de imagens de absorção, por meio da integração de uma região de interesse (ROI), como foi descrito na parte experimental do trabalho. Estas medidas foram realizadas em um tempo mínimo de $\mathrm{t}=$ $30 \mathrm{~ms}$ após o término do carregamento. Imagens obtidas em tempos inferiores a $30 \mathrm{~ms}$ mostravam átomos não aprisionados caindo na presença da gravidade e por isso foram 
descartadas. A sequência experimental com os parâmetros já otimizados é mostrada na Figura $25 \mathrm{a}$.

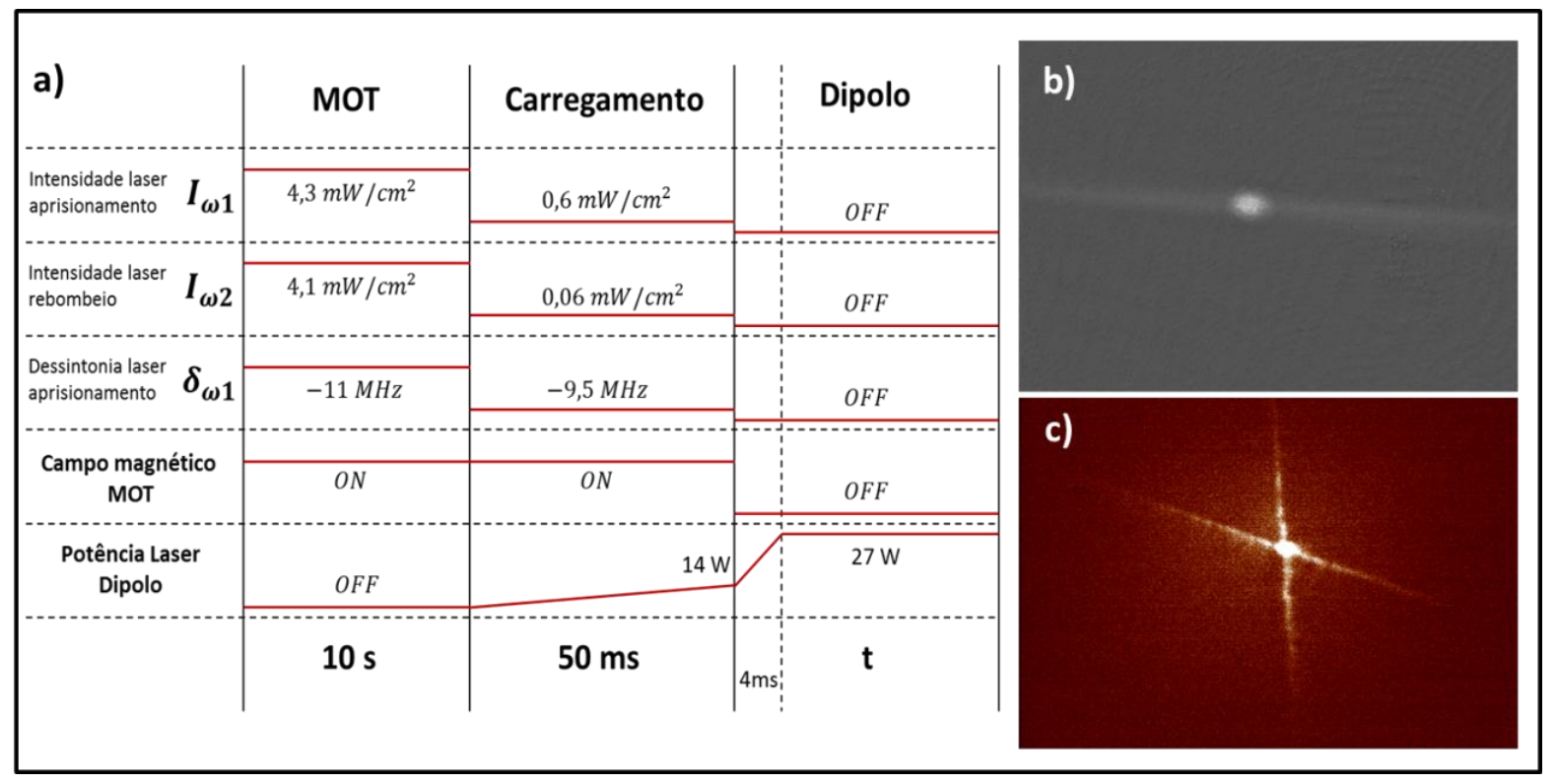

Figura 25 - a) Sequencia experimental otimizada para carregamento da armadilha de dipolo. b) Imagem de absorção da armadilha de dipolo cruzado e c) imagem de fluorescência. A frequência do laser de rebombeio era sempre fixa em $\Delta=-18 \mathrm{MHz}$.

Como descrito anteriormente, a imagem de absorção (Figura 25b) foi utilizada para obtermos os valores absolutos de grandezas importantes da amostra (número de átomos, dimensões da armadilha e densidade atômica máxima). As imagens de fluorescência mostradas na Figura 25c foram utilizadas apenas no início do processo de alinhamento e otimização da armadilha ótica. Como nesse estágio o número de átomos era bem reduzido na armadilha, a imagem de fluorescência apresentava maior sensibilidade pelo fato de podermos aumentar o tempo de exposição da câmera, e mais praticidade, por se tratar de uma imagem de rápido processamento. A Figura 26 mostra uma imagem de absorção transformada em um gráfico 3D de intensidades, onde os eixos $\mathbf{X}$ e $\mathbf{Y}$ correspondem aos pixels da CCD e o eixo $\mathbf{Z}$ à densidade óptica (Figura 26b). 


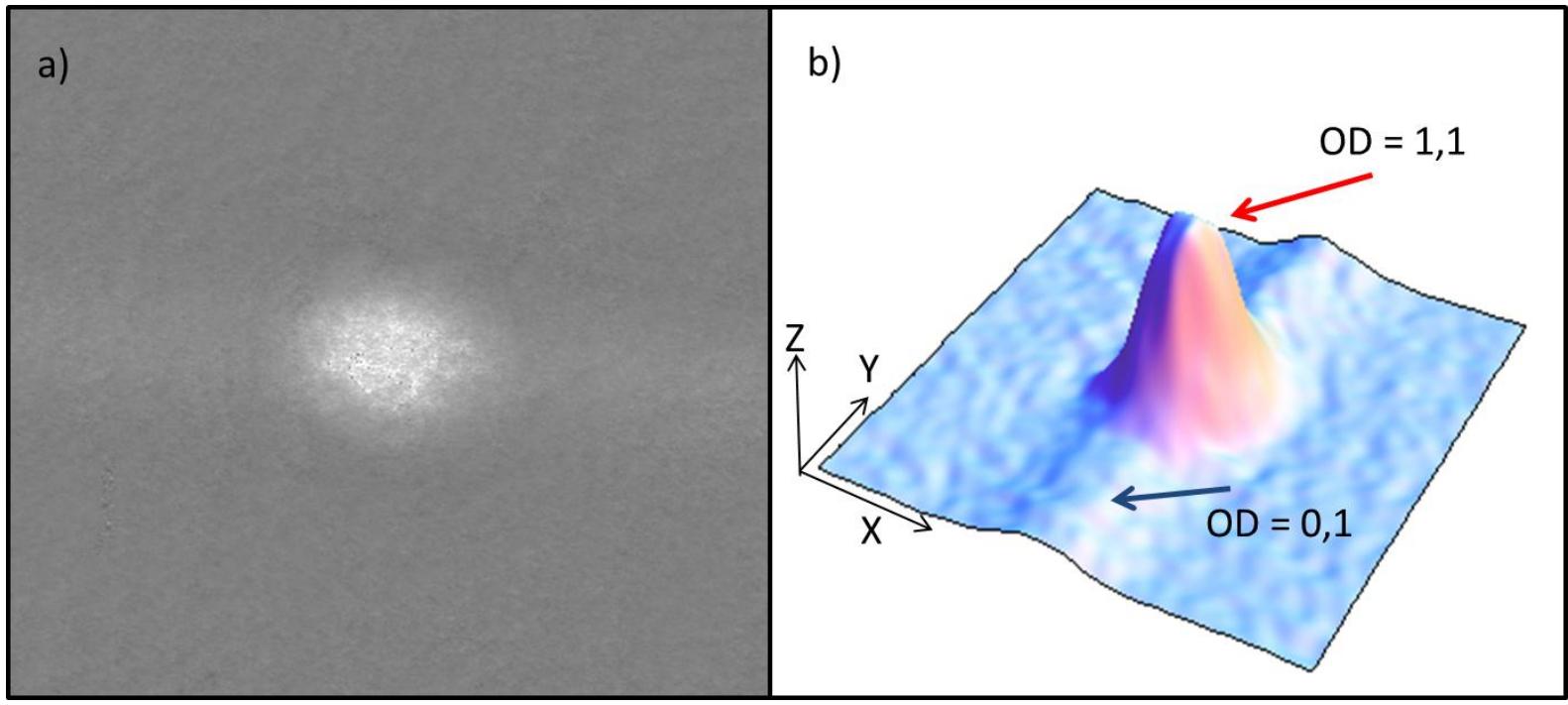

Figura 26 - a) Imagem de absorção obtida. Como a imagem é feita no mesmo plano que contém os feixes, a linha tracejada em azul corresponde a sobreposição do carregamento de dois feixes simples da armadilha e a região em vermelho corresponde a região cruzada. b) Gráfico de intensidade 3D da imagem de absorção para o ${ }^{39} \mathrm{~K}$. As coordenadas X e Y correspondem aos pixels da CCD enquanto que a coordenada $Z$ representa a densidade ótica (OD) da amostra, com valor máximo $O D=1,1$. As setas vermelha e azul correspondem respectivamente as áreas vermelha e azul delimitadas em "a". As imagens em "a" e "b" correspondem exatamente à mesma imagem com tratamento matemático diferente.

Na Figura 26b, podemos notar que a sobreposição de dois dipolos simples (seta azul), apresenta densidade uma ordem de grandeza menor que à região cruzada (seta vermelha). Esse ganho em densidade é importante para o estudo de colisões envolvendo dois corpos mais um fóton em $1071 \mathrm{~nm}$, que será abordado no capítulo seguinte.

\subsection{Caracterização do carregamento de ${ }^{39} \mathrm{~K}$ na armadilha dipolo}

Por se tratar de uma técnica de carregamento de armadilha de dipolo inédita, realizamos uma caracterização completa da armadilha com o intuito de maximizarmos o número total de átomos carregados na armadilha de dipolo na região cruzada. Para isso, variamos durante a fase de carregamento os seguintes parâmetros: Tempo total de carregamento $(\mathrm{t})$, potência final na rampa do laser de ODT $(P)$, dessintonia do laser de aprisionamento $\left(\delta_{w 1}\right)$ e intensidades dos feixes de aprisionamento $\left(I_{w 1}\right)$ e rebombeio $\left(I_{w 2}\right)$. Medindo o número de átomos na região cruzada em função da variação desses parâmetros, construímos gráficos e obtivemos os valores ótimos para a sequência mostrada na Figura 25a. 
Inicialmente, caracterizamos a carga do dipolo em função do tempo de carga $(\mathrm{t})$ e da potência final da rampa do laser de dipolo (P), os resultados da Figura 27 mostram valores máximos para $\mathrm{t}=50 \mathrm{~ms}$ e $\mathrm{P}=14 \mathrm{~W}$.
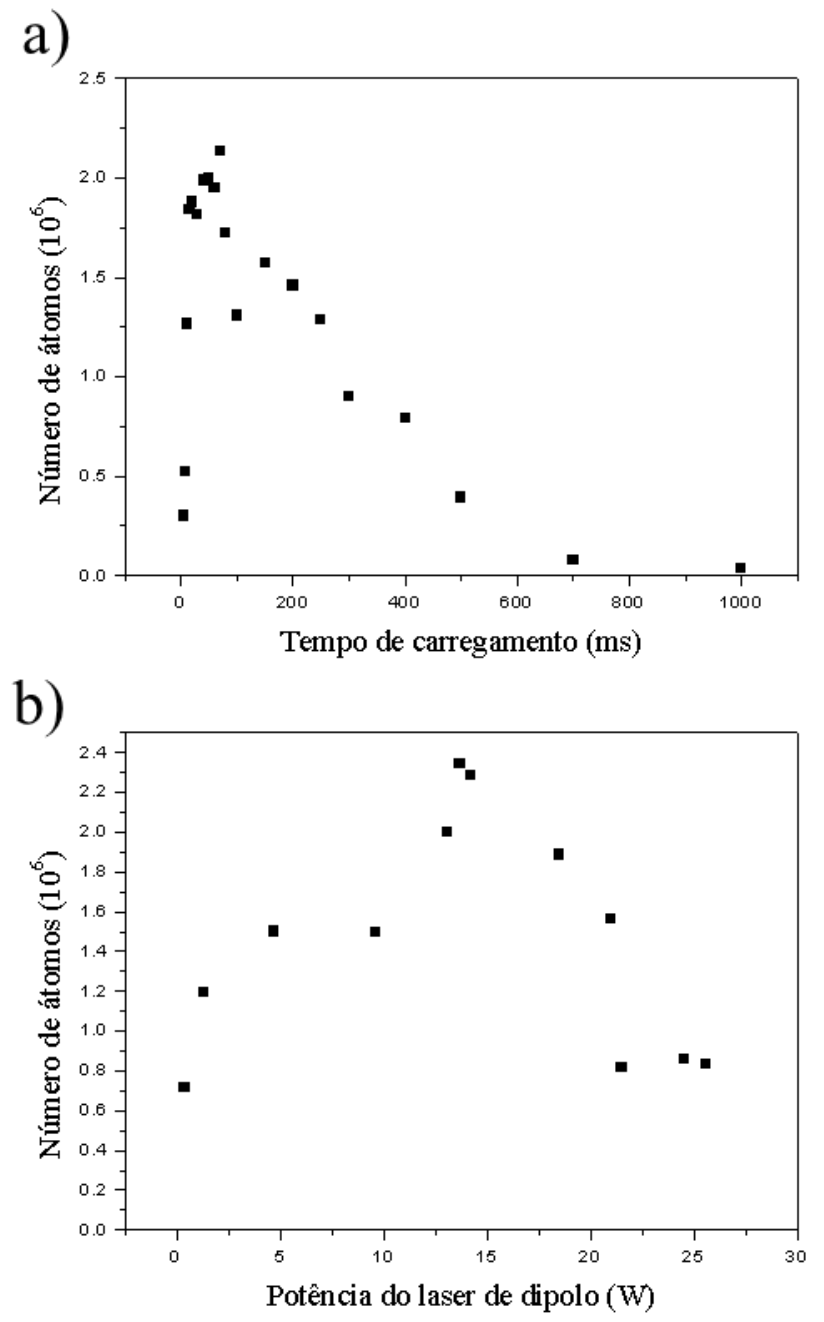

Figura 27 - a) Número de átomos em função da variação do tempo de carregamento. b) Número de átomos carregados em função da potência final do laser de dipolo no processo de carregamento.

Em seguida, variamos a dessintonia do laser de aprisionamento $\left(\delta_{\omega 1}\right)$, onde obtivemos como valor máximo $\delta_{\omega 1}=-9,5 \mathrm{MHz}$ (Figura 28). 


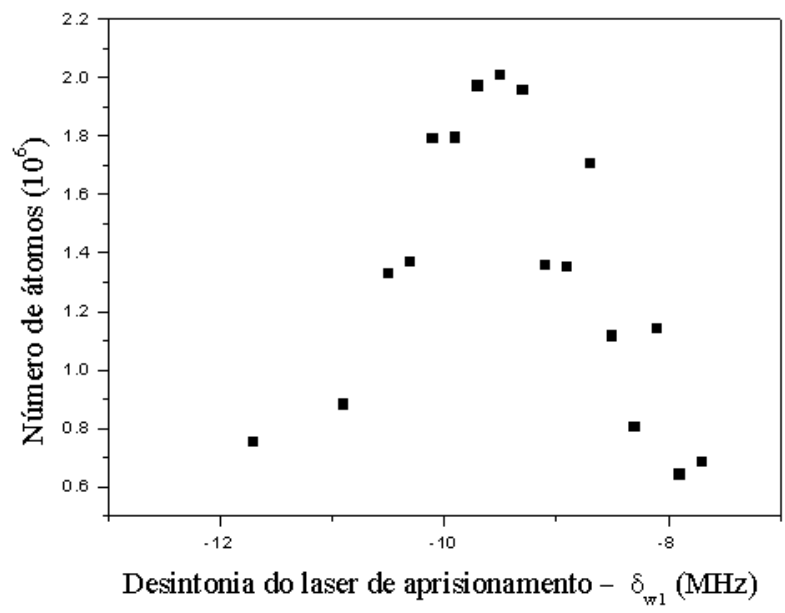

Figura 28 - Variação da dessintonia do laser de aprisionamento $\left(\delta_{\omega 1}\right)$ em relação a transição $4 S_{1 / 2}(F=2) \rightarrow 4 P_{3 / 2}\left(F^{\prime}=3\right)$.

Devemos nos atentar a dois fatores curiosos nesse carregamento. O primeiro é o valor de $\delta_{w 1}$ e $\Delta$ serem uma combinação dos valores utilizados em trabalhos anteriores que realizaram com sucesso o resfriamento sub-Doppler do ${ }^{39} \mathrm{~K}(62,64)$. O valor de $\Delta$ utilizado pelo nosso experimento, era tal que o feixe de rebombeio ficava dessintonizado abaixo de todas as transições hiperfinas do estado excitado $\left(4 \mathrm{P}_{3 / 2}\right)$, em acordo com o trabalho de Gokhroo e colaboradores (64). Já o valor de $\delta_{w 1}$, era condizente com Landini e colaboradores (62) para a configuração de MOT. Como ambos os trabalhos foram capazes de produzir amostras frias, tentamos inicialmente carregar a armadilha com uma sequência fiel a um dos dois trabalhos, porém, sem sucesso. A segunda observação é o melhoramento do carregamento da armadilha de dipolo, por um fator de quatro, quando a potência do laser de dipolo é aumentada em forma de rampa, e a dessintonia do feixe de aprisionamento $\delta_{w 1}$ é diminuída em módulo, como mostrado na Figura 25a. Analisando as duas observações em conjunto, temos fortes evidências de que o efeito Stark ac está influenciando no processo de carregamento.

Para o valor máximo de $14 \mathrm{~W}$ para a rampa de carregamento, acreditamos que tal comportamento possa ser explicado através do efeito Stark ac devido ao laser de $1071 \mathrm{~nm}$. Na presença do laser de dipolo, a frequência de aprisionamento $\left(\delta_{w 1}\right)$ terá uma dessintonia efetiva de $\delta_{e f f}=\delta_{w 1}+\delta_{a c}$, onde $\delta_{a c}$ é a dessintonia devido ao efeito Stark ac proveniente do laser de $1071 \mathrm{~nm}$. Através de uma medida da dessintonia através de imagens de absorção com o laser de dipolo ligado, obtivemos um valor de $\delta_{a c}=-10 \mathrm{MHz}$ para um total de $27 \mathrm{~W}$ na região cruzada da armadilha. Esta observação é consistente com um modelo simples baseado em um átomo de dois níveis, onde a separação energética entre os níveis aumenta 
com a intensidade da luz. Assim, quando o laser de $1071 \mathrm{~nm}$ tem a sua intensidade aumentada, o valor de $\delta_{a c}$ diminui, fazendo com que $\delta_{\text {eff }}$ também diminua. Assim, a rampa de potência do laser de dipolo faz com que a dessintonia para a frequência de aprisionamento mude seguindo uma rampa, se aproximando do esquema utilizado para o resfriamento do ${ }^{39} \mathrm{~K}$ em (62). Esse resultado corrobora com a dependência de $\delta_{w 1}$ para o número de átomos aprisionados, como mostrado na Figura 28.

Para a melhor condição de carregamento, tivemos que aumentar o valor de $\delta_{w 1}$, ao invés de diminuí-lo (62). Contudo, se considerarmos o efeito Stark ac do laser de dipolo, teremos que $\delta_{e f f}$ irá variar em forma de rampa de $\delta_{e f f}=-1,6 \Gamma$ para $\delta_{\text {eff }}=-2,4 \Gamma$ durante o processo de carregamento. Essa dessintonia é similar a que foi usada no processo de resfriamento em (62), como mencionado anteriormente. Para $\delta_{w 1}>-9,5 \mathrm{MHz}$, o processo de resfriamento durante a fase de carregamento não é tão eficiente e para $\delta_{w 1}<-9,5 \mathrm{MHz}$, o valor de $\delta_{\text {eff }}$ entraria na região III da Figura 29, causando o aquecimento da amostra e diminuindo a quantidade de átomos aprisionados. Também observamos que aplicando uma rampa na dessintonia do laser de aprisionamento durante a fase de carregamento, o número de átomos carregados cai consideravelmente. Isso é consistente com o fato de que $\delta_{\text {eff }}$ entra na região III (Figura 29) em algum momento da rampa de potência do laser de dipolo, causando aquecimento da amostra. A mesma situação ocorre se usarmos $\delta_{w 1}=-9,5 \mathrm{MHz}$ e um valor $P>14 W$, o que explica os resultados da Figura 28 . 
a)

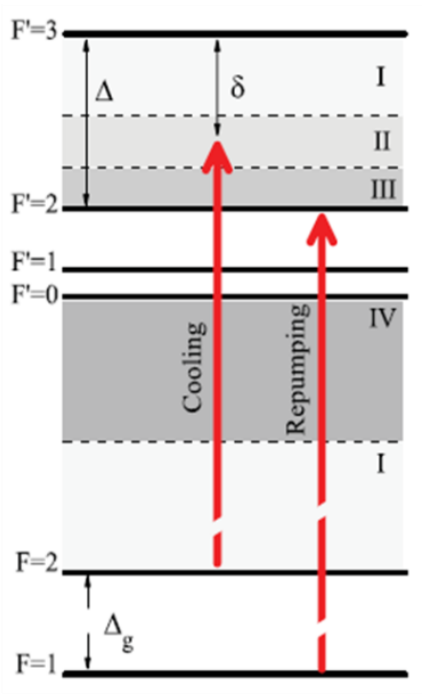

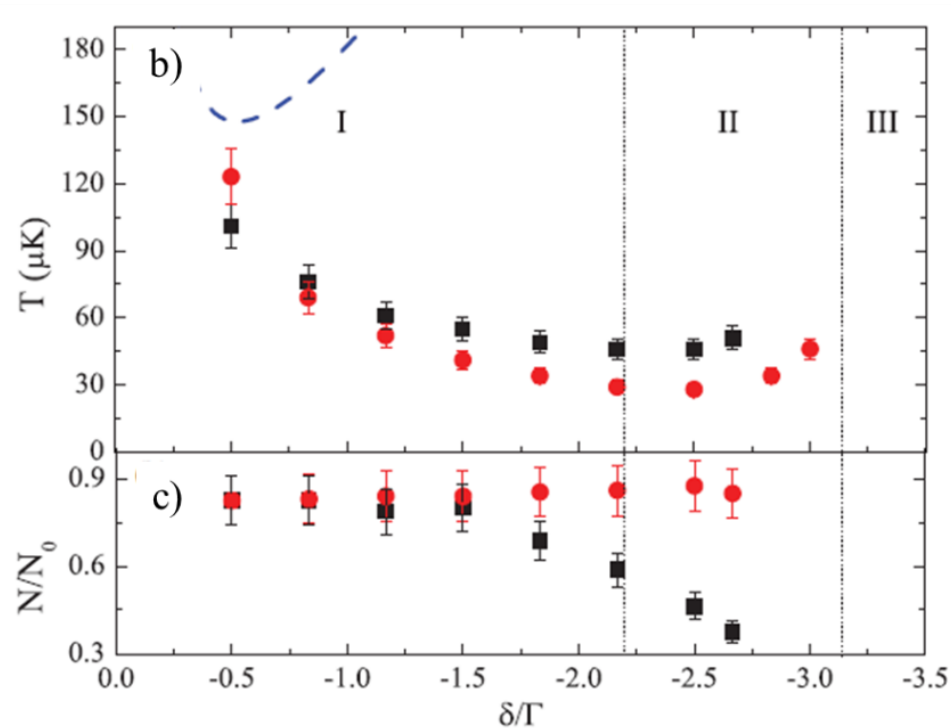

Figura 29

a) Diagrama de transições para ${ }^{39}{ }^{39} \mathrm{~K}$ indicando as regiões de alcance do laser. b) Medida da temperatura da amostra através da aplicação de rampa na dessintonia do laser de aprisionamento (círculos vermelhos) e através da mudança abrupta (quadrados pretos). c) Medida do número remanescente de átomos após o processo de resfriamento com (círculos vermelhos) e sem (quadrados pretos) a aplicação de rampa. As regiões I, II e III nos gráficos b) e c) são correspondentes as mesmas regiões em a) entre $F^{\prime}=2$ e $F^{\prime}=3$. Figura extraída de (62).

Observando a Figura 29, notamos que é essencial que o laser de aprisionamento se restrinja as regiões (I) e (II) e seja usada a estratégia da variação gradual da frequência. Uma boa região para se trabalhar, seria o intervalo $-3 \Gamma<\delta<-2 \Gamma$, lembrando que em (62) o MOT inicial é otimizado para a obtenção do melhor carregamento e depois é aplicada a sequência de resfriamento. No nosso caso, o melhor MOT correspondia à $\delta_{w 1}=-11 \mathrm{MHz}=$ $-1,8 \Gamma$. Na fase de carregamento, o valor da dessintonia era mudado abruptamente para $\delta_{w 1}=-9,5 \mathrm{MHz}=-1,6 \Gamma$. Como a potência do laser de dipolo é aumentada de forma gradual, a dessintonia irá ter o mesmo comportamento. A Figura 30 esquematiza o que ocorre com a dessintonia do nosso laser de aprisionamento se levado em conta o efeito Stark ac do laser de dipolo. Condizente com o processo realizado por (62) para atingir a menor temperatura. 


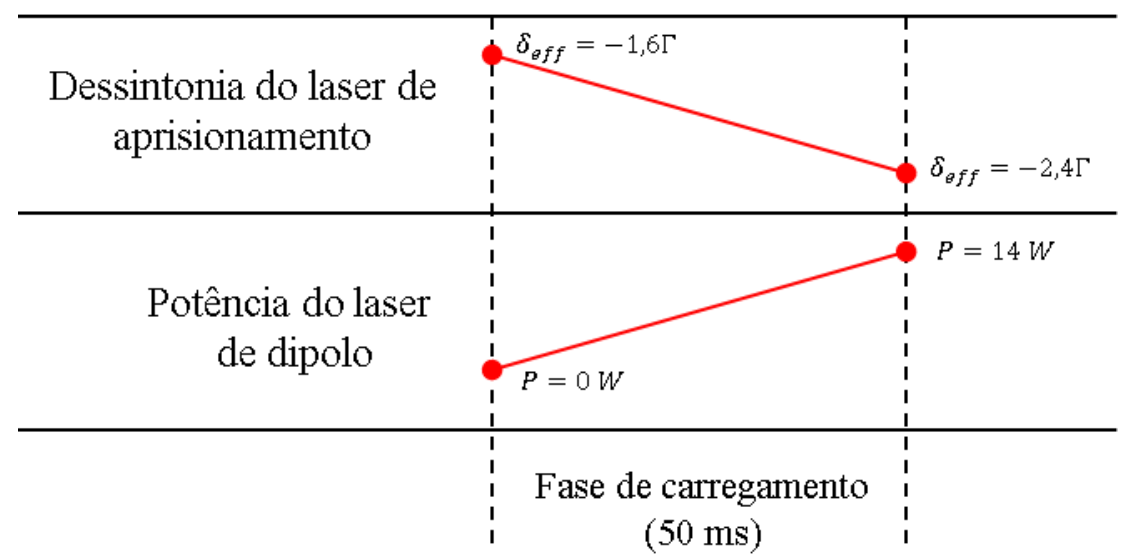

Figura 30 - Esquema de variação da dessintonia efetiva do laser de aprisionamento $\left(\delta_{e f f}=\delta_{w 1}+\delta_{a c}\right)$ em função do aumento da potência do laser de dipolo.

Para o processo de resfriamento sub-Doppler se manter eficiente para o ${ }^{39} \mathrm{~K}$, o valor da dessintonia do laser de aprisionamento deve respeitar o limite: $-3 \Gamma \leq \Delta \leq-2 \Gamma$ (62). Considerando que estamos trabalhando com $\delta_{\text {eff }}=-2,4 \Gamma$, uma variação de aproximadamente $0,5 \Gamma \approx 3 \mathrm{MHz}$ já seria suficiente para provocar um aquecimento na amostra e prejudicar o carregamento do dipolo. Isso faz com que o valor de P seja extremamente sensível a mudança de profundidade, necessitando de recalibração toda vez que o feixe de dipolo mudar as dimensões.

Devemos salientar que o efeito Stark ac também afeta a dessintonia do laser de rebombeio. Entretanto, devido a pequena separação para a estrutura hiperfina do estado (4 $\mathrm{P}_{3 / 2}$ ), essa explicação não é aplicável, sendo necessário um cálculo completo do fenômeno. Contudo, acreditamos que nossa configuração para a dessintonia do laser de aprisionamento seja igual à observada em (62).

Com relação ao trabalho desenvolvido em (64), podemos apontar como possível explicação para a diferença de dessintonia em relação ao nosso trabalho, o fato de o nosso laser de rebombeio ter a mesma polarização do laser de aprisionamento, enquanto que em (64) é utilizado polarizações opostas. Tal arranjo de polarizações afeta o resfriamento do ${ }^{39} \mathrm{~K}$, como já foi observado em outro trabalho (65).

Finalmente, variamos a intensidade dos feixes de aprisionamento e rebombeio na fase de carregamento e obtivemos as curvas descritas nos gráficos da Figura 31. Os valores ótimos são $\mathrm{I}_{\omega 1}=0,6 \mathrm{~mW} / \mathrm{cm}^{2}$ e $\mathrm{I}_{\omega 2}=0,06 \mathrm{~mW} / \mathrm{cm}^{2}$. 


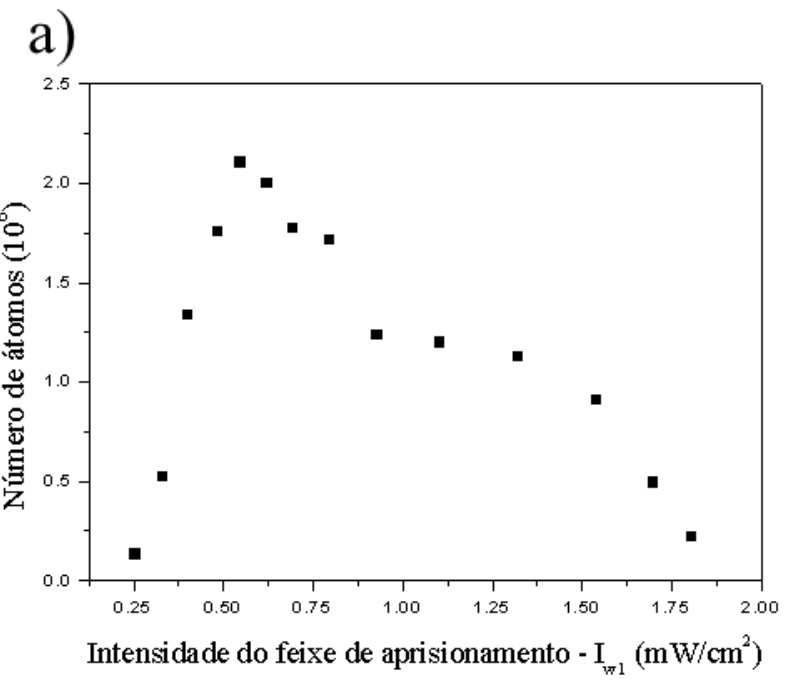

b)

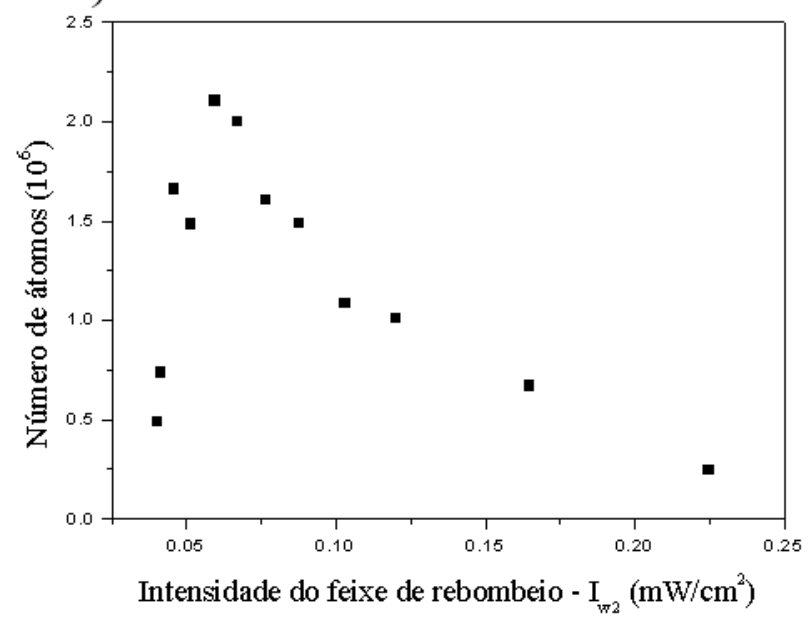

Figura 31 - Variação das intensidades dos lasers de a) aprisionamento e b) rebombeio na fase de carregamento. As intensidades são representadas por braço do MOT.

Para explicar a dependência do carregamento do dipolo em função das intensidades dos feixes, acreditamos que dois processos sejam relevantes. Para baixa intensidade, o processo de resfriamento fica afetado devido à falta de fótons. Conforme a intensidade vai aumentando, o número de átomos também aumenta até atingir um limite. Para intensidades mais altas que a otimizada, processos colisionais envolvendo estados excitados aquecem a amostra fazendo com que o número de átomos carregados seja menor. Os valores de $I_{\omega 1}$ e $I_{\omega 2}$ são condizentes com valores obtidos em outros trabalhos que aperfeiçoaram o resfriamento sub-Doppler para o ${ }^{39} \mathrm{~K}(62,64)$.

Fazendo um cálculo rápido para o fluxo de fótons no MOT, chegamos na seguinte expressão: 


$$
\emptyset_{\text {fótons }}^{\text {laser }}=\frac{6 I_{w 1}}{\left(\frac{h c}{\lambda}\right)} *\left(4 \pi \sigma^{2}\right)=5,3 \times 10^{14} \text { fótons } / s
$$

Onde $I_{w 1}=0,6 \mathrm{~mW} / \mathrm{cm}^{2}$ é a intensidade por braço do feixe de aprisionamento otimizada para o carregamento do dipolo e o fator multiplicativo " 6 " representa os seis braços do experimento ( 3 feixes contrapropagantes). O termo $\left(\frac{h c}{\lambda}\right)$ é a energia do fóton, sendo $h=$ 6,63 $\times 10^{-34} \mathrm{~m}^{2} \mathrm{Kg} / \mathrm{s}$ a constante de Planck, $c=3 \times 10^{8} \mathrm{~m} / \mathrm{s}$ a velocidade da luz no vácuo e $\lambda=766 \mathrm{~nm}$ o comprimento de onda da radiação. O valor $\sigma=550 \mu \mathrm{m}$ é a cintura do MOT, sendo $\left(4 \pi \sigma^{2}\right)$ a área transversal do mesmo.

Fazendo outro cálculo simples, podemos descobrir o número de fótons que são absorvidos pelo MOT, descrito pela equação (27).

$$
\emptyset_{\text {fótons }}^{M O T}=\left(\frac{\Gamma}{2}\right) * N=5,6 \times 10^{14} \text { fótons } / s
$$

Em que $\Gamma=2 \pi * 6 \mathrm{MHz}$ é a largura natural de linha e $N=3 \times 10^{7}$ é o número total de átomos no MOT. A grandeza $\left(\frac{\Gamma}{2}\right)$ representa a quantidade de ciclos de absorção e emissão realizados por um átomo em um segundo.

Como $\emptyset_{\text {fótons }}^{M O T} \cong \emptyset_{\text {fótons }}^{\text {laser }}$, temos um equilíbrio bem estabelecido, onde a quantidade de transições pode ser controlada pela dessintonia do laser para atingir a temperatura ideal. Um aumento da potência do laser saturaria o número de transições, impedido o controle e mantendo a temperatura alta. Já uma diminuição, provocaria perda de átomos, o que também não é vantajoso para o experimento.

Também caracterizamos a armadilha com relação à variação da temperatura em função das intensidades $I_{w 1}$ e $I_{w 2}$ e da dessintonia $\delta_{w 1}$. O valor permaneceu fixo em $10 \mu K$, indicando que a temperatura final na armadilha de dipolo é definida por parâmetros da armadilha e não depende do processo de carregamento. 


\section{Carregamento da armadilha de dipolo dupla de $\mathbf{R b}$ e $\mathbf{K}$.}

Nesse capítulo, revisamos brevemente o processo de carregamento e decaimento de uma armadilha de $\mathrm{Rb}$. Em seguida, apresentamos o processo de carregamento de uma armadilha de dipolo dupla de $\mathrm{Rb}$ e $\mathrm{K}$. Para finalizar, estudamos a evolução temporal da armadilha mista. Utilizando um modelo fenomenológico de equações de taxa obtemos as taxas de perdas devido à colisão inter e intra-espécies. A evolução da temperatura no sistema também é estudada.

\subsection{Carregamento de $\mathbf{R b}$ em uma armadilha de dipolo}

Nosso sistema experimental é capaz de aprisionar tanto ${ }^{85} \mathrm{Rb}$ como ${ }^{87} \mathrm{Rb}$. No MOT são carregados cerca de $10^{8}$ átomos com uma densidade de $2 \times 10^{10} \mathrm{~cm}^{-3}$. As frequências em que os lasers operam foram descritas na seção "montagem experimental". Durante a fase de MOT, independentemente da escolha do isótopo, a intensidade por braço do laser de aprisionamento é de $I_{w 1}^{R b}=8 \mathrm{~mW} / \mathrm{cm}^{2}$ com uma dessintonia de $\delta_{w 1}^{R b}=-20 \mathrm{MHz}$. O feixe de rebombeio tem intensidade por braço de $I_{w 2}^{R b}=1,6 \mathrm{~mW} / \mathrm{cm}^{2}$ e a dessintonia é zero.

O laser da armadilha de dipolo tem potência de $40 \mathrm{~W}$ com comprimento de onda central de $1071 \mathrm{~nm}$ (IPG Photonics model YLR-40-1070, com largura espectral de 1,5 nm). O laser é focalizado em uma cintura de $42 \mu \mathrm{m}$ gerando uma intensidade de pico de $3 \mathrm{MW} / \mathrm{cm}^{2}$. O processo de carregamento é esquematizado pela Figura 32 e tem a seguinte sequência temporal: i) Fase de carregamento do MOT, que dura aproximadamente $10 \mathrm{~s}$. Nessa fase, o feixe de dipolo permanece desligado; ii) Uma fase de carregamento do dipolo, com duração de $50 \mathrm{~ms}$. Nessa fase, o feixe de dipolo é ligado e as frequências e potências dos lasers são ajustadas de acordo com a Figura 32; iii) Em seguida, temos uma fase de bombeio óptico por $300 \mu \mathrm{s}$. Aqui, os isótopos são bombeados para o estado hiperfino mais baixo no estado eletrônico fundamental, respectivamente $5 S_{1 / 2}(F=1)$ e $5 S_{1 / 2}(F=2)$ para ${ }^{87} \mathrm{Rb}$ e ${ }^{85} \mathrm{Rb}$. Esse bombeamento é necessário para evitar o aquecimento da amostra, ocasionado pela inversão de estados hiperfinos devido a colisões inelásticas (66); iv) Finalmente, temos a fase de dipolo, onde os átomos estão aprisionados no estado hiperfino mais baixo. 


\begin{tabular}{|c|c|c|c|c|}
\hline & MOT & Carregamento & $\begin{array}{c}\text { Bombeamento } \\
\text { óptico }\end{array}$ & $\begin{array}{c}\text { Armadilha } \\
\text { de dipolo }\end{array}$ \\
\hline $\begin{array}{l}\text { Intensidade } \\
\text { bombeio }\end{array} I_{\omega 1} R b$ & $8 \mathrm{~mW} / \mathrm{cm}^{2}$ & $1,6 \mathrm{~mW} / \mathrm{cm}^{2}$ & & $O F F$ \\
\hline $\begin{array}{l}\text { Potência } \\
\text { rebombeio } \quad P_{\omega 2} R b\end{array}$ & $1,6 \mathrm{~mW} / \mathrm{cm}^{2}$ & $60 \mu W / \mathrm{cm}^{2}$ & & $O F F$ \\
\hline $\begin{array}{ll}\text { Dessintonia } & \\
\text { bombeio } & \delta_{\omega 1}\end{array}$ & $-20 \mathrm{MHz}$ & $-35 \mathrm{MHz}$ & $O F F$ & \\
\hline Campo magnético & $O N$ & $O N$ & $O F F$ & \\
\hline $\begin{array}{c}\text { Potência do laser } \\
\text { de dipolo }\end{array}$ & $O F F$ & $40 \mathrm{~W}$ & $\cdots$ & 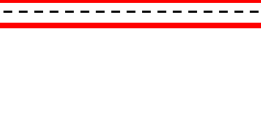 \\
\hline & $10 \mathrm{~s}$ & $50 \mathrm{~ms}$ & $300 \mu \mathrm{s}$ & \\
\hline
\end{tabular}

Figura 32 - Sequência temporal para o carregamento de uma armadilha de dipolo de ${ }^{85} \mathrm{Rb}$ ou ${ }^{87} \mathrm{Rb}$.

A detecção dos átomos é feita através de imagem de absorção, descrito em detalhes no capítulo "montagem experimental" desse trabalho. Como os átomos estão no estado hiperfino mais baixo, é necessário ligar o feixe de rebombeio junto com o feixe de imagem para promover a mudança dos estados hiperfinos e deixá-los ressonante. Esse é um método eficaz de verificação da pureza da amostra, pois sem a aplicação do feixe de rebombeio, os átomos permanecem no estado hiperfino inferior, não sendo ressonantes com o feixe de imagem. Medidas mostram que o grau de pureza da nossa amostra é maior que $99 \%$.

\subsection{Taxas de perda e evolução da temperatura de $\mathbf{R b}$ em uma armadilha de dipolo}

Em condições iniciais típicas, carregamos cerca de $3 \times 10^{6}$ átomos de $\mathrm{Rb}$ a uma densidade de $3 \times 10^{12} \mathrm{~cm}^{-3}$ na região cruzada da armadilha de dipolo. Esses parâmetros são correspondentes a um tempo de $\mathrm{t}=30 \mathrm{~ms}$ após o final da carga, pois a nuvem atômica proveniente do MOT influenciava na medida para tempos menores, como já foi discutido. A temperatura inicial da amostra foi calculada utilizando expansão balística na imagem de absorção, resultando em aproximadamente $30 \pm 10 \mu \mathrm{K}$. Na Figura 33, temos o resultado para a evolução da densidade máxima na armadilha de dipolo em função do tempo de 
aprisionamento. Claramente, vemos que a curva de decaimento não pode ser ajustada a uma exponencial simples, sugerindo uma influência de perdas dependentes da densidade.
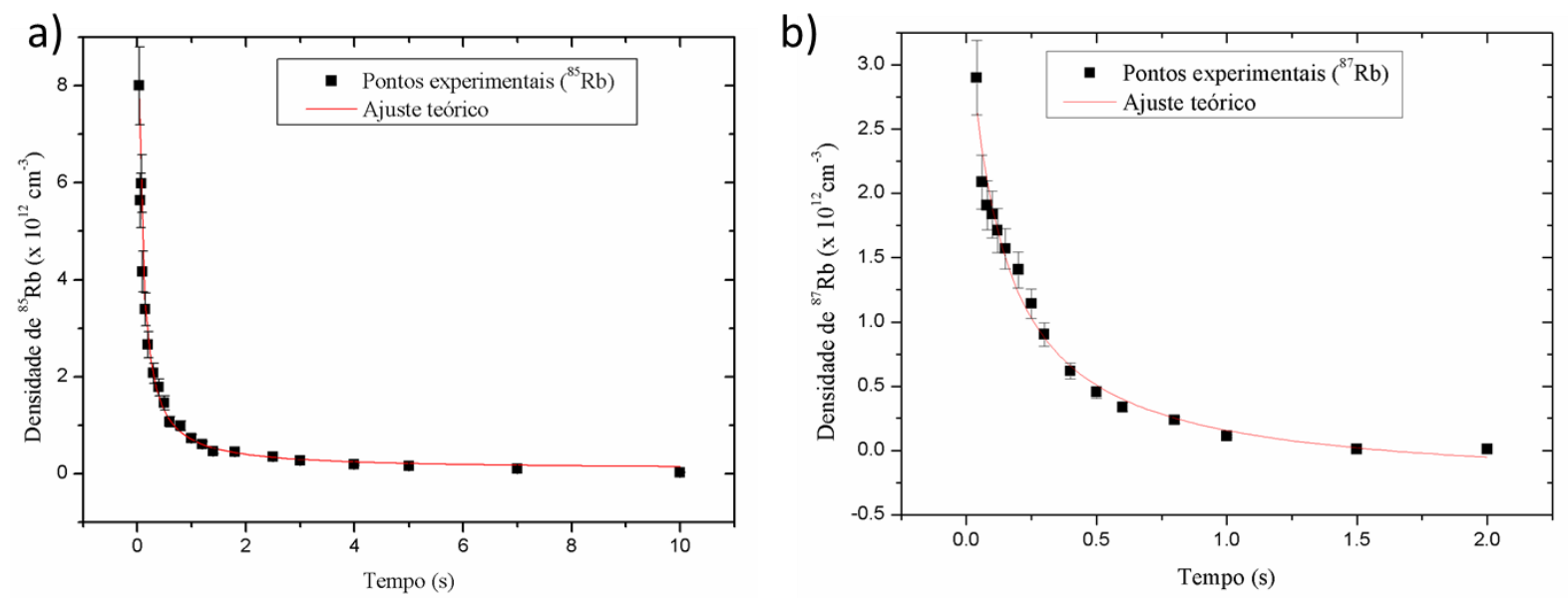

Figura 33 - Variação da densidade em função do tempo da armadilha de dipolo para a) ${ }^{85} \mathrm{Rb}$ e b) ${ }^{87} \mathrm{Rb}$.

A evolução da densidade da população atômica na armadilha de dipolo pode então ser descrita da seguinte forma:

$$
\frac{d n(t)}{d t}=-\gamma n(t)-\beta n(t)^{2}
$$

onde $\gamma$ é o termo devido a colisões entre átomos quentes (não aprisionados) e frios (aprisionados). Já $\beta$ se refere à colisão entre átomos frios. A solução analítica da equação (28) está representada pela equação (29), sendo $n_{0}$ a densidade inicial da amostra.

$$
n(t)=\frac{n_{0} e^{-\gamma t}}{\frac{\beta n_{0}}{\gamma}\left(1-e^{-\gamma t}\right)+1}
$$

Como o termo $\gamma$ não depende da densidade da amostra, ele foi extraído através do ajuste de um decaimento exponencial simples (equação (29), com $\beta=0$ ) para tempos superiores a 0,5 segundos, sendo um parâmetro dependente apenas da geometria do experimento e do vácuo. O valor obtido para essas configurações de laser e potência foi de $\gamma=0,04 s^{-1}$. 


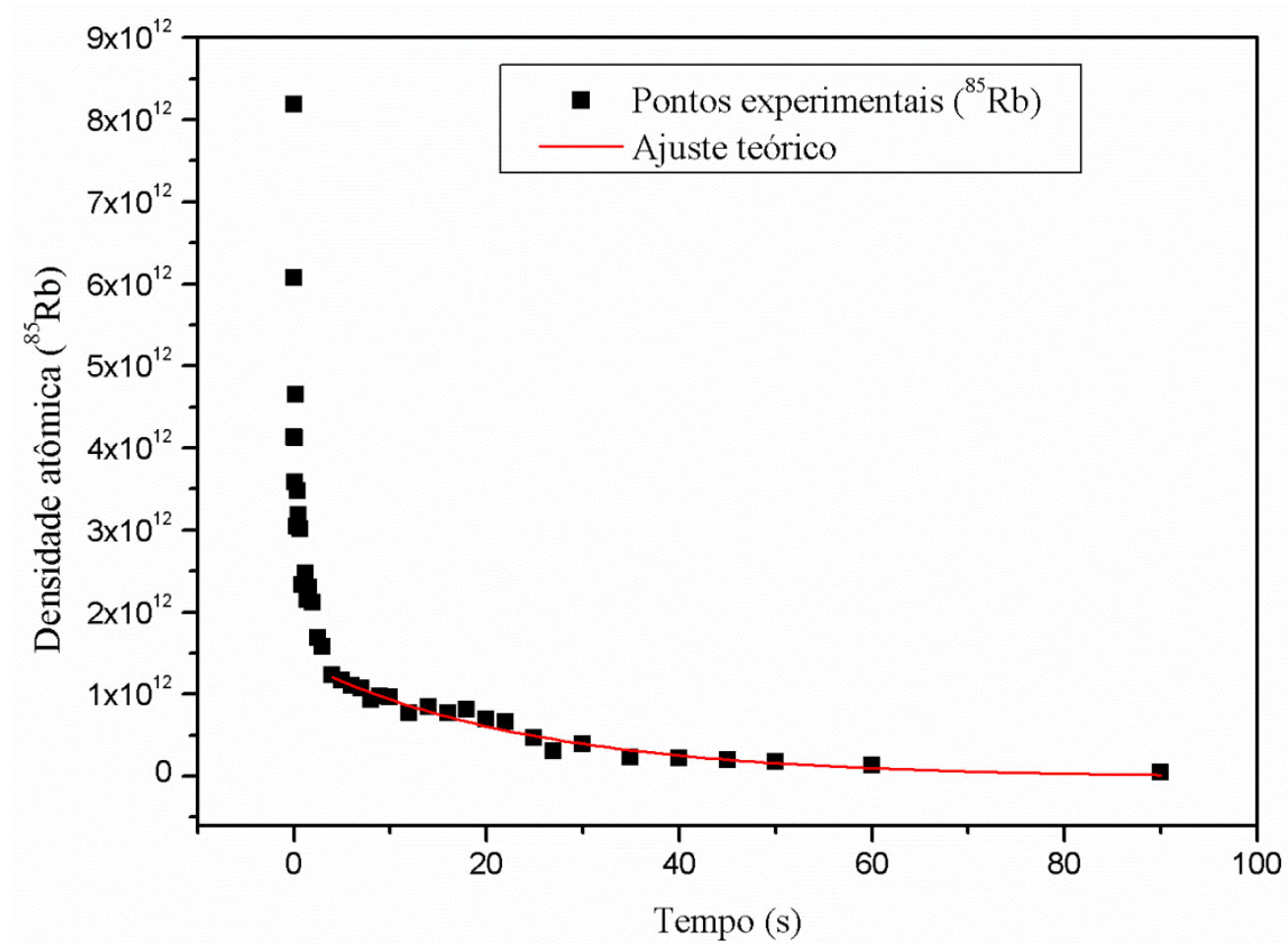

Figura 34 - Medida do parâmetro de perda devido ao vácuo $(\gamma)$. O ponto inicial de ajuste é $\mathrm{t}=500 \mathrm{~ms}$, onde a perda devido a dois corpos se torna desprezível.

Para justificar o valor de $\gamma$, podemos fazer um modelo simples considerando os parâmetros do experimento. Considerando o livre caminho médio para partículas devido à distribuição de Boltzmann, teremos:

$$
L=\frac{1}{\sqrt{2} n \sigma}=\bar{V} t
$$

Em que $n$ é a densidade de partículas, $\sigma$ é a seção de choque colisional entre duas partículas e $\bar{V}$ é a velocidade média da partícula para uma distribuição de Maxwell-Boltzmann. Considerando a temperatura ambiente $(\mathrm{T}=300 \mathrm{~K})$ e a massa de um átomo de rubídio $(\mathrm{m}=$ $1,41 \times 10^{-25} \mathrm{Kg}$ ), temos que $\bar{V}$ será dado por:

$$
\bar{V}=\sqrt{\frac{8 K T}{\pi m}}=27.336 \mathrm{~cm} / \mathrm{s}
$$


onde $K=1,38 \times 10^{-23} \mathrm{~m}^{2} \mathrm{Kgs}^{-1} \mathrm{~K}^{-1}$ é a constante de Boltzmann. Para o vácuo aferido em nossa câmara $\left(\sim 10^{-10}\right.$ Torr), temos uma densidade de $n \cong 2 \times 10^{7}$ partículas $/ \mathrm{cm}^{3}$. O raio do átomo, calculado pela definição do raio Bohr para o átomo de rubídio vale:

$$
R=n^{2} a_{0}=25 a_{0}
$$

Em que $a_{0}=0,53 \AA$ é o raio de bohr, resultando em uma seção de choque de colisão elástica de:

$$
\sigma=\pi R^{2}=5,5 \times 10^{-14} \mathrm{~cm}^{2} .
$$

Substituindo o valor de $R$ e $\sigma$ na equação (30), temos valor do caminho médio.

$$
L=6,5 \times 10^{5} \mathrm{~cm}=\bar{V} t
$$

Com o valor de $\bar{V}$ da equação (31), extraímos o valor do tempo médio (t) entre colisões para uma partícula $(t)$, de onde obtemos o valor de $\gamma=1 / t$.

$$
t=\frac{L}{\bar{V}}=23,7 s, \text { onde } \gamma=\frac{1}{t}=0,04 s^{-1}
$$

Apesar de o valor de $\gamma$ calculado ter dado exatamente o valor do $\gamma$ medido experimentalmente, o cálculo foi feito apenas para mostrar o princípio da dependência de $\gamma$ com os parâmetros da armadilha. O fato de apresentarem a mesma ordem de grandeza evidencia que o limitante para tempos de vida maiores que 25 segundos é o próprio vácuo do experimento.

Com o valor de $\gamma$ fixado, a equação (29) foi ajustada nos gráficos da evolução da densidade em função do tempo da armadilha de dipolo e os valores de $n_{0}$ e $\beta$ foram obtidos como parâmetros do ajuste. O valor obtido de $\beta$ do ajuste da equação (29) foi de $\beta_{85 R b}=(1,6$ $\pm 0,4) \times 10^{-12} \mathrm{~cm}^{3} / \mathrm{s}$ e $\beta_{87 R b}=(2,0 \pm 0,4) \times 10^{-12} \mathrm{~cm}^{3} / \mathrm{s}$. Já as densidades iniciais obtidas foram: $n_{0}^{85 R b}=(1,4 \pm 0,4) \times 10^{13} \mathrm{~cm}^{-3}$ e $n_{0}^{87 R b}=(4 \pm 3) \times 10^{12} \mathrm{~cm}^{-3}$. A pergunta óbvia neste ponto do trabalho é a origem desta perda, já que a princípio os átomos estão interagindo apenas entre eles. Uma possibilidade é a colisão entre três corpos. 
Realizamos um cálculo levando em conta a perda devido à recombinação de três corpos em outro trabalho (63). Para a densidade mais alta (tempo inicial, $\mathrm{t}=0 \mathrm{~s}$ ), $\mathrm{a}$ contribuição correspondia a aproximadamente $10^{3}$ e $10^{6} \mathrm{~s}^{-1}$, respectivamente para ${ }^{87} \mathrm{Rb}$ e ${ }^{85} \mathrm{Rb}$. O valor para o ${ }^{87} \mathrm{Rb}$ pode ser totalmente desprezado. Para o ${ }^{85} \mathrm{Rb}$, o valor é uma ordem de grandeza menor que a perda via dois corpos, podendo ser desprezada sem prejuízos também $(38,63,67)$. Esse resultado é esperado, pois esse mecanismo de perda só se torna relevante para densidades da ordem de $10^{14} \mathrm{~cm}^{-3}(68)$.

Em um trabalho recente, Lauber e colaboradores (69) associaram parte dessas perdas a mudança de estado hiperfino no estado eletrônico fundamental atômico. Nesse tipo de colisão, pelo menos um dos átomos tem que estar no estado hiperfino mais alto. Durante o processo colisional, ocorre o decaimento desse átomo para o estado hiperfino mais baixo, onde a energia remanescente é convertida em energia cinética, que é distribuída entre os átomos. A Figura 35 esquematiza o processo colisional.
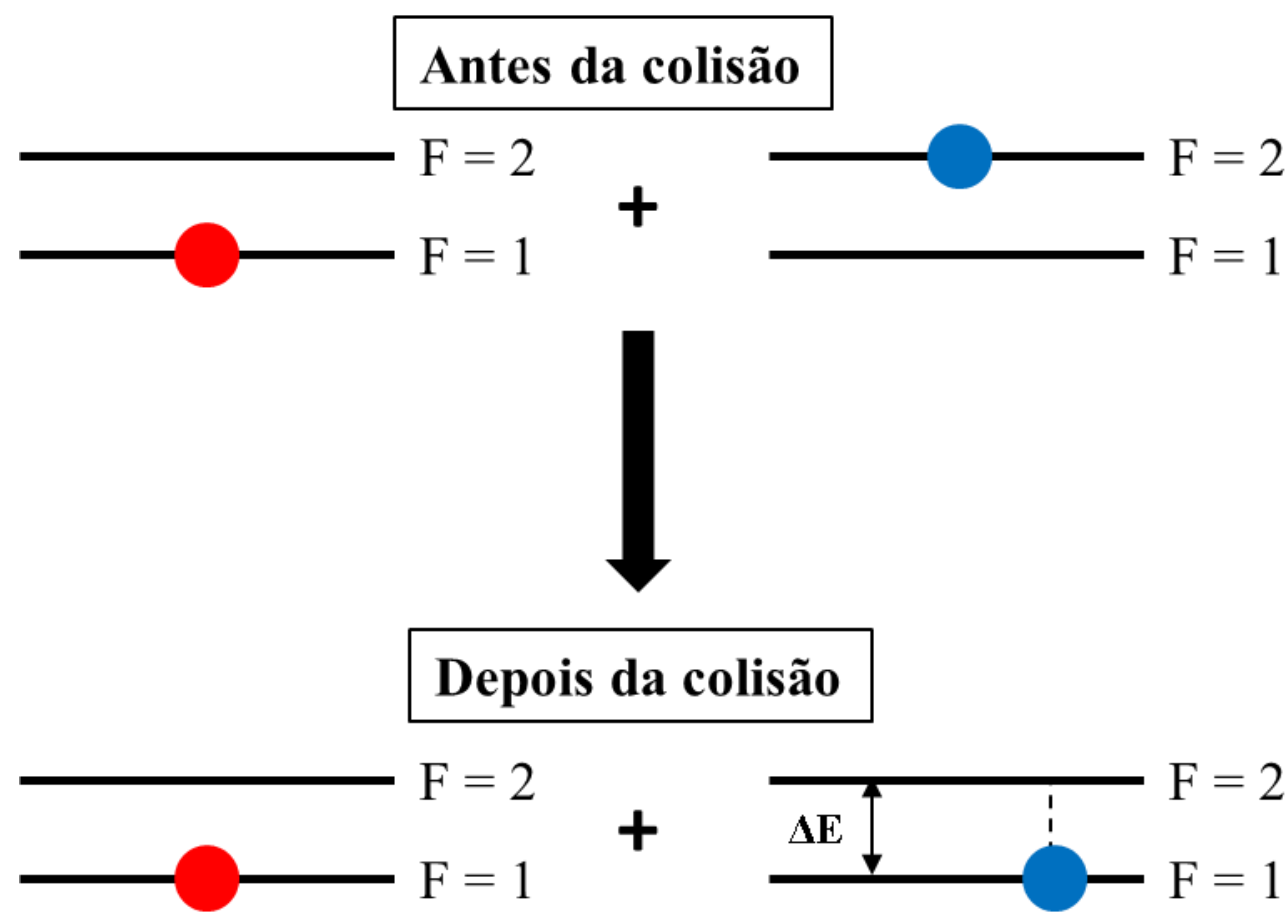

Figura 35 - Processo de colisão com inversão da estrutura hiperfina. A energia remanescente da inversão $(\Delta \mathrm{E})$ é convertida em energia cinética para os átomos.

Considerando os elementos que estamos estudando; ${ }^{87} \mathrm{Rb},{ }^{85} \mathrm{Rb}$ e ${ }^{39} \mathrm{~K}$, temos que a energia liberada em forma de energia cinética é respectivamente; $100 \mathrm{mK}, 50 \mathrm{mK}$ e 7,4 mK. Como a profundidade da armadilha de dipolo é da ordem de $1 \mathrm{mK}$, a energia liberada pela 
colisão é suficiente para arrancar a maioria dos átomos colidentes da armadilha. Os átomos que não são expulsos da armadilha, se retermalizam e causam aquecimento na amostra.

Devido ao caráter multimodo do laser e a alta intensidade na região de aprisionamento ( $3 \mathrm{MW} / \mathrm{cm}^{-3}$ ), Lauber e colaboradores (69) argumentam que transições do tipo Raman podem ocorrer, como ilustrado na Figura 36.

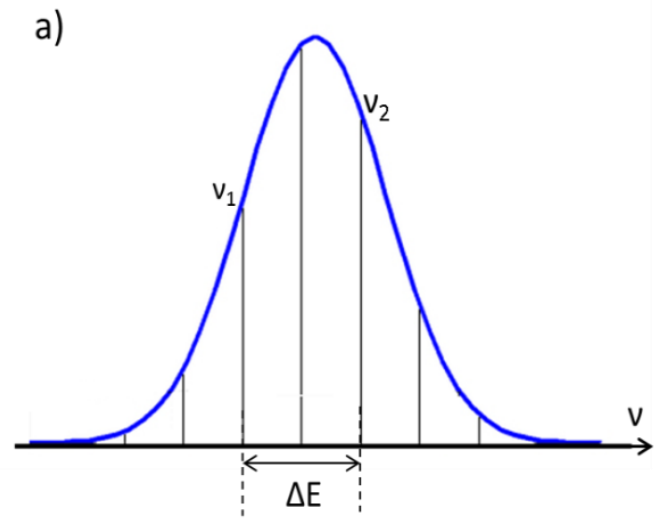

b) Estado virtual

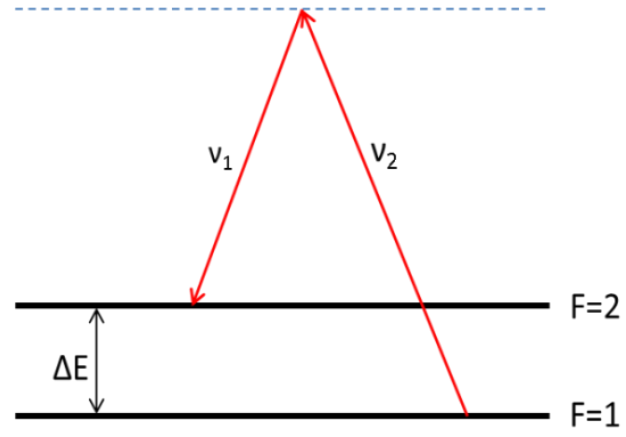

Figura 36 - Transições do tipo Raman induzidas devido ao caráter multimodo do laser. Em a) temos uma representação dos modos do laser e em b) O bombeamento realizado para $\mathrm{F}=2$ através de um estado virtual.

Através de dois modos do laser que estão separados pela mesma energia da separação dos estados hiperfinos, temos a indução de uma transição Raman que povoaria o estado superior de maneira gradativa, provocando perda e aquecimento da amostra. Para verificar essa mudança de estado hiperfino, medimos a população no estado $(\mathrm{F}=3)$ para ${ }^{85} \mathrm{Rb}$ e $(\mathrm{F}=2)$ para ${ }^{87} \mathrm{Rb}$ em função do tempo. O resultado obtido está mostrado na Figura 37a, nele uma parcela dos átomos realiza a transição para o estado hiperfino mais alto no estado eletrônico fundamental $\left(\mathrm{F}_{\mathrm{uh}}\right)$. Este processo é mais marcante para $\mathrm{o}{ }^{87} \mathrm{Rb}$. Porém, nos intervalos de tempo de 0 até $100 \mathrm{~ms}$, onde a densidade é mais alta, a quantidade de átomos em $\mathrm{F}_{\mathrm{uh}}$ é menor que $10 \%$. Para descobrir o efeito dessa mudança na nossa amostra, medimos a temperatura em função do tempo de aprisionamento (Figura 37b) e verificamos que esta se mantem constante em aproximadamente $30 \mu \mathrm{K}$. Se essa inversão de população fosse realmente importante em nosso experimento, seria esperado um aquecimento considerável da amostra, o que não é verificado (66). Uma possível explicação está no fato de a quantidade de átomos no estado $\mathrm{F}_{\mathrm{uh}}$ ser expressiva somente após $500 \mathrm{~ms}$, onde a densidade é uma ordem de grandeza menor e as colisões de dois corpos não são relevantes. Assim, o resultado da Figura 37 demonstra que apesar de ocorrerem transições para o estado hiperfino superior, as colisões inelásticas com mudança de estrutura hiperfina não são importantes em nosso experimento. Com isso 
podemos concluir que a parte majoritária das perdas de dois corpos não ocorre devido a colisão inelástica.
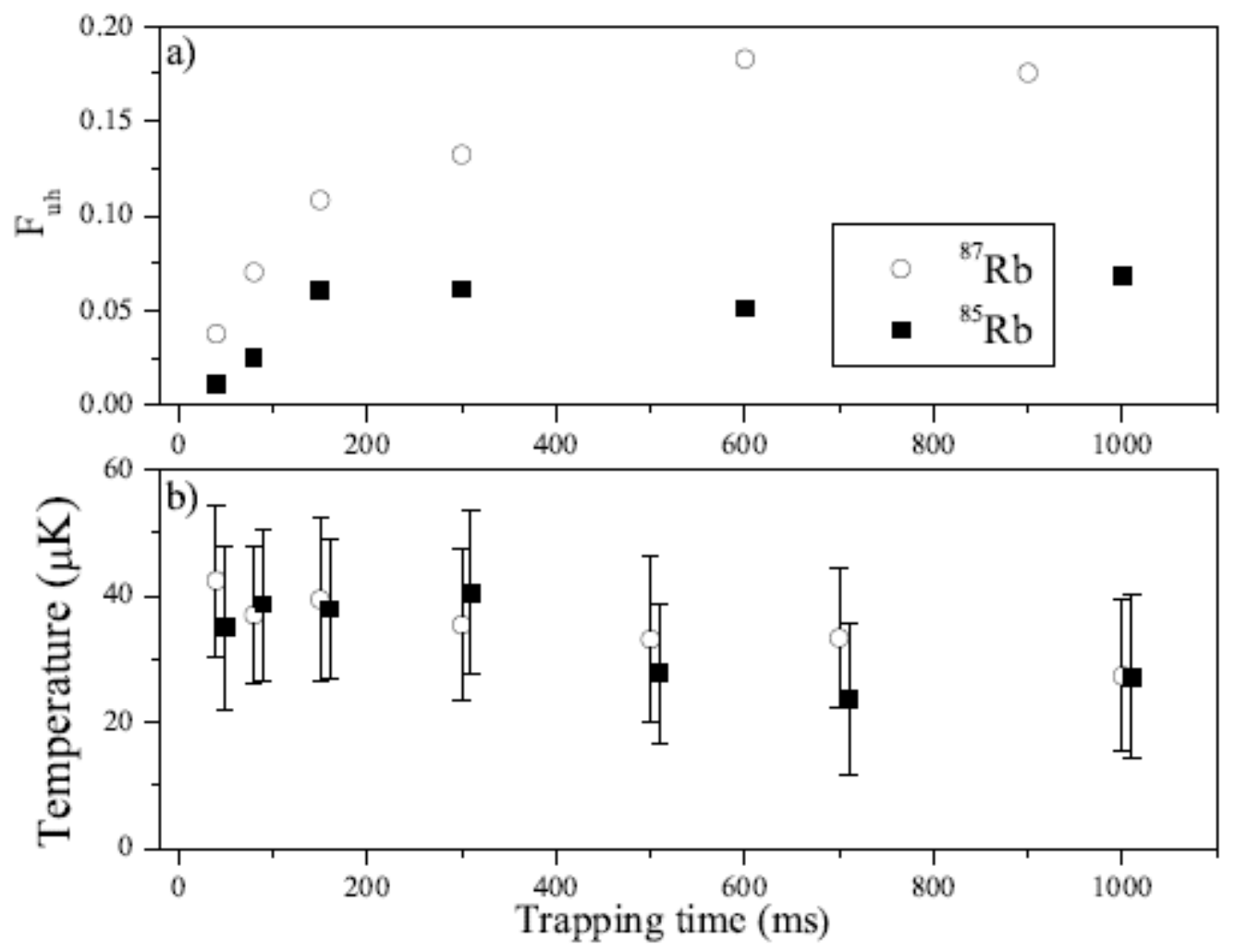

Figura 37 - Fração de átomos no estado hiperfino mais elevado ( $\mathrm{F}_{\mathrm{uh}}$ ) como função do tempo de aprisionamento para ambos os isótopos. b) Temperatura dos átomos em função do tempo de aprisionamento. Figura extraída de (49).

Como explicamos o processo de perdas então? Em um trabalho recente que desenvolvemos (49), medidas do valor de $\beta$ para os dois isótopos foram obtidas para uma configuração experimental diferente para o laser de $1071 \mathrm{~nm}$ (cintura de 72 um e potência de 25W). Para explicar as perdas colisionais presente nessa armadilha, um modelo teórico foi desenvolvido com base na possibilidade de o laser de dipolo estar fotoassociando pares de átomos em estados moleculares. $\mathrm{O}$ trabalho foi desenvolvido em parceria com o pesquisador Olivier Dulier do laboratoire Aimé Cotton, Universidade de Paris. O caminho para a fotoassociação está esquematizado na Figura 38. 


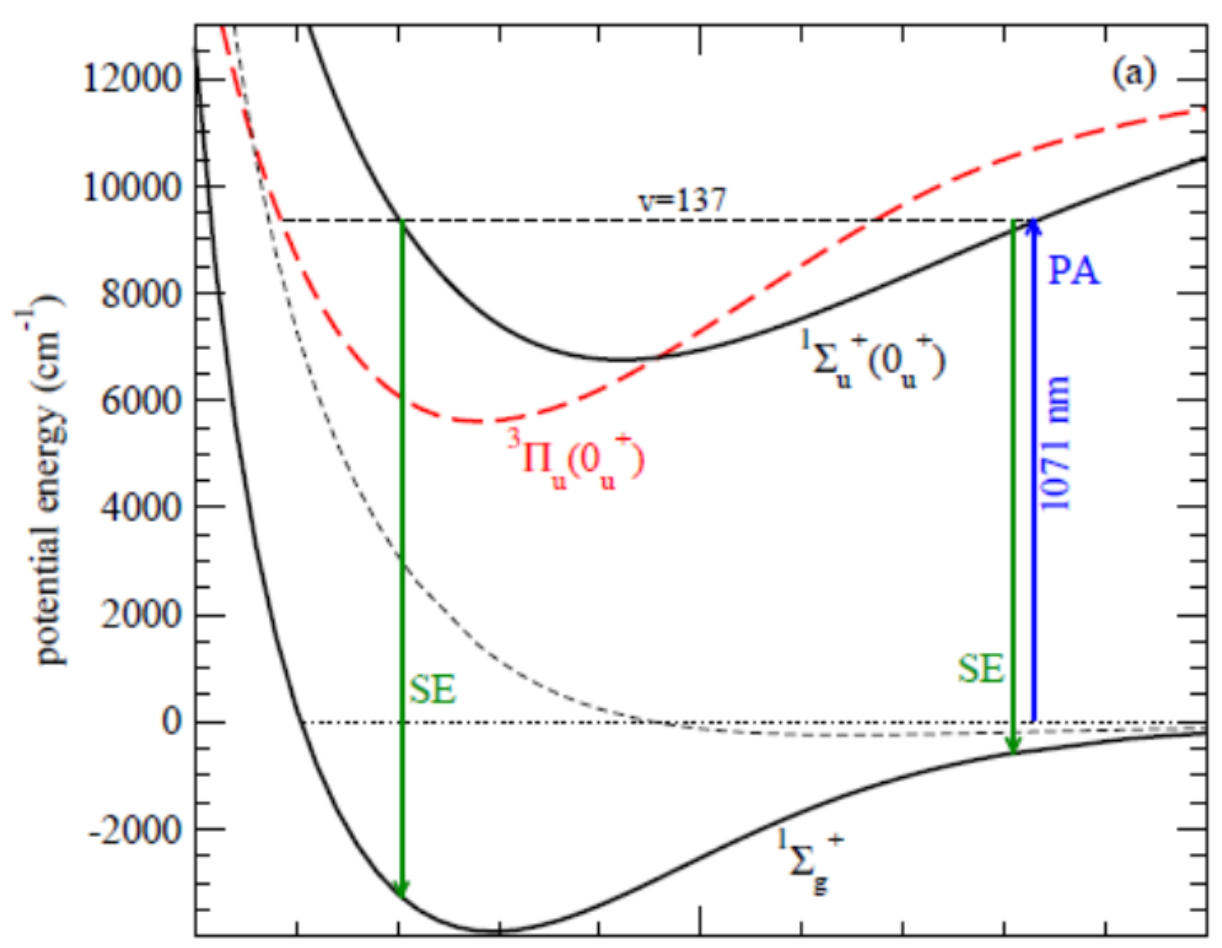

Figura 38 - Esquema proposto para a formação de moléculas frias. Os estados importantes para o processo de fotoassociação (PA) estão indicados (estado fundamental $X^{1} \Sigma_{g}^{+}$, extraído de (70) e estados excitados $A^{1} \Sigma_{u}^{+}$ e $b^{3} \Pi_{u}^{+}$, extraídos de (71)). O nível $v^{\prime}=137$ para o estado $0_{u}^{+}\left({ }^{87} \mathrm{Rb} 2\right)$ indicado, é populado devido ao processo de PA pelo laser de 1071 nm (seta azul). O processo de emissão espontânea (SE) é sugerido pelas setas verdes nos pontos de maior probabilidade de decaimento no estado $X^{1} \Sigma_{g}^{+}$.

Nesse modelo, um par de átomos interagentes é fotoassociado pelo laser de $1071 \mathrm{~nm}$ para níveis vibracionais dos estados $A^{1} \Sigma_{u}^{+}$e $b^{3} \Pi_{u}^{+}$, que são acoplados via interação spinórbita, dando origem a um par de estados acoplados de $0_{u}^{+}$. A força da transição é controlada pelo momento de transição de dipolo (TDM) entre os estados $X^{1} \Sigma_{g}^{+}$e $A^{1} \Sigma_{u}^{+}$(72). Devido à banda larga do laser, são esperados acoplamentos de dois níveis vibracionais $v^{\prime}$ dos estados acoplados de $0_{u}^{+}$, onde $v^{\prime}$ se refere aos estados acoplados de $0_{u}^{+}$e não a um dos estados individuais $\left(A^{1} \Sigma_{u}^{+}\right.$e $\left.b^{3} \Pi_{u}^{+}\right)$. Montamos a Tabela 1 com os possíveis acoplamentos entre o estado fundamental $X$ e os estados $A$ e $b$.

Tabela 1 - Resultados para a fotoassociação do ${ }^{87} \mathrm{Rb}$ e ${ }^{85} \mathrm{Rb}$.

\begin{tabular}{llllll}
\hline & $v^{\prime}$ & Componente b & Componente A & $\lambda_{v^{\prime}}(\mathrm{nm})$ & $(\mathrm{TDM})^{2}$ \\
\hline${ }^{85} \mathrm{Rb}_{2}$ & 136 & 0,1257 & 0,8742 & 1070,55 & $0,1876 \times 10^{-6}$ \\
${ }^{87} \mathrm{Rb}_{2}$ & 137 & 0,0989 & 0,9011 & 1072,33 & $0,1020 \times 10^{-5}$ \\
\hline
\end{tabular}


As componentes A e b representam o acoplamento entre funções eletrônicas $A^{1} \Sigma_{u}^{+} \mathrm{e}$ $b^{3} \Pi_{u}^{+}$e o estado fundamental X. Os valores foram normalizados e a comparação entre eles mostra que, o estado A será preferencialmente populado. A distribuição de intensidades do nosso laser pode ser considerada, em boa aproximação, como sendo gaussiana e da forma:

$$
I(\lambda)=I_{0} e^{-\left(\lambda-\lambda_{c}\right) / \Delta \lambda}
$$

Sendo $I_{0}=0,309 \mathrm{MW} / \mathrm{cm}^{2} \mathrm{~nm}, \quad \lambda_{c}=1071,3 \mathrm{~nm}$ e $\Delta \lambda=1,5 \mathrm{~nm}$. Considerando essa distribuição, os estados vibracionais possíveis de serem fotoassociados são $v^{\prime}=136 \mathrm{e}$ $v^{\prime}=137$ para o ${ }^{85} \mathrm{Rb}_{2}$ e ${ }^{87} \mathrm{Rb}_{2}$ respectivamente. Tais estados não são os mais eficientes para a transição, contudo, o decaimento se dá quase que inteiramente (> 95\%) para níveis acima de $v=20$ do estado fundamental $X^{1} \Sigma_{g}^{+}$, evidenciando um acúmulo de moléculas na armadilha.

O cálculo da taxa de fotoassociação foi feito de acordo com a referência (73), sendo proporcional ao quadrado do momento de dipolo da transição (TDM) e da intensidade do laser. Com base nos dados da tabela 1, e da distribuição de intensidades da equação (36), podemos estimar a razão entre a taxa de fotoassociação $\left(\mathrm{T}_{\mathrm{PA}}\right)$ dos dois isótopos.

$$
\frac{T_{P A}\left({ }^{87} R b ; v^{\prime}=137\right)}{T_{P A}\left({ }^{85} R b ; v^{\prime}=136\right)}=4,1
$$

O resultado está em acordo com a razão experimental encontrada, que foi de 3,3 (63). Essa medida reflete a razão devido às diferenças para o TDM das transições, ponderadas pela intensidade da $I(\lambda)$ da transição. Os valores obtidos nesse experimento são satisfatórios e condizem com os valores medidos anteriormente em nosso experimento com outra configuração de potência e cintura do feixe da armadilha de dipolo (49). O mais importante é que os cálculos teóricos preveem a presença de uma diferença isotópica, o que foi verificado.

Os valores de $\beta$ encontrados nesse trabalho (Tabela 1) foram obtidos de apenas um gráfico de tempo de vida (Figura 33) onde cada ponto representa uma média de 5 medidas, por isso, alguns valores apresentam um erro alto. Tais medidas servirão apenas como entrada para os cálculos que envolvem $\mathrm{K}$ e $\mathrm{Rb}$ aprisionados simultaneamente na armadilha de dipolo, já que envolvem equações diferenciais acopladas e sem solução analítica.

Como modificamos os parâmetros do laser de dipolo, foi preciso caracterizar a amostra de potássio novamente. O intuito era extrair o valor de $\beta_{39 K}$ e da densidade inicial 
$\left(n_{0}^{39 K}\right)$ para servir de entrada para os cálculos do KRb. O processo de carregamento foi o mesmo do indicado na Figura 25, do capítulo 4. A única modificação foi da potência do laser de dipolo no final da fase de carga ser de $8 \mathrm{~W}$ ao invés de $14 \mathrm{~W}$. A evolução da temperatura e o tempo de vida no dipolo estão na Figura 39.
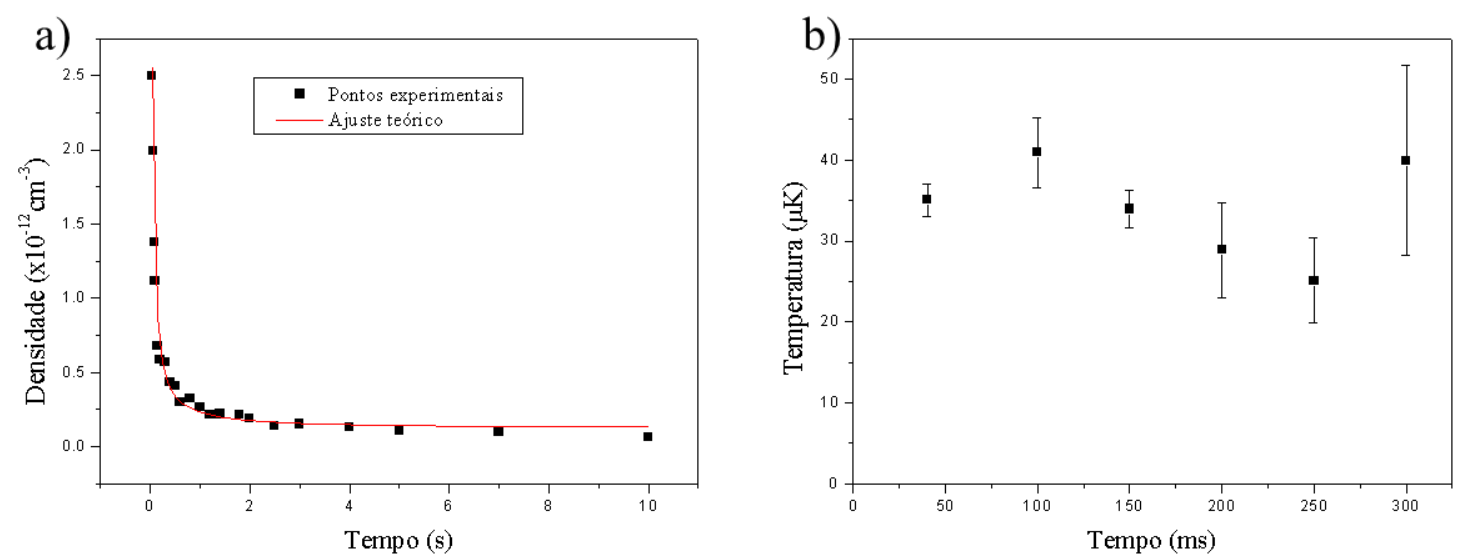

Figura 39 - Variação da densidade de ${ }^{39} \mathrm{~K}$ na armadilha de dipolo juntamente com o ajuste da curva teórica. b) Evolução da temperatura no sistema, demonstrando que não houve aquecimento na amostra.

O valor obtido do ajuste da curva teórica da equação (28) foi de $\beta_{39 K}=(9 \pm$ 1) $x 10^{-12} \mathrm{~cm}^{3} / \mathrm{s}$ e $n_{0}^{39 K}=(2,1 \pm 1,5) \times 10^{13} \mathrm{~cm}^{-3}$.

\subsection{Carregamento duplo de K-Rb em uma armadilha de dipolo}

Para o carregamento de duas espécies, foi utilizada a mesma configuração para o laser de dipolo: $40 \mathrm{~W}$ com cintura de $42 \mu \mathrm{m}$ e intensidade de pico de $3 \mathrm{MW} / \mathrm{cm}^{2}$. O primeiro inconveniente encontrado para o carregamento de duas espécies foi à competição entre o tamanho dos MOTs. Uma das maneiras de se explicar essa competição é devido a colisão onde um dos átomos está no estado excitado. Nesse tipo de colisão, o potencial interatômico é caracterizado pela interação de longo alcance $\left(\sim 1 / \mathrm{R}^{6}\right)$, para o caso heteronuclear. Devido a baixa energia de colisão, esse potencial pode afetar significativamente o encontro atômico. Como o tempo de colisão é muito maior do que o tempo de vida dos estados excitado, a emissão espontânea pode ocorrer durante a colisão, causando uma mudança repentina nos 
estados moleculares junto com a emissão de um fóton menos energético que o absorvido. A diferença energética é então compensada por um acréscimo na energia cinética dos átomos, que podem ser ejetados da armadilha. Esse mecanismo constitui um importante mecanismo de perda e recebe o nome de escape radiativo (RE) (74).

Outro importante canal de perdas entre colisões para átomos excitados e no estado fundamental vem da presença da estrutura hiperfina para o estado excitado $\left(\mathrm{P}_{3 / 2}\right.$ e $\mathrm{P}_{1 / 2}$, para átomos alcalinos). Durante a colisão, pode ocorrer a mudança na estrutura hiperfina do átomo excitado. A diferença energética é dissipada na forma de energia cinética entre os átomos, que são expelidos da armadilha (74).

Desta forma, no MOT, quando o número de $\mathrm{Rb}$ era muito alto, tínhamos uma redução no número de $\mathrm{K}$. Como o MOT de Rb era bem mais robusto que o de $\mathrm{K}$, tínhamos que limitar o número de átomos de $\mathrm{Rb}$ no MOT, o qual era feito através da diminuição do tempo de carregamento do $\mathrm{Rb}$, limitando o tempo de duração do feixe de desaceleração. Com essa estratégia, conseguíamos manipular a proporção de átomos no MOT, que era também reproduzida no dipolo. A Figura 40 mostra o número de átomos de um elemento em função do outro na armadilha de dipolo. Pelo comportamento linear do gráfico, podemos inferir que a soma das quantidades de átomos carregados é uma constante e a proporção é facilmente manipulada pelo feixe de desaceleração do $R b$. 


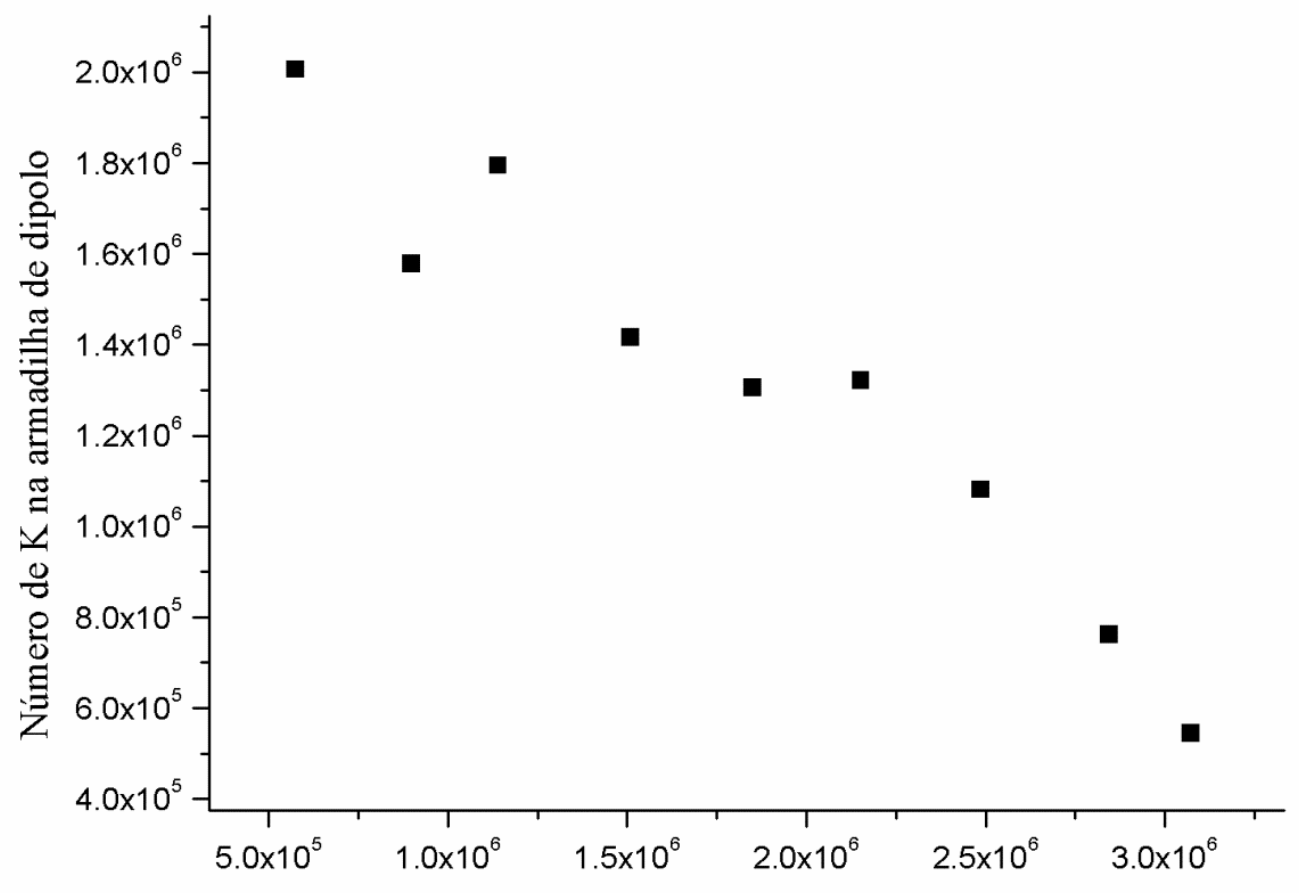

Número de $\mathrm{Rb}$ na armadilha de dipolo

Figura $40-$ Carregamento duplo de K e Rb na armadilha de dipolo. Nota-se que a quantidade total de átomos carregados é aproximadamente constante, porém a proporção pode ser manipulada sem muitos problemas.

O processo de carregamento duplo é um pouco mais complexo do que a simples superposição dos dois carregamentos separados. O fator problemático nessa situação está na necessidade de uma rampa de potência para o carregamento de $K$, o que não se mostrou eficiente para o Rb. A solução encontrada após várias tentativas foi dividir a fase de carregamento em duas partes. Primeiro a carga utilizando uma rampa de potência, que confina preferencialmente o potássio e um segundo estágio com a potência total, onde o rubídio continuar a ser carregado. Uma caracterização mais detalhada para essa parte em específico do processo foi realizado e está representado na Figura 41. 


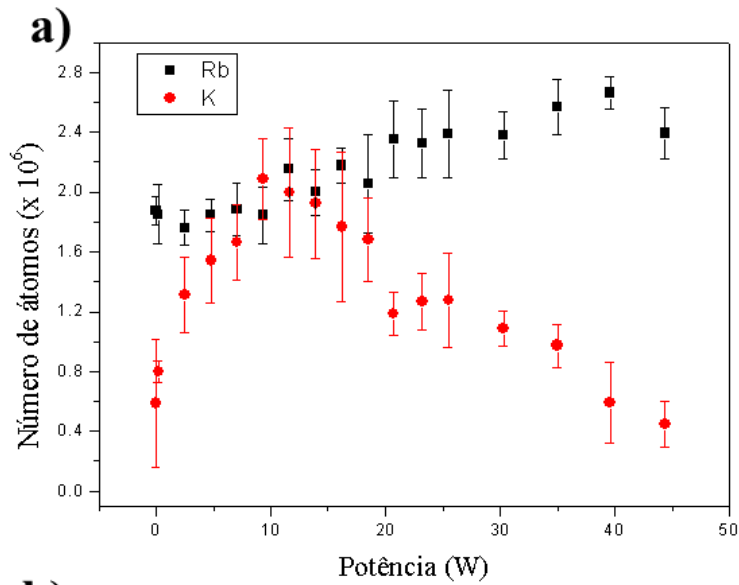

b)
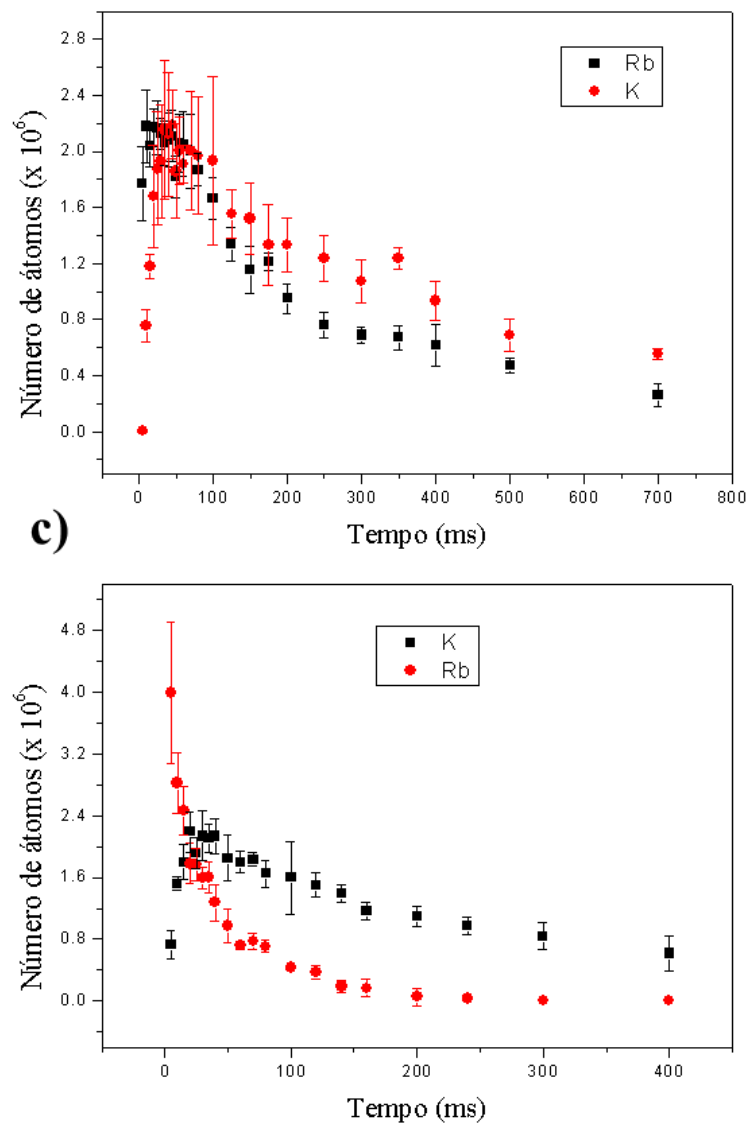

Figura 41 - Caracterização para o carregamento duplo de K e Rb na armadilha de dipolo. a) Temos o número de átomos em função da potência final da rampa de dipolo. Em b) temos o número de átomos carregados em função do tempo de aplicação da rampa de potência para o feixe de dipolo e em c) em função do tempo de carregamento após a rampa, com o laser de $1071 \mathrm{~nm}$ na potência máxima $(40 \mathrm{~W})$.

O tempo otimizado para a rampa de carregamento, foi de $\mathrm{t}=50 \mathrm{~ms}$, o mesmo obtido para o carregamento de somente o ${ }^{39} \mathrm{~K}$ no dipolo. O tempo de carregamento pós rampa que apresentou o melhor número foi de $20 \mathrm{~ms}$ e a potência final para a rampa do laser de $1071 \mathrm{~nm}$ se manteve em $\mathrm{P}=14 \mathrm{~W}$. 
Assim, o processo geral de carregamento ficou como esquematizado pela Figura 42 com a seguinte sequência temporal: i) Uma fase de carregamento dos MOTs com todos os feixes nas condições padrões do MOT. O tempo de $10 \mathrm{~s}$ se aplica somente a carga do K, já que o $\mathrm{Rb}$ tinha um tempo de carga menor, o qual podia variar entre 5 e $10 \mathrm{~s}$ para manter a proporção igual dos elementos no dipolo; ii) A fase de carregamento do dipolo é dividida em duas partes. A primeira corresponde a $50 \mathrm{~ms}$ de carga e tem os mesmos parâmetros de lasers dos carregamentos individuais já descritos, com a rampa de potência sendo a mesma utilizada na sequência do potássio. Na segunda parte, temos o aumento da potência do laser de dipolo para $40 \mathrm{~W}$ em $4 \mathrm{~ms}$ e o desligamento completo dos feixes de K. A configuração é mantida para o Rb e a fase de carregamento tem duração extra de $20 \mathrm{~ms}$, carregando somente $\mathrm{Rb}$ na armadilha; iii) Temos a fase de dipolo duplo. Nesse esquema de carregamento, o bombeamento dos átomos para o estado hiperfino inferior é feito através de atrasos provocados nos obstrutores que eram responsáveis por bloquearem os feixes de aprisionamento e de rebombeio. 


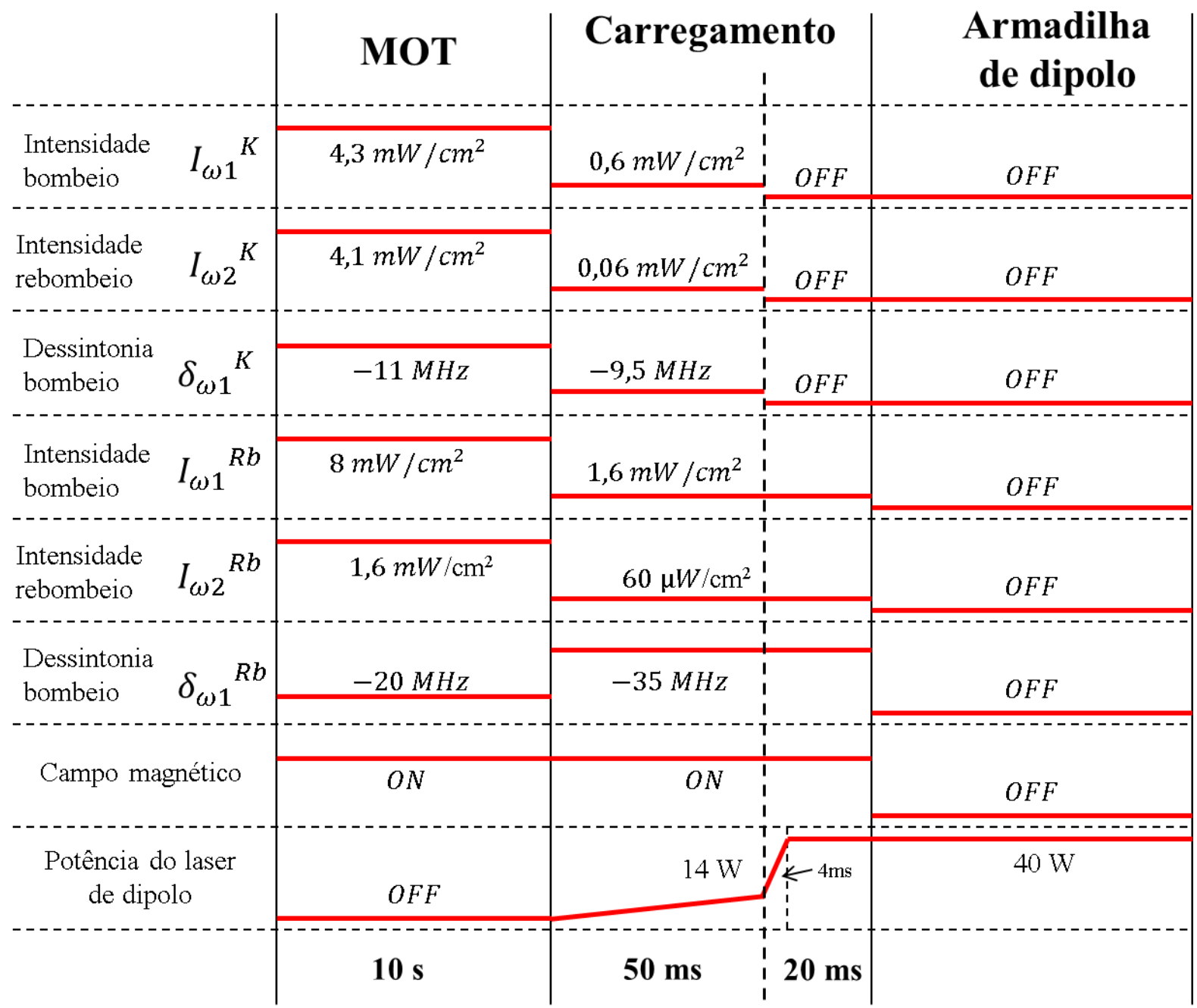

Figura 42 - Sequência temporal para o carregamento duplo de $\mathrm{K}$ e $\mathrm{Rb}$ na armadilha de dipolo.

A armadilha de dipolo foi carregada de forma a apresentar a mesma proporção entre potássio e rubídio. A princípio, esse ponto foi escolhido devido à baixa flutuação que apresentava perante outras configurações e ao fácil ajuste. Para isso, diminuímos a temperatura do forno do $\mathrm{Rb}$, o que limitou o fluxo e possibilitou os dois MOTs ficarem ligados durante os $10 \mathrm{~s}$ da fase de carregamento do MOT sem prejuízos ao K.

O número de átomos foi medido através de imagens de absorção obtidas de maneira independente, mas sincronizadas. Isso forneceu o número de $\mathrm{K}$ e $\mathrm{Rb}$ carregados em cada sequência. Para evitar flutuações muito grandes, a aquisição do número de átomos foi feita no esquema de "pontos gêmeos", onde as sequências eram alternadas entre um determinado tempo " $\mathrm{t}$ " e o tempo inicial da armadilha. No final da aquisição, somente os pontos para o tempo inicial que se encontravam dentro de uma determinada faixa de proporcionalidade de $\mathrm{Rb} / \mathrm{K}$, com erro máximo de $10 \%$, eram utilizados para o tratamento estatístico. 


\subsection{Perdas em uma armadilha de dipolo dupla de $\mathrm{K}$ e $\mathbf{R b}$.}

A equação de taxas que descreve o decaimento do $\mathrm{K}$ e $\mathrm{Rb}$ no dipolo é composta pelo decaimento individual de cada elemento, acoplado a um termo devido à colisão mútua entre as espécies. Esse termo de acoplamento mútuo faz com que a equação acoplada não tenha solução analítica, sendo necessário o uso de recursos numéricos para a sua solução. Com isso, e equação tem a seguinte forma:

$$
\begin{gathered}
\frac{d n_{R b}}{d t}=-\gamma n_{R b}-\beta_{R b} n_{R b}^{2}-\beta^{\prime} n_{R b} n_{K} \\
\frac{d n_{K}}{d t}=-\gamma n_{K}-\beta_{K} n_{K}^{2}-\beta^{\prime} n_{K} n_{R b}
\end{gathered}
$$

onde $\gamma$ é o termo de perda devido ao vapor de fundo e depende apenas do vácuo e da geometria do experimento. Esse valor já foi medido e vale $\gamma=0,04 s^{-1}$. $\beta_{R b}$ e $\beta_{K}$ é o termo de perda devido a colisão de dois corpos para átomos idênticos. Tais valores foram medidos anteriormente e tem os respectivos valores: $\beta_{85 R b}=(1,6 \pm 0,4) \times 10^{-12} \mathrm{~cm}^{3} / \mathrm{s} ; \beta_{87 R b}=(2,0 \pm$ $0,4) \times 10^{-12} \mathrm{~cm}^{3} / \mathrm{s}$ e $\beta_{39 K}=(9 \pm 1) \times 10^{-12} \mathrm{~cm}^{3} / \mathrm{s}$.

Como a evolução temporal da armadilha de dipolo duplo envolve o estudo de duas espécies simultaneamente, o sistema não apresenta solução analítica e é resolvido numericamente. Para isso, foi construído um programa em Mathematica 8 que resolvia numericamente a equação (38) e comparava a solução encontrada com os pontos experimentais. Tal comparação era feita subtraindo-se o ponto da solução numérica pelo seu respectivo ponto experimental. O valor era então elevado ao quadrado e somado para todos os pontos do experimento, dando um resultado que era compatível com a correlação entre os gráficos. Quanto menor era esse valor, maior era a proximidade entre os pontos.

Para a solução da equação (38)Erro! Fonte de referência não encontrada., era ecessário fornecer os valores das variáveis $\left(\gamma, \beta\right.$ e $\left.\beta^{\prime}\right)$ e das condições iniciais, correspondentes aos valores das densidades em $\mathrm{t}=0$ para $\mathrm{K}$ e $\mathrm{Rb}$. Com exceção do valor de $\beta^{\prime}$, todos os outros valores já foram medidos. O valor inicial de $\beta^{\prime}$ foi estimado como sendo da mesma ordem de grandeza que os valores de $\beta\left(\sim 10^{-12} \mathrm{~cm}^{3} / \mathrm{s}\right)$ e com isso foi obtido uma primeira solução que foi comparada com os dados experimentais. Com os outros valores 
fixos, o programa variava o valor de $\beta^{\prime}$ em um passo determinado e guardava o $\beta^{\prime}$ que correspondesse ao melhor ajuste dos pontos experimentais.

Em uma versão mais genérica, o programa otimizava variável a variável e repetia esse processo várias vezes para passos cada vez menores, até que o valor de correlação entre os gráficos não se alterasse significantemente. O processo demorou cerca de dois dias e como resultados, além dos valores de $\beta^{\prime}$, tivemos os valores das densidades iniciais e de $\beta$ mais confiáveis, já que esses resultados experimentais apresentam pontos com várias médias (30 a 50). O parâmetro $\gamma$ não foi variado pelo programa, já que não é muito importante no processo de ajuste, sendo sua influência mais importante para tempos longos da armadilha, onde a densidade é mais baixa. Os gráficos com os pontos experimentais e o ajuste teórico se encontram na Figura 43.
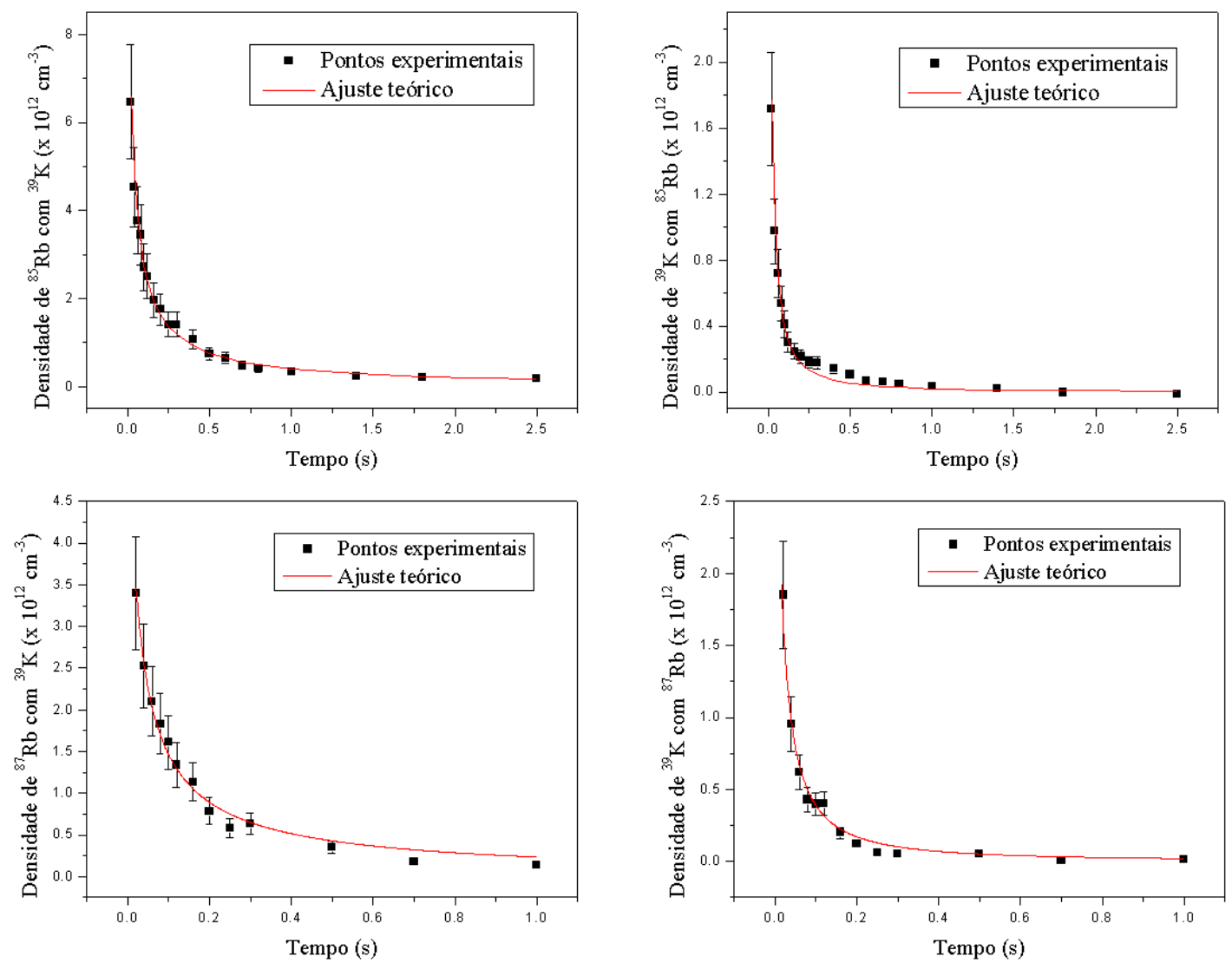

Figura 43 - Variação da densidade em função do tempo da armadilha para o carregamento duplo. 
Os valores obtidos do ajuste da curva teórica nos pontos experimentais foram organizados nas Tabelas 2 e 3 . Os valores obtidos de $\gamma$ e $\beta$ são válidos para a atual configuração do laser de dipolo, que consiste em $40 \mathrm{~W}$ de potência focalizado em uma cintura de $42 \mu \mathrm{m}$

Tabela 2 - Resultado dos parâmetros de perda da armadilha de dipolo cruzado com apenas um elemento carregado.

\begin{tabular}{cccc}
\hline & ${ }^{39} \mathbf{K}$ & ${ }^{85} \mathbf{R b}$ & ${ }^{87} \mathbf{R b}$ \\
\hline $\mathbf{n}_{\mathbf{0}}\left(\mathbf{x} 10^{12} \mathbf{c m}^{-3}\right)$ & $(21 \pm 5)$ & $(15 \pm 3)$ & $(4 \pm 1)$ \\
$\boldsymbol{\beta}\left(\mathbf{x} 10^{-12} \mathbf{c m}^{3} / \mathbf{s}\right)$ & $(9,1 \pm 2,3)$ & $(1,5 \pm 0,4)$ & $(2,0 \pm 0,5)$ \\
\hline
\end{tabular}

Tabela 3 - Resultado dos parâmetros de perda da armadilha de dipolo duplo. A descrição do carregamento é dado como "X com (Y)", onde "X" é o elemento que está sendo estudado na presença do elemento "Y". O valor de $\beta$ ' está em uma célula mesclada, pois é um parâmetro referente ao carregamento das duas espécies simultaneamente.

\begin{tabular}{lcccc}
\hline & ${ }^{39} \mathbf{K} \operatorname{com}\left({ }^{85} \mathbf{R b}\right)$ & ${ }^{85} \mathbf{R b} \operatorname{com}\left({ }^{39} \mathbf{K}\right)$ & ${ }^{39} \mathbf{K} \operatorname{com}\left({ }^{87} \mathbf{R b}\right)$ & ${ }^{87} \mathbf{R b} \operatorname{com}\left({ }^{39} \mathbf{K}\right)$ \\
\hline $\mathbf{n}_{\mathbf{0}}\left(\mathbf{x} 10^{12} \mathbf{c m}^{-3}\right)$ & $(4,7 \pm 1,2)$ & $(11,0 \pm 2,8)$ & $(4,3 \pm 1,1)$ & $(6,2 \pm 1,5)$ \\
$\boldsymbol{\beta}\left(\mathbf{x} 10^{-12} \mathbf{c m}^{3} / \mathbf{s}\right)$ & $(9,0 \pm 2,5)$ & $(2,1 \pm 0,5)$ & $(9,0 \pm 2,5)$ & $(3,2 \pm 0,7)$ \\
$\boldsymbol{\beta}^{\prime}\left(\mathbf{x} 10^{-12} \mathbf{c m}^{3} / \mathbf{s}\right)$ & $(\mathbf{2 , 8} \pm \mathbf{0 , 9})$ & $(\mathbf{5 , 2} \pm \mathbf{1 , 7 )}$ \\
\hline
\end{tabular}

Os resultados obtidos para o valor de $\beta_{85 \mathrm{Rb}}$ e $\beta_{87 \mathrm{Rb}}$, são compatíveis com os valores observados em trabalhos anteriores $(49,63)$ inclusive mostrando a diferença isotópica, mesmo em configurações experimentais diferentes. Para garantir que os valores obtidos não são devidos a perda por colisão inelástica e a mudança de estado hiperfino, medimos a temperatura dos átomos no dipolo duplo em função do tempo. Como pode ser visto nos gráficos da Figura 44, a temperatura se mantém constante dentro do erro experimental, descartando a possibilidade de aquecimento devido a colisão com mudança de estrutura hiperfina. 

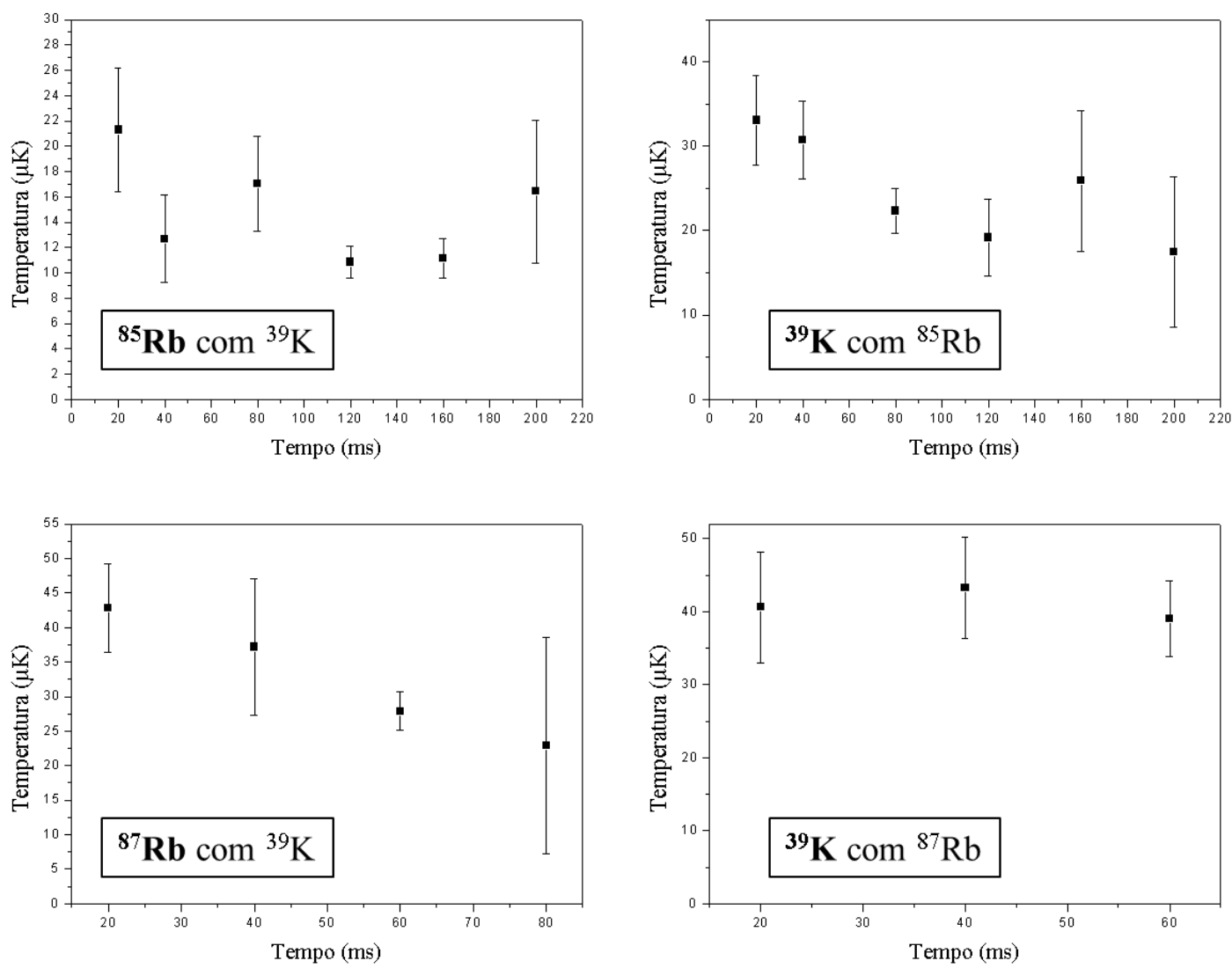

Figura 44 - Evolução da temperatura em função do tempo da armadilha para o carregamento duplo.

Com a configuração atual, verificamos $\beta_{39 \mathrm{~K}}=9,1 \times 10^{-12} \mathrm{~cm}^{3} / \mathrm{s}$ para o carregamento simples e confirmamos esse valor no carregamento duplo. Analisando a evolução da temperatura do potássio nessas configurações e não vimos uma tendência de aquecimento, que seria esperado se a perda fosse devido a colisão inelástica pela mudança de estado hiperfino (66). Uma possível explicação seria novamente a conexão devido ao laser de dipolo entre os estados de átomo livres interagentes no estado eletrônico fundamental com estados moleculares no estado excitado.

Outro resultado interessante foi o valor de $\beta^{\prime}$, resultante das colisões interespécies entre átomos de potássio e rubídio. O valor apresenta uma diferença devido à escolha do isótopo, onde a perda para a mistura ${ }^{87} \mathrm{Rb}+{ }^{39} \mathrm{~K}$ é aproximadamente o dobro se comparado com ${ }^{85} \mathrm{Rb}+{ }^{39} \mathrm{~K}$. Essa diferença também foi observada no valor de $\beta$ para os diferentes isótopos e foi atribuída aos diferentes canais de acoplamento para a fotoassociação molecular. Esse mesmo fenômeno pode estar sendo reproduzido no carregamento duplo e influenciando no valor de $\beta^{\prime}$, já que a formação de moléculas heteronucleares do tipo $\mathrm{KRb}$, se dá 
preferencialmente por canais de transições do rubídio (42), o qual será discutido no próximo capítulo. A quantificação desse fenômeno envolve contas que necessitam pleno conhecimento dos potenciais de interações moleculares e experiência teórica na área. No momento isso esta em estudo pelo grupo do pesquisador Olivier Dulier. 


\section{Bombeamento Óptico molecular em uma armadilha de dipolo}

Nesse capítulo, mostramos os possíveis canais de fotoassociação atômica e bombeamento molecular para diferentes níveis vibracionais do ${ }^{87} \mathrm{Rb}_{2},{ }^{85} \mathrm{Rb}_{2},{ }^{39} \mathrm{~K}^{85} \mathrm{Rb}$ e ${ }^{39} \mathrm{~K}^{87} \mathrm{Rb}$. Uma situação estacionária, para os níveis vibracionais no estado eletrônico fundamental foi alcançada, apresentando baixa perda no número inicial de átomos convertidos em moléculas. Através dessa distribuição estacionária foi possível inferir um caminho para a ionização e detecção molecular. Apresentaremos a atual situação do experimento e as perspectivas para o futuro.

\section{1 $\mathbf{R b}_{2}$ em uma armadilha de dipolo}

No capítulo anterior, apresentamos uma teoria que justifica a perda de dois corpos com base na fotoassociação (PA) de curto alcance devido ao laser de $1071 \mathrm{~nm}$. O intuito desse capítulo é calcular quais seriam os possíveis caminhos da PA e a distribuição estacionária dessas moléculas.

No trabalho realizado em conjunto com o pesquisador Olivier Dulieu (49), fomos capazes de prever a diferença isotópica para a taxa de fotoassociação, sendo esta favorecida para o ${ }^{87} \mathrm{Rb}$ em detrimento ao ${ }^{85} \mathrm{Rb}$. Foi constatado que essa perda ocorre devido à PA de átomos, preferencialmente no estado $A^{1} \Sigma_{u}^{+}$com níveis vibracionais $v^{\prime}=136$ e $v^{\prime}=137$ respectivamente para ${ }^{85} \mathrm{Rb}$ e ${ }^{87} \mathrm{Rb}$. Uma vez que são fotoassociadas, as moléculas podem decair para o estado molecular fundamental $\left(X^{1} \Sigma_{g}^{+}\right)$em uma distribuição de diferentes níveis vibracionais $(v)$, ou podem se dissociar em átomos livres, se perdendo do experimento. Contudo, cerca de $96 \%$ das moléculas fotoassociadas decaem para o estado fundamental $\left(X^{1} \Sigma_{g}^{+}\right)$para ambos os isótopos.

As moléculas que decaem para o estado fundamental $\left(A^{1} \Sigma_{u}^{+} ; v^{\prime} \rightarrow X^{1} \Sigma_{g}^{+} ; v\right)$, podem sofrer a ação do laser de ODT e serem excitadas para outros estados moleculares: $A^{1} \Sigma_{u}^{+}$ou $b^{3} \Sigma_{u}$, mas com um nível vibracional menor do que $v^{\prime} \approx 137$. As moléculas então decaem para o estado $X^{1} \Sigma_{g}^{+}$e podem ser excitadas novamente. Esse processo cíclico bombeia 
gradativamente as moléculas para estados vibracionais mais baixos, até que não exista mais a ação do laser de $1071 \mathrm{~nm}$. Apesar de levarmos em conta o estado excitado tripleto $\left(b^{3} \Sigma_{u}\right)$ no processo, verificamos que a sua contribuição é praticamente nula. Esse tipo de processo de bombeamento já foi usado na literatura (46) com o propósito de popular o estado vibrônico fundamental $\left(X^{1} \Sigma_{g}^{+} ; v=0\right)$ para o $\mathrm{Cs}_{2}$. Contudo, acreditamos que um processo similar é possível com um laser de aprisionamento banda larga, já que a largura do laser é de $54 \mathrm{~cm}^{-1}$ em (46) e o nosso laser apresenta uma largura de $17 \mathrm{~cm}^{-1}$. Assim, consideramos um modelo teórico simples, usando os estados moleculares $X^{1} \Sigma_{g}^{+}, A^{1} \Sigma_{u}^{+} e b^{3} \Sigma_{u}$ (Figura 45).

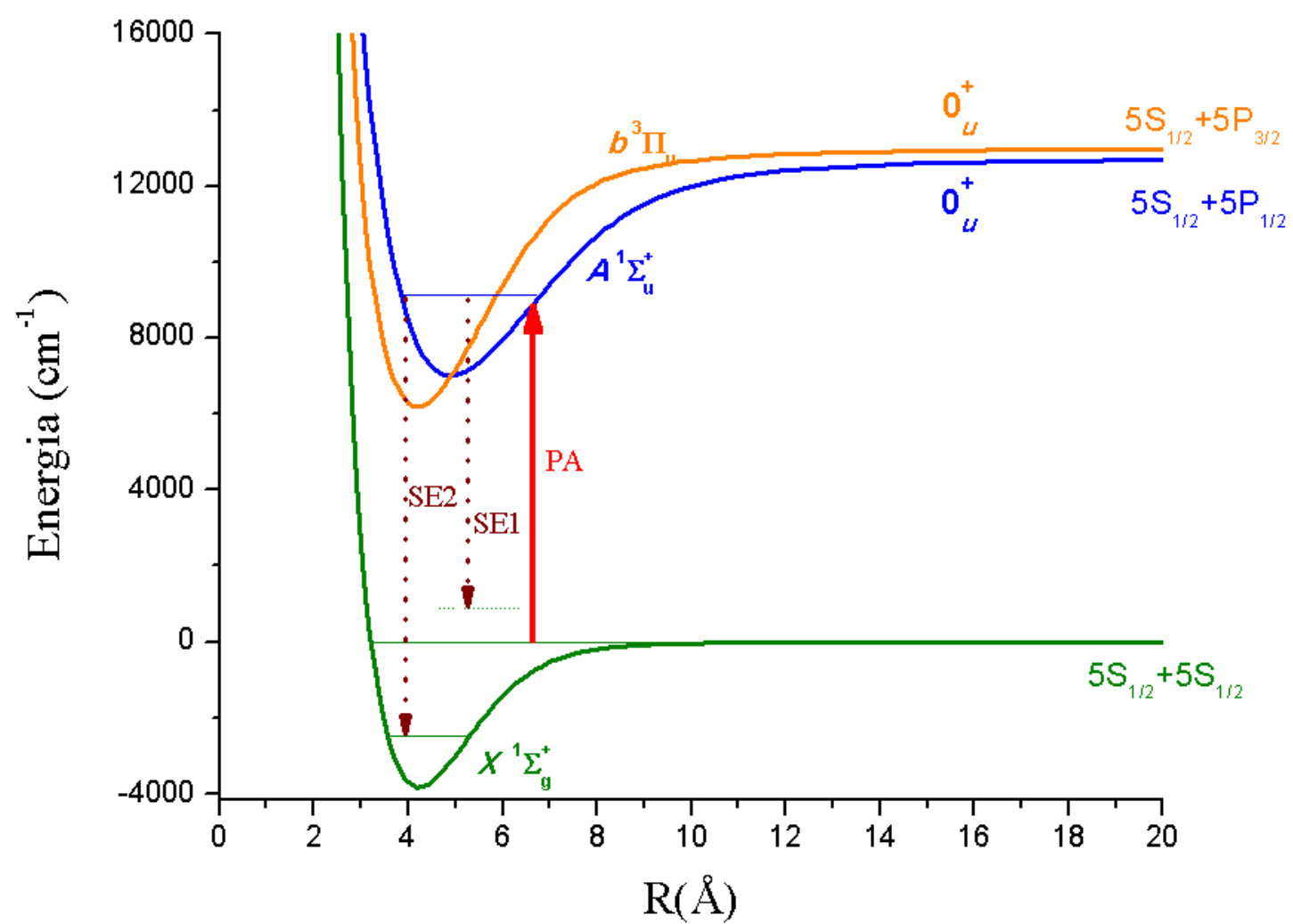

Figura 45 - Esquema de fotoassociação (PA) e decaimento espontâneo em átomos livres (SE1) e em moléculas (SE2).

Para resolver a função de onda para cada nível vibracional do estado da Figura 45, utilizamos o programa level 8.0 desenvolvido pelo professor Robert Leroy da universidade de Waterloo. Com isso, foi possível calcular a probabilidade de transição entre os estados vibracionais, dado pelo fator de Franck Condon (FCF) e a energia entre os acoplamentos. Com os resultados, montamos uma tabela contendo o FCF e a energia entre cada nível vibracional. Construímos um programa em Mathematica 9.0 que relaciona a população do estado vibracional fundamental $(v)$ e a sua probabilidade de transição para o estado 
vibracional excitado $\left(v^{\prime}\right)$ ponderado pela intensidade do laser e pelo FCF entre os estados. O decaimento de $v^{\prime}$ para $v$ ocorre via emissão espontânea e os átomos são distribuídos de acordo com o FCF entre os estados.

Considerando este modelo, aplicamos para os dois isótopos de $\mathrm{Rb}$. Como mencionado anteriormente, a distribuição de intensidades do nosso laser pode ser considerada como sendo gaussiana assumindo a forma:

$$
I(\lambda)=I_{0} e^{-\left(\lambda-\lambda_{c}\right) / \Delta \lambda}
$$

Onde $I_{0}=0,309 \mathrm{MW} / \mathrm{cm}^{2} \mathrm{~nm}, \lambda_{c}=1071,3 \mathrm{~nm}$ e $\Delta \lambda=1,5 \mathrm{~nm}$. Para o isótopo ${ }^{85} \mathrm{Rb}_{2}$, apresentamos a distribuição de níveis moleculares no estado fundamental $\left(X^{1} \Sigma_{g}^{+}\right)$após a fotoassociação atômica (Figura 46).

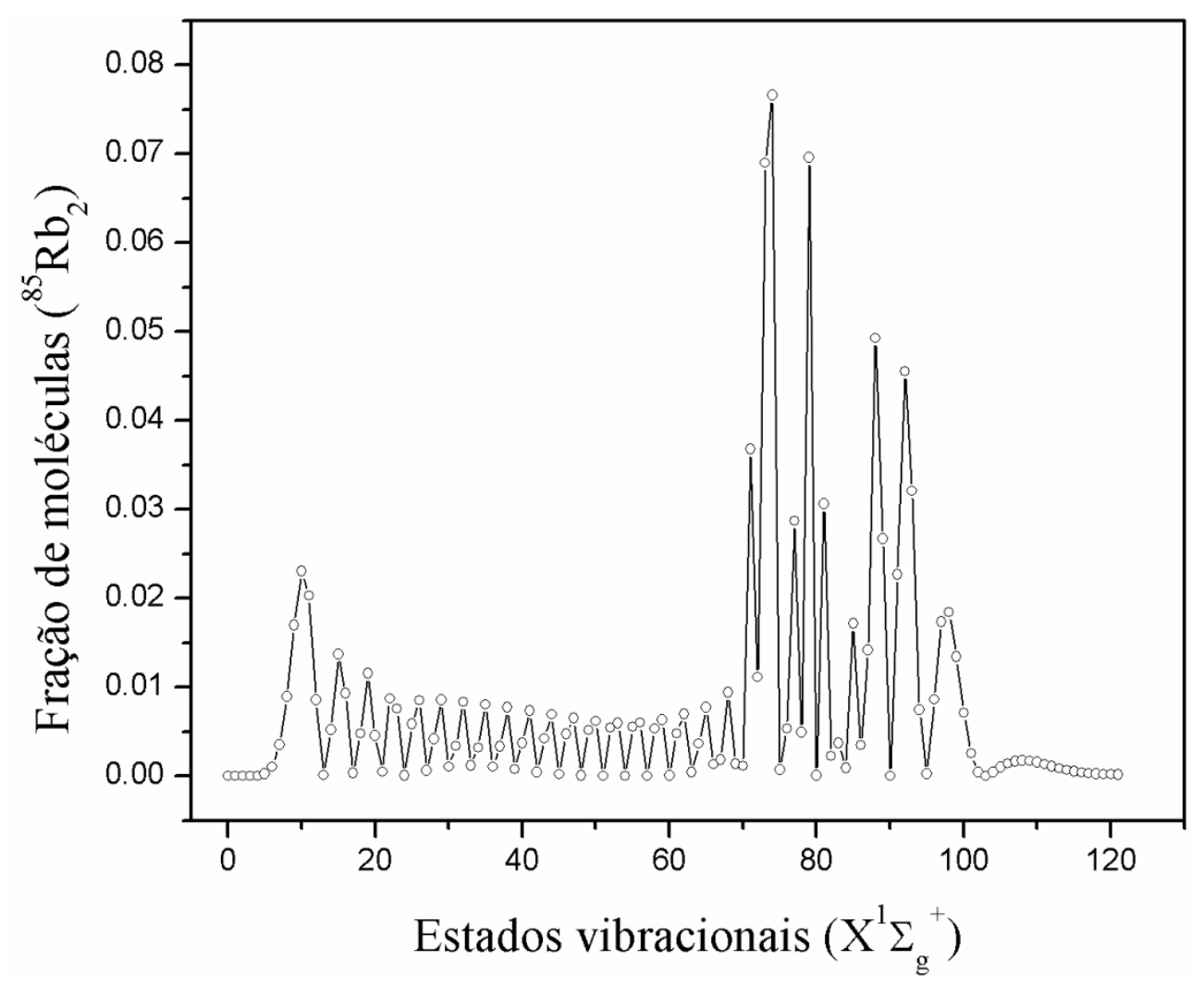

$\begin{aligned} \text { Figura } 46- & \text { Distribuição dos estados vibracionais no estado eletrônico } \\ & \text { fundamental }\left(X^{1} \Sigma_{g}^{+}\right) \text {após a fotoassociação (PA) do }{ }^{85} \mathrm{Rb} .\end{aligned}$

Nesse estágio, apenas 2,5\% das moléculas decaem para estados atômicos livres e são expelidas do experimento, o restante formam moléculas ligadas no estado fundamental $\left(X^{1} \Sigma_{g}^{+}\right)$. Nota-se um acúmulo considerável de moléculas para estados vibracionais entre 
$v=70-105$. Estados mais elevados, devido ao laser banda larga em $1071 \mathrm{~nm}$, são excitados novamente e decaem em uma configuração diferente. Após 13 ciclos de excitação e decaimento, menos de $1 \%$ das moléculas permanecem em estados acessíveis pelo $1071 \mathrm{~nm}$, e o estado entra em um regime estacionário, sendo dado pela Figura 47.

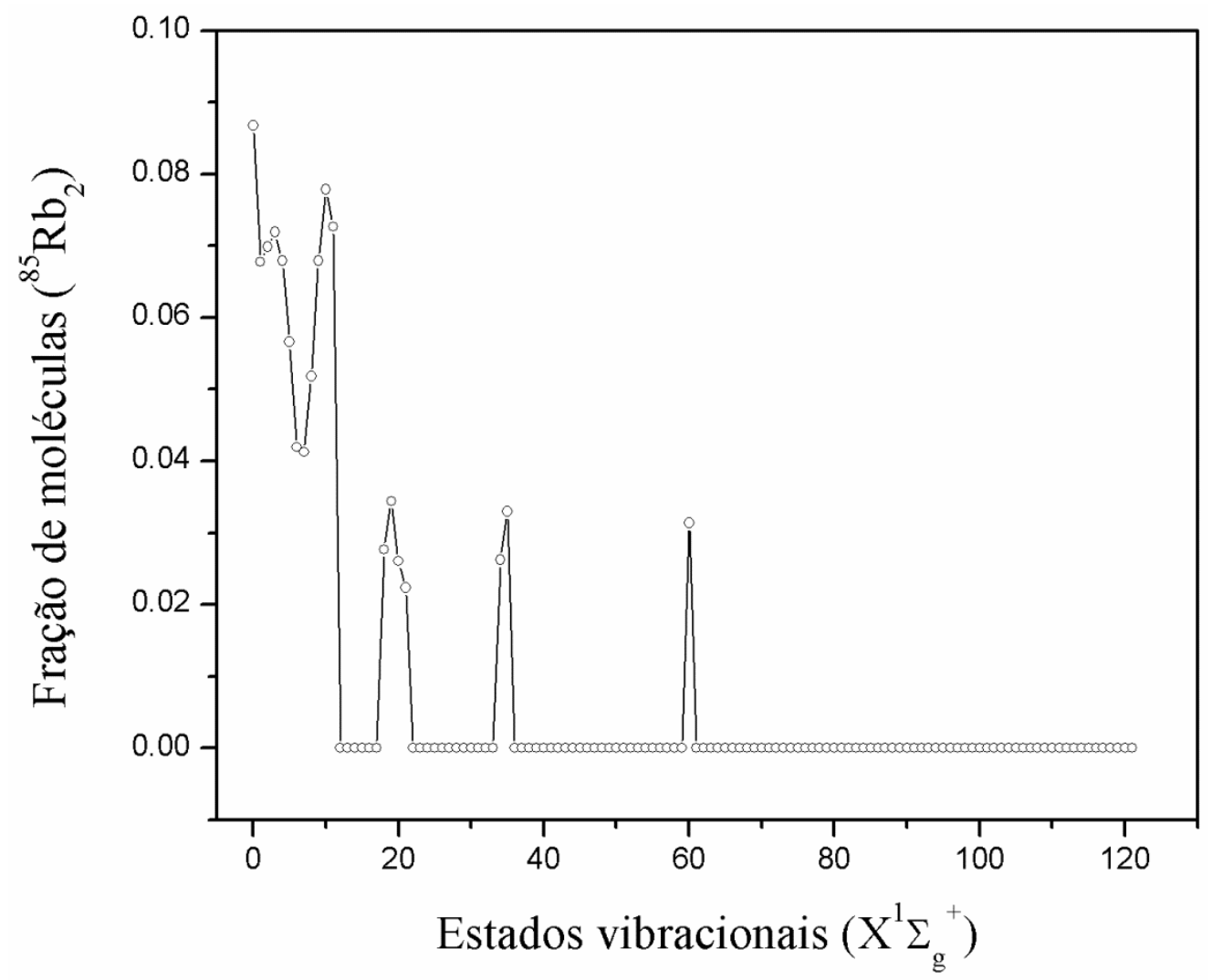

Figura 47 - Distribuição dos estados vibracionais no estado eletrônico fundamental $\left(X^{1} \Sigma_{g}^{+}\right)$após o equilíbrio para o ${ }^{85} \mathrm{Rb}_{2}$.

A perda no processo de bombeamento é de $3 \%$ e cerca de $80 \%$ das moléculas se encontram em $v<20$. A distribuição desses estados depende fortemente da largura do laser de dipolo. Como estamos usando uma intensidade alta $\left(\sim 3 \mathrm{MW} / \mathrm{cm}^{2}\right)$, a cintura do laser que devemos levar em conta para o bombeamento das moléculas pode ser maior que o valor considerado pelo manual do laser $(\Delta \lambda=1,5 \mathrm{~nm})$. Um aumento em $\Delta \lambda$, iria proporcionar maior bombeamento molecular para níveis $v$ inferiores. Para a largura atualmente utilizada $(\Delta \lambda=1,5 \mathrm{~nm})$, temos $7 \%$ das moléculas em $v=0$. Se considerarmos uma largura efetiva de $\Delta \lambda=3 \mathrm{~nm}$, esse valor sobe para $10 \%$, com praticamente $100 \%$ das moléculas contidas em $v<20$. 
Em seguida, aplicamos o modelo para o isótopo ${ }^{87} \mathrm{Rb}_{2}$. A distribuição de níveis vibracionais para o primeiro decaimento após a PA é mostrado na Figura 48.

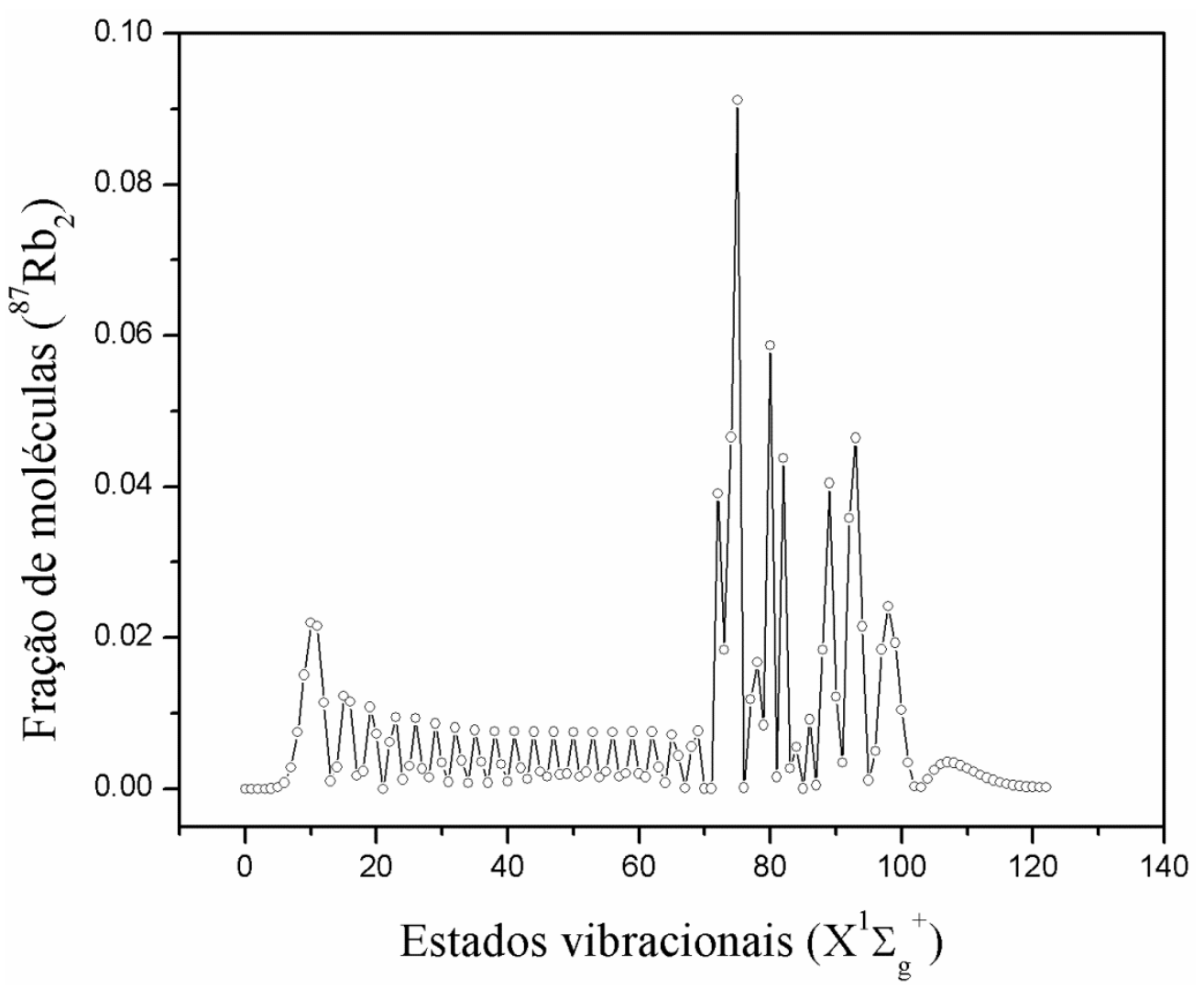

Figura 48 - Distribuição dos estados vibracionais no estado eletrônico fundamental $\left(X^{1} \Sigma_{g}^{+}\right)$após a fotoassociação $(\mathrm{PA})$ do ${ }^{87} \mathrm{Rb}$.

As perdas para o decaimento após a PA é de $2,4 \%$. Comparando com o ${ }^{85} \mathrm{Rb}_{2}$, temos um acúmulo similar para a região de $v=70-105$. Após 13 ciclos de absorção e emissão, a distribuição final é dada pela Figura 49. 


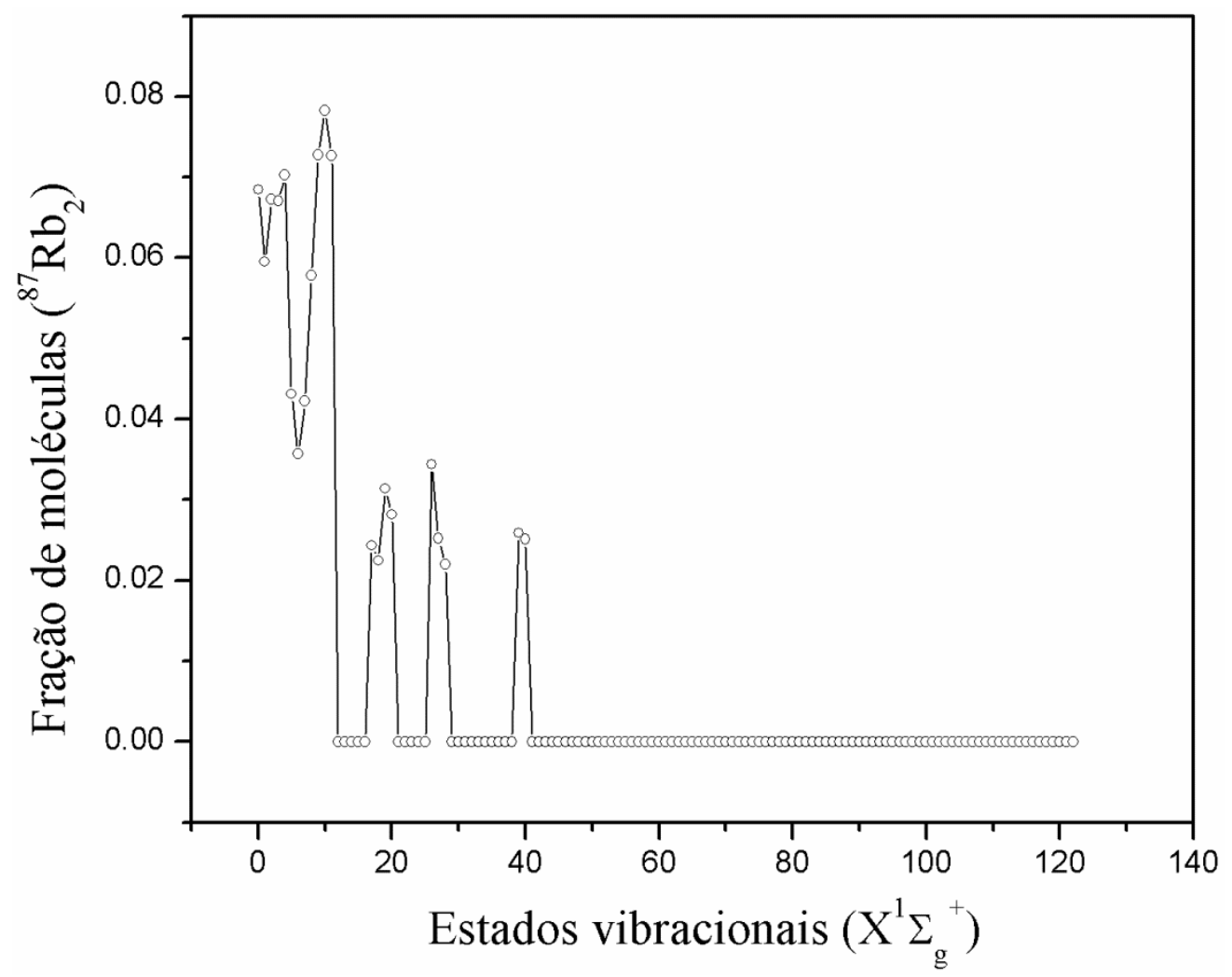

Figura 49 - Distribuição dos estados vibracionais no estado eletrônico fundamental $\left(X^{1} \Sigma_{g}^{+}\right)$após o equilíbrio para o ${ }^{87} \mathrm{Rb}_{2}$.

A perda no processo de bombeamento é de $2,5 \%$ e temos $84 \%$ das moléculas em $v<20$. Para $v=0$, temos $8,7 \%$ das moléculas. $\mathrm{O}$ valor sobe para $9 \%$ se considerarmos $\Delta \lambda=3 \mathrm{~nm}$, sendo menos sensível à variação de $\Delta \lambda$ se comparado ao ${ }^{85} \mathrm{Rb}_{2}$.

Visto que as moléculas formadas são esperadas estarem fortemente ligadas $(v<20$, ou seja, energia de ligação entre $3800 \mathrm{~cm}^{-1}$ e $2700 \mathrm{~cm}^{-1}$ ), sua detecção via fotoionização por dois fótons precisa ser investigada. Para a ionização eficiente das moléculas nessa configuração estacionária, onde a maioria se encontra em $v<20$, é preciso encontrar um estado que apresente um bom FCF e possa ser utilizado como estado intermediário, como o $(2)^{3} \Pi_{u}$, indicado na Figura 50. 


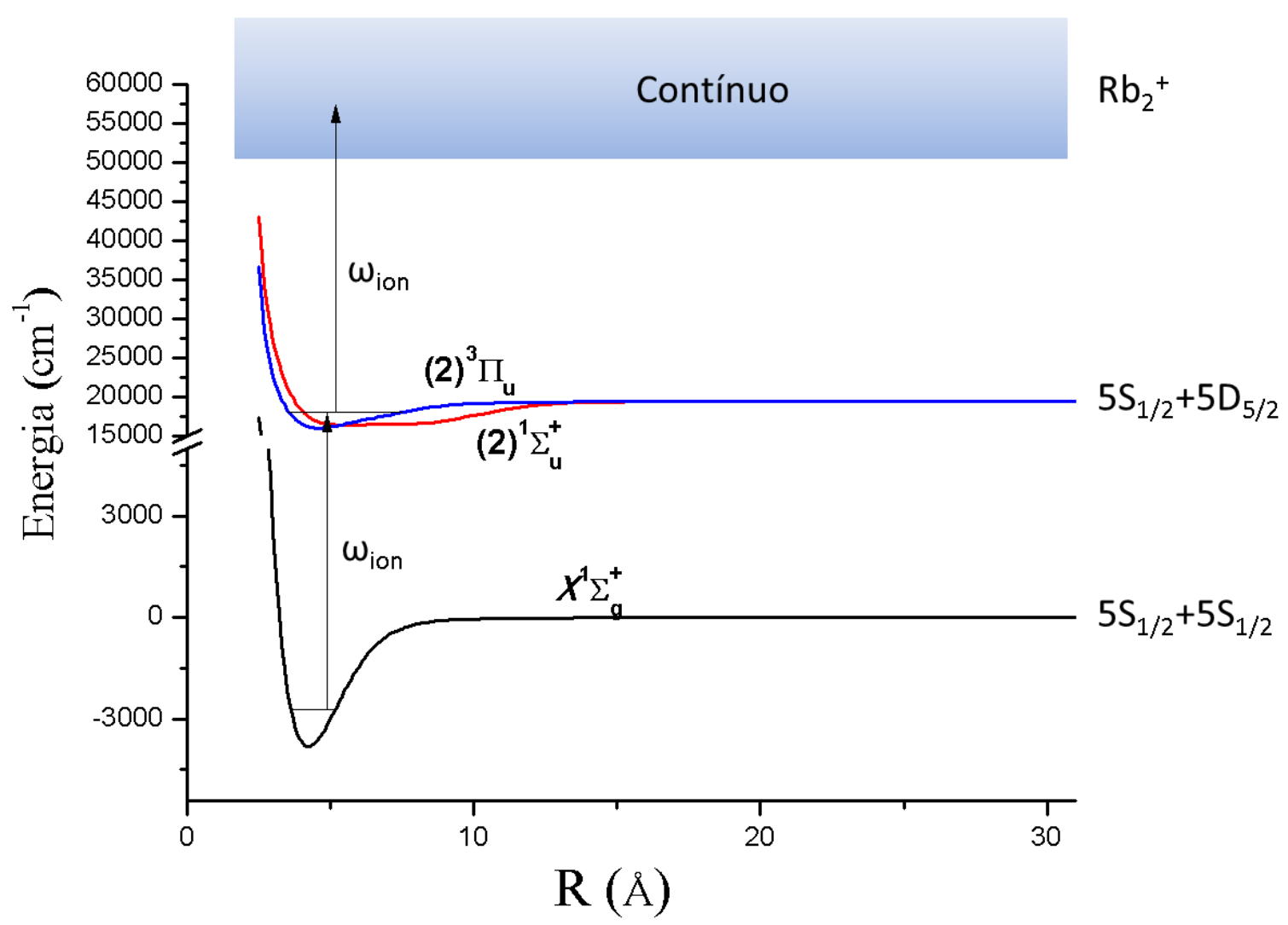

Figura 50 - Processo de ionização do $\mathrm{Rb}_{2}$ para detecção iônica. $\mathrm{O}$ estado intermediário $2 \Pi_{u}$ foi escolhido por apresentar alto FCF com os níveis $v<20$ para o estado fundamental $X^{1} \Sigma_{g}^{+}$.

Para esse caminho de ionização, o comprimento de onda do laser ficaria em torno de $520 \mathrm{~nm}$. Para a detecção da molécula em $v=0$, a transição mais forte $\left(X^{1} \Sigma_{g}^{+} ; v=\right.$ $\left.0 \rightarrow^{3} \Pi_{u} ; v^{\prime \prime}=5\right)$ corresponde a aproximadamente $500 \mathrm{~nm}$. Essa configuração de ionização e detecção vale para ambos os isótopos, já que a variação energética entre um isótopo e outro é desprezível se comparada com a capacidade de varredura do laser de ionização $(\sim 5 \mathrm{~nm})$. O valor do FCF entre os estados vibracionais de $X^{1} \Sigma_{g}^{+} e{ }^{3} \Pi_{u}$ estão representados no gráfico de intensidades da Figura 51, sendo as partes mais escuras correspondentes aos maiores FCFs. 


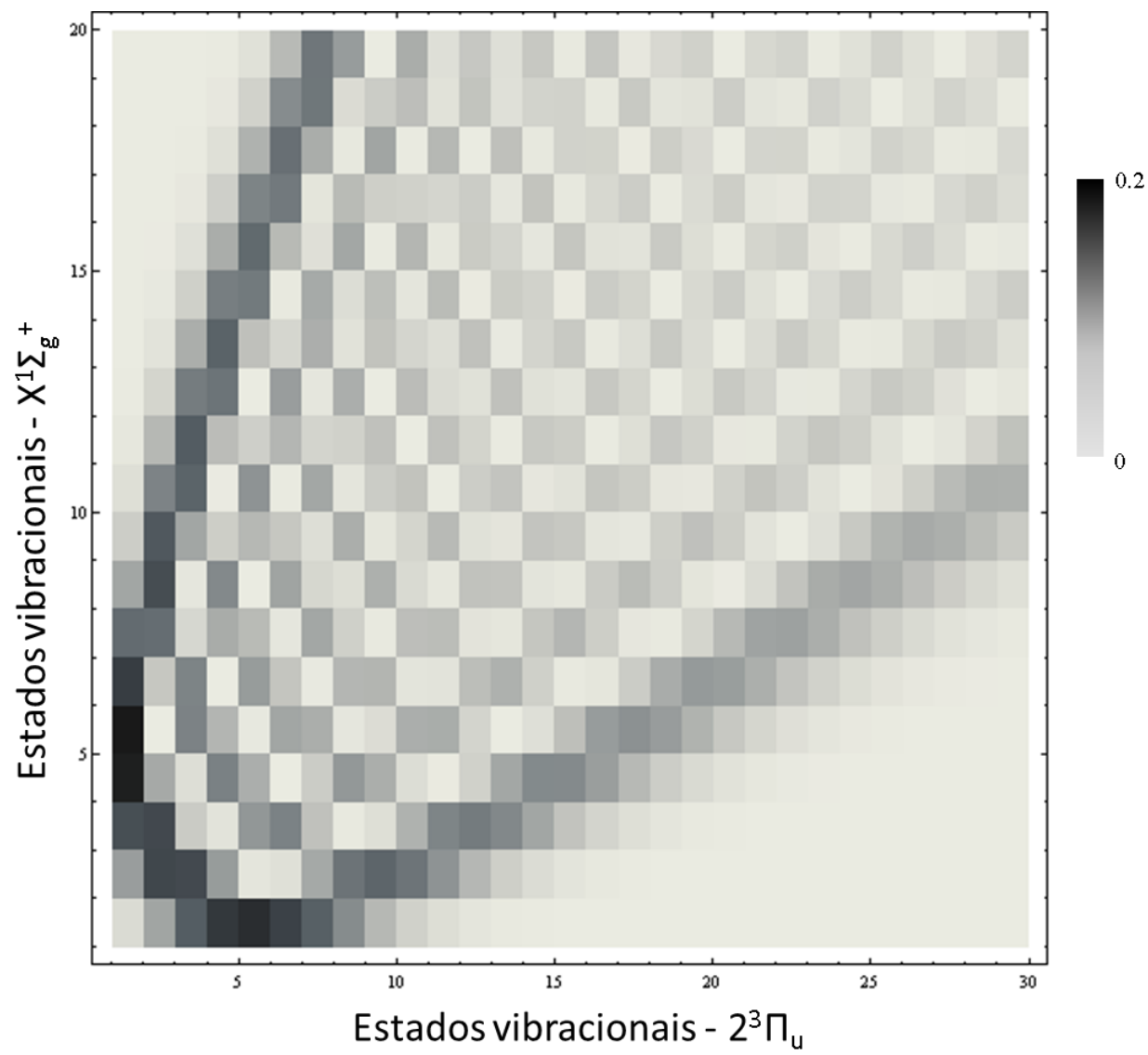

Figura 51 - Gráfico de intensidade do FCF entre os níveis vibracionais do estado fundamental $\left(X^{1} \Sigma_{g}^{+}\right)$e intermediário $\left(2 \Pi_{u}\right)$ para o processo de ionização do $\mathrm{Rb}_{2}$.

\subsection{KRb na armadilha de dipolo}

Na sequência, aplicamos o modelo para a molécula heteronuclear de KRb. Os estados acessíveis pelo laser de $1071 \mathrm{~nm}$ para a fotoassociação e para o processo de bombeamento estão descritos na Figura 52. 

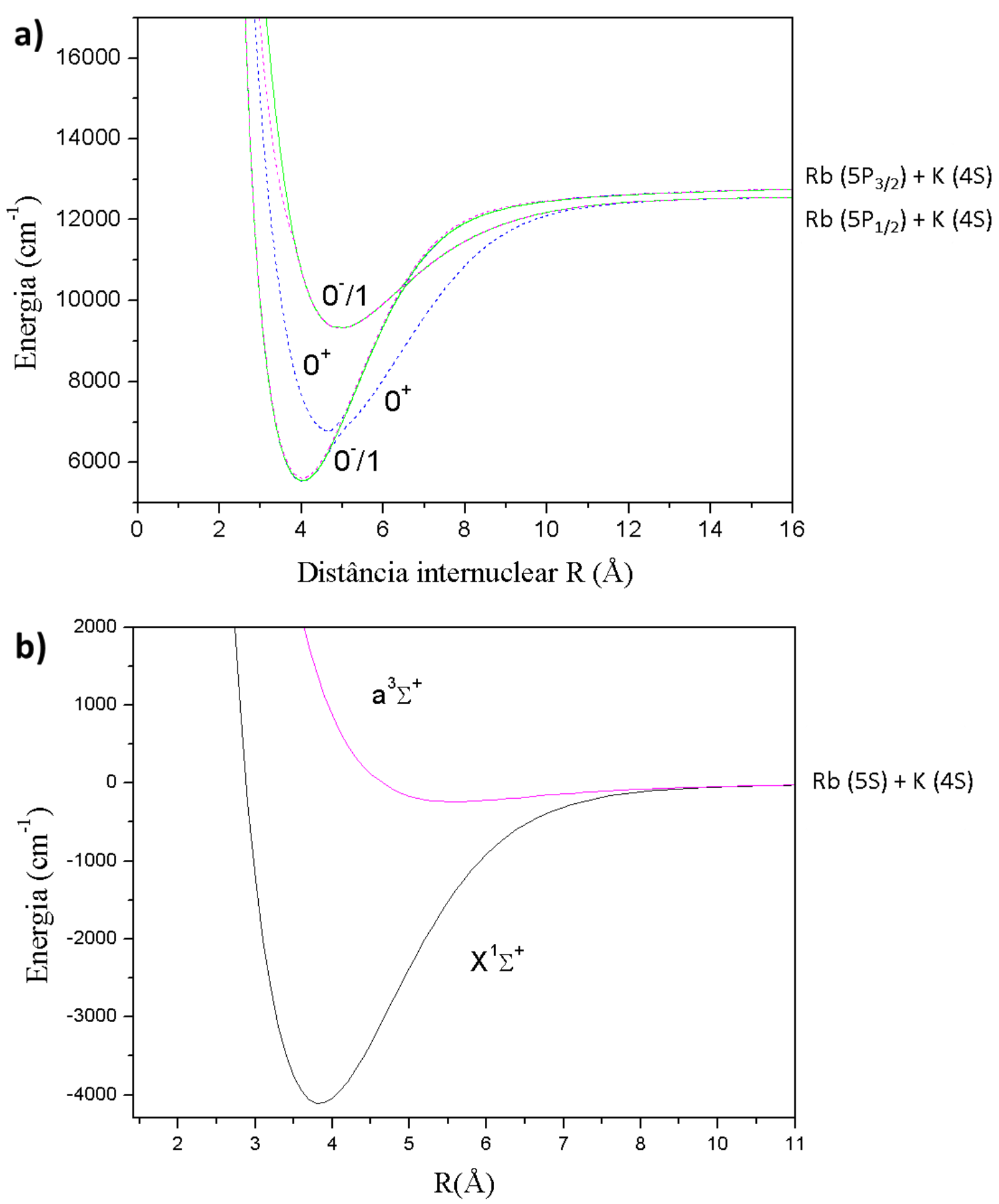

Figura 52 - Potenciais de interação atômico de interesse para a fotoassociação (PA) do $\mathrm{KRb}$ e bombeamento vibracional. a) Curvas de potencial do estado excitado considerando a estrutura hiperfina do $\mathrm{Rb}(5 \mathrm{P})$. b) Estados eletrônicos fundamentais.

Usando estes potenciais, realizamos os mesmos cálculos feitos para $\mathrm{o} \mathrm{Rb}_{2}$, de onde extraímos a distribuição de níveis vibracionais após a PA e a distribuição estacionária para ${ }^{39} \mathrm{~K}^{85} \mathrm{Rb} \mathrm{e}{ }^{39} \mathrm{~K}^{87} \mathrm{Rb}$.

Para a molécula heteronuclear de ${ }^{39} \mathrm{~K}^{87} \mathrm{Rb}$, temos que o processo de fotoassociação ocorre preferencialmente para o nível vibracional $v^{\prime}=68$ do estado $0^{+}\left[R b\left(5 P_{1 / 2}\right)+\right.$ 
$\left.K\left(4 S_{1 / 2}\right)\right]$ com $F C F=5,76 \times 10^{-4}$ com energia de transição de 1069,55 nm. Após a fotoassociação, a distribuição de níveis moleculares em $X^{1} \Sigma^{+}$fica como apresentado na Figura 53.

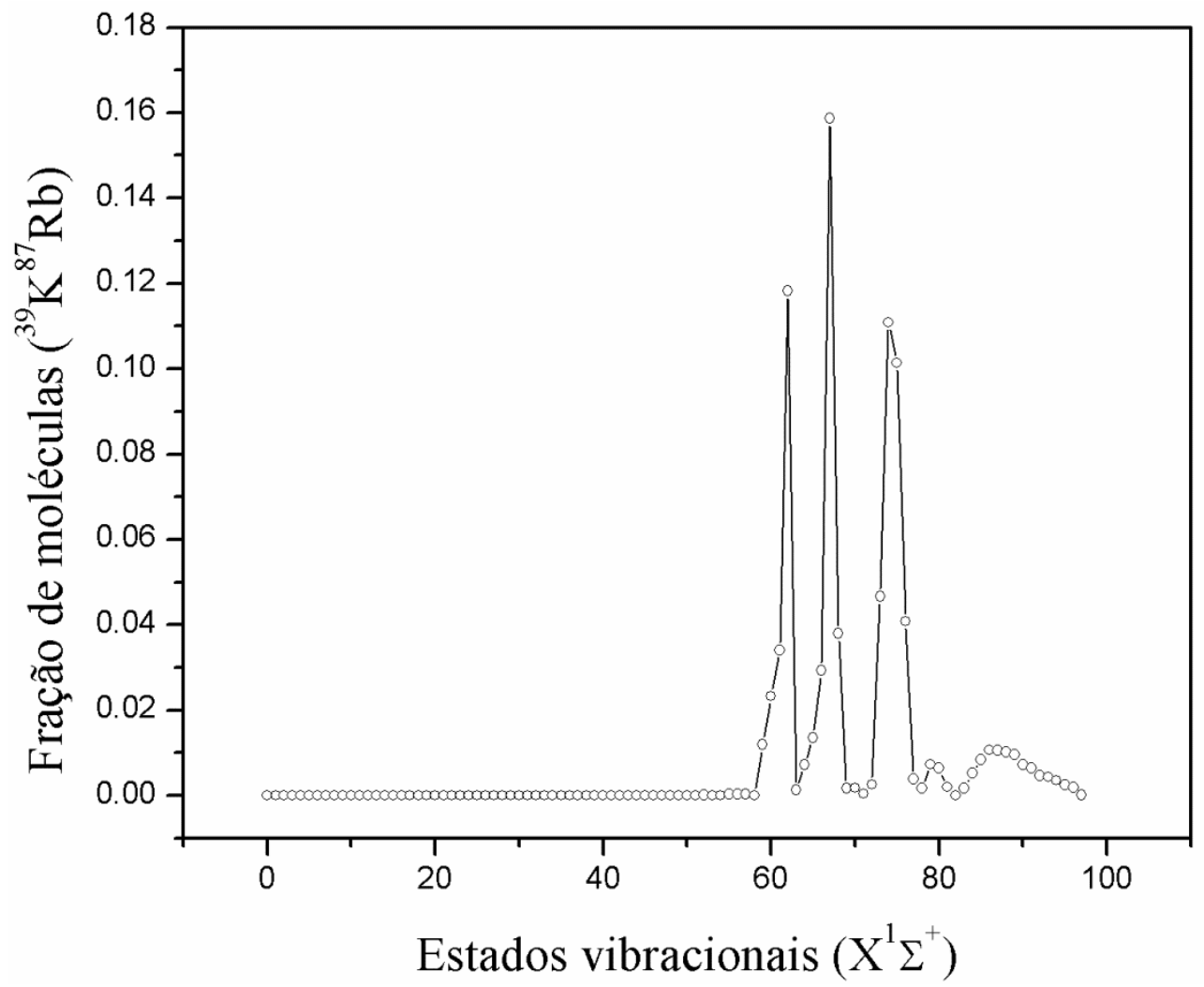

Figura 53 - Distribuição dos estados vibracionais no estado eletrônico fundamental $\left(X^{1} \Sigma^{+}\right)$após a fotoassociação (PA) do ${ }^{39} \mathrm{~K}^{87} \mathrm{Rb}$.

Para esse primeiro decaimento, cerca de $15 \%$ das moléculas decaem em átomos livres e se perdem do experimento. Notamos também que todas as moléculas estão contidas em níveis vibracionais $v>58$, fazendo com que o estado estacionário seja alcançado somente após 20 ciclos de bombeamento, representado pela Figura 54. 


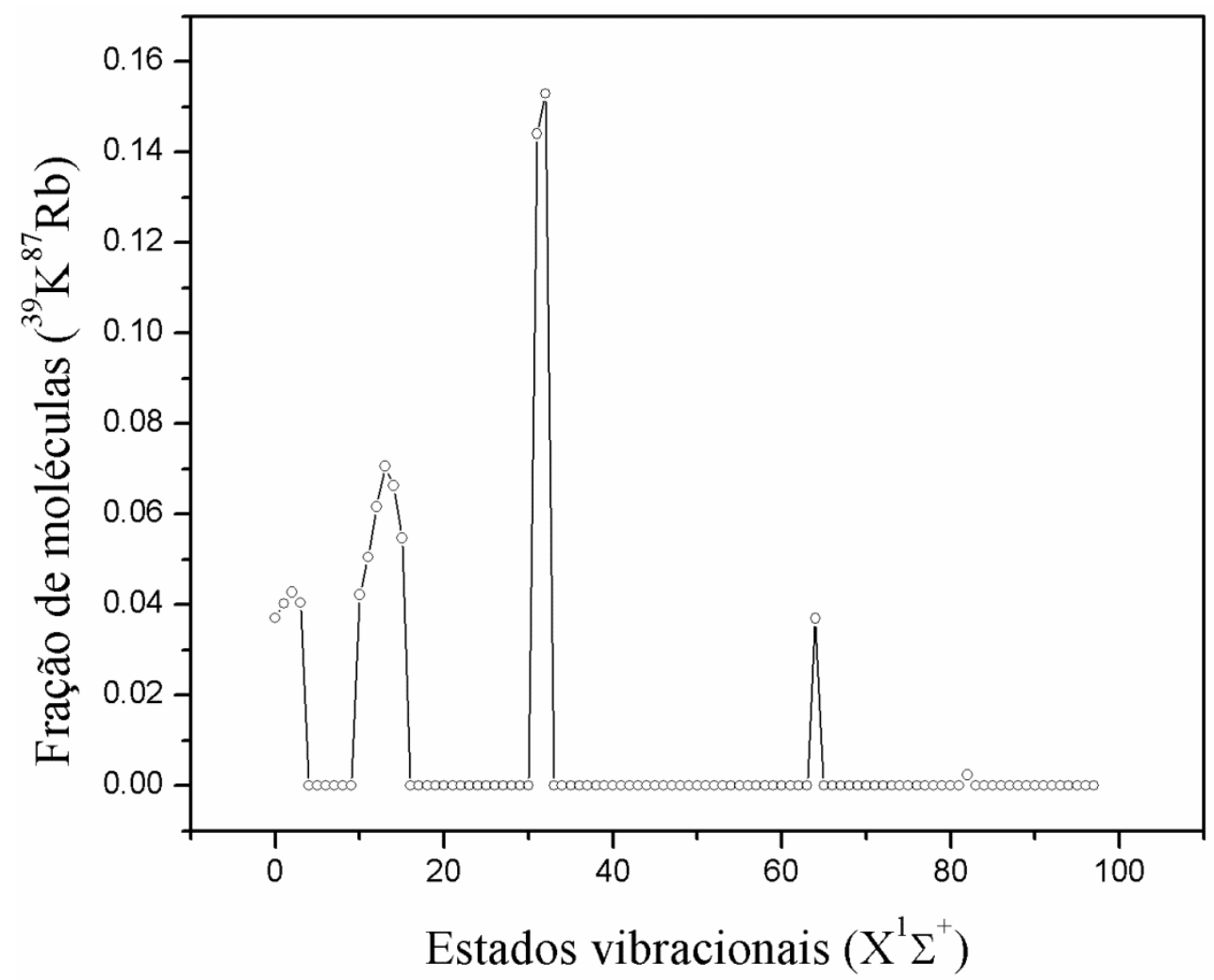

Figura 54 - Distribuição dos estados vibracionais no estado eletrônico fundamental $\left(X^{1} \Sigma^{+}\right)$após o equilíbrio para o ${ }^{39} \mathrm{~K}^{87} \mathrm{Rb}$.

No estado estacionário, vemos um acúmulo de moléculas localizado em pequenos intervalos de estados vibracionais. Esse efeito se deve a largura espectral do laser que foi considerada nas contas $(\Delta \lambda=1,5 \mathrm{~nm})$. Como dito anteriormente, esse valor pode não representar o valor real, pois é extraído da equação (39), que considera como limitante para a largura a intensidade de $I_{0} e^{-1}$. Considerando uma largura de $\Delta \lambda=3 \mathrm{~nm}$, teremos um cenário bem diferente, com $40 \%$ das moléculas em $v=1-5$ e $60 \%$ em $v=13-15$. Como não sabemos qual será o comportamento das moléculas perante a largura do laser, um bom ponto de partida para a detecção molecular seria a região de $v \leq 20$, pois a quantidade de moléculas nessa região será sempre satisfatória para a detecção.

Para a molécula ${ }^{39} \mathrm{~K}^{85} \mathrm{Rb}$, o processo de fotoassociação devido ao laser de $1071 \mathrm{~nm}$, ocorre preferencialmente para $v^{\prime}=53$ do estado $1\left[R b\left(5 P_{1 / 2}\right)+K\left(4 S_{1 / 2}\right)\right]$ com $F C F=$ $1,024 \times 10^{-4}$ e energia de transição de $1072,45 \mathrm{~nm}$. Após a fotoassociação, a distribuição de níveis vibracionais em $X^{1} \Sigma^{+}$assume a forma descrita na Figura 55. 


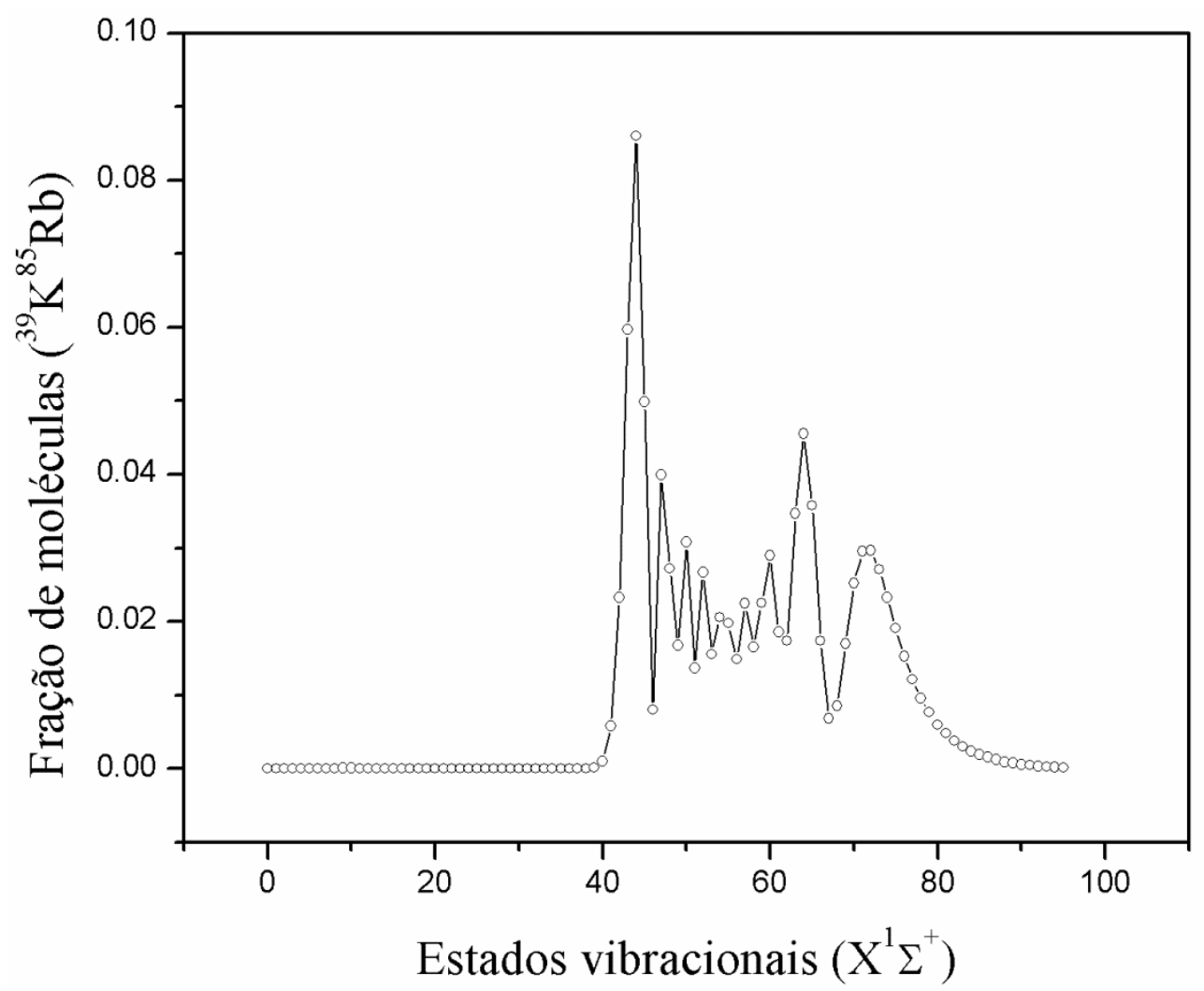

Figura 55 - Distribuição dos estados vibracionais no estado eletrônico fundamental $\left(X^{1} \Sigma^{+}\right)$após a fotoassociação (PA) do ${ }^{39} \mathrm{~K}^{85} \mathrm{Rb}$.

A perda de moléculas para o primeiro decaimento é de apenas $2 \%$ e o acúmulo ocorre principalmente para $v=40-80$. Após 15 ciclos de bombeamento, chega-se a configuração estacionária, descrita pela Figura 56. 


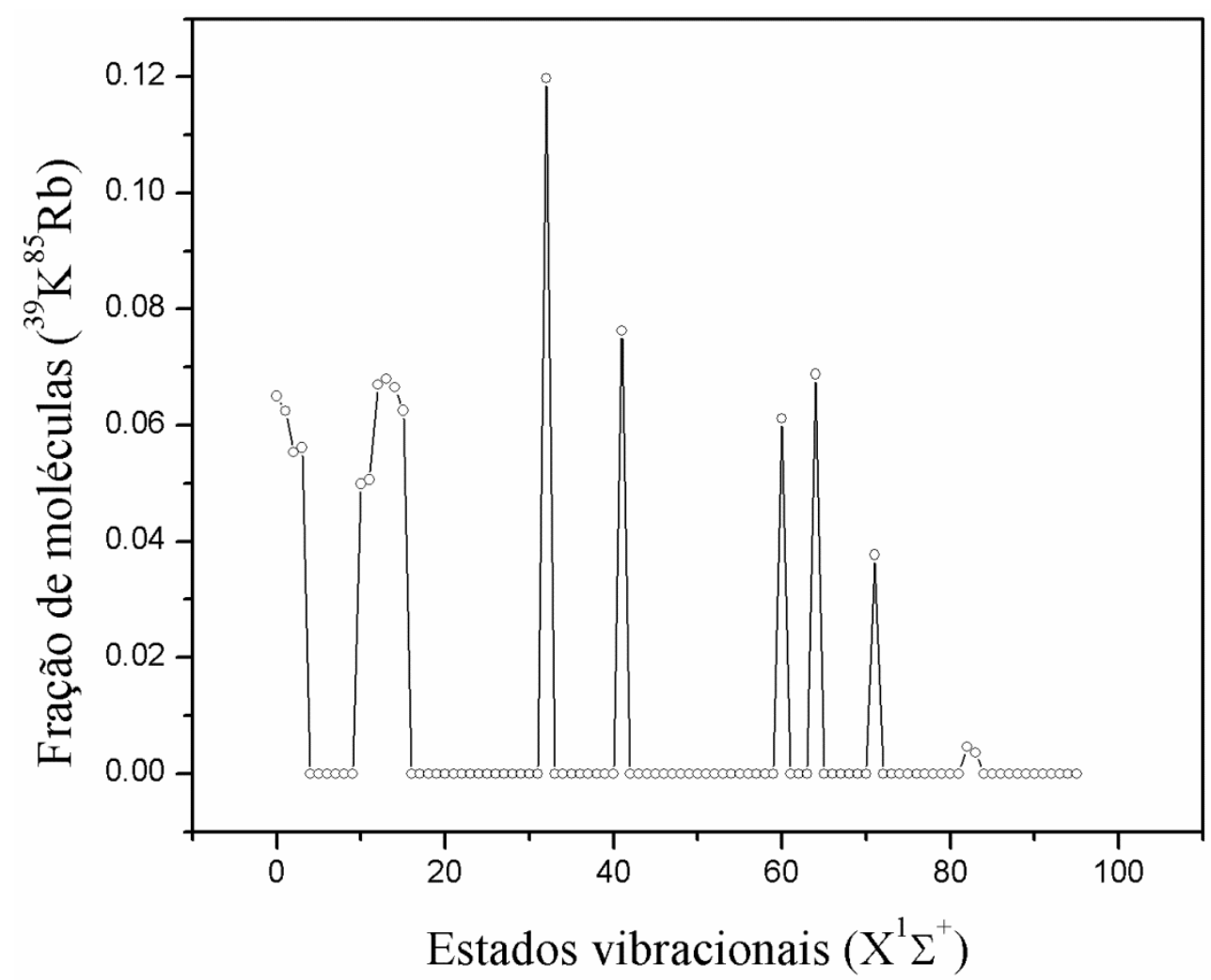

$\begin{aligned} \text { Figura } 56- & \text { Distribuição dos estados vibracionais no estado eletrônico } \\ & \text { fundamental }\left(X^{1} \Sigma^{+}\right) \text {após o equilíbrio para o }{ }^{39} \mathrm{~K}^{85} \mathrm{Rb} .\end{aligned}$

Como ocorrido no ${ }^{39} \mathrm{~K}^{87} \mathrm{Rb}$, temos o acúmulo de moléculas em níveis vibracionais específicos ao longo da distribuição. Contudo, $60 \%$ dessas moléculas se encontram em $v<20$, valor que sobe para $95 \%$ se considerarmos novamente $\Delta \lambda=3 \mathrm{~nm}$, sendo uma boa região para se procurar tais moléculas.

Com todos esses cálculos podemos fazer uma estimativa muito simplificada da taxa de fotoassociação do $\mathrm{K}+\mathrm{Rb}$, considerando uma transição do tipo ligado - ligado. Afinal a função de onda do ultimo nível vibracional de $X^{1} \Sigma^{+}$não pode ser muito diferente da função dos átomos livres. Considerando que a taxa de transição para o processo de fotoassociação é proporcional ao valor do FCF ponderado pela intensidade do laser na transição, podemos calcular a razão da taxa de PA para os diferentes isótopos. Com base nos valores calculados para o FCF e a energia de transição no processo de PA para o ${ }^{39} \mathrm{~K}^{87} \mathrm{Rb} \mathrm{e}{ }^{39} \mathrm{~K}^{85} \mathrm{Rb}$, e do perfil de intensidades do laser da equação (39), é possível estimar a razão entre as taxas de PA:

$$
\frac{T_{P A}\left({ }^{39} K^{87} R b\right)}{T_{P A}\left({ }^{39} K^{85} R b\right)}=\frac{I(1069,55) \times 5,76 \times 10^{-4}}{I(1072,45) \times 1,02 \times 10^{-4}}=2,6
$$


Experimentalmente, obtivemos que a taxa de perda devido a colisão heterogênea $\left(\beta^{\prime}\right)$ era de: $\beta_{K^{87}{ }_{R b}}=5,2 \times 10^{-12} \mathrm{~cm}^{3} / \mathrm{s}$ e $\beta_{K^{85} \mathrm{Rb}}=2,8 \times 10^{-12} \mathrm{~cm}^{3} / \mathrm{s}$, dando uma razão de:

$$
\frac{\beta_{K^{87} R b}^{\prime}}{\beta_{K^{85} R b}^{\prime}}=1,9
$$

Assim, temos que tanto o resultado experimental quanto o teórico preveem uma diferença entre a taxa de PA dos isótopos, corroborando com o fato de o valor de $\beta^{\prime}$ ser fortemente influenciado pelo processo de formação molecular na armadilha de dipolo. A abordagem teórica tem caráter qualitativo, na tentativa de explicar apenas a origem das perdas. Para uma análise quantitativa, seriam necessários potenciais de interação mais precisos, contudo, é uma forma eficaz de prever a diferença associada ao isótopo e pode ser estendido para outros elementos. Também é eficiente para fornecer um provável caminho para a detecção das moléculas formadas, já que fornece a distribuição dos estados vibracionais no estado fundamental após o equilíbrio.

\subsubsection{Ionização e detecção molecular do KRb}

Como vimos nos cálculos anteriores, ocorre um acúmulo considerável de moléculas para os níveis vibracionais $v<20$ e a porcentagem dessas moléculas aumenta com o aumento da largura espectral do laser de $1071 \mathrm{~nm}$. Como não sabemos qual será o comportamento espectral do laser perante as moléculas, podemos estimar que essa região de $v<20$ será ocupada por mais de $40 \%$ das moléculas, sendo uma boa área para início da busca molecular. Um estado intermediário adequado para a ionização dessas moléculas, seria o ${ }^{1} \Pi$, com energia de acoplamento em torno de 670 - $730 \mathrm{~nm}$. Para a ionização do estado fundamental vibracional $(v=0)$ especificamente, o estado intermediário que tem o maior acoplamento é o estado ${ }^{1} \Pi\left(v^{\prime}=3\right)$ com $\mathrm{FCF}=0,222$ e comprimento de onda do fóton de $660,14 \mathrm{~nm}$. Os valores do FCF entre os estados vibracionais de $X^{1} \Sigma^{+} e^{1} \Pi$ estão representados no gráfico de intensidades da figura 7 , sendo as partes mais escuras correspondentes aos maiores FCFs. 


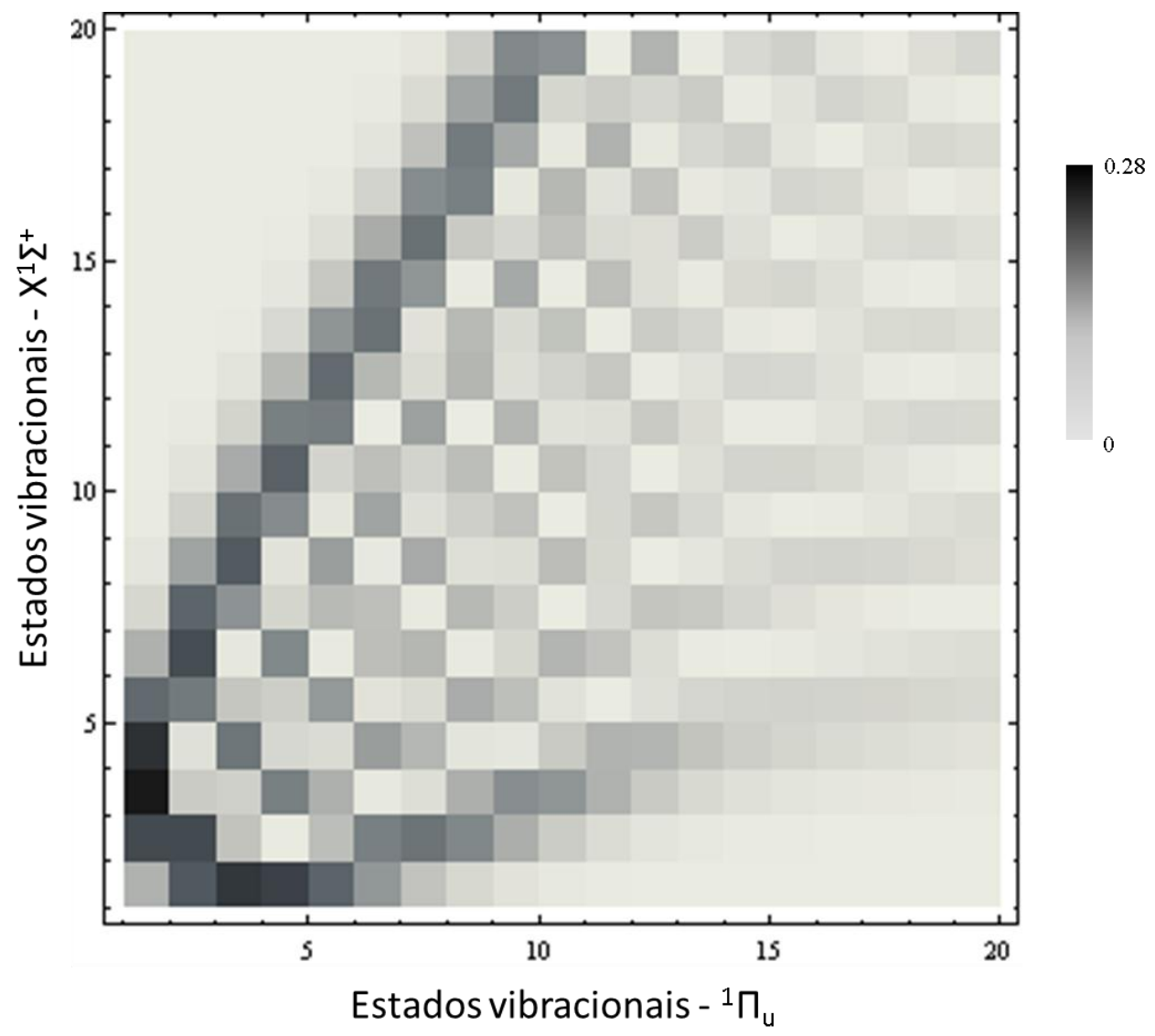

Figura 57 - Gráfico de intensidade do FCF entre os níveis vibracionais do estado fundamental $\left(X^{1} \Sigma_{g}^{+}\right)$e intermediário $\left({ }^{1} \Pi\right)$ para o processo de ionização do $\mathrm{KRb}$.

\subsection{Bombeamento de moléculas de KRb para o estado vibrônico fundamental}

Analisando os resultados experimentais dos capítulos anteriores e os cálculos que foram desenvolvidos nesse capítulo, estamos convencidos da formação molecular de $\mathrm{KRb}$ devido a fotoassociação do laser de $1071 \mathrm{~nm}$. Baseado no trabalho de Viteau e colaboradores (46), esperamos que a nossa amostra molecular também sofra um bombeamento para níveis vibracionais mais baixos devido a ação laser de ODT. Isso provocaria uma distribuição de estados vibracionais, o que é pouco desejado, como pode ser visto para as situações estacionárias previstas na Figura 54 e Figura 56 para ${ }^{39} \mathrm{~K}^{87} \mathrm{Rb}$ e ${ }^{39} \mathrm{~K}^{85} \mathrm{Rb}$ respectivamente. Para contornar esse problema, podemos aplicar uma técnica de bombeamento, similar ao que foi feito para o bombeamento do $\mathrm{Cs}_{2}$ (46). Utilizando um laser de femtossegundo e removendo a 
parte espectral correspondente a transição de $X^{1} \Sigma^{+}(v=0)$ para qualquer outro estado excitado, ocorrerá o acúmulo de moléculas no estado escuro $v=0$. Uma das maneiras para se remover componentes espectrais é abrindo espacialmente o espectro do laser com uma grade de difração e em seguida bloqueando espacialmente a parte indesejada do espectro, o que pode ser feito por meio de um obstrutor simples ou com um modulador espacial. Nosso grupo está em processo de compra de um modulador espacial para essa finalidade, o qual possibilitará bloquear qualquer parte do espectro. Uma vez bloqueado parte do espectro, a parte transmitida pelo modulador é então recombinada utilizando outra grade de difração e enviada ao experimento.

$\mathrm{O}$ estado intermediário que pretendemos utilizar para realizar esse bombeamento é o ${ }^{1} \Pi$, e a energia de corte para o espectro do laser será de $15030 \mathrm{~cm}^{-1}$. Assim, teríamos as transições proibidas como indicado pelos quadrados brancos da Figura 58.

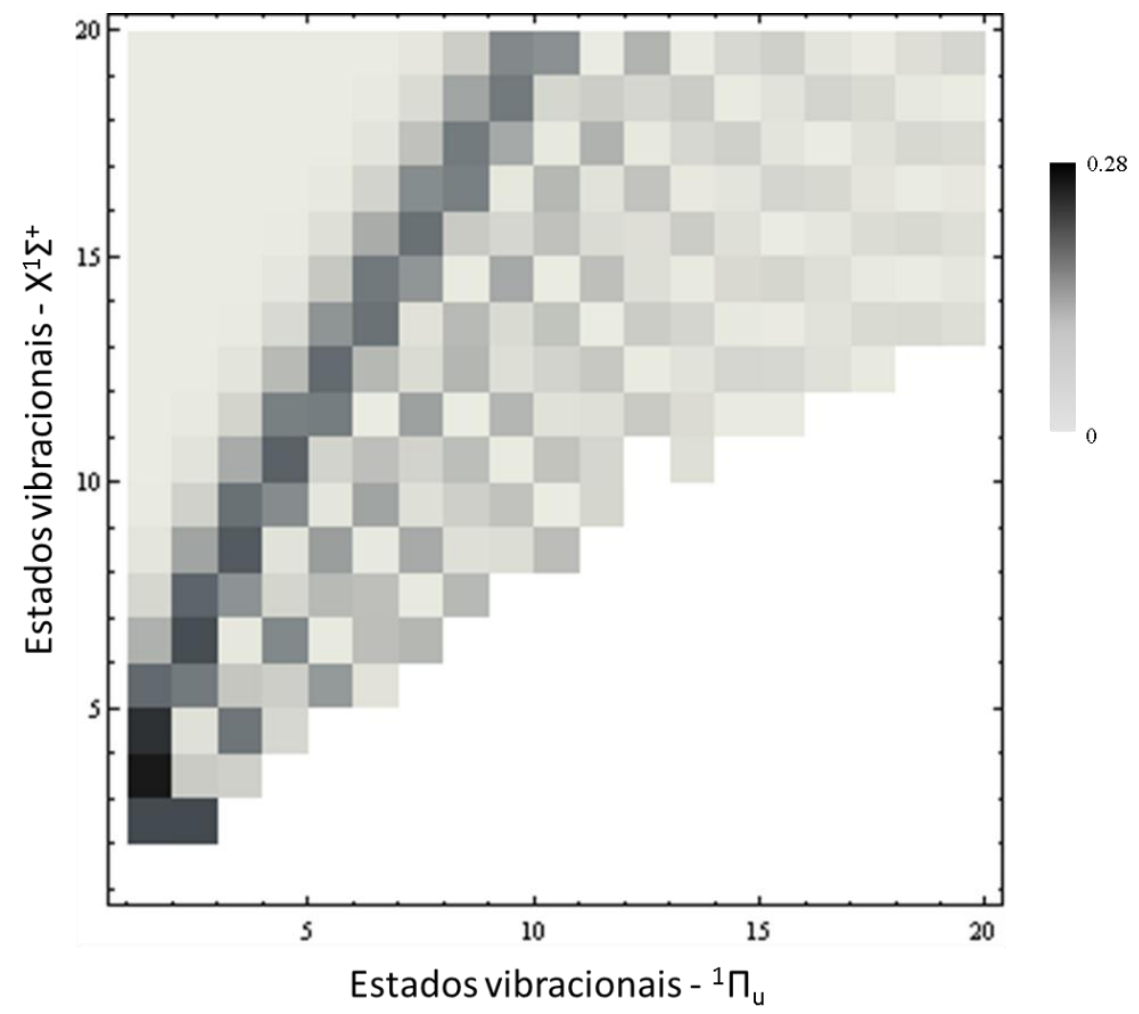

Figura 58 - Gráfico de intensidade do FCF entre os níveis vibracionais do estado fundamental $\left(X^{1} \Sigma^{+}\right)$e intermediário $\left({ }^{1} \Pi\right)$ para o processo de bombeamento do KRb. Os valores representados por quadrados brancos são transições proibidas devido ao corte de frequência em $15031 \mathrm{~cm}^{-1}$.

Para esse experimento, iremos utilizar um laser de corante com largura espectral de 5 a $10 \mathrm{~nm}$ e comprimento de onda central de aproximadamente $670 \mathrm{~nm}$. O laser corresponde ao 
mesmo que será usado para a ionização, porém, sem a grade de difração que seleciona o comprimento de onda do laser, deixando o espectro largo.

Filtrando espectralmente o laser de modo a termos somente os fótons com energias entre 14900 e $15030 \mathrm{~cm}^{-1}$, somos capazes de bombear qualquer estado no estado fundamental abaixo de $v=30$, como representado na Figura 59. Isso nos indica que as moléculas formadas e bombeadas pelo laser de $1071 \mathrm{~nm}$ serão gradativamente bombeadas para $v=0$, o que representa um bombeamento de mais de $40 \%$ do total de moléculas formadas.

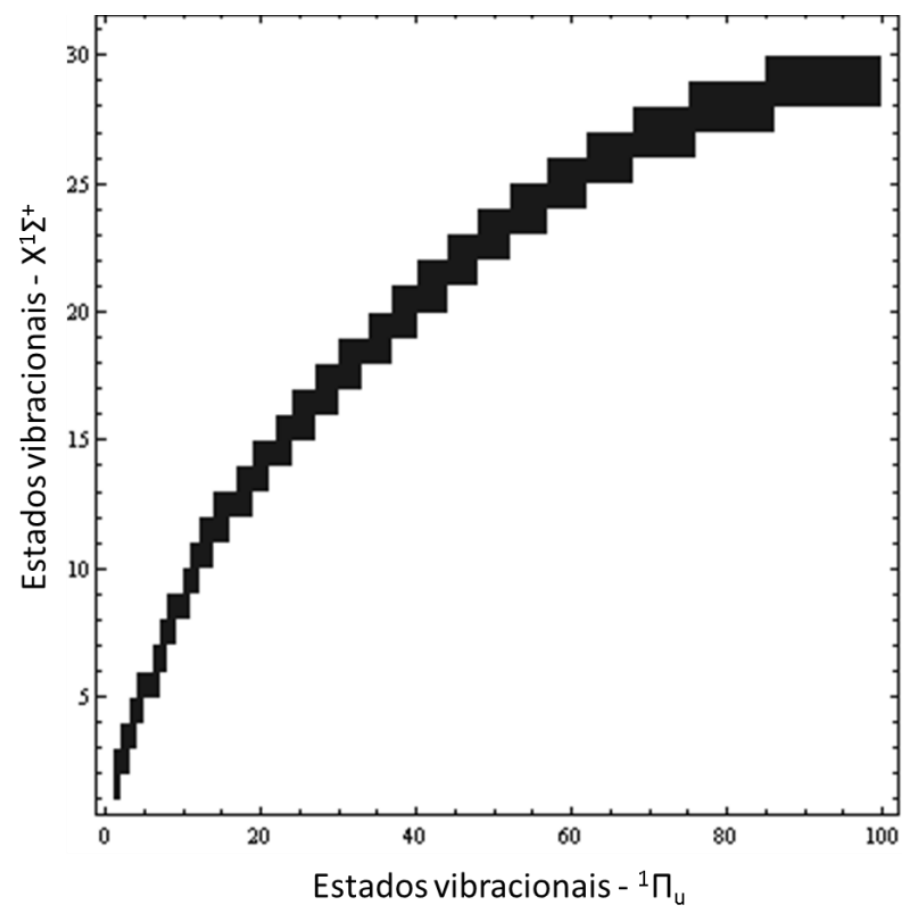

Figura 59 - Transições permitidas (quadrados pretos) entre o estado fundamental $\left(X^{1} \Sigma^{+}\right)$e intermediário $\left({ }^{1} \Pi\right)$ para o processo de bombeamento do $\mathrm{KRb}$ para $\left(X^{1} \Sigma^{+} ; v=0\right)$ para o laser de bombeamento limitado espectralmente $\left(14900-15030 \mathrm{~cm}^{-1}\right)$.

Esse valor de $40 \%$ das moléculas em $v=0$ representa o valor mínimo esperado, pois não temos certeza de como será o bombeamento realizado pelo laser de $1071 \mathrm{~nm}$. Devido a sua alta intensidade, a largura considerada em nossos cálculos pode ser maior que a fornecida pelo manual de $\Delta \lambda=1,5 \mathrm{~nm}$. Para uma largura efetiva de $\Delta \lambda=3 \mathrm{~nm}$, temos que $95 \%$ das moléculas formadas poderão ser bombeadas para $v=0$. 


\section{Conclusões e perspectivas}

Nesse trabalho, demostramos com sucesso a montagem de um experimento robusto para o aprisionamento de átomos de ${ }^{87} \mathrm{Rb},{ }^{85} \mathrm{Rb}$ e ${ }^{39} \mathrm{~K}$ e moléculas. Os resultados obtidos mostram importantes avanços na área e cálculos teóricos demonstram o potencial para futuros experimentos.

Do ponto de vista experimental, projetamos e construímos um aparato complexo e robusto com base no experimento do professor Ketterle do Massachusetts Institute of Technology (MIT) (59). A montagem foi dividida em três partes: Forno, desacelerador e câmara, os quais foram projetados e montados separadamente. O sistema se mostrou eficiente na desaceleração e aprisionamento em uma armadilha magneto óptica (MOT) de átomos de K e Rb. O processo de automação do experimento também merece destaque, pois permite a sincronização de qualquer equipamento com precisão de aproximadamente $100 \mathrm{~ns}$ em passos de $0,1 \mathrm{~ms}$, contribuindo de maneira decisiva para um carregamento efetivo da armadilha dipolar. O sistema de aquisição de imagens desenvolvido foi responsável pela obtenção da maior parte dos resultados apresentados. Inclusive, a montagem atual permite o monitoramento das duas espécies atômicas ( $\mathrm{K}$ e $\mathrm{Rb}$ ) simultaneamente. Assim, o sistema se encontra funcionando em sua plena capacidade e com grandes perspectivas para trabalhos futuros.

Em relação aos trabalhos realizados, obtivemos o carregamento robusto de uma amostra de ${ }^{39} \mathrm{~K}$ em uma armadilha de dipolo cruzada. Os átomos foram transferidos diretamente do MOT para o dipolo. Como fomos o primeiro grupo a conseguir esse tipo de transferência para o ${ }^{39} \mathrm{~K}$, uma caracterização detalhada da armadilha foi feita, resultando em um carregamento eficiente. Verificamos que dois fatores foram cruciais para o bom carregamento da armadilha: A potência dos lasers de carregamento e rebombeio; e a criação de controles independentes entre as duas frequências. Tais fatores foram destacados em trabalhos recentes sobre o resfriamento do ${ }^{39} \mathrm{~K}(62,64)$ e serviram de guia para o desenvolvimento do nosso carregamento. O número total de átomos de ${ }^{39} \mathrm{~K}$ carregados foi de $2 \times 10^{6}$, sendo um número satisfatório para a realização dos experimentos. Esse trabalho rendeu uma publicação (47) e possibilitou a execução de experimentos mais complexos, como o carregamento duplo de $\mathrm{K}$ e $\mathrm{Rb}$. 
Outro trabalho relevante realizado foi o carregamento de $\mathrm{Rb}$ em uma armadilha dipolar. Nessa armadilha, fomos capazes de aprisionar dois isótopos do rubídio $\left({ }^{85} \mathrm{Rb}\right.$ e $\left.{ }^{87} \mathrm{Rb}\right)$ com aproximadamente $3 \times 10^{6}$ átomos, densidades iniciais de $10^{13} \mathrm{~cm}^{-3}$ e temperaturas de $30 \mu K$. Através do decaimento de ${ }^{85} \mathrm{Rb}$ e ${ }^{87} \mathrm{Rb}$ na armadilha de dipolo, verificamos uma perda devido a colisão de dois corpos. Um modelo teórico elaborado pelo pesquisador Olivier Dulier do laboratoire Aimé Cotton, Universidade de Paris, indicou que parte dessa perda possa ser causada pela fotoassociação (PA) devido ao laser de $1071 \mathrm{~nm}$ (49). Inclusive, este modelo foi capaz de explicar a diferença isotópica observada experimentalmente na taxa de perda devido ao processo de PA. Através da evolução da temperatura das amostras $\left({ }^{85} \mathrm{Rb} e\right.$ ${ }^{87} \mathrm{Rb}$ ), pudemos ver que não ocorrem perdas relevantes devido à colisões com mudança de estrutura hiperfina, já que nenhum aquecimento foi observado (66).

Com a experiência e conhecimento adquiridos nos carregamentos independentes de $\mathrm{K}$ e $\mathrm{Rb}$, conseguimos realizar o carregamento de duas espécies simultâneas na armadilha de dipolo. Foram feitos apenas alguns ajustes na fase de carregamento, já que havia competição entre as espécies nessa fase, como abordado no capítulo 5. Com um carregamento onde o número de átomos era equivalente entre as espécies ( $\mathrm{K}$ e Rb), estudamos a evolução temporal da densidade em função do tempo. Através de um modelo fenomenológico de decaimento, medimos a taxa de colisão intra e interespécies. Pela análise da evolução da temperatura no carregamento duplo, não observamos aquecimento, evidenciando a não ocorrência de colisões inelásticas com inversão de estado hiperfino (52). Utilizando um modelo teórico simples, similar ao que foi desenvolvido para o $\mathrm{Rb}$, verificamos uma diferença isotópica na taxa de PA entre ${ }^{39} \mathrm{~K}$ com ${ }^{85} \mathrm{Rb}^{87} \mathrm{Rb}$. Essa diferença condiz com o valor medido experimentalmente para as colisões interespécies, corroborando com a existência da PA no dipolo duplo também.

Por fim, elaboramos um modelo teórico onde apontamos os possíveis canais para a PA devido ao laser de dipolo em $1071 \mathrm{~nm}$. O modelo é baseado na força de acoplamento (FCF) e energia entre os níveis vibracionais. Assim, além da verificação da formação espontânea de moléculas de $\mathrm{KRb}$, por causa da banda larga do laser de dipolo, verificamos um bombeamento molecular para diversos níveis vibracionais. Após vários ciclos de absorção e emissão espontânea, uma possível configuração estacionária para a distribuição desses níveis é encontrada. Com isso, previmos a existência de um bombeamento para níveis vibracionais inferiores com perdas menores que $15 \%$, onde obtivemos uma possível distribuição final de níveis vibracionais para as moléculas de ${ }^{87} \mathrm{Rb}_{2},{ }^{85} \mathrm{Rb}_{2},{ }^{39} \mathrm{~K}^{85} \mathrm{Rb}$ e ${ }^{39} \mathrm{~K}^{87} \mathrm{Rb}$. Através dessa distribuição, inferimos um possível caminho para a ionização e detecção que será útil futuramente para a medida de tais moléculas. 
Levando em conta as configurações atuais da armadilha de dipolo, conseguimos estimar através do modelo teórico que mais de $40 \%$ das moléculas de $\mathrm{KRb}$ são bombeadas para níveis inferiores a $X^{1} \Sigma^{+}(v=20)$. Uma vez que tais moléculas forem medidas experimentalmente, uma técnica auxiliar de bombeamento será implementada. Para isso, adquirimos um laser de Femtossegundo (FemtoFiber - Toptica) para essa finalidade. Com esse laser extra, poderemos excitar as moléculas dos níveis vibracionais no estado fundamental para níveis vibracionais nos potenciais: ${ }^{3} \Pi,{ }^{3} \Sigma,{ }^{1} \Sigma$ e ${ }^{1} \Pi$. O processo é similar ao que foi implementando com sucesso no bombeamento de $\mathrm{Cs}_{2}$ (46). Assim, esperamos que todas as moléculas em níveis $X^{1} \Sigma^{+}(v<20)$ sejam bombeadas para $X^{1} \Sigma^{+}(v=0)$ e acumuladas na armadilha de dipolo. 


\section{Referências}

1 CHU, S. Nobel lecture: the manipulation of neutral particles. Reviews of Modern Physics, v. 70, n. 3, p. 685-706, 1998.

2 COHEN-TANNOUDJI, C.N. Nobel lecture: manipulating atoms with photons. Reviews of Modern Physics, v. 70, n. 3, p. 707-719, 1998.

3 PHILLIPS, W.D. Nobel lecture: laser cooling and trapping of neutral atoms. Reviews of Modern Physics, v. 70, n. 3, p. 721-741, 1998.

4 CORNELL, E. A.; WIEMAN, C. E. Nobel lecture: Bose-Einstein condensation in a dilute gas, the first 70 years and some recent experiments. Reviews of Modern Physics, v. 74, n. 3, p. 875-893, 2002.

5 KETTERLE, W. Nobel lecture: when atoms behave as waves: Bose-Einstein condensation and the atom laser. Reviews of Modern Physics, v. 74, n. 4, p. 1131-1151, 2002.

6 HEINZEN, D. et al. Superchemistry: dynamics of coupled atomic and molecular boseeinstein condensates. Physical Review Letters, v. 84, n. 22, p. 5029-5033, 2000.

7 HUDSON, E. et al. Cold molecule spectroscopy for constraining the evolution of the fine structure constant. Physical Review Letters, v. 96, n. 14, p. 143004-0, 2006.

8 GÓRAL, K.; SANTOS L.; LEWENSTEIN M. Quantum phases of dipolar bosons in optical lattices. Physical Review Letters, v. 88, n. 17, p. 170406, 2002.

9 DOYLE, J. et al. Editorial: Quo vadis, cold molecules? The European Physical Journal D, v. 31, n. 2, p. 149-164, 2004.

10 AVDEENKOV, A. ; BOHN J. Collisional dynamics of ultracold oh molecules in an electrostatic field. Physical Review A, v. 66, n. 5, p. 052718, 2002.

11 DE MIRANDA M.H.G. et al. Controlling the quantum stereodynamics of ultracold bimolecular reactions. Nature Physics, v. 7, n. 6, p. 502-507, 2011. 
12 TICKNOR, C. ; BOHN J. Influence of magnetic fields on cold collisions of polar molecules. Physical Review A, v. 71, n. 2, p. 022709-0, 2005.

13 BAHNS, J.T.; STWALLEY W.C.; GOULD P.L.. Laser cooling of molecules: a sequential scheme for rotation, translation, and vibration. The Journal of Chemical Physics, v. 104, n. 24, p. 9689, 1996.

14 DOYLE, J. et el. Buffer-gas loading of atoms and molecules into a magnetic trap. Physical Review A, v. 52, n. 4, p. R2515-R2518, 1995.

15 BOHN, J.; AVDEENKOV A.; DESKEVICH M. Rotational feshbach resonances in ultracold molecular collisions. Physical Review Letters, v. 89, n. 20, p. 203202-0, 2002.

16 MAXWELL, S.E. et al. High-flux beam source for cold, slow atoms or molecules. Physical Review Letters, v. 95, n. 17, p. 173201-0, 2005.

17 DOYLE, J.M. et al. Magnetic trapping of calcium monohydride molecules at millikelvin temperatures. Nature, v. 395, n. 6698, p. 148-150, 1998.

18 MAUSSANG, K. et al. Zeeman relaxation of CaF in low-temperature collisions with helium. Physical Review Letters, v. 94, n. 12, p. 123002-0, 2005.

19 BETHLEM, H.; BERDEN G.; MEIJER G. Decelerating neutral dipolar molecules. Physical Review Letters, v. 83, n. 8, p. 1558-1561, 1999.

20 BETHLEM, H.L. et al. Electrostatic trapping of ammonia molecules. Nature, v. 406, n. 6795, p. 491-494, 2000.

21 SAWYER, B. et al. Magnetoelectrostatic trapping of ground state $\mathrm{OH}$ molecules. Physical Review Letters, v. 98, n. 25, p. 253002-0, 2007.

22 BLACK, A.; CHAN,H.; VULETIĆ, V. Observation of collective friction forces due to spatial self-organization of atoms: from rayleigh to bragg scattering. Physical Review Letters, v. 91, n. 20, p. 203001-0, 2003.

23 LAMBO, R. et al. Spectroscopy of low-energy atoms released from a solid noble-gas matrix: Proposal for a trap-loading technique. Physical Review A, v. 76, n. 6, p. 061401-0, 2007. 
24 STWALLEY, W.C. Stability of spin-aligned hydrogen at low temperatures and high magnetic fields: new field-dependent scattering resonances and predissociations. Physical Review Letters, v. 37, n. 24, p. 1628-1631, 1976.

25 CHIN, C. et al. High resolution feshbach spectroscopy of cesium. Physical Review Letters, v. 85, n. 13, p. 2717-2720, 2000.

26 COURTEILLE, P.; FREELAND R.S.; HEINZEN D.J. Observation of a feshbach resonance in cold atom scattering. Physical Review Letters, v. 81, n. 1, p. 69-72, 1998.

27 KETTERLE, W. et al. Observation of feshbach resonances in a Bose-Einstein condensate. Nature, v. 392, n. 6672, p. 151-154, 1998.

28 ROBERTS, J.L. et al. Resonant magnetic field control of elastic scattering in cold ${ }^{85} \mathrm{Rb}$. Physical Review Letters, v. 81, n. 23, p. 5109-5112, 1998.

29 JAKSCH, D. et al. Creation of a molecular condensate by dynamically melting a mott insulator. Physical Review Letters, v. 89, n. 4, p. 040402-0, 2002.

30 STWALLEY, W.C. Collisions and reactions of ultracold molecules. Canadian Journal of Chemistry, v. 82, n. 6, p. 709-712, 2004.

31 BAHNS, J.T.; GOULD P. L., STWALLEY W.C. Formation of cold molecules. Advances In Atomic, Molecular, and Optical Physics, v. 42, p. 171-224, 2000.

32 JONES, K. et al. Ultracold photoassociation spectroscopy: Long-range molecules and atomic scattering. Reviews of Modern Physics, v. 78, n. 2, p. 483-535, 2006.

33 WEINER, J. ; JULIENNE P.S. Experiments and theory in cold and ultracold collisions. Reviews of Modern Physics, v. 71, n. 1, p. 1-85, 1999.

34 FIORETTI, A. et al. Formation of cold $\mathrm{Cs}_{2}$ molecules through photoassociation. Physical Review Letters, v. 80, n. 20, p. 4402-4405, 1998.

35 NIKOLOV, A. et al. Efficient production of ground-state potassium molecules at sub-mk temperatures by two-step photoassociation. Physical Review Letters, v. 84, n. 2, p. 246-249, 2000. 
36 NIKOLOV, A. et al. Observation of ultracold ground-state potassium molecules. Physical Review Letters, v. 82, n. 4, p. 703-706, 1999.

37 FIORETTI, A. et al. Cold rubidium molecule formation through photoassociation: a spectroscopic study of the $0 \mathrm{~g}$ - long-range state of $87 \mathrm{rb}$ 2. The European Physical Journal D, v. 15, n. 2, p. 189-198, 2001.

38 GABBANINI, C. et al. Cold rubidium molecules formed in a magneto-optical trap. Physical Review Letters, v. 84, n. 13, p. 2814-2817, 2000.

39 HUANG, Y. et al. Formation, detection and spectroscopy of ultracold rb2 in the ground $\mathrm{x} 1 \sigma \mathrm{g}+$ state. Journal of Physics B: Atomic, Molecular and Optical Physics, v. 39, n. 19, p. S857-S869, 2006.

40 LOZEILLE, J. et al. Detection by two-photon ionization and magnetic trapping of cold $\mathrm{Rb}_{2}$ triplet state molecules. The European Physical Journal D, v. 39, n. 2, p. 261-269, 2006.

41 KERMAN, A. et al. Production and state-selective detection of ultracold rbcs molecules. Physical Review Letters, v. 92, n. 15, p. 153001-0, 2004.

42 MANCINI, M. et al. Observation of ultracold ground-state heteronuclear molecules. Physical Review Letters, v. 92, n. 13, p. 133203-0, 2004.

43 HAIMBERGER, C. et al. Processes in the formation of ultracold nacs. Journal of Physics B: Atomic, Molecular and Optical Physics, v. 39, n. 19, p. S957-S963, 2006.

44 KRAFT, S.D. et al. Formation of ultracold lics molecules. Journal of Physics B: Atomic, Molecular and Optical Physics, v. 39, n. 19, p. S993-S1000, 2006.

45 MANAI, I. et al. Rovibrational cooling of molecules by optical pumping. Physical Review Letters, v. 109, n. 18, p. 183001-0, 2012.

46 VITEAU, M. et al. Optical pumping and vibrational cooling of molecules. Science, v. 321, n. 5886, p. 232-234, 2008. 
47 MARANGONI, B.S.; MENEGATTI C.R.; MARCASSA L.G. Loading a ${ }^{39} \mathrm{~K}$ crossed optical dipole trap from a magneto-optical trap. Journal of Physics B: Atomic, Molecular and Optical Physics, v. 45, n. 17, p. 175301, 2012.

48 MENEGATTI, C.R.; MARANGONI B.S.; MARCASSA L.G. Observation of cold $\mathrm{rb}_{2}$ molecules trapped in an optical dipole trap using a laser-pulse-train technique. Physical Review A, v. 84, n. 5, p. 053405-0, 2011.

49 MENEGATTI, C.R. et al. Trap loss and ultracold molecule formation in a rubidium crossed dipole trap. Physical Review A, 2013. Artigo submetido.

50 GRIFFIN, P.F. Laser cooling and loading of $\mathbf{R b}$ in to a large periodic, quasieletrostatic optical lattice. 2005. 154 p. (Ph.D. Thesis). Department of Physics, Durham University, 2005

51 GREINER, M. Ultracold quantum gases in three-dimensional optical lattice potencials. 2003. 121 p. (Ph.D. Thesis). Ludvig-Maximiliang, Unversitat Munchen, Munchen, 2003.

52 DEIGLMAYR, J. et al. Formation of ultracold polar molecules in the rovibrational ground state. Physical Review Letters, v. 101, n. 13, p. 133004-0, 2008.

53 CUNDIFF, S. ; YE J. Colloquium: femtosecond optical frequency combs. Reviews of Modern Physics, v. 75, n. 1, p. 325-342, 2003.

54 DEMARCO, B. Quantum behavior of an atomic fermi gas. 2001. 596 p. (Ph.D. Thesis). Department of Physics, University of Colorado, 2001

55 NI, K.K. et al. A high phase-space-density gas of polar molecules. Science, v. 322, n. 5899, p. 231-235, 2008.

56 NI, K.K., et al. Dipolar collisions of polar molecules in the quantum regime. Nature, v. 464, n. 7293, p. 1324-1328, 2010.

57 QUÉMÉNER, G. ; BOHN J.L. Electric field suppression of ultracold confined chemical reactions. Physical Review A, v. 81, n. 6, p. 060701-0, 2010.

58 DECHAR, T.A. Vaccum physics and techniques. London:Chapman, 1993. 
59 STREED, E.W. Rubidium bose-einstein condensates: machine construction and quantum zero experiment. 2005. 128 p. (Ph.D. Thesis). Departament of Physics, Massachusetts Institute of Technology, Cambridge, 2005.

60 STECK, D.A. Rubidium 85 d line data. Oregon: Oregon Center for Optics and Department of Physics, University of Oregon, 2012. 31p.

61 PHILliPS, W.; METCALF H. Laser deceleration of an atomic beam. Physical Review Letters, v. 48, n. 9, p. 596-599, 1982.

62 LANDINI, M. et al. Sub-doppler laser cooling of potassium atoms. Physical Review A, v. 84, n. 4, p. 043432-0, 2011.

63 MENEGATTI, C.R. Armadilha de dipolo para átomos e moléculas. 2011. 162 p. (Doutor em Ciências) - Instituto de Física de São Carlos, Universidade de São Paulo, São Carlos, 2011.

64 GOKHROO, V. et al. Sub-doppler deep-cooled bosonic and fermionic isotopes of potassium in a compact $2 \mathrm{~d}+-3 \mathrm{~d}$ mot set-up. Journal of Physics B: Atomic, Molecular and Optical Physics, v. 44, n. 11, p. 115307, 2011.

65 FORT, C. et al. Cooling mechanisms in potassium magneto-optical traps. The European Physical Journal D - Atomic, Molecular and Optical Physics, v. 3, n. 2, p. 113-118, 1998.

66 MUDRICH, M. et al. Hyperfine-changing collisions in an optically trapped gas of ultracold cesium and lithium. Physical Review A, v. 70, n. 6, p. 062712-0, 2004.

67 BURT, E. et al. Coherence, correlations, and collisions: what one learns about BoseEinstein condensates from their decay. Physical Review Letters, v. 79, n. 3, p. 337-340, 1997.

68 ROBERTS, J. et al. Magnetic field dependence of ultracold inelastic collisions near a feshbach resonance. Physical Review Letters, v. 85, n. 4, p. 728-731, 2000.

69 LAUBER, T. et al. Optimized Bose-Einstein-condensate production in a dipole trap based on a 1070-nm multifrequency laser: influence of enhanced two-body loss on the evaporation process. Physical Review A, v. 84, n. 4, p. 043641-0, 2011. 
70 SETO, J.Y. et al. Direct potential fit analysis of the $\mathrm{x}^{1} \mathrm{\sigma}_{\mathrm{g}}{ }^{+}$state of $\mathrm{Rb}_{2}$ : nothing else will do! The Journal of Chemical Physics, v. 113, n. 8, p. 3067, 2000.

71 SALAMI, H. et al. Spectroscopic observations, spin-orbit functions, and coupled-channel deperturbation analysis of data on the $\mathrm{a}^{1} \sigma_{\mathrm{u}}{ }^{+}$and $\mathrm{b}^{3} \pi_{\mathrm{u}}$ states of $\mathrm{Rb}_{2}$. Physical Review $\mathbf{A}$, v. 80, n. 2, p. 022515-0, 2009.

72 BEUC, R. et al. Absorption spectroscopy of the rubidium dimer in an overheated vapor: An accurate check of molecular structure and dynamics. Physical Review A, v. 75, n. 3, p. 032512-0, 2007.

73 PILLET, P. et al. Photoassociation in a gas of cold alkali atoms: I. perturbative quantum approach. Journal of Physics B: Atomic, Molecular and Optical Physics, v. 30, n. 12, p. 2801-2820, 1997.

74 MANCINI, M.W. et al. Trap loss rate for heteronuclear cold collisions in two species magneto-optical trap. The European Physical Journal D, v. 30, n. 1, p. 105-116, 2004. 